\title{
Analyse des Vorkommens, der Morphologie und der genetischen Diversität von Biologischen Bodenkrusten extrazonaler Gebirgssteppenstandorte der nördlichen Mongolei
}

\author{
Dissertation \\ zur Erlangung des Doktorgrades \\ der mathematisch-Naturwissenschaftlichen Fakultäten \\ der Georg-August-Universität zu Göttingen
}

vorgelegt von

Anne Kemmling

aus Northeim

Göttingen 2010 
D7

Referent: Prof. Dr. M. Mühlenberg

Korreferent: PD Dr. M Hoppert

Tag der mündlichen Prüfung: 


\section{Inhaltsverzeichnis}

Inhaltsverzeichnis i

Abkürzungsverzeichnis iv

Abbildungs- und Tabellenverzeichnis: $v$

1 Einleitung 1

1.1 Einführung in die Thematik und Literaturübersicht 1

1.2 Ziele der Arbeit und Methodenwahl___ 4

2 Untersuchungsgebiet 10

2 Lage des Untersuchungsgebietes __ 10

2.2 Geologie und Boden ___ 11

$2.3 \mathrm{Klima}$

2.4 Pflanzengeographische Einteilung und Vegetationstypen ___ 14

2.5 Naturschutz und Landnutzung __ 16

3 Material und Methoden

3.1 Freilandmethoden___ 18

3.1.1 Allgemeine Freilandmethodik _ 18

3.1.2 Bestimmung der Organismen___ 20

3.1.3 Versuchsflächen und Plotdesign __ 22

3.1.3.1 Vergleich verschiedener Standortsituationen von BSCs 22

3.1.3.2 Der Einfluss verschiedener Standortfaktoren auf das Vorkommen und die Ausprägung

Biologischer Bodenkrusten (BSCs)

3.1.3.2.1 Analyse der Standortfaktoren 22

3.1.3.2.2 Der Einfluss von Exposition und Inklination auf die Ausprägung Biologischer

Bodenkrusten (BSCs)

3.1.3.2.3 Der Einfluss der phanerogamen Vegetation auf das Vorkommen und die Ausprägung

Biologischer Bodenkrusten (BSCs)

3.1.3.2.4 Der Einfluss von Störung auf das Vorkommen und die Ausprägung Biologischer

Bodenkrusten (BSCs)

3.1.3.3 Heuschreckenfraß

3.1.3.4 Bodenoberflächentemperaturen 24

3.2 Molekulare Methoden 25

3.2.1 Grundlegende Methoden__ 25

3.2.1.1 Stämme und Wachstumsbedingungen 25

3.2.1.1.1 Bakterielle Stämme, Plasmide und Oligonucleotide__ 25

3.2.1.1.2 Medien — 27

3.2.1.1.3 Antibiotika und Medienzusätze — 28

3.2.1.1.4 Wachstumsbedingungen___ 28

3.2.1.1.5 Lagerung der Stämme___ 28

3.2.1.2 Ermittlung von Wachstumsparametern/Optische Dichte __ 29

3.2.1.3 Isolation genomischer (Gesamt-)DNA__ 29

3.2.1.4 Grundlegende Methoden zur qualitativen und quantitativen Bestimmung von DNA-Fragmenten

3.2.1.4.1 Agarose-Gelelektrophorese (Sambrook 1989) _ 30

3.2.1.4.2 Konzentrationsbestimmung für DNA__ 31

3.2.1.5 Polymerase-Kettenreaktion (Polymerase chain reaction, PCR) __ 32 
3.2.1.6 Gelextraktion 36

3.2.2 TOPO $^{\circledR}$-Klonierung___ 36

3.2.3 Denaturierende Gradientengelelektrophorese (DGGE) __ 37

3.2.4 Sequenzierung__ 39

3.3 Bodenanalysen — 42

3.3.1 Entnahme von Bodenproben im Gelände _ 42

3.3.2 Analysen zur Bestimmung bodenchemischer Standortfaktoren___ 42

3.3.2.1 Bestimmung des Wassergehaltes __ 42

3.3.2.2 Messung des Boden-pH-Wertes _ 43

3.3.2.3 Bestimmung der effektiven Kationenaustauscherkapazität (AKe) und der Basensättigung _ 44

3.3.2.4 Glühverlust, Gehalt an organischem Kohlen- und Stickstoff und C/N-Verhältnis___ 45

3.3.3 Bestimmung der Wasserspeicherungskapazität $\mathrm{WHK}_{\max } \_47$

3.4 Bildgebende Verfahren _ 48

3.4.1 Fotografie _ 48

3.4.2 Lichtmikroskopie___ 48

3.5 Statistik — 49

3.6 Anreicherung und Isolation von Bodenkrustenorganismen__ 50

4 Ergebnisse _ 52

4.1 Standorte Biologischer Bodenkrusten und abiotische Standortfaktoren $\_52$

4.1.1 Vorkommen von Biologischen Bodenkrusten im Khentej-Gebirge _ 52

4.1.2 Temperaturvergleiche _ 55

4.1.2.1 Wärmemengen einzelner Standorte __ 55

4.1.2.2 Minimale und maximale Bodenoberflächentemperaturen __ 56

4.1.3 Bodenanalysen

4.1.3.1 pH- Wert des Auflagehorizonts _ 58

4.1.3.2 Weitere Ergebnisse der bodenchemischen Analysen __ 60

4.2 Vergleichende Morphologie Biologischer Bodenkrusten ___ 61

4.2.1 Makroskopische Untersuchungen __ 61

4.2.1.1 Beteiligte Kryptogamen _ 61

4.2.1.2 BSC-Typen__ 67

4.2.1.2.1 Mikroskopische Untersuchungen __ 67

4.2.1.2.2 Makroskopische Untersuchungen___ 72

4.2.1.2.2 Maximale Wasserspeicherungskapazität (WHKmax) verschiedener BSC-Typen ___ 75

4.3 Der Einfluss verschiedener Standortfaktoren auf das Auftreten Biologischer

Bodenkrusten und ihre Zusammensetzung _ 76

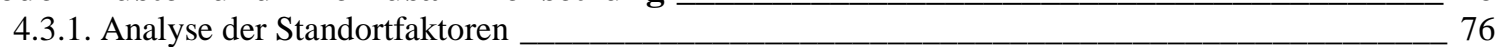

4.3.1.1 Artemisia frigida-Gebirgstrockensteppe___ 77

4.3.1.2 Artemisia frigida-Pulsatilla ambigua-Gebirgstrockensteppe___ 81

4.3.1.3 Pulsatilla ambigua - Gebirgstrockensteppe __ 85

4.3.1.4 PCA (Hauptkomponentenanalyse) aller Vegetationstypen zusammen ___ 89

4.3.2 Einfluss der Gefäßpflanzen auf die Bedeckung mit biologischen Bodenkrusten und deren Zusammensetzung _ 90

4.3.3 Einfluss von Exposition und Inklination auf die Anzahl von Kryptogamenarten__ 97

4.3.4 Die Auswirkungen von Trittbelastung auf die Bedeckung mit BSCs und Pflanzen _ 101 
4.4 Analyse der mikrobiellen Diversität in Biologischen Bodenkrusten über die Konstruktion von 16S rDNA-Genbanken 103

4.5 Sonstige Ergebnisse 120

4.5.1 Archaeen -DGGE (denaturing gradient gel electrophoresis) 120

5 Diskussion 123

5.1 Diskussion der Einzelergebnisse 123

5.1.1 Standorte Biologischer Bodenkrusten und abiotische Faktoren 123

5.1.2 Vergleichende Morphologie Biologischer Bodenkrusten 127

5.1.2.1 BCS-Organismen

5.1.2.2 BCS-Typen

5.1. 2.2.1 Sukzession 129

5.1.2.2.2 Der Einfluss von Störung auf Biologische Bodenkrusten

5.1.3 Der Einfluss verschiedener Standortfaktoren auf das Auftreten Biologischer Bodenkrusten und ihre Zusammensetzung

5.1.3.1 Abiotische Faktoren

5.1.3.3 Biotische Faktoren

5.1.3.3. Weitere Einflüsse 138

5.1.4 Analyse der mikrobiellen Diversität in Biologischen Bodenkrusten über die Konstruktion von 16S rDNA-Genbanken 141

5.2 Schlussfolgerungen für den Naturschutz 154

5.2.1 Funktion und „Nutzen“ Biologischer Bodenkrusten 154

5.2.2 BSCs und ihre Gefährdungssitiation im westlichen Khentej 157

5.2.3 Management Biologischer Bodenkrusten 159

6 Zusammenfassung 161

7 Literaturverzeichnis 163 


\section{Abkürzungsverzeichnis}

\begin{tabular}{|l|l|}
\hline ad & lat. = bis zu (hier als ,auffüllen auf“) \\
\hline AKe & Effektive Kationenaustauschkapazität \\
\hline BEG & Bunte Erdflechtengesellschaft \\
\hline BLAST & $\begin{array}{l}\text { Basic Local Alignment Search Tool = Datenbankanwendung zum } \\
\text { Sequenzvergleich }\end{array}$ \\
\hline BSC & Biological Soil Crust/s = Biologische Bodenkruste/n \\
\hline DGGE & $\begin{array}{l}\text { Denaturing gradient gel electrophoresis = Denaturierende } \\
\text { Gradientengelelektrophorese }\end{array}$ \\
\hline DMSO & Dimethylsulfoxid \\
\hline DNA & Desoxyriboncleic Acid = Desoxyribonucleinsäure \\
\hline EDTA & Ethylendiamintetraacetat \\
\hline FG & Frischgewicht \\
\hline g & Gramm \\
\hline GTS & Gebirgstrockensteppe \\
\hline h & Stunde/n \\
\hline H2O ${ }_{\text {demin }}$ & Demineralisiertes Wasser \\
\hline H2O Millipore & $\begin{array}{l}\text { Durch Ionenautauscher und Aktivkohle vollentsalztes und von gelösten } \\
\text { organischen Stoffen gereinigtes Wasser }\end{array}$ \\
\hline KKSPA & Khan Khentii Strictly Protected Area \\
\hline MW & Messwert \\
\hline OD \\
\hline OTU & Optische Dichte \\
\hline OWG & Operational Taxonomical Unit = Taxonomische Arbeitseinheit \\
\hline PAR & Offenes Waldgebiet \\
\hline PCR & Photosynthetic Active Radiation = photosynthetisch nutzbare Strahlung \\
\hline RT & Polymerase Chain Reaction, Polymerasekettenreaktion \\
\hline TAG & Trockenbodenanteil \\
\hline TAG & Trockenbodenanteil \\
\hline UNESCO & $\begin{array}{l}\text { United Nations Educational, Scientific and Cultural Organization } \\
\text { = Organisation der Vereinten Nationen für Erziehung, Wissenschaft und Kultur }\end{array}$ \\
\hline WG & Prozentualer Wassergehalt \\
\hline WHK & Maximax \\
\hline
\end{tabular}




\section{Abbildungs- und Tabellenverzeichnis:}

Abb. 1.1: Schematische Übersicht einer Biologischen Bodenkruste...............................2

Abb. 1.1: Standortfaktoren, die möglicherweise das Wachstum von BSCs beeinflussen. 5

Abb. 1.2: Die drei Domänen des Lebens. ..6

Abb. 1.3: Molekularbiologische Versuchsstrategie zur Erfassung der Mikroorganismen.

Abb. 2.1: Topographische Karte der Mongolei mit selbst eingezeichneter Lage des Khentej und Lage von Khonin Nuga.

Abb.2.2: Niederschlagsmengen und Tage mit Taubildung von Juni 2005 bis Mai 2006.13

Abb. 2.3: Photosynthetisch wirksame Strahlung im Jahresverlauf Juni 2005 bis Mai

2006.

Abb. 2.4: unbewaldeter Südhang bei Khonin Nuga.

Abb. 2.5: A= Schutzgebiete der Mongolei, $B=$ Khan Khentej Strictly Protected Area mit Lage der Forschungsstation Khonin Nuga.

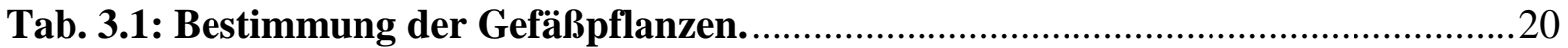

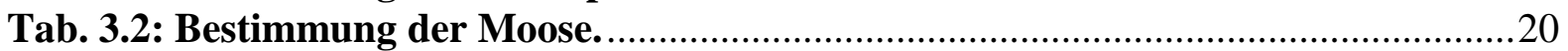

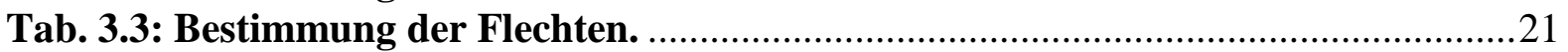

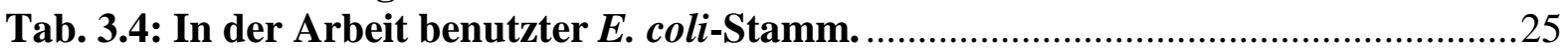

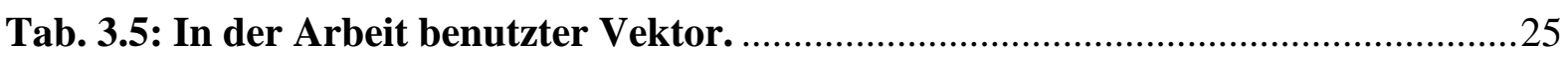

Tab. 3.6: In der Arbeit benutzte Primer, Sequenz und Spezifität..................................26

Tab 3.7: In der Arbeit verwendete Antibiotika und weitere Medienzusätze. ..................28

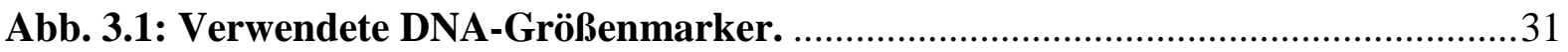

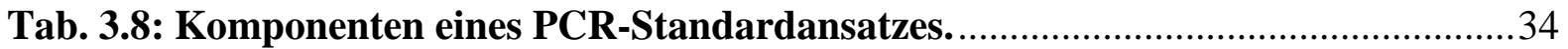

Tab. 3.9: Erste, universelle Amplifikation der Archaeen-16S rDNA..............................34

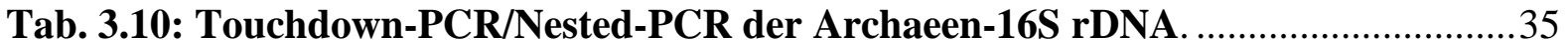

Tab. 3.11: Universelle Amplifikation der Bakterien-16S rDNA......................................35

Tab. 3.12: Konzentrationen zur Herstellung der 0 \% und 80\%igen DGGE-Gellösungen.

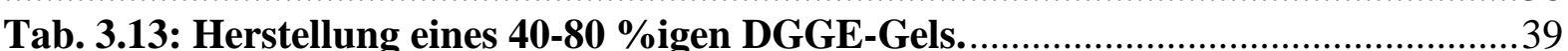

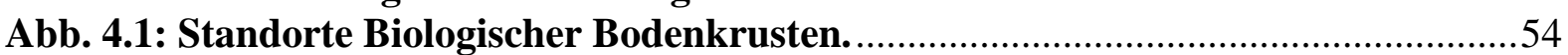

Abb. 4.2: Durch die Pallmann- Methode ermittelte Glucose- Inversionsraten. .............55

Abb. 4.3: Bodenoberflächentemperaturen von BSC-Standorten, erste Vertikalachse...57

Abb. 4.4: Bodenoberflächentemperaturen von BSC-Standorten, Horizontalachse........57

Abb. 4.5: Bodenoberflächentemperaturen von BSC-Standorten, zweite Vertikalachse. 58

Abb. 4.6: pH-Wert des Auflagehorizontes verschiedener BSC-Standorte.....................59

Abb. 4.7: Absenkung des pH-Wertes des Auflagehorizontes verschiedener BSC-

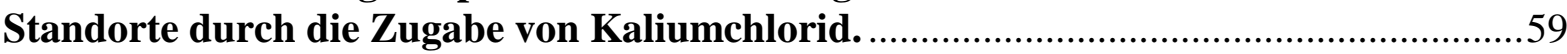

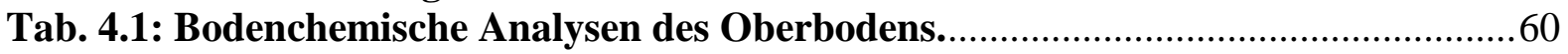

Abb. 4.7: In den BSCs vorkommende Flechtenarten I.................................................63

Abb. 4.8: In den BSCs vorkommende Flechtenarten II. .............................................64

Tab. 4.2: Standortansprüche der gefundenen Flechtenarten und Arealdiagnose............65

Abb. 4.9: In den BSCs vorkommende Moosarten. ......................................................66

Abb. 4.10: Mikroskopische Übersichtsaufnahmen Biologischer Bodenkrusten..............69

Abb. 4.11: Mikroskopische Detailaufnahmen Biologischer Bodenkrusten......................70

Abb. 4.12: Mikroskopische Autofluoreszenzaufnahmen Biologischer Bodenkrusten. ...71

Tab. 4.3: Ergebnisse der mikroskopischen Analysen der häufigsten BSC-Typen. .........73 


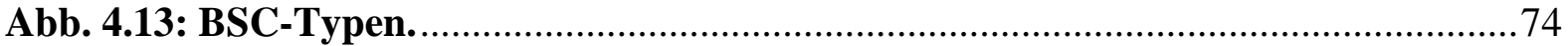

Abb. 4.14: Maximale Wasserspeicherungskapazität verschiedener Bodenkrusten....... 75

Abb. 4.15: Matrix-Scatterplot für die Artemisia-frigida-Gebirgstrockensteppe. ............78

Tab. 4.4: Spearmans Rangkorrelation für die Artemisia frigida-Gebirgstrockensteppe..

Abb. 4.16: Lineare Regression von der Anzahl der Kryptogamenarten und der Entfernung vom Bergrücken..

Abb. 4.17: Lineare Regression von der Anzahl der Kryptogamenarten und der Pflanzenbedeckung..

Abb. 4.18: Matrix-Scatterplot für die Artemisia-frigida-Pulsatilla ambigua-

Gebirgstrockensteppe..

Tab. 4.5: Spearmans Rangkorrelation für die Artemisia frigida-Pulsatilla ambigua

Gebirgstrockensteppe.

Abb. 4.19: Lineare Regression von der Anzahl der Kryptogamenarten und der Bedeckung mit Stein..

Abb. 4.20: Lineare Regression von der Anzahl der Kryptogamenarten und der Bedeckung mit BSCs.

Abb. 4.21: Lineare Regression von der Anzahl der Kryptogamenarten und der Pflanzenbedeckung.

Abb. 4.22: Matrix-Scatterplot für die Pulsatilla ambigua-Gebirgstrockensteppe. .........86

Tab. 4.6: Spearmans Rangkorrelation für die Pulsatilla ambigua -

Gebirgstrockensteppe..

Abb. 4.23: Lineare Regression von der Anzahl der Kryptogamenarten und der

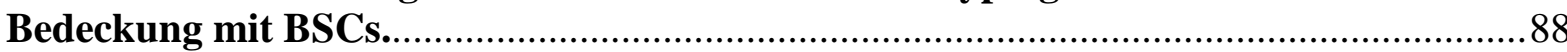

Abb. 4.16: Hauptkomponentenanalyse (PCA) aller Vegetationstypen zusammen. ........89

Abb. 4.25: Bedeckung mit Pflanzen auf den Linientransekten des Berges A. .................92

Abb. 4.25: Bedeckung mit BSCs auf den Linientransekten des Berges A.......................92

Abb. 4.27: Matrix-Scatterplot für die Abhängigkeiten zwischen BSC-Bedeckung und

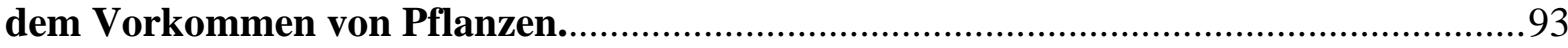

Tab. 4.7: Spearmans Rangkorrelation für die Abhängigkeiten zwischen BSC-

Bedeckung und dem Vorkommen von Pflanzen.

Abb. 4.28: Lineare Regression von der Pflanzenbedeckung und der Bedeckung mit

BSCs.

Abb. 4.28: Lineare Regression von der Bedeckung mit BSCs und der Bedeckung mit Gras.

Abb. 4.28: Lineare Regression von der Bedeckung mit BSCs und der Bedeckung mit „mittleren Kräutern“.

Abb. 4.31: Matrix-Scatterplot für die Anzahl der Kryptogamenarten in Abhängigkeit von Exposition und Inklination.

Tab. 4.8: Spearmans Rangkorrelation für die Anzahl der Kryptogamenarten in

Abhängigkeit von Exposition und Inklination.

Abb. 4.32: Polynomale Regression (zweiten Grades) von der Anzahl der

Kryptogamenarten und der Exposition.

Abb. 4.33: Lineare Regression von der Anzahl der Kryptogamenarten und der Inklination.

Abb. 4.34: Blasendiagramm von der Anzahl der Kryptogamenarten gegen die Exposition und die Inklination.

Abb. 4.35: Die Pflanzenbedeckung ein Jahr nach starker Trittbelastung.

Abb. 4.36: Die Bedeckung mit BSCs ein Jahr nach starker Trittbelastung.

Tabelle 4.9: Vergleich verschiedener Parameter der Standorte $G$ und $H$. 
Tab. 4.10: Chimären in den Standortgenbanken G01 und H01, detektiert durch Mallard und Bellerophon.

Tab. 4.11: Tatsächlich gefundene OTUs (operational taxonomical units) im Vergleich mit Schätzwerten und der Shannon-Weaver-Index für die Genbanken der Standorte G und $H$.

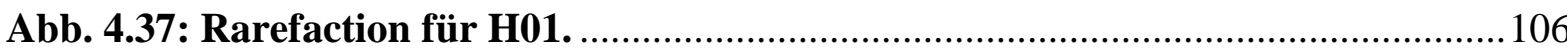

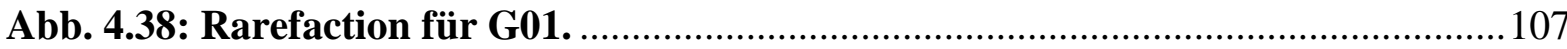

Abb. 4.39: Phylaverteilung der 16S rDNA-Genbanken der Standorte G01 und H01. .108 Abb. 4.40: Evolutionäre Beziehungen der 16S rDNA- Genbanken der Standorte G und H.

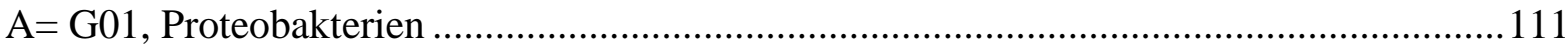

B= G01, Cyanobakterien, Chloroflexi und Actinobakterien .............................................111

C= G01, Bacteroidetes; G01, Acidobakterien, Nitrospira und Verrucomicrobia...................111

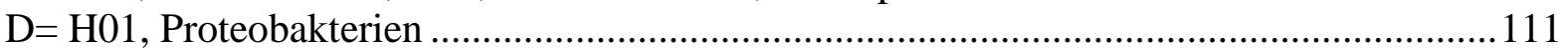

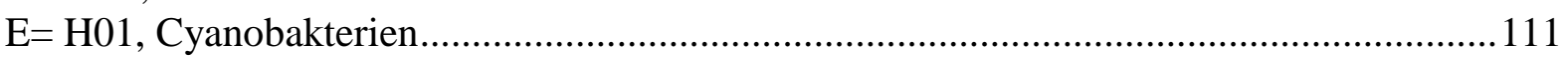

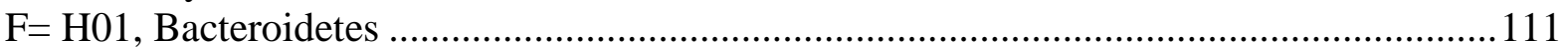

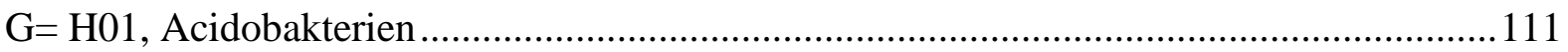

$\mathrm{H}=\mathrm{H} 01$, Actinobakterien, Gemmatimonadetes, Chloroflexi, Planctomyceten und

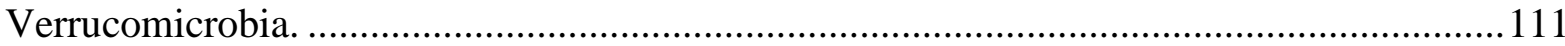

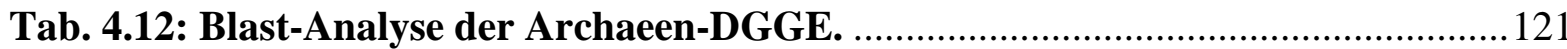

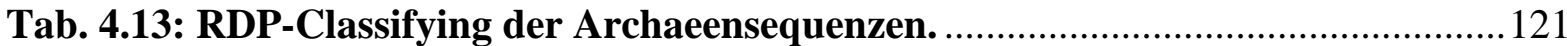

Tab. 4.14: Nahrungsspektrum der gefangenen Heuschreckenarten............................122

Abb. 5.1: Verwandtschaft der bakteriellen Phyla............................................................ 142

Abb. 5.1: Das Nahrungsnetz Biologischer Bodenkrusten in Weidelandökosystemen...155

Abb. 5.2: Tiere in der Umgebung von Biologischen Bodenkrusten. ..............................156 


\section{Einleitung}

\subsection{Einführung in die Thematik und Literaturübersicht}

Bevor sich für die Assoziation aus Substratpartikeln und verschiedenen Organismen wie u.a. Cyanobakterien, Algen, Bakterien, Mikropilzen, Flechten und Bryophyten der Begriff „Biologische Bodenkruste“ durchzusetzen begann, gab und gibt auch heute noch in der Literatur viele andere Bezeichnungen für dieses Phänomen, wie z.B. die Begriffe Organogenische (Evenari, 1985), Mikrophytische (West, 1990), Mikrobiotische (Eldridge, 1994), Kryptogamische (Johansen, 1993), Kryptobiotische (Belnap, 1993), Biogenische (Orlvsky et al., 2004), Mikrophytische (Cameron, 1978) und Mikroflorale (Loope and Gifford, 1972) Krusten oder Bodenkrusten. Oft wird dem gesamten Komplex auch ein dem Hauptbestandteil entlehnter Name gegeben, wie zum Beispiel von Bowker et al. (2002) der Term „Desert cyanobacterial soil crust“ oder der Begriff „Bunte-Erdflechten-Gesellschaft“ (z.B. Paus, 1997). In diesen Fällen wurde meist jener namensgebende Bestandteil vornehmlich bis ausschließlich behandelt. Aus verschiedenen Gründen wurde für die vorliegende Arbeit der Begriff Biologische Bodenkrusten (BSCs) gewählt, da es in der Fragestellung der Arbeit wichtig ist, das Vorhandensein von Organismen, die den verschiedenen spezielleren Kriterien nicht entsprechen, nicht zu unterschätzen. Hier sind zum Beispiel Bakterien, Mikroarthropoden, Mikropilze und höhere Pflanzen zu nennen, deren Anteil oft unzureichend beachtet wird.

Für diese Arbeit wurde die Entscheidung getroffen, für die Definition zugrunde zu legen, dass wirklich eine Aggregation des Substrates stattfindet und dass dieses Substrat Erde, nicht Gestein ist. So werden Gesteinsflechten und reine Moosgesellschaften, die dem Substrat ja meist nur aufliegen, in dieser Arbeit nicht behandelt. Abbildung 1.1 zeigt eine schematische Übersichtszeichnung einer Biologischen Bodenkruste.

Obwohl es nach Jahrzehnten intensiver Forschung auf dem Gebiet biologischer Bodenkrusten zahlreiche Untersuchungen über deren Zusammensetzung, Verbreitung und ihrer Stellung in verschiedenen Ökosystemen gibt, besteht Bedarf an weiteren Studien. Es gibt bislang 


\section{Einleitung}

mehrere „Hot Spots“ der Forschung, etwa in Israel, Nordamerika und Australien, welche vornehmlich in Wüsten und Steppen angesiedelt sind.

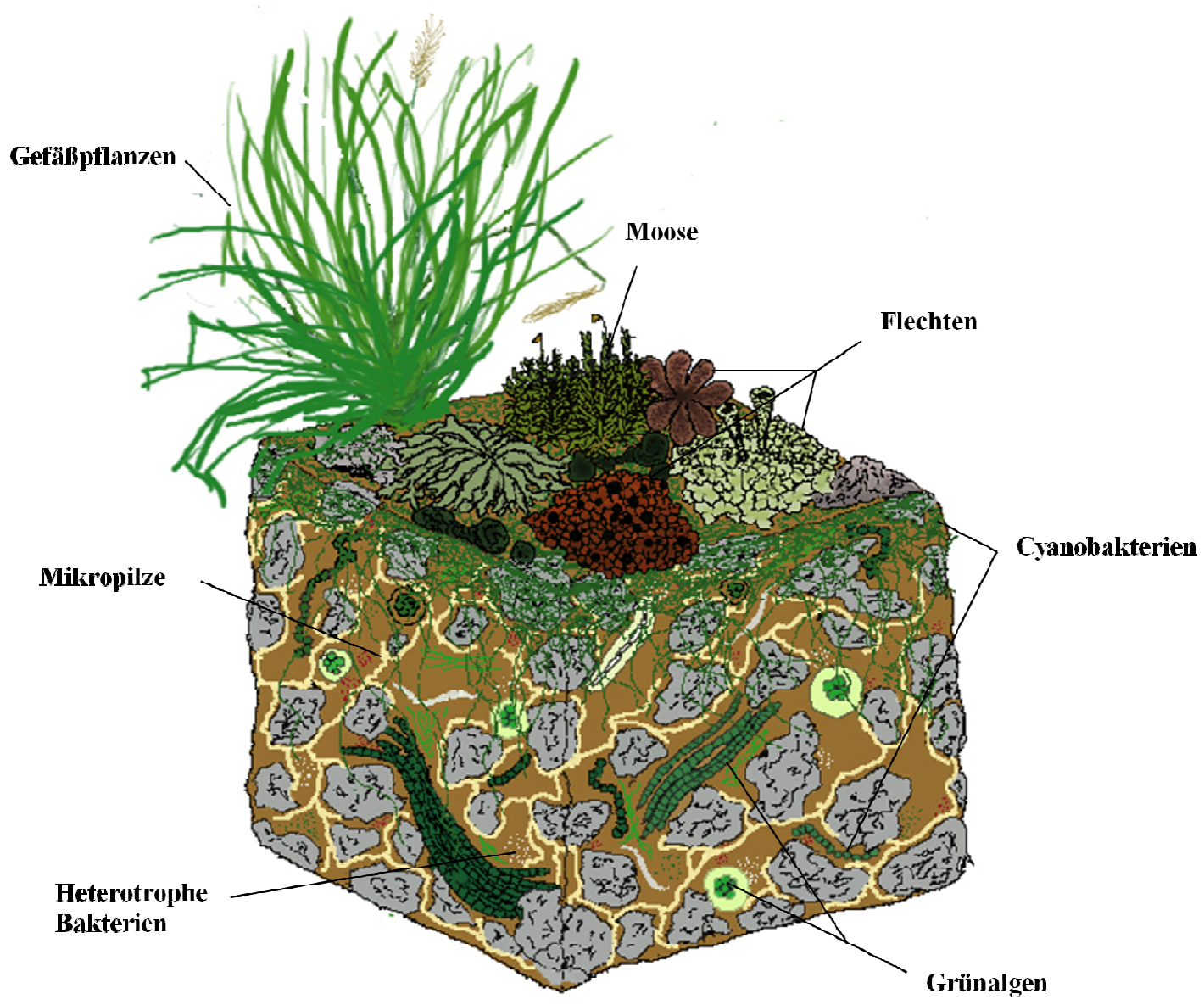

Abb. 1.1: Schematische Übersicht einer Biologischen Bodenkruste.

Für das nördliche Asien gibt es wenige Untersuchungen, die direkt auf die Thematik von BSCs abzielen, für die äußere Mongolei nur einzelne in den eher südlichen und zentralen Bereichen des Landes (Belnap et al., 1999). Diese unterscheiden sich floristisch stark vom Khan Khentej. Auch für das benachbarte Sibirien gibt es einzelne Beobachtungen, obwohl es an diesen Orten sehr wohl viele interessante Standorte gibt. Eine Studie von NovichkovaIvanova (1977) beschäftigte sich unter anderem mit der Diversität der Bodenalgen einiger Wüsten und Steppen Turkmenistans. Es wurden insgesamt über 400 Arten von Algen entdeckt und es wurde die Beobachtung gemacht, dass die Zellzahlen stark von der Bodenbeschaffenheit und der Bodenfeuchtigkeit abhängen. In den Wüsten wurde ein 
1 Einleitung

dominierendes Auftreten von Cyanobakterien festgestellt, welche in Filmen und Krusten assoziiert waren. Es gibt einige Arbeiten über Algen der Mongolei in russischer oder mongolischer Sprache. Ultziikhutag und Tsetsegma (1980) und Tsetsegma und Ultziikhutag (1985) beschäftigen sich vornehmlich mit der organismischen Diversität von Süßwasseralgen der gesamten Mongolei, Novichkova-Ivanova (1977, 1980 und 1988) mit oft zu Krusten assoziierten Bodenalgen (Phytozönosen) in der Gobi.

Über das Vorkommen von Kryptogamen an sich gibt es jedoch eine lange Reihe von Veröffentlichungen. Hier werden jedoch zumeist alle Arten einer Gruppe eines Gebietes katalogisiert, die Arbeiten beziehen sich also weniger detailliert auf einzelne Standorte. So wird denn über Flechten in der Mongolei schon über ein Jahrhundert geforscht. Elenkin (1901) bestimmte erstmalig einige Arten, bis 1950 waren etwa 40 Arten erwähnt (z.B. Gyelnik, 1930; Rassadina, 1950). In den sechziger bis achtziger Jahren des vergangenen Jahrhunderts wand sich das Forschungsinteresse vermehrt den Flechten der Mongolei zu (z.B. Huneck et al., 1984; Schubert und Klement, 1971). Cogt (1979) inventarisierte die bisher bekannten Bodenflechten der Mongolei. Er fand insgesamt 212 Arten. Junatov (1950) unterscheidet für die Mongolei sechs verschiedene geographische Zonen. Das KhentejGebirge wird hier als der Gebirgstaiga-Region und der Region der Bergsteppen und des Waldes zugehörig gesehen, wobei das Untersuchungsgebiet der letzteren Region angehört. Für Bergsteppen dieser Region fand Cogt (1979) in den kurzrasigen Kräutersteppen z.B. Parmelia vagans, Psora asiacentralis, Dermatocarpon lachneum und in den Festuca-StipaAssoziationen zusätzlich noch Arten wie Acarospora schleicheri, Rinodina sp. und Toninia sp. Pflanzengeographisch wird die Mongolei in 16 verschiedene Gebiete eingeteilt (Grubov und Junatov, 1952). In den Steppen des Khentej-Gebirgstaiga-Bezirkes fand Cogt (1979) die Vertreter der Lecideaceae (vier Arten) und der Dermatocarpaceae (drei Arten) als dominierend vor.

Die aktuellste Artenliste der Moosflora der Mongolei hat Tsegmed (2001) veröffentlicht. Dort sind für den Khentej 428 Moosarten aufgefürt. Man kann daraus ableiten, dass der Khentej eine Vielfalt an Standorten beherbergt. Karczmarz und Swies (1981) beschrieben für den Khentej in Wiesen- und Gebirgssteppen Barbula acuta, Bryum caespiticum, Bryum cirratus, Grimmia ovalis und seltener Ditrichum flexicaule und Pohlia elongata. In Steinsteppen fanden sie meist epipetrisch Vertreter der Gattungen Barbula, Bryum, Ceratodon, Didymodon und Grimmia. Zahlreiche Studien beschäftigen sich ausführlich mit 
1 Einleitung

der Moosflora biologischer Bodenkrusten in den Wüstengebieten der Inneren Mongolei. Diese dürften in ihrer Zusammensetzung einige Ähnlichkeiten mit den biologischen Bodenkrusten des Khentej aufweisen. Dort wurden zum Beispiel Tortula muralis, Tortula desertorum, Crossidium squamiferum, Bryum argenteum und Bryum bicolor (Zheng et al. 2009) und Bryum argenteum, Bryum capillare, Grimmia anodon und Grimmia pulvinata gefunden (Zhang 2002). Man sammelt in Nordchina auch Erkenntnisse über die Austrocknungstoleranz der Moose (Zheng et al. 2009)) und über die Auswirkungen biologischer Bodenkrusten auf die Stabilität der Dünen (Li et al. 2002) und das Vorkommen von höheren Pflanzen (Su et al. 2007).

\subsection{Ziele der Arbeit und Methodenwahl}

Die Untersuchungen fanden im Khentej-Gebirge in der nördlichen Mongolei statt (näheres dazu im nächsten Kapitel). Dort ist in Kooperation der Georg-August Universität Göttingen und der Nationaluniversität der Mongolei in Ulaanbaatar ein Forschungscamp in der Übergangszone der „Strictly protected Area Khan Khentej“ entstanden (Mühlenberg et al., 2004). Die untersuchten Standorte der Gebirgstrockensteppe weisen eine extrazonale Vegetation auf, das heißt, dass ihr Mikroklima und sonstige Standortverhältnisse so stark vom Großklima abweichen, dass sie eher einer Vegetationseinheit einer anderen Klimazone gleichen. Sie sind vergleichbar mit den in Mitteleuropa vorkommenden Trockenrasen oder Xerothermrasen, welche ebenfalls eine extrazonale Vegetation besitzen.

Es wird vermutet, dass das Auftreten und die Zusammensetzung von Biologischen Bodenkrusten von verschiedenen biotischen und abiotischen Standortfaktoren abhängen, die wiederum untereinander vernetzt sind (siehe Abbildung 1.2). Ein Ziel dieser Arbeit war es, diese Abhängigkeiten zu erfassen. Es wurden dafür Linientransekte gewählt, entlang derer die BSC-Bedeckung und Zusammensetzung innerhalb von Zählquadraten aufgenommen wurden. Bei diesen Analysen lag der Fokus unter den Standortfaktoren auf dem Faktor Störung, beziehungsweise Erosion. Diese beiden Faktoren sind an Hangstandorten oft nicht klar zu unterscheiden, da sie sich gegenseitig verstärken.

Daneben wurden noch die Standortfaktoren direkt oder indirekt erfasst (siehe Kapitel 3). So sollte es neben der Einflussnahme der Standortfaktoren ermöglicht werden, auch Hinweise 
1 Einleitung

auf Konkurrenz- oder Synergieeffekte der BSC-Organismen untereinander zu erhalten. Es sollte außerdem die ökologische Bandbreite der Standorte Biologischer Bodenkrusten veranschaulicht werden.

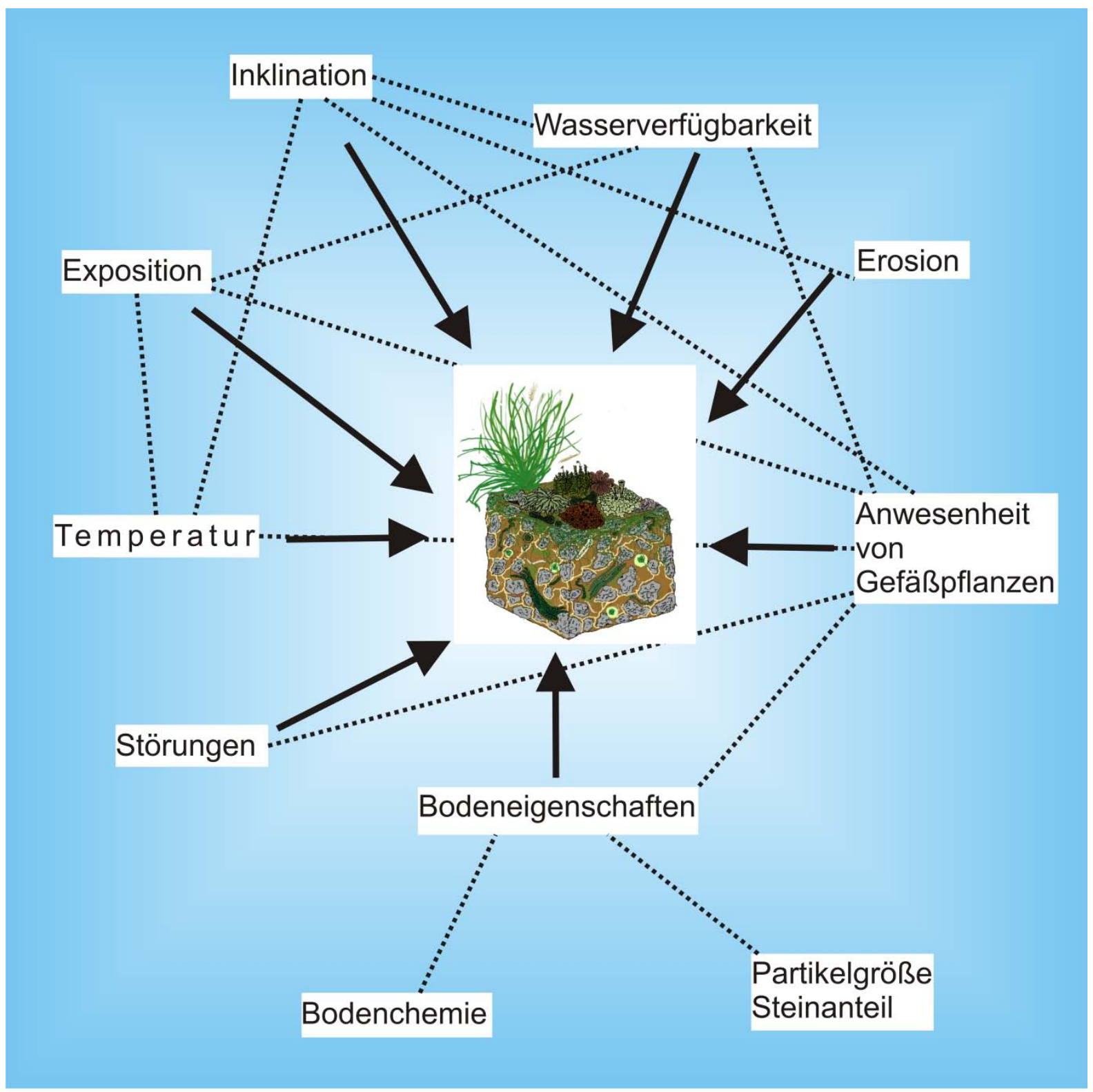

Abb. 1.2: Standortfaktoren, die möglicherweise das Wachstum von BSCs beeinflussen. 
1 Einleitung

Ein weiteres Ziel war es, den Aufbau und die Zusammensetzung verschiedener Typen von Biologischen Bodenkrusten zu ermitteln und wiederum mit den Standortfaktoren in Verbindung zu bringen. Das Thema erforderte eine breit gefächerte Methodik, da BSCs Organismen aller drei Reiche enthalten können. Wie in Abbildung 1.3 dargestellt ist, sind die meisten Taxa makroskopisch nicht sichtbar. Ihr Einfluss auf Ökosystemprozesse ist aber nichtdestotrotz sehr groß, deshalb sollte unter anderem mit Hilfe von Lichtmikroskopie ihr Anteil am Aufbau verschiedener Biologischer Bodenkrusten sichtbar gemacht werden.

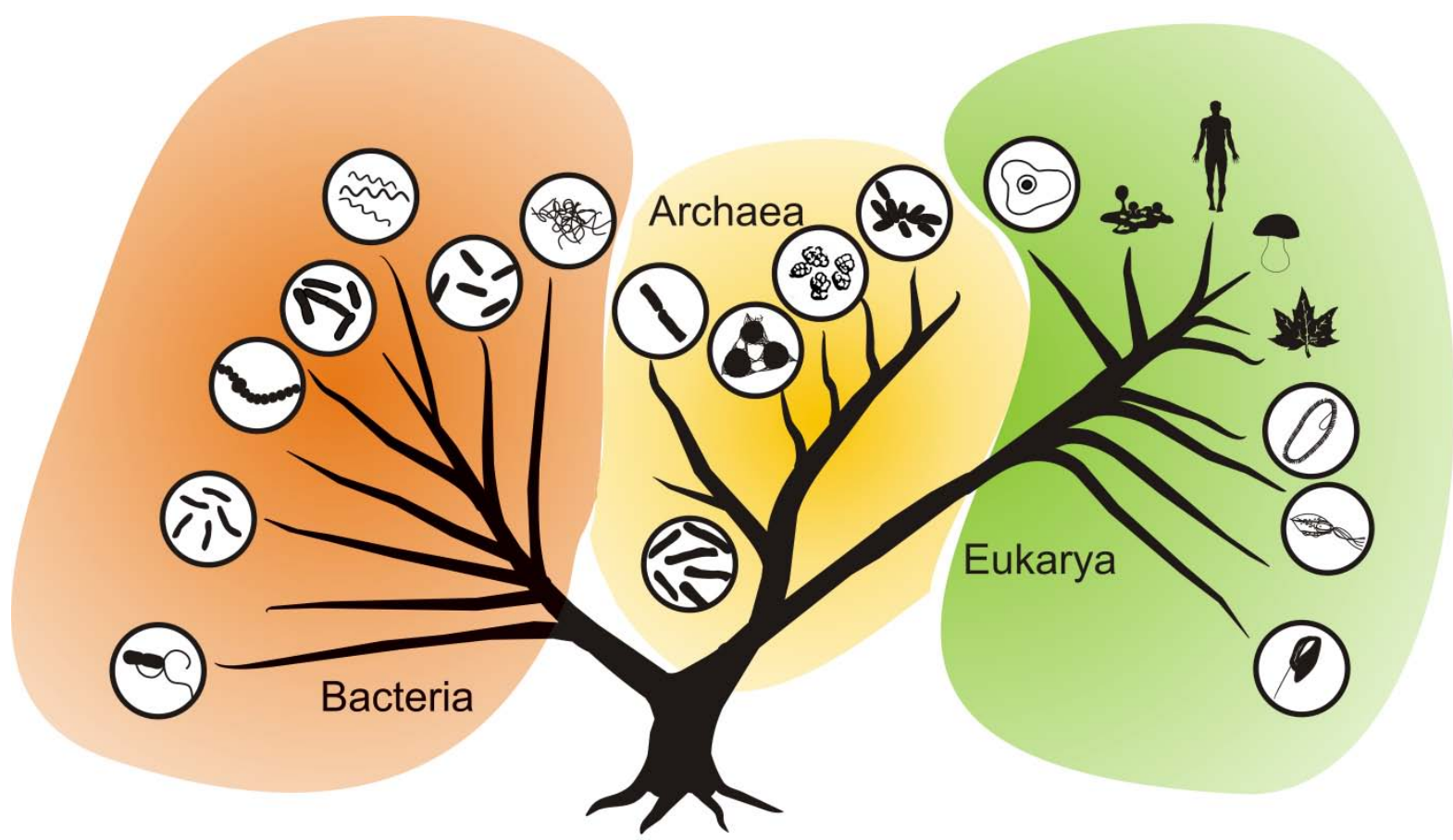

Abb. 1.3: Die drei Domänen des Lebens. Es sind alle Taxa umkreist, welche nur mikroskopisch wahrnehmbar sind.

Lichtmikroskopie allein reicht allerdings zur Erfassung von Artengemeinschaften selten aus, da die meisten Bakterien und alle Archaeen zu klein sind, um sie auf diese Weise zu bestimmen oder auch nur zu sehen. Hinzu kommt, dass auch die Isolierung und Kultivierung für einen großen Teil der Mikroorganismen nicht möglich ist (Amann et al., 2003), so dass kulturunabhängige Methoden gewählt werden sollten.

Es wurde eine 16S rDNA-basierte Versuchsstrategie gewählt, um die mikroorganismische Zusammensetzung der BSCs zweier Standorte miteinander zu vergleichen. Diese zwei 
Standorte unterschieden sich aufgrund ihrer Standortfaktoren sehr voneinander. Das 16SrDNA-Gens ist aufgrund seiner hohen evolutiven Konservierung sehr gut zu phylogenetisch vergleichenden Analysen geeignet (Amann et al., 2003). Es kann aus der Anzahl der verschiedenartigen Mutationen errechnet werden, wann in etwa sich Taxa voneinander getrennt haben. Die Abbildung 1.3 zeigt die in dieser Arbeit verwendete molekularbiologische Versuchsstrategie, wobei der Aufbau von Genbanken für die Bakterien gewählt wurden, um die Bakterien zu erfassen, während eine DGGE (Denaturierende Gelelektrophorese) gewählt wurde, um die DNA-Moleküle der Archaeen voneinander zu trennen und anschließend sequenzieren zu können. Eine DGGE ist zwar weniger aufwändig als die Erstellung von Standortgenbanken, sie ist aber für Proben mit einer sehr hohen Diversität nicht geeignet. Für die Archaeen wurde eine geringere Diversität erwartet. 


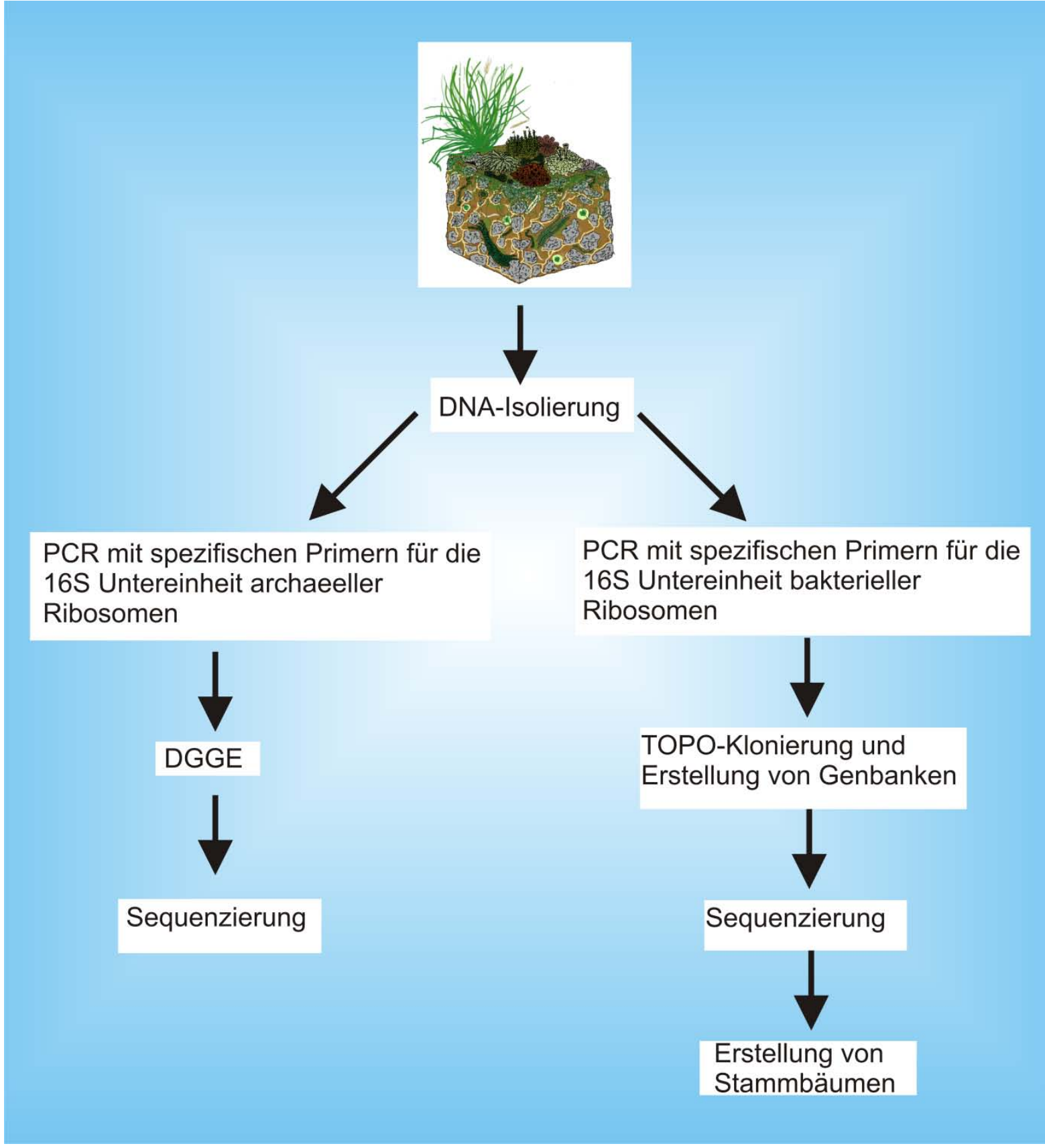

Abb. 1.3: Molekularbiologische Versuchsstrategie zur Erfassung der Mikroorganismen.

Ein weiterer Teil dieser Arbeit beschäftigt sich weiterhin mit der Fragestellung, inwieweit die Gebirgssteppenhänge des Khentej in Hinsicht auf die dort angesiedelten BSCs Schutzwürdigkeit besitzen.

In Deutschland sind dem untersuchten ähnliche Habitattypen stark im Rückzug begriffen und benötigen intensiven Schutz und Pflege. Es gilt als erwiesen, dass die meisten Trockenrasen hier sekundärer Natur, also durch anthropogene Nutzung entstandene Biotope sind 
(Ellenberg). Pott (1996) gibt als Gefährdungsfaktoren die Intensivierung der Grünlandnutzung, eine Nutzungsaufgabe (und damit eintretende Versaumung und Verbuschung), Düngung, Trittbeeinträchtigung und Aufforstung an. Die Bedeutung der Zerstörungsproblematik biologischer Bodenkrusten offenbart sich beim Studium der aktuellen Roten Liste der Biotoptypen (RIECKEN et al 1995). Fast alle der bekannten Biotoptypen, in welchen Bodenkrusten in Deutschland vorkommen können, sind hier aufgeführt. Auch in der Liste der Lebensraumtypen von gemeinschaftlichem Interesse (Anlage I zu der FFH-Richtlinien, Der Rat der europäischen Gemeinschaften 1992) werden viele der Habitate als besonders schutzwürdig herausgestellt (z. b. Dünen im Binnenland, trockene Sandheiden, naturnahe Kalktrockenrasen und deren Verbuschungsstadien, Geröllund Schutthalden).

Von den Gebirgssteppenstandorten im Khentej allerdings wird angenommen, dass sie ohne menschliche Einflussnahme entstanden sind (Dulamsuren et al., 2005). Dies bedingt natürlich Unterschiede im Management dieser Ökosysteme, die es zu diskutieren gilt.

Da Biologische Bodenkrusten aufgrund ihrer Sensibilität gegenüber Störungen eine Indikatorfunktion für die Gesundheit eines Ökosystems besitzen (Eldridge und Koen, 1998), können die durch diese Arbeit gewonnenen Ergebnisse in eine allgemeine Diskussion über den Naturschutzwert des Untersuchungsgebietes einfließen. 


\section{Untersuchungsgebiet}

\subsection{Lage des Untersuchungsgebietes}

Die Freilanduntersuchungen fanden im Westlichen Teil des Khan Khentej in der nördlichen

Mongolei, am Zusammenfluss der Flüsse Scharlan und Khongijn Gol statt. Aus diesen Flüssen entsteht der Eroo, welcher in den Orkhon fließt. Der Orkhon mündet in den BaikalSee. Das genaue Arbeitsgebiet befindet sich im Nordwestkhentej, in der Nähe der Forschungsstation Khonin Nuga $\left(49^{\circ} 05^{`} \mathrm{~N}, 107^{\circ} 17^{`} \mathrm{E}\right)$. Hier wurden auch die Proben für die Laboruntersuchungen genommen.

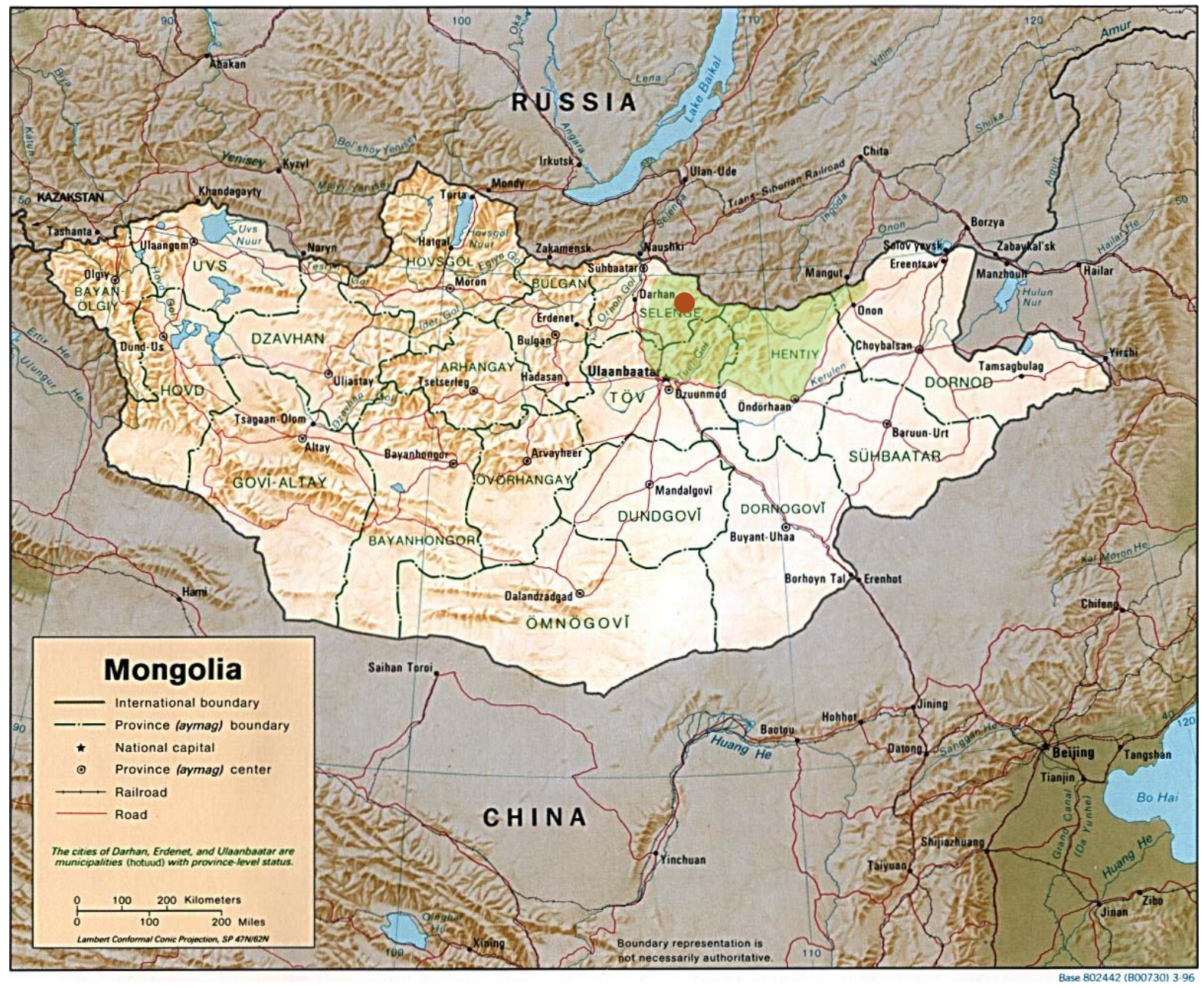

Abb. 2.1: Topographische Karte der Mongolei mit selbst eingezeichneter Lage des Khentej (hellgrünliche Fläche) und Lage von Khonin Nuga (roter Punkt). Quelle: http://www.gps.caltech.edu/ rkanda/GPS_TienShan2006/GPSFieldTrip_Main.html. 


\subsection{Geologie und Boden}

Khan Khentej ist ein Mittelgebirge mit über $48.000 \mathrm{~km}^{2}$ Ausdehnung und grenzt im Norden an Sibirien. Er ist Teil des transbaikalischen Gebirgssystems, welches größtenteils aus proterozoischen und paläozoischen Gesteinsformationen, hauptsächlich aus Granit, aufgebaut ist. Seine Erhebungen reichen von ca. $2800 \mathrm{~m}$ üNN im zentralen Teil bis ca. $600 \mathrm{~m}$ üNN in den nordöstlichen Ausläufern. Khonin Nuga liegt nordwestlich vom Zentralkhentej. Die Flusstäler liegen auf etwa 900 m üNN, die höchsten Erhebungen bei etwa $1600 \mathrm{~m}$ üNN.

Die Täler im Khentej liegen oft in Ost-Westrichtung, die Bergrücken sind meist flach bis gerundet. Da die hauptsächlichen Windrichtungen Nord und Nordwest sind, kommt es zu einer Vielzahl von mesoklimatischen Bedingungen, die in Abhängigkeit von Höhe und Exposition erheblich variieren können (siehe nächstes Kapitel).

Die Böden im Khentej sind stark vom Permafrost geprägt. Dieser bewirkt kryogene Prozesse, welche zusammen mit den generell tiefen Temperaturen, geringen Niederschlagsmengen und dem regelmäßigen Auftreten von Wildfeuern zu den für diese Gegend typischen, wenig stark ausgeprägten Podsolböden führt (Wyss, 2006), genauer gesagt, dem Gebirgstaiga-Podsol. Podsolböden zeichnen sich durch einen geringen Gehalt an Tonmineralen und somit einem geringen Nährstoffgehalt und eine schwache Pufferwirkung gegenüber der Bodenversauerung aus (Scheffer und Schachtschabel, 1984).

Ein weiteres Charakteristikum des Untersuchungsgebieten sind sog. Golez-Terrassen (auch Kryoplanationsterrassen, Lehmkuhl und Lang, 2001). Diese sind im Verlauf der Gletscherbildung durch Nivation im Pleistozän entstandene Terrassen, an deren Fuß sich oft sehr große Geröllfelder gebildet haben.

\subsection{Klima}

Das Klima der Mongolei ist extrem kontinental geprägt. Dieses beinhaltet eine verglichen mit ozeanisch geprägten Gebieten jahreszeitlich bedingte sehr große Schwankung der Durchschnittstemperaturen und deutlich geringere Niederschlagsmengen, welche ein 
2 Untersuchungsgebiet

deutliches Maximum im Sommer aufweisen. In der Mongolei fallen in den Monaten Juli und August 80-85 \% des durchschnittlichen jährlichen Niederschlages von 350 ml (Walther, 1974). Auch ist typisch, dass die extremen Sommer und Winter nur von kurzen Übergangsjahreszeiten getrennt werden. Ebenfalls kommt es häufig zu großen täglichen Temperaturdifferenzen.

Im Untersuchungsgebiet gibt es große Unterschiede im Mesoklima von Nord- und Südhängen. Die Nordseite der Berge stellt hier die Luvseite dar. Durch Verlangsamung und damit verbundene Abkühlung der Luftmassen kommt es hier zum verstärkten Abregnen und somit sind an den Nordhängen die Niederschlagsmengen größer. Die Südhänge hingegen liegen an der niederschlagsarmen Leeseite (Ogorodnikov, 1981). Je nach Entfernung zum Bergrücken nimmt an den Südhängen die Temperatur zu, Niederschlag und Luftfeuchte hingegen ab (Vipper, 1953). Die Exposition wirkt sich natürlich auch auf die Strahlungsmengen aus. So ist es nicht verwunderlich, dass die Nordhänge während der Vegetationszeit 15 \% weniger Wärme als die Südhänge bekommen (Bannikova, 2003). Die Lufttemperatur im Khentej sinkt je $100 \mathrm{~m}$ Meereshöhe um $6{ }^{\circ} \mathrm{C}$ (Geokriologiceskie uslovija MNR 1974). In Hanglagen hängt dieser Temperaturabfall vom Grad der Hangneigung ab. Je steiler der Hang, desto schwächer ist der Temperaturabfall. Während auf Südhängen bei einer Hangneigung von $20^{\circ}$ die Temperaturabsenkung um 10-20 \% geringer ist als in der Ebene, ist auf den Nordhängen für den gleichen Effekt eine Neigung von $28^{\circ}$ nötig.

In Untersuchungsgebiet Khonin Nuga wurde durch Hauck et al. (2007) und Dulamsuren und Hauck (2008) das Mikroklima eines Südhanges über den Verlauf eines Jahres festgestellt (siehe auch Abb. 2.2). Dabei konnte ein Jahresniederschlag von 294 mm ermittelt werden. Die maximale Lufttemperatur betrug im Juli $200539{ }^{\circ} \mathrm{C}$; die höchste Bodentemperatur bei $1 \mathrm{~cm}$ Tiefe wurde mit $49{ }^{\circ} \mathrm{C}$ gemessen. Im Februar 2006 betrug die niedrigste gemessene Temperatur $-48{ }^{\circ} \mathrm{C}$ und $-26{ }^{\circ} \mathrm{C}$ im Boden. Es wurde dort außerdem festgestellt, dass in den hauptsächlichen Regenmonaten Juni - August auch die meisten Tage mit Taubildung liegen. 


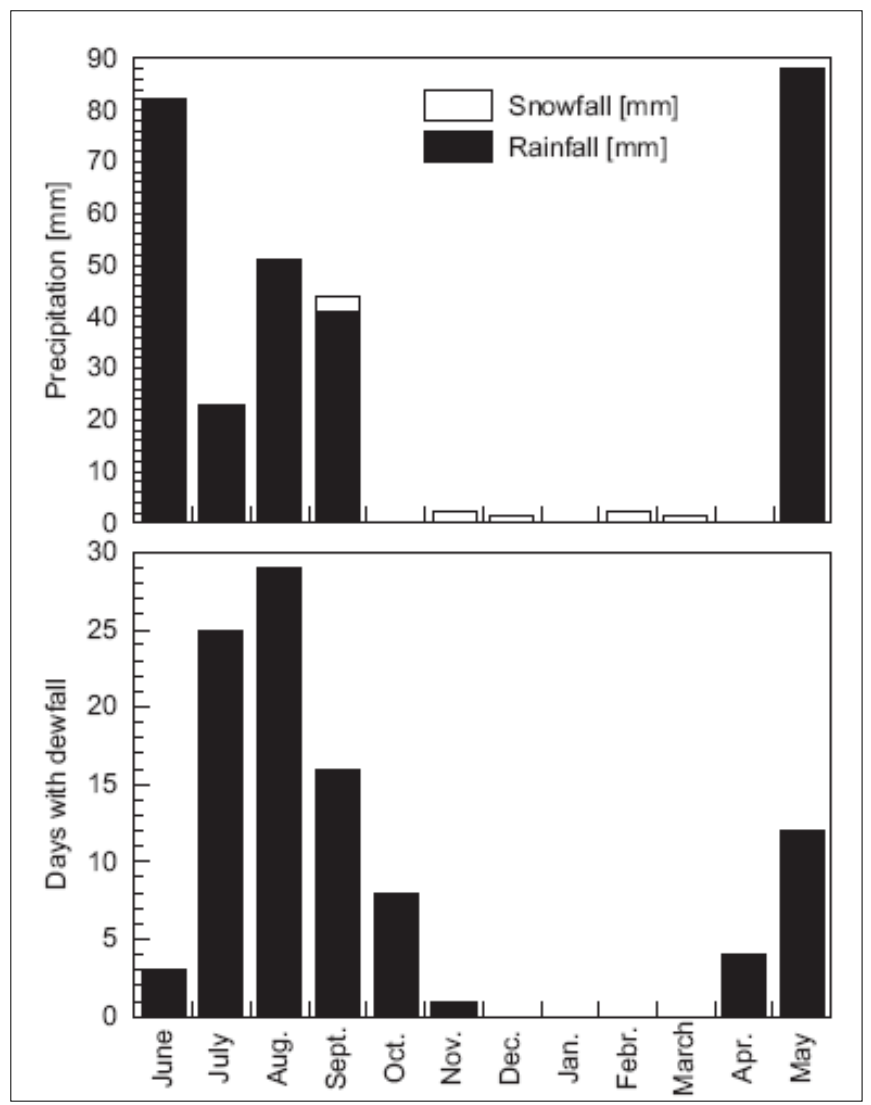

Abb.2.2: Niederschlagsmengen und Tage mit Taubildung von Juni 2005 bis Mai 2006 (Hauck et al., 2007).

Die photosynthetisch wirksame Strahlung (photosynthetic active radiation, PAR) wurde von Hauck et al. ebenfalls für den Zeitraum von Juli 2005 bis Mai 2006 an einem Südhang gemessen (siehe Abb. 2.3). Die Strahlungsmaxima lagen hier im Juni und Juli und überschnitten sich somit mit der Zeit der größten Niederschläge. 


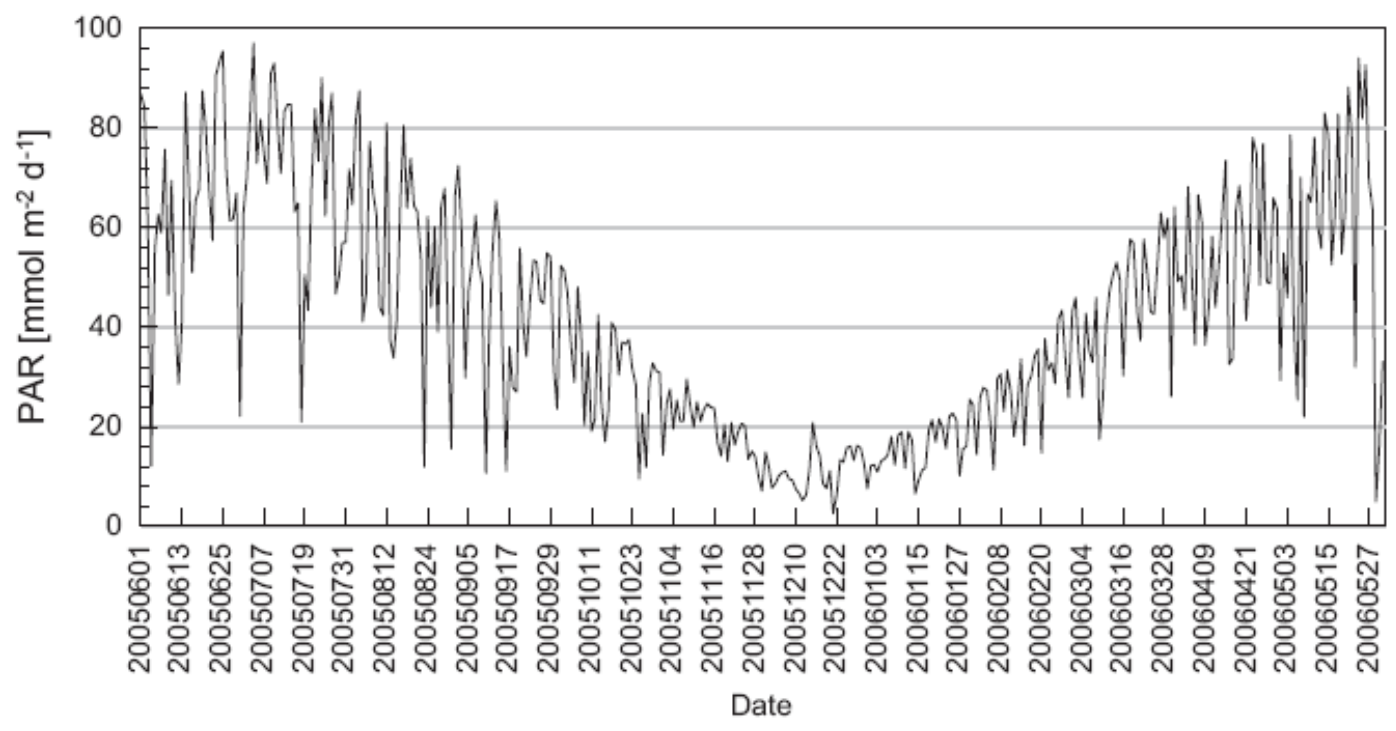

Abb. 2.3: Photosynthetisch wirksame Strahlung (PAR, in $\mathrm{mmol} \mathrm{m}^{-2} \mathrm{~d}^{-1}$ ) im Jahresverlauf Juni 2005 bis Mai 2006 (Hauck et al. 2007).

\subsection{Pflanzengeographische Einteilung und Vegetationstypen}

Die nördliche Mongolei zeichnet sich pflanzengeographisch durch einige Besonderheiten aus. Sie liegt direkt in der Übergangszone zwischen dem borealem Nadelwaldgürtel der südsibirischen Gebirgstaiga und der zentralasiatischen Steppenzone (Meusel et al., 1965). Es entsteht eine einzigartige Mischung von Vegetationstypen der dunklen Taiga, hellen Taiga und der Waldsteppe (Dulamsuren, 2004). Die Gebirgswaldsteppe des Khentej ist durch die Mischung von borealen, temperaten und daurischen Elementen besonders reich an Pflanzenund Tierarten und somit ein Biodiversitäts-Hotspot der Mongolei (Mühlenberg und Samiya, 2002). Dieses resultiert unter anderem aus dem Vorhandensein vieler verschiedener Vegetationstypen nebeneinander, die außerdem teilweise relativ kleinräumig abwechseln, so dass an Übergangsbereichen weiterer Raum für ökologische Nischenbildung entsteht. Die wichtigsten Vegetationstypen im Untersuchungsgebiet stellen die dunklen Bergtaigawälder der höheren Bergstufe, die dunklen Bergtaigawälder und hellen Subtaigawälder der Nordhänge der unteren Bergstufe, die Auenvegetation und die Trockenrasenvegetation der Südhänge der unteren Bergstufe dar (Dulamsuren, 2004). Die Südhänge sind aufgrund der mesoklimatischen Bedingungen in der Regel unbewaldet, es können sich, wenn überhaupt, nur Einzelbäume etablieren (siehe Abb. 2.4). 


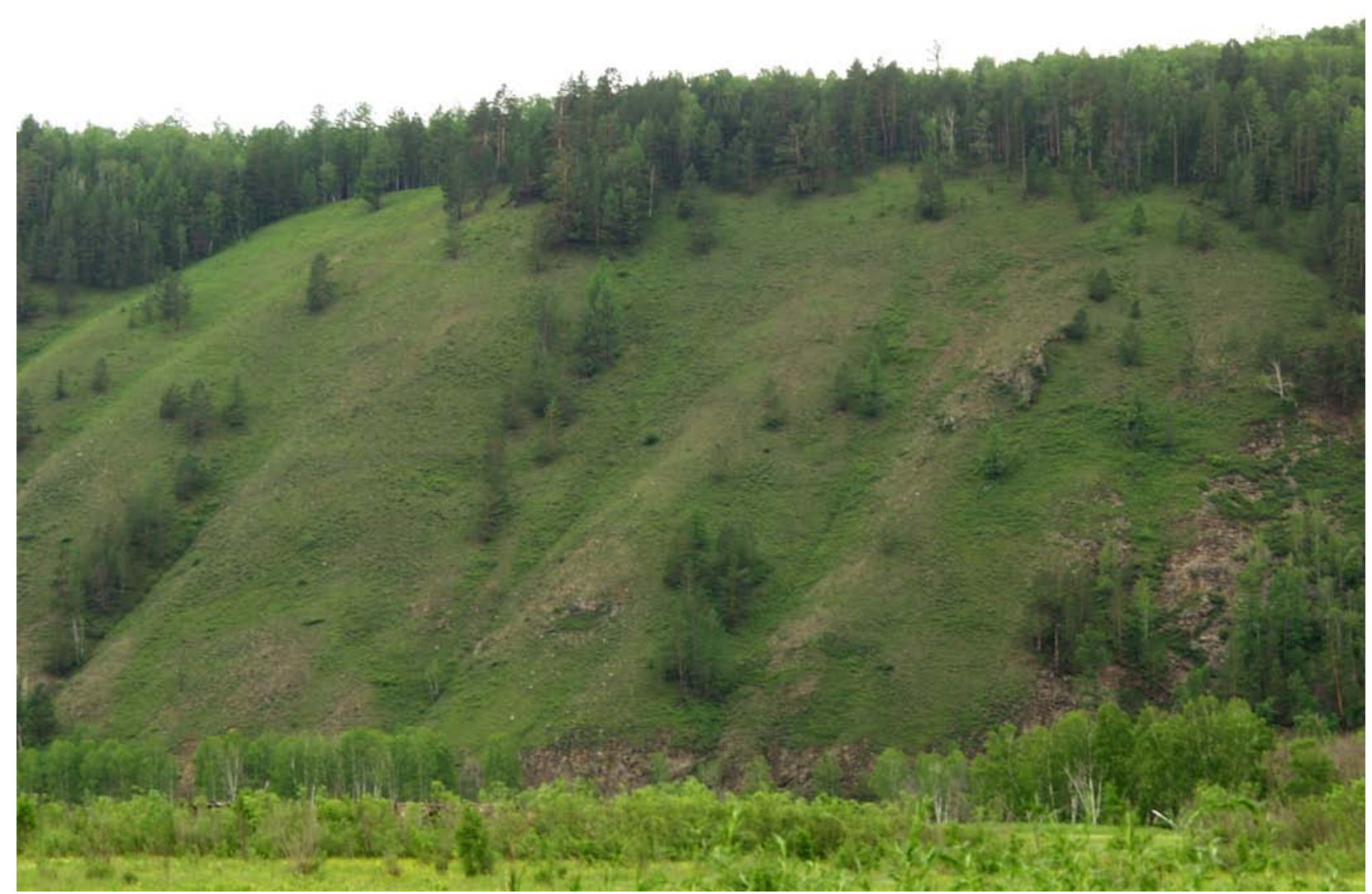

Abb. 2.4: unbewaldeter Südhang bei Khonin Nuga.

Die Trockenrasenvegetation (auch Gebirgstrockensteppe) wird von Dulamsuren (2004) noch weiter unterteilt. Je nach Auftreten von Charakterarten werden hier die Carex amgunensis -, Festuca lenensis-, Pulsatilla ambigua- und die Artemisia frigida-Gebirgstrockensteppe unterschieden. Außerdem konnte an den Süd- und Westhängen noch der Vegetationstyp Ulmus pumil-offenes Waldgebiet angetroffen werden.

Die Carex amgunensis-Gebirgstrockensteppe zeichnet sich durch die Charakterarten Carex amgunensis und Elymus confusus aus und wird an Waldrändern sonnenexponierter Hänge gefunden, die zum Teil auch beschattet sind. Die Festuca lenensis-Gebirgstrockensteppe zeichnet sich durch die Charakterarten Allium strictum, Campanula glomerata, Dendranthema zawadskii, Elymus gmelinii, Festuca lenensis, Galatella dahurica, Potentilla nivea und Scutellaria scordifolia aus und wird an mäßig steilen (20-30) Süd- und Westhängen mit relativ guter Wasserversorgung gefunden. Die Pulsatilla ambiguaGebirgstrockensteppe zeichnet sich durch die Charakterarten Bupleurum bicaule, Papaver 
nudicaule, Poa botryoides und Pulsatilla ambigua aus und kann an steileren (30-45) und trockeneren Süd- und Westhängen gefunden werden. Die Artemisia frigidaGebirgstrockensteppe zeichnet sich durch die Charakterarten Alyssum lenense, Chamaerodes erecta, Dontostemon integrifolius, Goniolimon speciosum, Heteropappus altaicus, Koeleria cristata, Orostachys malacophylla, Patrinia sibirica und Polygala tenuifolia aus und kommt an den steilsten Süd- und Westhängen mit dünner Erdschicht und schlechter Wasserversorgung vor. Die Pflanzenbedeckung ist hier nur 30-60\%. Das Ulmus pumilaoffene Waldgebiet zeichnet sich durch die Charakterarten Artemisia gmelinii, Carex pediformis, Potentilla acaulis, Pulsatilla turczaninovii, Youngia tenuicaulis, Ribes diacantha, Spiraea aquilegifolia und Ulmus pumila aus und wird auf xerothermen, steilen und steinigen Südhängen gefunden.

\subsection{Naturschutz und Landnutzung}

In der Mongolei wurden 1992 zwölf Schutzzonen, darunter die Khan Khentej Strictly Protected Area (KKSPA) ausgewiesen (Law on Special Protected Areas, LSPA), in deren Pufferzone das Untersuchungsgebiet Khonin Nuga fällt (siehe Abb. 2.5). Die Ausweisung von Pufferzonen orientiert sich am Man and Biosphere - Programm (MAB) der UNESCO und hat zum Ziel, Biosphärenreservate zu schaffen, in denen menschliche Aktivitäten überwacht werden und in denen Forschung und Bewahrung der natürlichen Umwelt an einem Ort vereint werden (Primack, 1995).

Die Nutzung dieser Pufferzone erfolgt demzufolge extensiv. Khonin Nuga wird bis auf das Forschungscamp nur von einer einzigen Familie von Tierhaltern besiedelt. Im Tal gibt es durchschnittlich in den Sommermonaten etwa bis zu 60 und in den Wintermonaten 10 bis 30 Pferde. Diese halten sich in den Sommermonaten größtenteils in den Flussauen auf, wo sie ausreichend Futter finden. Nur in den Wintermonaten kann es vorkommen, dass sie auf Futtersuche auch flachere Südhänge aufsuchen. Die vereinzelten, hauptsächlich mongolischen Touristen halten sich im Allgemeinen ebenfalls in den Tälern auf, so dass auch diese keine Trittschäden verursachen. 
2 Untersuchungsgebiet
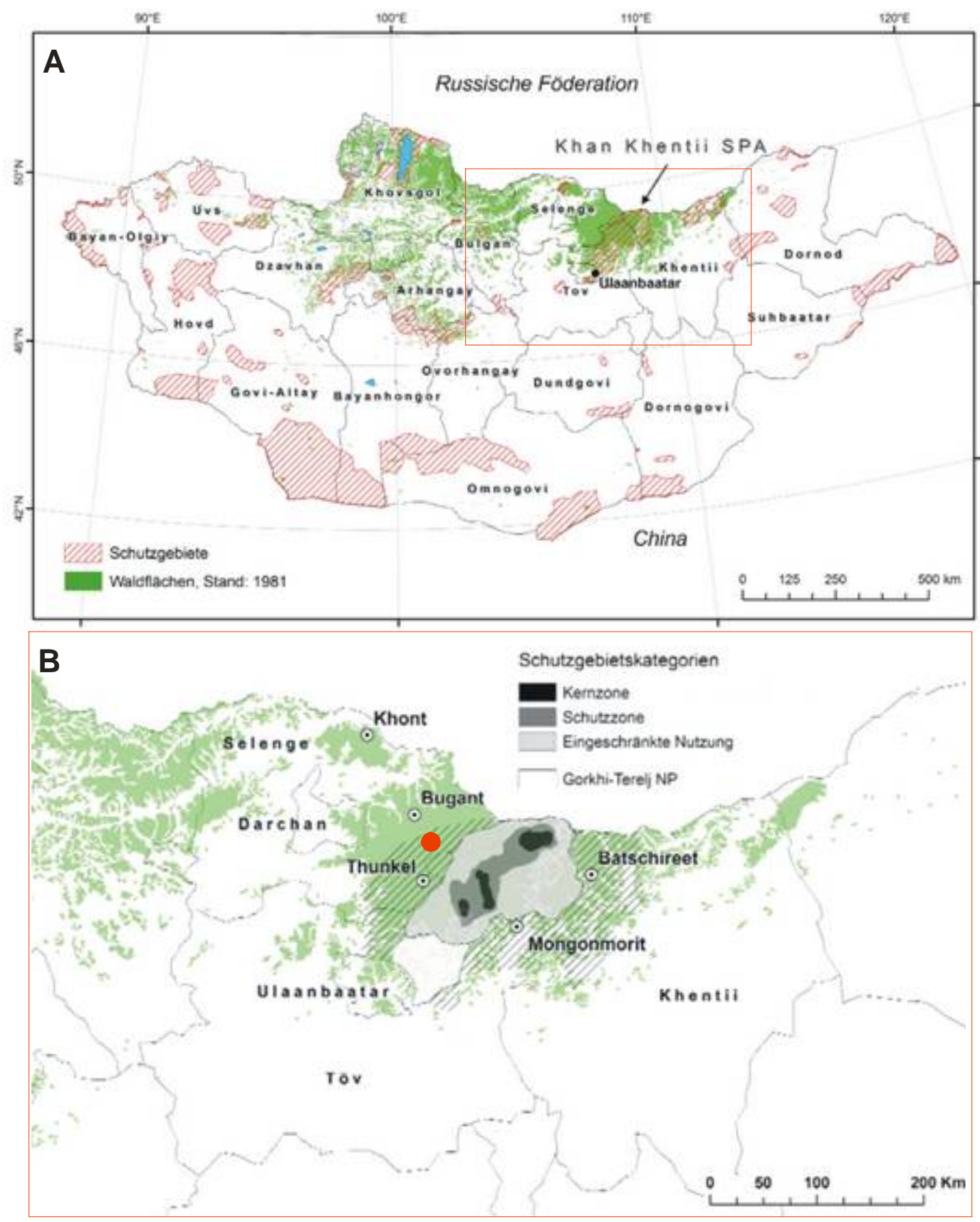

Abb. 2.5: A= Schutzgebiete der Mongolei, $B=$ Khan Khentej Strictly Protected Area mit Lage der Forschungsstation Khonin Nuga (roter Punkt). Quelle: GTZ. 


\section{Material und Methoden}

\subsection{Freilandmethoden}

\subsubsection{Allgemeine Freilandmethodik}

Zur Abschätzung und Auszählung der verschiedenen Parameter wurde ein Zählquadrat von 50 x 50 cm Kantenlänge verwendet. Dieses wurde entlang von Linientransekten in definierten Abständen ausgelegt oder je nach Plotdesign auch mit geschlossenen Augen zufällig ausgeworfen. Linientransekte wurden gewählt, um räumliche Gradienten zu erfassen, ein zufälliger Wurf sollte diese gerade ausklammern, um eine größere Variationsbreite der Daten zu ermöglichen. Dabei bewegte sich der Werfer allerdings auf zwei gedachten Linien über das gesamte Untersuchungsgebiet, um den gesamten Raum auszunutzen und die Lage der Quadrate nicht von den Wurffertigkeiten des Untersuchenden abhängig zu machen. Innerhalb dieses Quadrates wurden je nach Versuchsdesign folgende Parameter aufgenommen:

a) Exposition: Mit Hilfe eines Kompasses (TCM, München) wurde die Exposition bestimmt. Dazu wurde der Kompass streng hangabwärts ausgerichtet und die Exposition in Grad $\left(^{\circ}\right)$ festgehalten.

b) Inklination: Mit Hilfe einer Neigungswasserwaage (Sola, Götzis, Österreich) wurde die Inklination bestimmt. Die Wasserwaage wurde dabei streng hangabwärts ausgerichtet und die Inklination in Grad $\left(^{\circ}\right)$ festgehalten.

c) Bedeckung mit Gestein: Es wurde der Anteil der Fläche, der mit kleineren oder größeren Gesteinsbrocken bedeckt war und somit für die Besiedlung mit BSCs ungeeignet war, abgeschätzt. Dieser Wert wurde in Prozent (\%) notiert.

d) Reliefposition: Es wurde die Lage der vom Quadrat eingefassten Fläche innerhalb des Hangreliefs notiert. Dabei wurde zwischen Ober-, Mittel- und Unterhang unterschieden. 
e) Wölbung: Die vom Quadrat eingefasste Fläche wurde hinsichtlich ihrer Wölbung beurteilt und die Beurteilung wurde in Wölbungsgraden ausgedrückt, wobei $3=$ stark konvex, $0=$ neutral und $-3=$ stark konkav war.

f) Anzahl der Phanerogamenarten: Es wurden die Pflanzenarten, die innerhalb des Quadrates wurzelten, gezählt. Für einige Analysen wurden auch die Artnamen, so weit möglich, angegeben. Wenn dies nicht möglich war, wurden Herbarexemplare gesammelt und später nachbestimmt.

g) Bedeckung mit Phanerogamen: Es wurde der Anteil der Fläche, der mit Phanerogamen bedeckt war, abgeschätzt. Für manche Analysen wurden die Pflanzenarten zusätzlich noch in unterschiedliche Morphologieklassen eingeteilt und die Flächenbedeckung dieser Klassen einzeln eingeschätzt. Diese Werte wurden in Prozent (\%) notiert.

h) Anzahl der Kryptogamenarten: Es wurden, soweit möglich, die Flechten-, Moos- und Algenarten auf der vom Quadrat umschlossenen Fläche gezählt. Dieser Wert dient nur dem Vergleich der Quadrate untereinander, da es im Freiland nicht möglich war, alle Arten zu detektieren. Manche Bodenflechten waren so klein, dass sie erst unter dem Binokular wahrgenommen werden konnten. Da man nicht davon ausgehen kann, dass die Existenz dieser Spezies in jedem Fall nachgewiesen konnte, gingen zufällige Funde an mitgebrachtem Material nicht in die Studien ein. An Algenarten wurde nur ein sehr auffälliges Nostoc-Lager in die Studien aufgenommen, alle anderen waren selbstverständlich ebenfalls zu klein. Für einige Analysen wurden auch die Artnamen, so weit möglich, angegeben. Wenn dies nicht möglich war, wurden Herbarexemplare gesammelt und später nachbestimmt.

i) Bedeckung mit BSCs: Es wurde der Anteil der Fläche, der mit Biologischen Bodenkrusten (BSCs) bedeckt war, abgeschätzt. Diese Werte wurden in Prozent (\%) notiert.

j) Störungsgrad: Für manche Analysen wurde noch der Störungsgrad der Flächen in Klassen von 0-4 abgeschätzt, wobei 0 keine Störung bezeichnete und 4 eine starke. Hierzu wurden Erosionsspuren (z.B. Wasserrinnen) oder Trittspuren (meist von Pferden) berücksichtigt.

k) Enfernung zum Bergrücken: Für manche Analysen wurde die Entfernung des Mittelpunktes des Zählquadrates zum Bergrücken (in m) angegeben. 


\subsubsection{Bestimmung der Organismen}

Die phanerogomen Pflanzen, Moose und Flechten wurden anhand der in den Tabellen 3.1-3.3 gezeigten Materialien bestimmt. Wo eine zweifelsfreie Bestimmung bis zur Art nicht möglich war, wurde nach Möglichkeit bis zur Gattung bestimmt. Algen wurden nach Ettl und Gärtner (1995) bestimmt.

\begin{tabular}{|l|l|}
\hline \multicolumn{2}{|c|}{ Bestimmung der Gefäßpflanzen } \\
\hline Bestimmungsliteratur & Weitere Hilfsmittel \\
\hline - Schmeil-Fitschen (1983) & - Dulamsuren (2006), Artenliste für Khonin \\
- Grubov (2000) & Nuga \\
& - Mongoleisammlung des Herbariums der \\
& Universität Halle \\
\hline
\end{tabular}

Tab. 3.1: Bestimmung der Gefäßpflanzen.

\begin{tabular}{|l|l|}
\hline \multicolumn{2}{|c|}{ Bestimmung der Moose } \\
\hline Bestimmungsliteratur & Weitere Hilfsmittel \\
\hline - Frahm und Frey (2004) & $\begin{array}{l}\text { - Tsegmed (2001), Artenliste für die } \\
\text { Mongolei }\end{array}$ \\
& $\begin{array}{l}\text {-Karczmarz und Swies (1981), Artenliste für } \\
\text { den Khentej }\end{array}$ \\
& - Grolle et al. (1983, 1986) \\
& - Schubert et al. (1977) \\
\hline
\end{tabular}

Tab. 3.2: Bestimmung der Moose. 


\begin{tabular}{|c|c|c|}
\hline \multicolumn{3}{|c|}{ Bestimmung der Flechten } \\
\hline $\begin{array}{c}\text { Erste Orientierung bis zur } \\
\text { Gattung }\end{array}$ & Gattung/Gruppe & $\begin{array}{l}\text { Schlüssel und } \\
\text { Monographien }\end{array}$ \\
\hline \multirow{8}{*}{$\begin{array}{l}\text { - Poelt (1969). } \\
\text {-Wirth (1987, 1995) } \\
\text { - Doll (1981) } \\
\text {-Goward et al. (1994, 1999) }\end{array}$} & Catapyrenium & -Breuss (1996) \\
\hline & Cladonia & -Ahti (2000) \\
\hline & Collema & -Degelius (1974) \\
\hline & Diploschistes & -Lumbsch (1993a und b) \\
\hline & Heppia & $\begin{array}{l}\text {-Büdel (1987) } \\
\text {-Schultaz und Büdel (2002) }\end{array}$ \\
\hline & Peltigera & - Hartwig (1993) \\
\hline & Psora & $\begin{array}{l}\text {-Schneider (1979) } \\
\text {-Timdahl (1986) } \\
\text {-Timdahl (2004) }\end{array}$ \\
\hline & Xanthoparmelia & $\begin{array}{l}\text { - Hale (1990) } \\
\text {-Nash et al. (1995) }\end{array}$ \\
\hline \multicolumn{3}{|c|}{$\begin{array}{l}\text { Weitere Hilfsmittel: Cogt (1979)-Artenliste, Schubert und Klement (1971)- Artenliste, } \\
\text { Vergleich mit der Mongoleisammlung des Herbariums der Universität Halle, } \\
\text { http://www.nhm.uio.no/botanisk/lav/Photo_Gallery/PG_index.html -Fotosammlung der } \\
\text { Universität Oslo, sehr viele Bodenflechten. }\end{array}$} \\
\hline
\end{tabular}

Tab. 3.3: Bestimmung der Flechten. 


\subsubsection{Versuchsflächen und Plotdesign}

\subsubsection{Vergleich verschiedener Standortsituationen von BSCs}

Hierfür wurden in der Umgebung der Forschungsstation zehn Standorte Biologischer Bodenkrusten ausgewählt, die sich in Bezug auf Exposition, Inklination, Flora und andere standörtliche Faktoren wie z.B. die Beschattung möglichst stark unterscheiden sollten. An diesen wurden Gesamtaufnahmen der vorkommenden Pflanzen- und Flechtenarten gemacht (wobei die sehr seltenen Arten hier nicht gewichtet wurden) und es wurden Proben für Bodenanalysen und die Erstellung bakterieller 16S rDNA-Standortgenbanken bzw. die Archaeen-DGGE entnommen. Für die Bodenanalysen wurde an verschiedenen Stellen des jeweiligen Hanges eine definierte Menge Boden des O-Horizontes entnommen und anschließend vereinigt.

\subsubsection{Der Einfluss verschiedener Standortfaktoren auf das Vorkommen und die Ausprägung Biologischer Bodenkrusten (BSCs)}

Hier wurde zunächst vergleichend an zwei Standorten eine größere Anzahl von Faktoren gleichzeitig aufgenommen und mit dem Auftreten (in \% Bedeckung mit BSCs) und der Ausprägung (Anzahl der aufgenommenen Kryptogamenarten) in Bezug gesetzt. Weiterhin wurden für einzelne Standortfaktoren (Exposition/Inklination, Störung und dem Auftreten von Phanerogamen) jeweils deren einzelnener Einfluss auf Vorkommen und Ausprägung der BSCs untersucht.

\subsection{Analyse der Standortfaktoren}

Es wurde an Standort A ein Netz aus Linientransekten und an Standort F ein Linientransekt angelegt. Entlang dieser wurden dann das Zählquadrat ausgelegt und die Beobachtungsquadrate fest markiert, da die Analysen längere Zeit dauern sollten. Zwischen den Quadraten lag jeweils ein Meter. Für diese Quadrate wurden jeweils die Parameter a) - i) (siehe Kap. 3.1.1) festgehalten und diese später verschiedenen statistischen Prozeduren unterzogen (siehe Kap. 3.4). 


\subsubsection{Der Einfluss von Exposition und Inklination auf die Ausprägung Biologischer Bodenkrusten (BSCs)}

Es wurde entlang von sehr langen Linientransekten, welche an den unbewaldeten Hängen dreier Bergketten entlangliefen, alle $5 \mathrm{~m}$ das Zählquadrat abgelegt und innerhalb dessen wurden die Exposition, die Inklination und die Anzahl der innerhalb des Quadrates gefundenen Kryptogamen aufgenommen.

\subsection{Der Einfluss der phanerogamen Vegetation auf das Vorkommen und die Ausprägung Biologischer Bodenkrusten (BSCs)}

Das Zählquadrat wurde entsprechend der in Kap. 3.1.1 beschriebenen Zufallsmethode an drei verschiedenen Standorten insgesamt 165-mal ausgeworfen. Innerhalb des Quadrates wurden die Bedeckung mit BSCs, die Anzahl an Kryptogamenarten, die Gesamtpflanzenbedeckung, die Anzahl an Pflanzenarten und die Bedeckung der Pflanzen in fünf verschiedenen Morphologieklassen aufgenommen. Diese Klassen orientierten sich an der Wuchsform der Pflanzen, da vermutet wurde, dass sich z.B. die Anwesenheit einer relativ niedrigen Pflanze, die wenig Boden beschattet, anders auswirkt als die Anwesenheit von Gras oder höheren Kräutern.

\subsection{Der Einfluss von Störung auf das Vorkommen und die Ausprägung Biologischer Bodenkrusten (BSCs)}

Eine im Jahr 2006 durch mehrere Monate andauernde, regelmäßige Trittbeschädigung gestörte Fläche wurde im Jahr darauf auf die Bedeckung mit BSCs und phanerogamen Pflanzen untersucht und mit ungestörten Flächen, die direkt benachbart lagen, verglichen. Auch hier wurden entlang von Linientransekten Zählquadrate ausgebracht. 


\subsubsection{Heuschreckenfraß}

Es wurden an Standort B bei sonnigem Wetter Exemplare jeder dort zu diesem Zeitpunkt anzutreffenden Heuschreckenart gefangen. Diese wurden bestimmt und für eine Woche einzeln gehalten. Es wurden jeder Heuschrecke gleichzeitig und nacheinander verschiedene Kräuter, BSCs und fleischliche Nahrung angeboten, um ihre Nahrungspräferenzen zu ermitteln.

\subsubsection{Bodenoberflächentemperaturen}

Mithilfe eines Infrarotthermometers (Easyflash; TFA, Wertheim-Reichlzheim) wurden in den an Standort A installierten Zählqadraten (Vgl. Kap. 3,1.2.2.1) Bodenoberflächentemperaturen gemessen. Dazu wurden pro Quadrat und Durchlauf 12 Werte festgehalten. Diese Messungen wurden transektweise innerhalb weniger Minuten fertiggestellt, um die Quadrate miteinander vergleichen zu können. Die Messungen wurden zu unterschiedlichen Tageszeiten wiederholt und fanden vom 18.08. bis zum 21. 08. 2006 statt. 


\subsubsection{Grundlegende Methoden}

\subsubsection{Stämme und Wachstumsbedingungen}

\subsection{Bakterielle Stämme, Plasmide und Oligonucleotide}

Der verwendete Escherichia coli-Stamm, das Plasmid und die 16S-rDNA-Gen-Primer für die Amplifikation sind in den folgenden Tabellen 3.4 - 3.6 dargestellt.

\begin{tabular}{|c|c|c|}
\hline $\begin{array}{l}\text { E. coli - } \\
\text { Stamm }\end{array}$ & Genotyp & Quelle \\
\hline TOP10 ${ }^{\circledR}$ & $\begin{array}{l}\text { F- mcrA } \Delta(m m r-h s d \text { RMS -mcrBC } \\
\varphi 80 l a c Z \Delta l a c X 74 \text { recA1 araD139 } \\
\Delta \text { (araleu)7697 galU galK rpsL (StrR) endA1 } \\
\text { nupG }\end{array}$ & Invitrogen, Karlsruhe \\
\hline
\end{tabular}

Tab. 3.4: In der Arbeit benutzter E. coli-Stamm.

\begin{tabular}{|l|l|l|}
\hline Plasmid & Relevantes Charakteristikum & Quelle \\
\hline pCR2.1-TOPO $^{\circledR}$ & $\mathrm{Ap}^{\mathrm{r}}, \mathrm{Kan}^{\mathrm{r}}$, pMB1-Replikon & Invitrogen, Karlsruhe \\
\hline
\end{tabular}

Tab. 3.5: In der Arbeit benutzter Vektor. 
3 Material und Methoden

\begin{tabular}{|c|c|c|c|}
\hline Primer & Sequenz $\left(5^{`}-3^{`}\right)$ & Spezifität & Referenz \\
\hline $8 \mathrm{~F}$ & GGATCCAGACTTTGATYMTGGCTCAG & Bacteria & $\begin{array}{l}\text { Ben-Dov et al., } \\
2006\end{array}$ \\
\hline 1114R & GGGTTGCGCTCGTTRC & Bacteria & $\begin{array}{l}\text { Modifiziert von } \\
\text { Reysenbach und } \\
\text { Pace, } 1995\end{array}$ \\
\hline $\mathrm{A} 21 \mathrm{~F}$ & TTCCGGTTGATCCTGCCGGA & Archaea & Alain et al., 2002 \\
\hline A958R & YCCGGCGTTGAMTCCAATT & Archaea & Alain et al., 2002 \\
\hline $\begin{array}{l}\text { ARC } \\
344 F\end{array}$ & ACGGGGYGCAGCAGGCGCGA & Archaea & $\begin{array}{l}\text { Casamayor et al., } \\
2000\end{array}$ \\
\hline $\begin{array}{l}\text { ARC } \\
344 F- \\
\text { GC }\end{array}$ & $\begin{array}{l}\text { CGCCCGCCGCGCCCCGCGCCCGTCCCGCCG } \\
\text { CCCCCGCCCGAACGGGGYGCAGCAGGCGC } \\
\text { GA }\end{array}$ & Archaea & $\begin{array}{l}\text { Casamayor et al., } \\
2000\end{array}$ \\
\hline 915R & GTGCTCCCCCGCCAATTCCT & Archaea & $\begin{array}{l}\text { Casamayor et al., } \\
2000\end{array}$ \\
\hline
\end{tabular}

Tab. 3.6: In der Arbeit benutzte Primer, Sequenz und Spezifität. 


\subsection{Medien}

Medien wurden durch Autoklavieren bei $121^{\circ} \mathrm{C}$ für 30 min sterilisiert. Zur Herstellung von Agarplatten wurden dem Medium vor dem Autoklavieren noch 1,5\% $[\mathrm{w} / \mathrm{v}]$ Agar-Agar (Difco, Heidelberg) zugegeben.

\section{LB ( Luria-Bertani)-Medium (Sambrook, 1989)}

$\begin{array}{lc}\text { Trypton } & 10 \mathrm{~g} \\ \text { Hefeextrakt } & 5 \mathrm{~g} \\ \mathrm{NaCl} & 10 \mathrm{~g} \\ \mathrm{H}_{2} \mathrm{O}_{\text {Millipore }} & \text { ad } 1000 \mathrm{ml}\end{array}$

SOC-Medium (Hanahan, 1983)

$\begin{array}{lc}\text { Trypton } & 20 \mathrm{~g} \\ \text { Hefeextrakt } & 5 \mathrm{~g} \\ \mathrm{NaCl} & 0,5 \mathrm{~g} \\ 1 \mathrm{M} \mathrm{KCl} & 2,5 \mathrm{ml} \\ \mathrm{H}_{2} \mathrm{O}_{\text {Millipore }} & \text { ad } 1000 \mathrm{ml}\end{array}$

Das SOC-Medium wurde vor dem Autoklavieren mit $10 \mathrm{NaOH}$ auf pH 7,0 eingestellt. Nach dem Autoklavieren wurden noch $20 \mathrm{ml}$ sterilfiltrierte $1 \mathrm{M}$ Glucoselösung und $20 \mathrm{ml}$ sterile $1 \mathrm{M} \mathrm{MgCl}_{2}$-Lösung hinzugegeben. 


\subsection{Antibiotika und Medienzusätze}

\begin{tabular}{|l|l|l|}
\hline Supplement & Stammlösung & Arbeitskonzentration \\
\hline Ampicillin & $50 \mathrm{mg} / \mathrm{ml} 50 \%$ Ethanol & $50-100 \mathrm{mg} / \mathrm{ml}$ \\
\hline IPTG & $26 \mathrm{mg} / \mathrm{ml} \mathrm{H}_{2} \mathrm{O}_{\text {Millipore }}$ & $50 \mathrm{mg} / \mathrm{ml}$ \\
\hline X-Gal & $20 \mathrm{mg} / \mathrm{ml}$ & $40 \mathrm{mg} / \mathrm{ml}$ \\
& Dimethylformamid & \\
\hline
\end{tabular}

Tab 3.7: In der Arbeit verwendete Antibiotika und weitere Medienzusätze.

Alle Medienzusätze wurden sterilfiltriert. Die Zugabe der Supplemente fand nach der Abkühlung des autoklavierten Mediums auf mindestens $60^{\circ} \mathrm{C}$ statt. Die Supplemente wurden bei $-20{ }^{\circ} \mathrm{C}$ aufbewahrt.

\subsection{Wachstumsbedingungen}

Die rekombinanten Stämme von E. coli, DH5 $\alpha$ und Top $10^{\circledR}$ wurden auf LB-Festmedium über Nacht bei $37{ }^{\circ} \mathrm{C}$ gezogen. Die erforderlichen Supplemente (siehe Tab. 3.7) wurden dem Medium vor dem Erstarren zugegeben.

\subsection{Lagerung der Stämme}

E. coli- Stämme auf Agarplatten wurden höchstens für zwei Wochen bei $4{ }^{\circ} \mathrm{C}$ gelagert. Für eine längerfristige Lagerung wurden die geeigneten Kolonien in 96-Well-Platten mit LBFlüssigmedium mit Ampicillin [50 mg/ml] gepickt und in der logarithmischen Phase ihres Wachstums mit je 10 Volumenprozent DMSO vermischt. Nun konnten sie bei $-70{ }^{\circ} \mathrm{C}$ für längere Zeit gelagert werden. 


\subsubsection{Ermittlung von Wachstumsparametern/Optische Dichte}

Die optische Dichte $\left(\mathrm{OD}_{600}\right)$ bakterieller Suspensionen wurde während des Wachstums mittels eines Spektrophotometers (Ultrospec 3000; Pharmacia, Cambridge) bestimmt. Dazu wurden die Suspensionen gegen einen Nullwert des jeweiligen Mediums gemessen. Bei optischen Dichten über 0,3 wurde die Suspension 1:1 mit frischem Medium verdünnt.

\subsubsection{Isolation genomischer (Gesamt-)DNA}

Es wurde je zu untersuchender Fläche eine in Art und räumlicher Verteilung (also verschiedene Krustentypen von verschiedenen Punkten im Gelände) repräsentative Anzahl biologischer Bodenkrusten vereinigt und fein zermörsert. Das Mazerat wurde durch Schütteln sehr gut vermischt und anschließend wurden jeweils 0,25 g des Pulvers zur DNA-Isolation verwendet.

Diese wurde mit Hilfe des Power Soil ${ }^{T M}$ DNA-Kits (Mo Bio, Carlsbad, Kalifornien, USA) isoliert. Dabei wurde weitestgehend das vom Hersteller beigefügte Protokoll eingehalten. Da auch geringe Mengen Ethanol eine PCR nachhaltig stören können, wurde jedoch der Schritt des Abzentrifugierens des Waschpuffers auf drei Minuten erhöht. Um die DNA-Ausbeute zu erhöhen, wurde nach Zugabe des Wassers (statt des Elutionspuffers) drei Minuten inkubiert, damit mehr DNA in Lösung gehen konnte, bevor das Eluat durch Zentrifugation aus der Säule gewaschen wurde. Dieses sollte nun die die gesamte genomische DNA aller in der Probe zu findenden Organismen enthalten und musste durch weitere Schritte auf die 16SrDNA der Bacteria und der Archaea selektiert werden. Dies geschah durch die Auswahl der Primer in der PCR (siehe Tab. 3.6). 


\subsubsection{Grundlegende Methoden zur qualitativen und quantitativen Bestimmung von DNA-Fragmenten}

\subsection{Agarose-Gelelektrophorese (Sambrook 1989)}

Durch Agarose-Gelelektrophorese konnte geprüft werden, ob DNA im Produkt eines Isolations- oder Amplifikationsschrittes enthalten war, wenn ja, ob das Fragment die richtige Größe hatte und abgeschätzt werden, wie groß die Menge dieser DNA war. Die DNA musste dazu mit 10x Ladepuffer beschwert werden.

\section{0x Ladepuffer}

Bromphenolblau

$125 \mathrm{mg}$

$150 \mathrm{mM}$ Tris $(\mathrm{pH} 7,6) \quad 16,5 \mathrm{ml}$

Glycerin $30 \mathrm{ml}$

$\mathrm{H}_{2} \mathrm{O}_{\text {Millipore } \quad 3,5 \mathrm{ml}}$

Für die Gelelektrophorese wurden je 1-3 $\mu$ der DNA-Lösungen mit jeweils $1 \mu \mathrm{l} 10 \mathrm{x}$ Laufpuffer vermischt auf ein 1\%iges, mit TAE angesetztes [w/v] Agarosegel von etwa 1525ml Volumen aufgetragen und an die Gelkammer (Selbstbau der Werkstatt des Institutes) wurde für 40-60 min. eine konstante Spannung von 90 -120 V angelegt (Power Supply: Power Pac 300; Bio Rad, Berkeley, Kalifornien, USA). Als Laufmittel diente 1x TAEPuffer, der aus einer Stammlösung (50x TE) jeweils frisch hergestellt wurde.

\section{0x TAE-Puffer}

Tris $242 \mathrm{~g}$

Essigsäure (100\%) $\quad 57,1 \mathrm{ml}$

0,5 M EDTA (pH 8,0) $100 \mathrm{ml}$

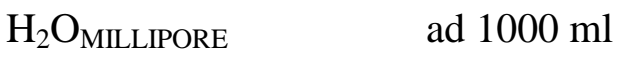

Zur Beurteilung der DNA-Fragmente wurden diese gegen Standards aufgetragen. Es wurden dazu die Größenmarker Gene Ruler ${ }^{T M} 1$ kb DNA ladder und 100 bp DNA ladder (Fermentas, St. Leon-Rot) verwendet (siehe Abb. 3.1). 
3 Material und Methoden

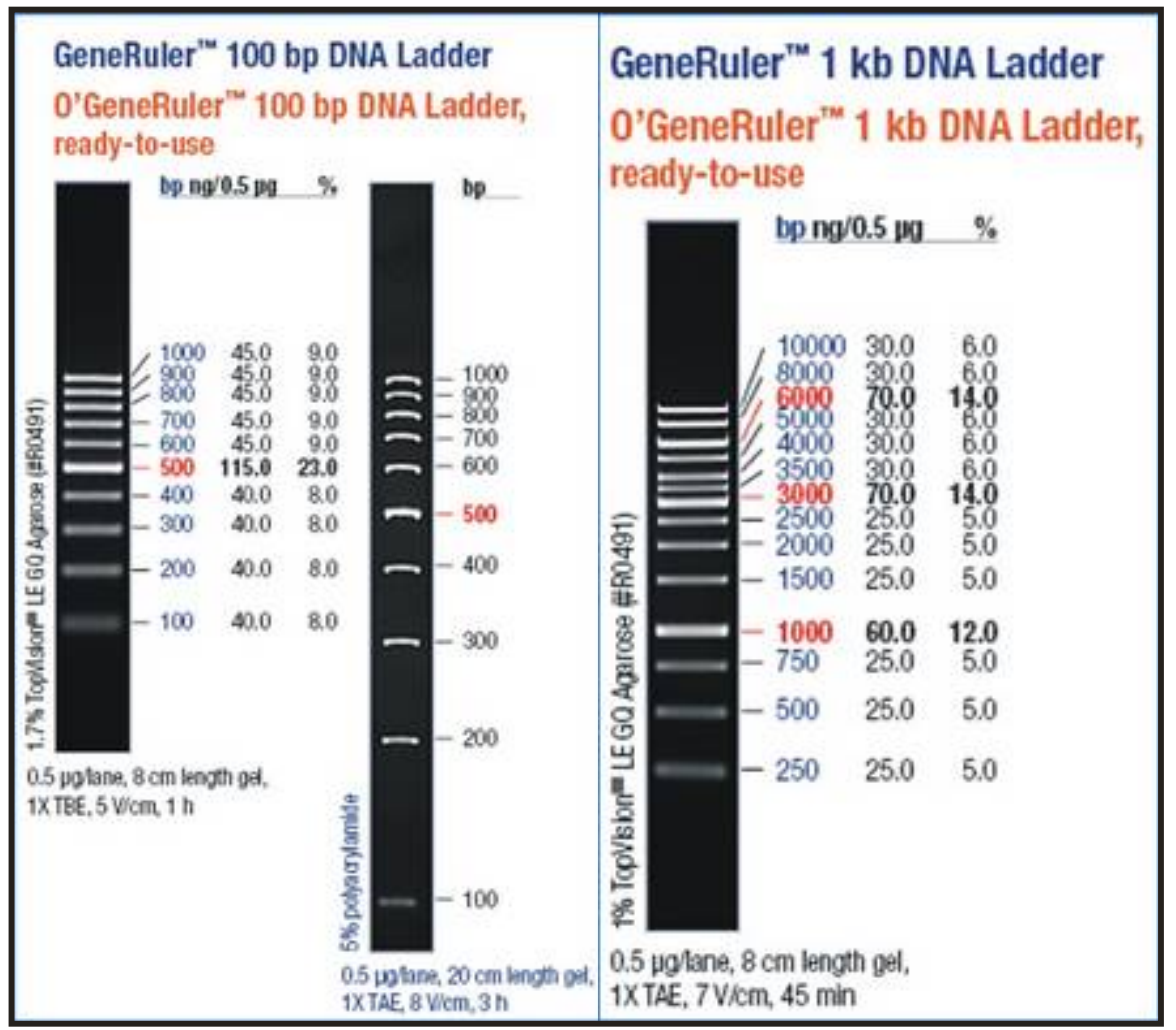

Abb. 3.1: Verwendete DNA-Größenmarker.

Nach dem Gellauf wurde das Gel zur Sichtbarmachung der DNA in einer Ethidiumbromidlösung $\left(1 \mu \mathrm{g} / \mathrm{ml} \mathrm{H}_{2} \mathrm{O}_{\text {Millipore }}\right)$ für 10-20 min. gefärbt und danach kurz im Wasserbad von überflüssigem Ethidiumbromid befreit. Die DNA-Banden konnten dann unter UV-Licht mit Hilfe einer Geldokumentationsanlage (ImageQuant 100; GE Healthcare, München) detektiert und dokumentiert werden.

\subsection{Konzentrationsbestimmung für DNA}

Die Konzentration eines in sterilem $\mathrm{H}_{2} \mathrm{O}_{\text {Millipore }}$ eluierten PCR-Produktes konnte mittels eines Spektrophomtometers (Nano Drop ND 1000; Peqlab Biotechnology, Erlangen) gegen Wasser ermittelt werden. 


\subsubsection{Polymerase-Kettenreaktion (Polymerase chain reaction, PCR)}

Zur gezielten Amplifikation von Bakterien- bzw. Archaeen-16S-rDNA wurden jeweils für diese Gruppen spezifische Primerpaare (siehe Tab. 3.6) eingesetzt. Zur Analyse von Fragmenten mittels einer denaturierenden Gradientengelelektrophorese (DGGE) war es notwendig, einen Primer mit einer zusätzlichen Guanin- und Cytosinreichen Sequenz (GCClamp) am 5'-Ende zu verwenden. Diese verhindert ein vollständiges Aufschmelzen der dsDNA im DGGE-System und steigert die Detektierbarkeit der Sequenzunterschiede sehr stark. Die Auswahl der Primer sollte gewährleisten, dass 1. die Amplifikation einer ausreichenden Menge von 16S rDNA stattfinden kann, 2. die rDNA möglichst vieler Arten der Zielorganismengruppe amplifiziert wird, ohne dass DNA einer anderen Gruppe amplifiziert wird, 3. sich die Größe der synthetisierten rDNA-Fragmente möglichst nicht unterscheidet und 4. sollten die Sequenzen der amplifizierten DNA-Region sich innerhalb der Gruppe stark genug unterscheiden, damit, zumindest im Falle der Archaeen-Sequenzen, eine auswertbare Auftrennung mittels DGGE stattfinden kann. Wegen der vor Versuchsbeginn angenommenen großen Artenzahl der Bakterienarten in den Proben wurde für die Bacteria ein anderer Ansatz gewählt, da zu befürchten stand, dass diese Anzahl zu stark übereinander liegenden Banden führen würde und eine vollständige Auftrennung und somit Abgrenzung der einzelnen Arten nicht stattfinden würde.

Die isolierten DNA-Mengen aus den Bodenkrusten waren meist nicht sehr groß. Da die Häufigkeit der Archaeen-DNA für Proben dieses Standortes als sehr gering angenommen werden konnte, wurden verschiedene Anpassungen der PCR-Bedingungen vorgenommen, welche die DNA-Ausbeute steigern sollten. Es wurde eine sog. nested PCR durchgeführt. Diese besteht aus zwei Amplifikationsrunden mit jeweils unterschiedlichen Primerpaaren. Bei der ersten Runde wird das extrahierte DNA-Material (siehe Kap. 3.2.1.3) eingesetzt. Das so gewonnene Amplifikat wurde dann in einer zweiten Runde wiederum vervielfältigt. Dafür war es selbstverständlich notwendig, dass die Bindestellen des zweiten Primerpaares innerhalb der Sequenz des ersten Primerpaares liegen. Die Sequenzen des zweiten Amplifikates sind also etwas kürzer als die des zweiten. Durch diese Methode wird außer der Ausbeute auch die Spezifität der PCR erhöht. Dies wurde mit der sog. touchdown PCR kombiniert (Tab. 3.10; Muyzer et al., 1993 und 1996). Die Methode erhöht durch eine schrittweise Annäherung der Annealingtemperatur an die zu erwartende Schmelztemperatur 
3 Material und Methoden des Primers die Spezifität der Primerbindung und es werden Primer-Dimere und Artefakte vermindert.

Nach der DGGE (siehe Kap. 2.3) musste die archaeelle DNA aus dem Gel ausgeschnitten und durch eine PCR (siehe Tab. 3.10) reamplifiziert werden. Dieses geschah nach dem gleichen Protokoll wie dem der vorangegangenen nested PCR.

Die PCRs wurden jeweils in $200 \mu$ l PCR-Gefäßen (Greiner, Nürtlingen) durchgeführt. Das Reaktionsvolumen betrug jeweils $50 \mu$ l. Für die PCR-Ansätze wurde jeweils ein Mastermix angefertigt. Es wurde zweifach autoklaviertes $\mathrm{H}_{2} \mathrm{O}_{\text {Millipore verwendet. Die Komponenten eines }}$ Standardansatzes sind Tab. $3.8 \mathrm{zu}$ entnehmen. Die PCRs wurden für die verschiedenen Primerpaare unter unterschiedlichen Bedingungen durchgeführt. Die Archaeen-PCRs wurden in einem FlexCycler (Analytik Jena, Jena) vorgenommen, die Programme können den Tabellen 3.9 und 3.10 entnommen werden. Die PCRs für Bacteria fanden in einem Gerät statt, in welchem Gradienten-PCRs durchgeführt werden können (Mastercycler Gradient; Eppendorf, Hamburg). Aus Erfahrung weiß man, dass eine PCR mit Boden-DNA oft bei unterschiedlichen Annealingtemperaturen unterschiedlich ausfällt. So konnten je Probe und Primerpaar die besten Bedingungen ausgetestet werden und es wurde anschließend die Probe weiterverarbeitet, die die meiste und sauberste DNA enthielt. Dies stellte man mittels der Agarose-Gelelektophorese (siehe Kap. 3.2.1.4.2) fest. Es wurden je PCR drei Gradienten eingestellt, dabei variierte die mittlere in der Tabelle 3.11 angegebene Annealingtemperatur jeweils nach oben und nach unten um $1,8^{\circ} \mathrm{C}$.

Alle PCR-Produkte wurden durch Agarose-Gelelektrophorese überprüft, die Ergebnisse konnten durch Paralleluntersuchungen an je einer Negativ- und einer Positivkontrolle verifiziert werden. Dann wurde das Amplifikat entweder durch Gelelektrophorese und anschließende Gelextraktion oder durch ein PCR-Aufreinigungskit (PeqGold Cycle Pure Kit, PeqLab Biochemikalien GmbH, Erlangen; Aufreinigung nach Herstellerprotokoll, Elution in $35 \mu \mathrm{l}$ sterilem $\mathrm{H}_{2} \mathrm{O}_{\text {Millipore}}$ ) von Präparationsartefakten befreit. 


\begin{tabular}{|c|c|}
\hline \multicolumn{2}{|c|}{ Komponenten eines 50 pl PCR-Standardansatzes } \\
\hline $31,2 \mu \mathrm{l}$ & steriles $\mathrm{H}_{2} \mathrm{O}_{\text {Millipore }}$ \\
\hline $1 \mu \mathrm{l}$ & dNTPs (10 mM) \\
\hline $5 \mu \mathrm{l}$ & 10x Taq-Puffer (NH4)SO4 \\
\hline $3,5 \mu \mathrm{l}$ & $\mathrm{MgCl} 2$ \\
\hline $4 \mu \mathrm{l}$ & F-Primer (siehe Tab. 3.6) \\
\hline $4 \mu \mathrm{l}$ & R-Primer (siehe Tab. 3.6) \\
\hline $0,3 \mu \mathrm{l}$ & Taq-Polymerase (5 U/ $\mu \mathrm{l})$ \\
\hline $1 \mu \mathrm{l}$ & DNA-Template* \\
\hline \multicolumn{2}{|c|}{$\begin{array}{l}\text { *Die Mengen des eingesetzten DNA-Templates variierten je nach DNA-Konzentration der Lösung. } \\
\text { Entsprechend wurde mehr oder weniger steriles } \mathrm{H}_{2} \mathrm{O}_{\text {Millinore }} \text { eingesetzt. }\end{array}$} \\
\hline
\end{tabular}

Tab. 3.8: Komponenten eines PCR-Standardansatzes.

Es wurden die nachfolgenden Programme benutzt:

\begin{tabular}{|l|l|l|l|}
\hline Zyklusbezeichnung & Temperatur $^{\circ} \mathbf{C}$ & Zeit (min) & Anzahl der Zyklen \\
\hline Initiale Denaturierung & 94 & 3 & 1 \\
\hline Denaturierung & 94 & 1 & 28 \\
Annealing & 58 & 1,5 & \\
Elongation & 72 & 2 & \\
\hline Terminale Elongation & 72 & 76 & \\
\hline
\end{tabular}

Tab. 3.9: Erste, universelle Amplifikation der Archaeen-16S rDNA (Alain et al., 2005; Primer vgl. Tab. 3.6: A21f und A958r). 


\begin{tabular}{|l|l|l|l|}
\hline Zyklusbezeichnung & Temperatur $^{\circ}$ C & Zeit (min) & Anzahl der Zyklen \\
\hline Initiale Denaturierung & 94 & 5 & 1 \\
\hline Annaturierung & 94 & 1 & 20 \\
Elongation & $\begin{array}{l}71-61(-1 \text { alle } 2 \\
\text { Zyklen) }\end{array}$ & 1 & 3 \\
\hline Annaturierung & 72 & 1 & 15 \\
Elongation & 61 & 1 & 1 \\
\hline Terminale Elongation & 72 & 3 & 10 \\
\hline
\end{tabular}

Tab. 3.10: Touchdown-PCR/Nested-PCR der Archaeen-16S rDNA (Muyzer et al., 1993 und 1996; Primer vgl. Tab. 3.6: ARC344F-GC und 915R) und Reamplifikation der Archaeen-16S rDNA nach der DGGE (Primer vgl. Tab. 3.6: ARC344F und ARC915R).

\begin{tabular}{|l|l|l|l|}
\hline Zyklusbezeichnung & Temperatur $^{\circ} \mathbf{C}$ & Zeit (min) & Anzahl der Zyklen \\
\hline Initiale Denaturierung & 94 & 2 & 1 \\
\hline Denaturierung & 94 & 1 & 25 \\
Annealing & $58+$ Grad. 5 & 1,5 & 1 \\
\hline Elongation & 72 & 1,33 & 10 \\
\hline Terminale Elongation & 72 & 10 & \\
\hline
\end{tabular}

Tab. 3.11: Universelle Amplifikation der Bakterien-16S rDNA (Modifiziert von Reysenbach und Pace, 1995; Primer vgl. Tab. 3.6: 8F und 1114R). 


\subsubsection{Gelextraktion}

Zur Aufreinigung der bakteriellen 16S rDNA nach der PCR wurde eine Gelextraktion durchgeführt. Dazu wurde der gesamte PCR-Ansatz bis auf $6 \mu$ auf ein 1\%iges Agarosegel (w/v TAE) geladen und äquivalent zum Vorgehen, wie es in Kap. 3.2.1.4.1 beschrieben wurde, elektrophoriert. Dabei wurden in die Geltaschen links und rechts neben der Hauptmenge der DNA noch jeweils $3 \mu \mathrm{l}$ der gleichen DNA aufgetragen. Daneben wurde jeweils der Größenstandard pipettiert. Nach dem Gellauf wurden nun die Gelstücke mit den Vergleichsbanden und dem Größenstandard vom Gel abgeschnitten und nur diese wurden gefärbt und die DNA mittels UV-Licht detektiert. Auf diesen Gelstücken wurde nun durch Einschnitte mit einem Skalpell die untere und obere Laufgrenze der gewünschten Bande markiert. Nach dem Abschalten des UV-Lichtes konnte nun das Gel wieder zusammengesetzt werden und anschließend die Bande auf dem Hauptstück des Gels entlang ihrer geschätzten Verlaufslinien ausgeschnitten werden.

Die DNA wurde anschließend mit Hilfe des PeqGold Gel Extraction Kits ${ }^{T M}$ (PeqLab Biotechnologie GmbH, Erlangen) aufgereinigt. Dabei wurde das Herstellerprotokoll insofern leicht abgewandelt, als dass die DNA in nur $30 \mu \mathrm{l}$ sterilem $\mathrm{H}_{2} \mathrm{O}_{\text {Millipore }}$ eluiert wurde und dafür eine dreiminütige Inkubation vor dem letzten Zentrifugationsschritt stand.

Diese DNA konnte nach quantitativer und qualitativer Kontrolle in die TOPO ${ }^{\circledR}$-Klonierung (siehe Kap. 2.2) eingesetzt werden.

\subsubsection{TOPO ${ }^{\circledR}$-Klonierung}

Für die Konstruktion je einer bakteriellen 16S rDNA-Standortgenbank der Standorte H und G wurden die wie in Kapitel 3.2.1 beschrieben behandelten DNA-Proben mit Hilfe einer Topoisomerase in den Vektor pCR2.1-TOPO ${ }^{\circledR}$ (Invitrogen, Karlsruhe) ligiert und anschließend in durch Hitzeschock zur Kompetenzentwicklung gebrachten Escherichia coliTOP10 ${ }^{\circledR}$ - Zellen (Invitrogen, Karlsruhe) kloniert. Für dieses Vorgehen lag dem Kit ein detailliertes Protokoll vor, welches für diese Arbeit in allen Punkten befolgt wurde. Die 
3 Material und Methoden

Ligationsdauer betrug 30 min. und der Vektor wurde vor der Tranformation 30 min auf Eis inkubiert. Der Vektor liegt linerarisiert vor und besitzt am 3'-Ende einen Desoxythymidinrest. An diesen können Sequenzen mit einem Desoxyadenosinüberhang durch die schon in den Vektor integrierte Topoisomerase ligiert werden. Um den Desoxyadenosinüberhang nicht verloren zu haben, mussten die PCR-Produkte absolut frisch sein und möglichst am selben Tag aufgereinigt worden sein. Nach der Transformation und anschließender einstündiger Inkubation bei $37^{\circ} \mathrm{C}$ wurden von den Zellen jeweils 1 x $10 \mu \mathrm{l}, 1$ x $30 \mu \mathrm{l}$ und der Rest in $50 \mu \mathrm{l}-$ Portionen auf Selektionsplatten (siehe Kap. 3.2.1.1.2) ausgestrichen. Nach einer Inkubation über Nacht konnten die weißen Klone mit autoklavierten Zahnstochern in frisches Flüssigmedium übertragen werden. Diese Ansätze wurden über Nacht wiederum bei $37{ }^{\circ} \mathrm{C}$ inkubiert und konnten dann einer Plasmidpräparation unterzogen werden. Diese wurde mit dem Quiagen Plasmid Midi Kit (Quiagen, Hilden) nach den Herstellerangaben vorgenommen.

Anschließend wurde ein Kontrollverdau mit EcoRI vorgenommen. Dafür wurden je $1 \mu \mathrm{l}$ Plasmid mit je einem $\mu \mathrm{l}$ EcoRI und EcoRI-Puffer (MBI Fermentas, St. Leon-Rot) versetzt, der Ansatz für $1 \mathrm{~h}$ bei $37^{\circ} \mathrm{C}$ inkubiert und anschließend einer Agarose-Gelelektrophorese unterzogen. War das Insert im Vektor enthalten, erhielt man drei Banden von charakteristischer Laufhöhe.

Dieser Test und eine Testsequenzierung wurden an jeweils 20 Klonen einer Klonierung vorgenommen. Für die Testsequenzierung wurde jeweils $1 \mu \mathrm{l}$ des Plasmides mit $3 \mu$ sterilem $\mathrm{H}_{2} \mathrm{O}_{\text {Millipore }}$ und einem $\mu \mathrm{l}$ des jeweiligen Primers (jeweils einmal mit dem Forward- und einmal mit dem Reverse-Primer) zur Sequenzierung gebracht. Lieferte dieses zufriedenstellende Ergebnisse, wurden die Klone im 96-Well-Platten-Maßstab sequenziert (siehe Kap. 2.4).

\subsubsection{Denaturierende Gradientengelelektrophorese (DGGE)}

Die DGGE wurde von Fisher und Lerman (1993) entwickelt, um Punktmutationen zu detektieren. Die durch PCR amplifizierten Fragmente des 16s rDNA-Gens haben ungefähr die gleiche Länge. Dieses ist durch die hohe evolutive Konservierung des Gens bedingt und 
dieses ist auch der Grund für seine Eignung zu phylogenetisch vergleichenden Analysen. So wird sich schon eine Einzelbasenmutation auf das Laufverhalten im DGGE-Gel auswirken. Die Fragmente werden also im Idealfall nach Spezies aufgetrennt.

Es werden hierfür Polyacrylamidgele mit ansteigendem denaturierenden Gradienten verwendet, wobei die Separation aufgrund der unterschiedlichen elektrophoretischen Mobilität der partiell aufgeschmolzenen DNA-Fragmente stattfindet. Diese entsteht durch das unterschiedliche Schmelzverhalten ungleicher Sequenzen, AT-reiche Sequenzen schmelzen hierbei bereits bei geringeren Konzentrationen an Harnstoff und Formamid als GC-reiche. Die an die Sequenz angehängte GC clamp verhindert durch ihre GC-Paarungen und die somit hohe Zahl an Wasserstoffbrückenbindungen, dass die doppelsträngige DNA vollständig zu einzelsträngiger denaturiert (Myers et al., 1985).

Für diese Arbeit wurden je Standort je ca. 200 ng archaeeller DNA in die DGGE mit dem Ingeny PhorU System (Ingeny International BV; Goes, Niederlande) eingesetzt. Der Gradient lief von 80\% zu 50\%. Tabelle 3.12 und 3.13 können die eingesetzten Konzentrationen der Chemikalien entnommen werden, wobei Tab. 3.12 die Stammlösungen wiedergibt, aus denen die Arbeitslösungen (Tab. 3.13) gemischt wurden. Als Laufpuffer wurde 1 x TAE (siehe Kap. 3.2.1.4.2) verwendet.

\begin{tabular}{|l|l|}
\hline 80 \%iger DGGE-Ansatz & $0 \%$ iger DGGE-Ansatz \\
\hline $15 \mathrm{ml}$ Bisacrylamid & -- \\
\hline $32 \mathrm{ml}$ Formamid & -- \\
\hline 33,6 g Harnstoff & -- \\
\hline $2 \mathrm{ml} 50 \mathrm{x}$ TAE & $2 \mathrm{ml} 50 \mathrm{x}$ TAE \\
\hline ad $100 \mathrm{ml} \mathrm{H}_{2} \mathrm{O}_{\text {Millipore }}$ & ad $100 \mathrm{ml} \mathrm{H}_{2} \mathrm{O}_{\text {Millipore }}$ \\
\hline
\end{tabular}

Tab. 3.12: Konzentrationen zur Herstellung der 0 \% und $80 \%$ igen DGGE-Gellösungen. 


\begin{tabular}{|l|l|l|l|}
\hline Gradientenlösungen & Sammelgel & $80 \%$ & $40 \%$ \\
\hline $80 \%$ ige Lösung & $0 \mathrm{ml}$ & $24 \mathrm{ml}$ & $12 \mathrm{ml}$ \\
\hline 0 \%ige Lösung & $6 \mathrm{ml}$ & 0 & $12 \mathrm{ml}$ \\
\hline TEMED & $6 \mu \mathrm{l}$ & $5 \mu \mathrm{l}$ & $5 \mu \mathrm{l}$ \\
\hline APS & $60 \mu \mathrm{l}$ & $50 \mu \mathrm{l}$ & $50 \mu \mathrm{l}$ \\
\hline
\end{tabular}

Tab. 3.13: Herstellung eines 40-80 \%igen DGGE-Gels. APS = Ammoniumpersulfat, TEMED = $N, N, N^{\prime}, N^{\prime}$, Tetramethylendiamin.

Nach dem DGGE-Lauf wurden die Banden mit SybrR Gold Nucleic Acid Gel Stain (Invitrogen, Carlsbad, Kalifornien, USA) gefärbt und mit einem Dark Reader ${ }^{\circledR}$ Transilluminator (Clarechemical; Dolores, Kalifornien, USA) sichtbar gemacht. Die Banden wurden einzeln ausgeschnitten und in vorbereitete Eppendorfcups, gefüllt mit sterilem

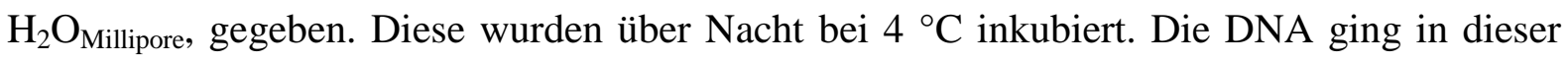
Zeit in Lösung und konnte aus der wässrigen Lösung durch erneute PCR (Protokoll siehe Tab. 3.10) reamplifiziert und anschließend sequenziert werden.

\subsubsection{Sequenzierung}

Das Göttinger Genomlabor $\left(\mathrm{G}_{2} \mathrm{~L}\right)$ bestimmte die Sequenzen von PCR-Produkten und Plasmiden. Anschließend wurden sie mit dem Staden Package (Staden et al., 2000) weiterbearbeitet, wobei zunächst Pregap4 (Bonfield et al., 1995) zum Entfernen von vektoriellen Kontaminationen und zu einer ersten Auslese von Sequenzen sehr schlechter Qualität verwendet wurde. Nach der Pregap4-Prozessierung wurden die Sequenzen in Gap4 assembliert. Dieses geschah über den PHRAP-Algorithmus (http://bozeman.mbt.washington.edu/phrap.docs/phrap.html), der in der Lage ist, Sequenzüberlappungen zu finden. Diese können für ein alignment und anschließendes joining 
3 Material und Methoden

der Sequenz zu einem contig genutzt werden. An diesem gibt das Programm die base confidence an, anhand derer die Qualität der Sequenz beurteilt werden kann. Fehler in der Assemblierung können nach manueller Sichtung korrigiert werden.

Anschließend wurden alle geeigneten Sequenzen manuell in eine Textdatei übertragen, welche abermals in das fasta-Format umgewandelt wurde. Im Anschluss daran wurde der Orientation Checker (http://www.bioinformatics-toolkit.org/) verwendet, um alle Sequenzen in sense - Richtung auszurichten.

Chimären wurden mit dem Bellerophon chimera detection program (http://foo.maths.uq.edu.au/ huber/bellerophon.pl, Huber et al., 2004) und Mallard (Ashelford et al., 2006) detektiert und aus den Datensätzen entfernt. Für die Verwendung in Mallard wurden die Sequenzen zuvor noch einem ClustalW-Alignment (Thompson et al., 1994) gegen eine E. coli-Referenzsequenz unterzogen.

Basierend auf einem Alignment von RDP wurden distance matrices über ein ebenfalls von RDP bereit gestelltes Tool auf der Webseite des Projektes (Ribosomal Database Project; Maidak et al., 1994, http://rdp.cme.msu.edu/) errechnet. Dabei wurden sie einer Korrektur nach Jukes und Cantor (1969) unterzogen. Mit diesen distance matrices wurden die OTUs (operational taxonomical units, Schloss und Handelsmann, 2005) über das Programm DOTUR errechnet. Eine OTU repräsentiert eine Anzahl von Sequenzen, die sich in nicht mehr als einer bestimmten Prozentzahl von Basen unterscheidet. In dieser Studie wurden die OTUs für die genetischen Distanzen von $3 \%$ (Unterscheidung auf Artebene) und $20 \%$ (Unterscheidung auf Phylla-Ebene) näher untersucht. Pro OTU auf Artebene wurde nur je eine Sequenz in die Berechnung der Stammbäume übernommen. DOTUR errechnet unter anderem den Shannon-Weaver-Index und den Simpson-Index als Maß für die Biodiversität eines Habitats. Die Artenvielfalt der Habitate in Abhängigkeit zur Zahl der untersuchten Sequenzen konnte über sog. rarefaction curves dargestellt werden. Weiterhin konnte DOTUR die potentielle Artenvielfalt des Habitats als abundance based coverage estimator (ACE, nicht parametrischer Artenvielfaltsschätzer, der auf der Verteilung von häufigen und seltenen OTUs beruht) und dem Bias-korrigierten Chao1-Schätzer (nicht parametrischer Schätzer, der auf der Verteilung von ein- und zweielementigen Mengen beruht) errechnen und ihre tatsächliche Ausschöpfung durch die Analyse konnte somit berechnet werden. 
Je OTU (bei 3 \%) wurde nun eine Sequenz mithilfe des Programmes BioEdit Sequence Alignment Editor in eine fasta-file pro Genbank kopiert. Die Sequenzdaten wurden nun über den RDP Classifier (Larsen et al., 1993, http://rdp.cme.msu.edu/) nach Phyla getrennt und anschließend wurden durch BLAST (Basic Local Alignment Search Tool; National Center for Biotechnology Information, Altschul et al., 1990) die Sequenzen der nächsten Verwandten innerhalb der BLAST-Datenbank ermittelt und den eigentlichen Sequenzdaten für die Errechnung der Stammbäume hinzugeladen.

Die Stammbäume wurden in Mega 4.0 (Molecular Evolution Genetics Analysis, Kumar et al., 2008) errechnet. Die Konstruktion der Stammbäume basierte auf einem neighbor-joining Algorithmus (Bruno et al., 2000). Die 16S rDNA-Sequenz des mit den gefundenen Bakterien entfernt verwandten Thermotoga maritima wurde als Wurzel des Stammbaumes verwendet. 


\subsection{Bodenanalysen}

\subsubsection{Entnahme von Bodenproben im Gelände}

Für diese Studie wurden an den unterschiedlichen Standorten bei trockenem Wetter jeweils etwa $50 \mathrm{ml}$ des Auflagehorizontes (O-Horizontes) entnommen. Es wurde an jeweils drei verschiedenen Stellen innerhalb des Hanges gesammelt und die Proben anschließend vereinigt. Wo die Reliefposition von Bedeutung war (Ober- Mittel- und Unterhang), wurde entlang einer Höhenlinie gesammelt. Bei den Standortgesamtproben wurde entlang einer Vertikallinie hangabwärts gesammelt. Die Proben wurden in sterilen $50 \mathrm{ml}$ Reagiergefäßen (Falcon-Tubes) aufbewahrt. Dabei war aufgrund des langen Zeitraumes ohne Kühlmöglichkeit im Gelände darauf zu achten, dass der Boden bei der Entnahme wirklich trocken war. Es wurde bei der Lagerung regelmäßig auf etwaige Kondenswasserbildung kontrolliert.

\subsubsection{Analysen zur Bestimmung bodenchemischer Standortfaktoren}

Zur Vorbereitung für die Laboranalysen wurden die Bodenproben mit einem Sieb der Maschenweite $2 \mathrm{~mm}$ gesiebt und das im Sieb verbliebene Material (meist größere Gesteinspartikel und Pflanzen- und Flechtenbruckstücke) verworfen. Anschließend wurden sie gut durchmischt und das Frischgewicht bestimmt.

\subsubsection{Bestimmung des Wassergehaltes}

Etwa $20 \mathrm{~g}$ des gesiebten Bodenmaterials wurden in vorgetrocknete und vorgewogene Bechergläser eingewogen, das genaue Frischbodengewicht notiert und im Trockenschrank bei $70{ }^{\circ} \mathrm{C} 48 \mathrm{~h}$ lang getrocknet. Anschließend wurde das Trockenbodengewicht bestimmt. Die Berechnung des auf das Trockenbodengewicht bezogenen prozentualen Wassergehaltes WG erfolgte nach der Formel: 
WG $=\frac{\text { "Frischbodengewicht” } \mathrm{x} \text { Trockenbodengewicht }}{\text { Trockenbodengewicht }} \times 100 \%$

Der Wassergehalt hat hier selbst keinen Analysewert, da es sich in dieser Studie nicht um Frischboden im eigentlichen Sinne handelte. Er wurde aber benötigt, um die späteren Analyseergebnisse, die an dem nicht im Labor nachgetrockneten Boden vorgenommen

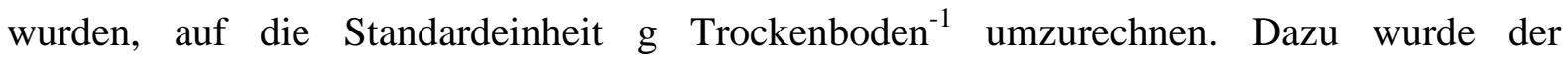
Trockenbodenanteil TAG am „Frischbodengewicht“ benötigt:

$\mathbf{T A G}=\frac{\mathrm{TB}}{\mathrm{FB}}=\frac{\mathrm{TB}}{\mathrm{TB}+\mathrm{WB} / 100 \mathrm{xBB}}=\frac{100}{100+\mathrm{WG}}$

\subsubsection{Messung des Boden-pH-Wertes}

Von den gesiebten Bodenproben wurden jeweils $2.5 \mathrm{~g}$ des O-Horizontes mit $10 \mathrm{ml}$ Milliporewasser vermischt. Nach 24 h war ein Gleichgewichtszustand zwischen Boden und Wasser eingetreten und die Messung wurde mit einer Glaselektrode (WTW Vario $p H$ ) durchgeführt. Dazu wurde unter ständigem Rühren mit der Elektrode ein konstanter Wert abgewartet, dieses war der sog. $\mathrm{pH}_{\mathrm{H} 2 \mathrm{O}}$-Wert. Nach der Messung wurden jeweils 1,86 g KCl hinzugegeben. Nach zehnminütiger Inkubation wurde dann der sog. $\mathrm{pH}_{\mathrm{KCl}}$-Wert gemessen. Bei der $\mathrm{pH}$ - Messung in Wasser werden nur die $\mathrm{H}^{+}$-Ionen in der Bodenlösung erfasst, bei der Messung in $1 \mathrm{~N} \mathrm{KCl}$ werden die $\mathrm{H}^{+}$-Ionen in der Bodenlösung und am Austauscher erfasst. Die Differenz dieser beiden Werte lässt also eine Aussage über die Austauscherfunktion des Bodens zu, wobei bei:

$\mathrm{pH}_{\mathrm{H} 2 \mathrm{O}}>\mathrm{pH}_{\mathrm{KCl}}$ : im Boden hauptsächlich Kationenaustauscher vorhanden sind. $\mathrm{pH}_{\mathrm{H} 2 \mathrm{O}}<\mathrm{pH}_{\mathrm{KCl}}$ : im Boden hauptsächlich Anionenaustauscher vorhanden sind. 


\subsubsection{Bestimmung der effektiven Kationenaustauscherkapazität (AKe) und der}

\section{Basensättigung}

Vor Beginn der Perkolation mussten alle verwendeten Geräte und die Filterflockenmasse zweimal mit $\mathrm{H}_{2} \mathrm{O}_{\text {demin }}$ gespült werden, um Verunreinigungen zu entfernen. Danach wurden je

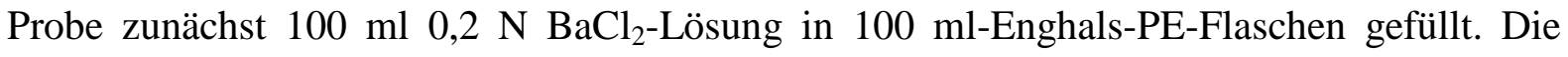
Perkolationsröhrchen wurden mit einer etwa $1 \mathrm{~cm}$ dicken Schicht aus Filterflocken bestückt und dann je 2,5 g Feinboden eingewogen. Danach wurde der Silikon-Ablaufschlauch mit einer Schlauchklemme verschlossen und zu den im Röhrchen befindlichen Proben so lange 0,2 $\mathrm{N} \mathrm{BaCl}_{2}$-Lösung zugesetzt, bis diese davon bedeckt waren. Als Blindproben wurden zwei Ansätze ohne Bodenmaterial mitgeführt. Daraufin erfolgte eine Inkubation bei RT über Nacht, während derer eine Sättigung des Bodens mit der Lösung erreicht wurde. Zur Perkolation wurde nun ein mit einem Gummistopfen versehener Schlauch vom Boden der mit der $\mathrm{BaCl}_{2}$-Lösung gefüllten Flasche in das Perkolationsröhrchen geführt, der Silikonschlauch des Röhrchens in einen 100 ml-Messkolben geführt und die Schlauchklemme so weit geöffnet, dass das Perkolat langsam in den Messkolben tropfte. Gegen Ende der Perkolation wurde der in der PE-Flasche verbliebene Rest der $\mathrm{BaCl}_{2}$-Lösung in das Röhrchen geschüttet, weil der Unterdruck im Perkolationsröhrchen nicht mehr ausreichte, um Lösung nachzuziehen. Während der Perkolation war darauf $\mathrm{zu}$ achten, dass die Proben nicht trockenliefen. Um eine quantitative Vergleichbarkeit zu gewährleisten, wurde das Perkolat nach der Perkolation auf $100 \mathrm{ml}$ mit $\mathrm{BaCl}_{2}$-Lösung aufgefüllt und gut geschüttelt. Das im Überschuss zugegebene $\mathrm{Ba}^{2+}$ tauschte in diesem Versuch alle austauschbar gebundenen Kationen ab. Diese konnten dann im Perkolat quantitativ gemessen werden.

Dazu wurden von jedem Perkolat je $5 \mathrm{ml}$ abgenommen und an dieser Probe der $\mathrm{pH}$-Wert zur Ermittlung der ausgetauschten $\mathrm{H}^{+}$-Ionen bestimmt. Es musste für die Errechnung ebenfalls noch der $\mathrm{pH}$-Wert der ursprünglichen $\mathrm{BaCl}_{2}$-Lösung bestimmt werden. Die verbliebenen 95 ml dienten zur Bestimmung der Kationen (Na), $\mathrm{K}^{+}, \mathrm{Ca}^{2+}, \mathrm{Mg}^{2+}, \mathrm{Al}^{3+}, \mathrm{Fe}^{2+}$ und $\mathrm{Mn}^{2+}$ an einem ICP-OES-Gerät (Inductively Coupled Plasma, optisches Emissionsspektrometer mit induktiv gekoppeltem Plasma; Perken Elmer, Optima 5300). Es wurden die austauschbar gebundenen Gehalte der einzelnen Ionen in $\mu \mathrm{mol}_{\mathrm{c}}(=\mu \mathrm{mol}$ charge $=\mu \mathrm{mol}$ Ionenäquivalent $)$ je $\mathrm{g}$ Trockenboden berechnet. Aus der Summe der Ionenäquivalente ergibt sich die effektive Austauschkapazität AKe. Die Belegung der Austauscher durch die jeweiligen Elemente wurde folgendermaßen berechnet: 
(1) gewichtsbezogene Kationenkonzentration:

$\frac{\mathrm{ICP}-\mathrm{MW}[\mu \mathrm{g} / \mathrm{ml}] \mathrm{x} \text { Verdünnungsfaktor-ICP-MW Blindprobe }[\mu \mathrm{g} / \mathrm{ml}] \mathrm{x} \text { Verdünnungsfaktor Blindprobe x Perkolatmenge [ } \mathrm{m}] \mathrm{x} \text { Elementwertigkeit }}{\text { Frischbodeneinwaage }[\mathrm{gFG}] \mathbf{x} \text { TrockenbodenanteilTAG }}\left[\frac{\mu \mathrm{mol} c}{\mathrm{~g}}\right]$

Die Konzentration der austauschbaren $\mathrm{H}^{+}$-Ionen wurde durch die oben beschriebene Formel errechnet. Dazu wurden die beiden Werte (der der Ausgangslösung und des Perkolats) entlogarithmiert und aus beiden Konzentrationen die Differenz gebildet. Diese wurde dann in folgende Formel eingesetzt:

(2) gewichtsbezogene Protonenkonzentration

$\frac{\left.\text { Protonenkonzentration Perkolat }[\mathrm{mol} / \mathrm{L}] \text { Protonenkonzentration BaCl -Lösung x } 1000000 \text { x Elementwertigkeif } \mathrm{H}^{+}\right\}}{\text {Frischbodeneinwaage }[\mathrm{gFG}] \text { x Trockenbodenanteil TAG }}\left[\begin{array}{c}\mu^{\mathrm{mol}} \mathrm{g} \\ \mathrm{g}\end{array}\right]$

So konnten die Austauscher-Verhältnisse hinsichtlich der Verfügbarkeit der für das

Wachstum bedeutenden sog. „basischen Kationen“ $\left(\mathrm{Na}^{+}\right), \mathrm{K}^{+}, \mathrm{Mg}^{2+}$ und $\mathrm{Ca}^{2+}$ als sog. „Basensättigung“ (in \%) berechnet werden.

\subsubsection{Glühverlust, Gehalt an organischem Kohlen- und Stickstoff und C/N-Verhältnis}

Zunächst wurde mittels eines $\mathrm{C} / \mathrm{N}$-Analyzers (Vario EL III) das $\mathrm{C} / \mathrm{N}$-Verhältnis einer gesiebten und gemahlenen, aber sonst unbehandelten Bodenprobe von festgehaltener Einwaage bestimmt. Die Probe wurde in eine Zinnkapsel gegeben und im Gerät in einem Ofen bei $1030{ }^{\circ} \mathrm{C}$ mineralisiert. Es fand eine vollständige Oxidation des Materials statt, wobei als Produkte $\mathrm{CO}_{2} / \mathrm{CO}, \mathrm{H}_{2} \mathrm{O}$ und $\mathrm{NO}_{\mathrm{x}}$ entstanden. Von diesen wurde im Gerät bei $650^{\circ} \mathrm{C}$ anschließend der Restsauerstoff gebunden und Stickoxide wurden zu Stickstoff reduziert. Die Gasmischung enthielt nun die Analytgase $\mathrm{CO}_{2}, \mathrm{H}_{2} \mathrm{O}$ und $\mathrm{N}_{2}$. Anschließend wurde das Produktgas über Magnesiumperchlorat getrocknet und über eine Säule aufgetrennt. Die Detektion fand im Anschluss daran im Wärmeleitdetektor statt. Die so gewonnenen 
Werte dienten als Rechengrundlage für die Bestimmung des Gesamtgehaltes an Kohlen- und Stickstoff, also aus organischen und anorganischen Verbindungen zusammen.

(1) Gewichtsbezogener C-Gehalt:

$\mathbf{C}_{\text {total }}=\frac{\text { prozentualer N-Gehalt }[\%] \times 1000}{\text { Molgewicht C }\{12,011\}\left[\frac{\mathrm{g}}{\mathrm{mol}}\right] \times 100}\left[\frac{\mathrm{mmol}}{\mathrm{g}}\right]$

(2) Gewichtsbezogener N-Gehalt:

$\mathbf{N}_{\text {total }}=\frac{\text { prozentualer N-Gehalt }[\%] \times 1000}{\text { Molgewicht } \mathrm{N}\{14,007\}\left[\frac{\mathrm{g}}{\mathrm{mol}}\right] \times 100}\left[\frac{\mathrm{mmol}}{\mathrm{g}}\right]$

Der Glühverlust wurde bestimmt, indem $500 \mathrm{mg}$ der bei $70{ }^{\circ} \mathrm{C}$ für $48 \mathrm{~h}$ getrockneten Bodenprobe für $4 \mathrm{~h}$ im Muffelofen bei $600{ }^{\circ} \mathrm{C}$ verascht wurden. Anschließend wurde die Probe erneut gewogen. Die Differenz aus dem Gewicht vor und nach der Veraschung ergibt den Glühverlust.

Die so behandelte Probe wurde anschließend ein weiteres Mal einer C/N-Analyse unterzogen. Analog zu den Formeln (1) und (2) konnten nun $\mathrm{C}_{\text {anorg }}$ und $\mathrm{N}_{\text {anorg }}$ berechnet werden, die jeweilig anorganischen Gehalte dieser Elemente. Durch Anzug des anorganischen C-Gehaltes vom Gesamt-C-Gehalt konnte der organische C-Gehalt der Bodenproben berechnet werden. Der organische N-Gehalt ist identisch mit dem Gesamt-N-Gehalt. Aus den organischen Cund N-Gehalten konnte im Anschluss das C/N-Verhältnis berechnet werden. 


\subsubsection{Bestimmung der Wasserspeicherungskapazität $\mathrm{WHK}_{\max }$}

Als maximale Wasserhaltekapazität wird die Wassermenge bezeichnet, die der Boden in der Lage ist, gegen die Schwerkraft zu halten. Sie wurde bestimmt, indem eine definierte Menge des gesiebten Bodens (in diesem Fall etwa 20 g) auf einem angefeuchteten und abgewogenen Faltenfilter platziert wurde. Dieser wurde in ein Becherglas gestellt und der Boden wurde nun vollständig mit Wasser bedeckt und bis zur Sättigung 30h bei RT inkubiert. Anschließend wurden die Proben mitsamt dem Faltenfilter in einen Trichter gestellt und das überschüssige Wasser konnte so abtropfen. Sobald keine Wasserabgabe mehr erfolgte, wurde der Wassergehalt der Probe gravimetrisch bestimmt, indem zuerst die feuchte Probe und selbige nach einer $48 \mathrm{~h}$ dauernden Trocknung bei $70{ }^{\circ} \mathrm{C}$ gewogen wurde. Die vom Faltenfilter gespeicherte Wassermenge wurde bei der Rechnung berücksichtigt. Der gravimetrische Wassergehalt entspricht hier also $100 \% \mathrm{WHK}_{\max }$.

Die Wasserhaltekapazitäten der gemischten Bodenkrusten und Kryptogamenproben wurden analog dazu bestimmt. 


\subsection{Bildgebende Verfahren}

\subsubsection{Fotografie}

Bilder von den Standorten wurden im Wesentlichen mit der Digital-Spiegelreflexkamera E10 (Olympus; Tokio, Japan) aufgenommen. Makrofotos von den Standorten und von den BSCs und Pflanzen wurden mit einer PowerShot ${ }^{\circledR}$ A420 (Canon; Tokio, Japan) aufgenommen.

\subsubsection{Lichtmikroskopie}

Für alle lichtmikroskopischen Untersuchungen wurde ein Axiophot-Mikroskop (Zeiss, Oberkochen) verwendet. Für die Epifluoreszenzmikroskopie stand der Filtersatz Nr. 09 (Anregungsfilter: BP 450-490, Teilerspiegel: FT 510, Emissionsfilter: LP 515) der Fa. Zeiss, Oberkochen zur Verfügung. Das Mikroskop war für diesen Zweck mit einer HochdruckQuecksilberdampflampe (HBO 100, Zeiss) bestückt worden. Das Mikroskop verfügte über einen Fotoaufsatz. Dieser war mit einer PowerShot ${ }^{\circledR}$ G2 (Canon; Tokio, Japan) verbunden. 


\subsection{Statistik}

Es wurden hauptsächlich die Programme Excel 2007 und Statistica 9 (StatSoft, Tulsa, USA) verwendet. Für die Freilanddaten wurde zunächst ein Test auf Normalverteilung (ShapiroWilks-Test) vorgenommen. Dieser ergab, dass die meisten Messreihen nicht normal verteilt waren. Zur Korrelationsanalyse der einzelnen Standortparameter untereinander wurde deshalb ein nichtparametrisches Verfahren, nämlich Spearmans Rangkorrelation verwendet. Signifikanzen wurden erst ab $\mathrm{p}<0,5$ angegeben.

Außerdem wurden Matrix-Scatterplots durch Statistica berechnet. Hier wurden diejenigen Scatterplots, deren Rangkorrelation eine Signifikanz ergab, optisch hervorgehoben. Diejenigen Korrelationen, die die Zielvariablen „Bedeckung mit Bodenkrusten“ und „Kryptogamenarten“ betrafen, wurden anschließend in Excel erneut aufgetragen. Hierbei war es möglich, eine meist lineare Trendlinie einzufügen und das Bestimmtheitsmaß anzugeben. An den Messreihen des Standortes A wurde zusätzlich eine PCA (principle component analysis = Hauptkomponentenanalyse durchgeführt. Dazu wurde das Programm Canoco for Windows $^{T M} 4.5$ (ter Braak, 1986 und 1994) verwendet.

Die Statistik für die Sequenzdaten wird in Kapitel 3.2.4 ausführlich beschrieben. 


\subsection{Anreicherung und Isolation von Bodenkrustenorganismen}

Es wurden auf Agarplatten kleine Fragmente der BSC-Proben ausgebracht und bei RT am Tageslicht inkubiert. Die daraus hervor wachsenden Algen wurden vereinzelt und auf neue Platten überimpft. Es wurde folgendes Medium verwendet.

\section{Basalmedium für Cyanobakterien:}

$\begin{array}{lll} & \text { Stammlösung }(\mathrm{g} / 100 \mathrm{ml}) & \text { davon eingesetzt } \\ \mathrm{KNO}_{3} & 1,0 & 20 \mathrm{ml} \\ \mathrm{K}_{2} \mathrm{HPO}_{4} & 1,0 & 20 \mathrm{ml} \\ \mathrm{MgSO}_{4} \text { x } 7 \mathrm{H}_{2} \mathrm{O} & 0,1 & 20 \mathrm{ml} \\ \text { Erdextrakt } & - & 30 \mathrm{ml} \\ \text { Spurenelementlösung } & - & 5 \mathrm{ml} \\ \mathrm{H}_{2} \mathrm{O}_{\text {Millipore }} & - & 905 \mathrm{ml}\end{array}$

\section{Spurenelementlösung:}

$\begin{array}{lll} & \text { Stammlösung }(\mathrm{g} / 100 \mathrm{ml}) & \text { davon eingesetzt } \\ \mathrm{ZnSO}_{4} \times 7 \mathrm{H}_{2} \mathrm{O} & 0,1 & 1 \mathrm{ml} \\ \mathrm{MnSO}_{4} \times 4 \mathrm{H}_{2} \mathrm{O} & 0,1 & 2 \mathrm{ml} \\ \mathrm{H}_{3} \mathrm{BO}_{3} & 0,2 & 5 \mathrm{ml} \\ \mathrm{Co}\left(\mathrm{NO}_{3}\right)_{2} \times 6 \mathrm{H}_{2} \mathrm{O} & 0,02 & 5 \mathrm{ml} \\ \mathrm{Na}_{2} \mathrm{MoO}_{4} \times 2 \mathrm{H}_{2} \mathrm{O} & 0,02 & 5 \mathrm{ml} \\ \mathrm{CuSO}_{4} \times 5 \mathrm{H}_{2} \mathrm{O} & 0,0005 & 1 \mathrm{ml} \\ \mathrm{H}_{2} \mathrm{O}_{\mathrm{Millipore}} & - & 981 \mathrm{ml} \\ \mathrm{FeSO}_{4} \times 7 \mathrm{H}_{2} \mathrm{O} & - & 0,7 \mathrm{~g} \\ \text { EDTA } & - & 0,8 \mathrm{~g}\end{array}$

Die Lösungen wurden in folgenden Zusammensetzungen autoklaviert und anschließend vereinigt:

Lsg. 1: $881 \mathrm{ml} \mathrm{H}_{2} \mathrm{O}_{\text {Millipore }}$ und alle Stammlösungen außer $\mathrm{FeSO}_{4}$ x $7 \mathrm{H}_{2} \mathrm{O}$ und 0,4 g EDTA Lsg. 2: $100 \mathrm{ml} \mathrm{H}_{2} \mathrm{O}_{\text {Millipore }}$ und 0,4 g EDTA 
3 Material und Methoden

Der Erdextrakt wurde hergestellt, indem 500 g Gartenboden mit mittlerem Humusgehalt in $1000 \mathrm{ml} \mathrm{H} \mathrm{O}_{2} \mathrm{O}_{\text {Millipore }}$ suspendiert wurde. Die Suspension wurde innerhalb von $24 \mathrm{~h}$ zweimal autoklaviert und anschließend dekantiert und filtriert. Das Filtrat wurde erneut autoklaviert. 


\section{Ergebnisse}

\subsection{Standorte Biologischer Bodenkrusten und abiotische Standortfaktoren}

In diesem Kapitel soll zunächst beschrieben werden, in welchen naturräumlichen Situationen Biologische Bodenkrusten (BSCs) im Untersuchungsgebiet vorgefunden wurden. Es folgen vergleichende Analysen abiotischer Umweltfaktoren von acht Standorten. Einige der Standorte wurden wie in den folgenden Kapiteln beschrieben noch weiteren Analysen zu unterschiedlichen Themengebieten unterzogen.

Es wurden die abiotischen Faktoren Temperatur und Boden untersucht. Man geht zwar davon aus, dass die Temperatur allgemein mit dem Abstand zum Bergrücken zunimmt (Vipper, 1953) und diese wurde für die einzelnen Zählquadrate festgehalten, jedoch wurde angenommen, dass die Bodenoberflächentemperatur je nach Pflanzenbedeckung und Bodenrelief beträchtlich variieren kann. Auch die „Standortgesamttemperatur“ dürfte je nach naturräumlichen Bedingungen unterschiedlich sein. Außerdem wurde die Bodenchemie untersucht.

Andere abiotische Faktoren, wie z.B. die Feuchtigkeit oder die photosynthetisch wirksame Strahlung) konnte nicht ermittelt werden, hier stehen jedoch Vergleichsdaten (Hauck et al., 2007 und Dulamsuren und Hauck, 2008) zur Verfügung. In den weiterführenden Analysen dieser Studie wurde sich diesen Faktoren durch die Exposition, die Inklination, die Wölbung und den Abstand zum Bergrücken angenähert.

\subsubsection{Vorkommen von Biologischen Bodenkrusten im Khentej-Gebirge}

Die dieser Arbeit zugrundeliegende Definition von Biologischen Bodenkrusten beinhaltet, dass eine Assoziation der Organismen mit dem Substrat besteht und dass dieses Substrat Boden ist. Diese Definition klammert demzufolge sämtliche Gesteinsflechten und auch die in Wäldern oft gefundenen Assoziationen aus Moosen und Flechten auf Boden aus. Ebenfalls werden in Tälern und an Waldrändern häufig gefundene Felder, die meistens aus Cladonia 
spec. oder Cladina spec. Bestehen, in dieser Arbeit nicht behandelt; diese assoziieren nur wenig mit dem Substrat und bieten kaum ökologische Nischen für andere kryptogame Organismen und Mikroorganismen. Außerdem hängt ihr Auftreten von gänzlich anderen Faktoren ab als das der Biologischen Bodenkrusten der Gebirgssteppenstandorte.

Betrachtet werden hier die Gebirgssteppenstandorte der unbewaldeten Südhänge. Hier ist grundsätzlich auch nach der Art des Substrates zu unterscheiden. Zum Beispiel gibt es im Untersuchungsgebiet größere Blockhalden, die ebenfalls oft an Berghängen, auch an Südhängen, zu finden sind. Sie bestehen aus oft kubikmetergroßen Granitblöcken. Boden ist an diesen Standorten nur in geringem Maße zu finden. Die Blöcke sind demzufolge mit gesteinsbewohnenden Flechten und Moosen bewachsen.

Auch die Südhänge, die mit kleinerformatigen Gesteinsbrocken bedeckt sind, bieten wenig Raum für BSCs (siehe Bildtafel I, A). Es wird vermutet, dass durch die rollenden Gesteinsbrocken der Erosionsdruck zu hoch ist. Die Bedeckung mit BSCs schwankt hier sehr stark und wirkt eher zufällig. Man findet sie häufig ohne Bodenassoziation, die vor Hindernissen im Gelände angespült wurden (Bildtafel I, E), manchmal findet man auch ober oder unterhalb von „Fixpunkten“ im Gelände, z.B. größeren Steinen oder mehrjährigen Pflanzen relativ gut entwickelte BSCs (siehe Bildtafel I, C und G). Da unter diesen Umständen jedoch keine randomisierten Analysen möglich sind, wurde sich für die Untersuchungen, auf denen diese Arbeit basiert, auf Standorte mit feinkörnigem Substrat und oft ausgeprägten Krustenfeldern beschränkt (siehe Bildtafel I, B; hier ist „Berg A“ gezeigt). Hier findet man BSCs in vielen unterschiedlichen Situationen und Ausprägungen (Bildtafel I, $\mathrm{C}, \mathrm{F}$ und $\mathrm{H}$ ). Auch hier besteht natürlich ein gewisser Erosionsdruck durch Wind und Wasser, dieser ist aber gleichmäßiger verteilt, weil zumindest keine größeren Steine die BSCs von ihren Plätzen entfernen können. Die Strategien, diesem Erosionsdruck zu entgehen, sind ähnlich wie an den Standorten mit groberem Substrat, die BSCs wachsen oft im Radius von festen Geländemerkmalen wie z.B. vereinzelt vorkommenden größeren Steinen (die aber am Platz verbleiben) oder mehrjährigen Pflanzen. Diese sind hier auch gleichmäßiger und häufiger anzutreffen, auch auf diese dürfte der Erosionsdruck an den Grobsubstratstandorten wirken. 
4 Ergebnisse

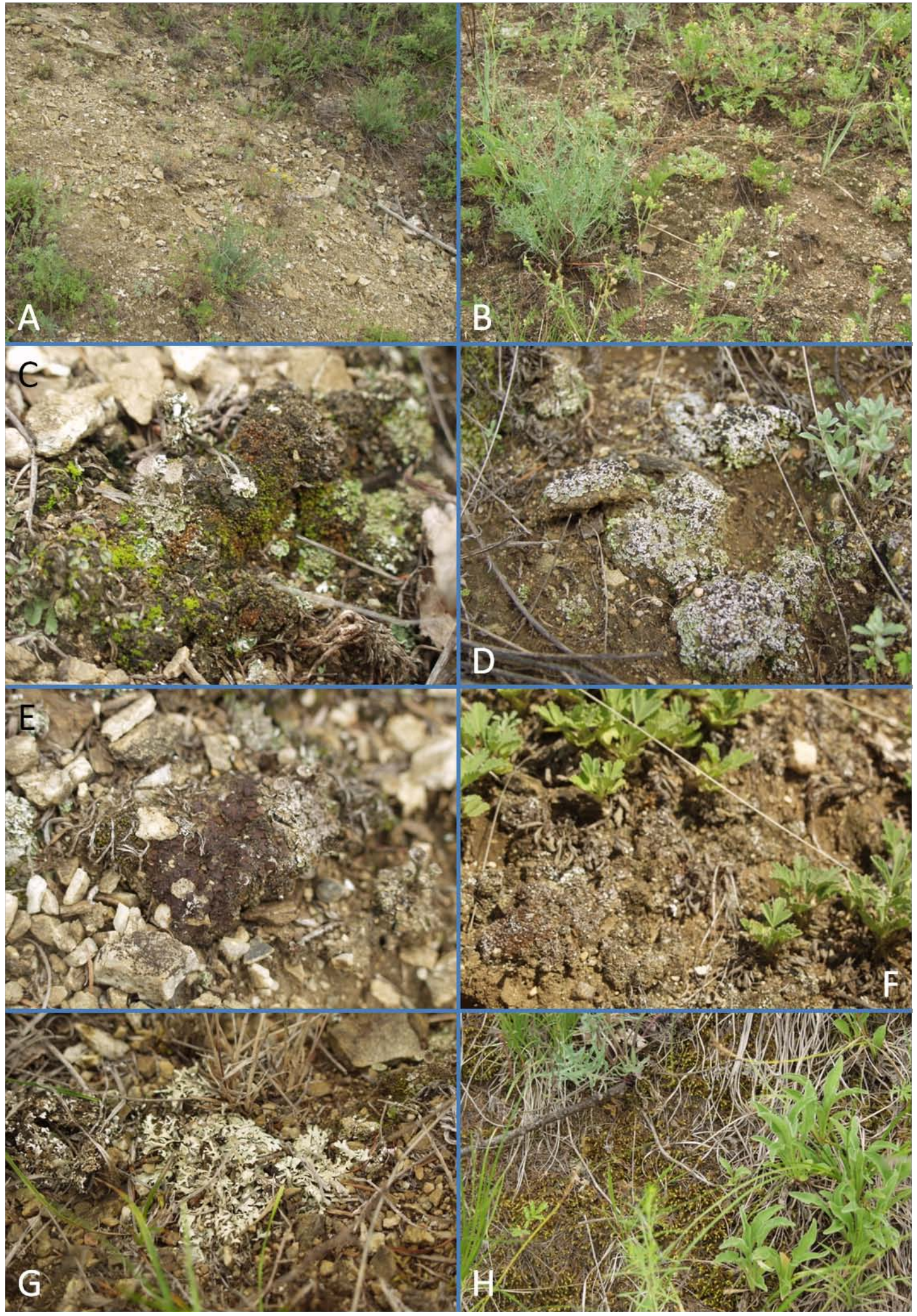

Abb. 4.1: Standorte Biologischer Bodenkrusten. A:für BSCs aufgrund des Erosionsdruckes relativ ungeeigneter Standort, BSCs sind hier nur in Sondersituationen zu finden (C,E,F). B = für BSCs gut geeigneter Standort, viele unterschiedliche BSC-Typen werden hier gefunden (D,F,H). 


\subsubsection{Temperaturvergleiche}

\subsubsection{Wärmemengen einzelner Standorte}

Es wurden nach einer von Pallmann et al. (1940) entwickelten Methode akkumulierte „Wärmemengen“, die auf die verschiedenen Standorte eingewirkt hatten, indirekt bestimmt. Zu diesem Zweck wurde der Drehwinkel einer am Standort in einem Reagiergefäss ausgebrachten Glucoselösung gemessen. Da die Inversion von Zucker temperaturabhängig ist, konnte durch den Anteil des invertierten Zuckers indirekt Rückschlüsse auf die akkumulierte Wärmemenge gezogen werden. Die Ergebnisse sind in Abb. 4.1. dargestellt. Hierbei ist $\mathrm{zu}$ beachten, dass in der Grafik nicht die Wärmemengen selbst dargestellt wurden, sondern der Anteil nicht invertierten Zuckers. Dieser verhält sich umgekehrt proportional zur Wärmemenge, d.h. die Standorte mit der größten Prozentzahl waren die kältesten.

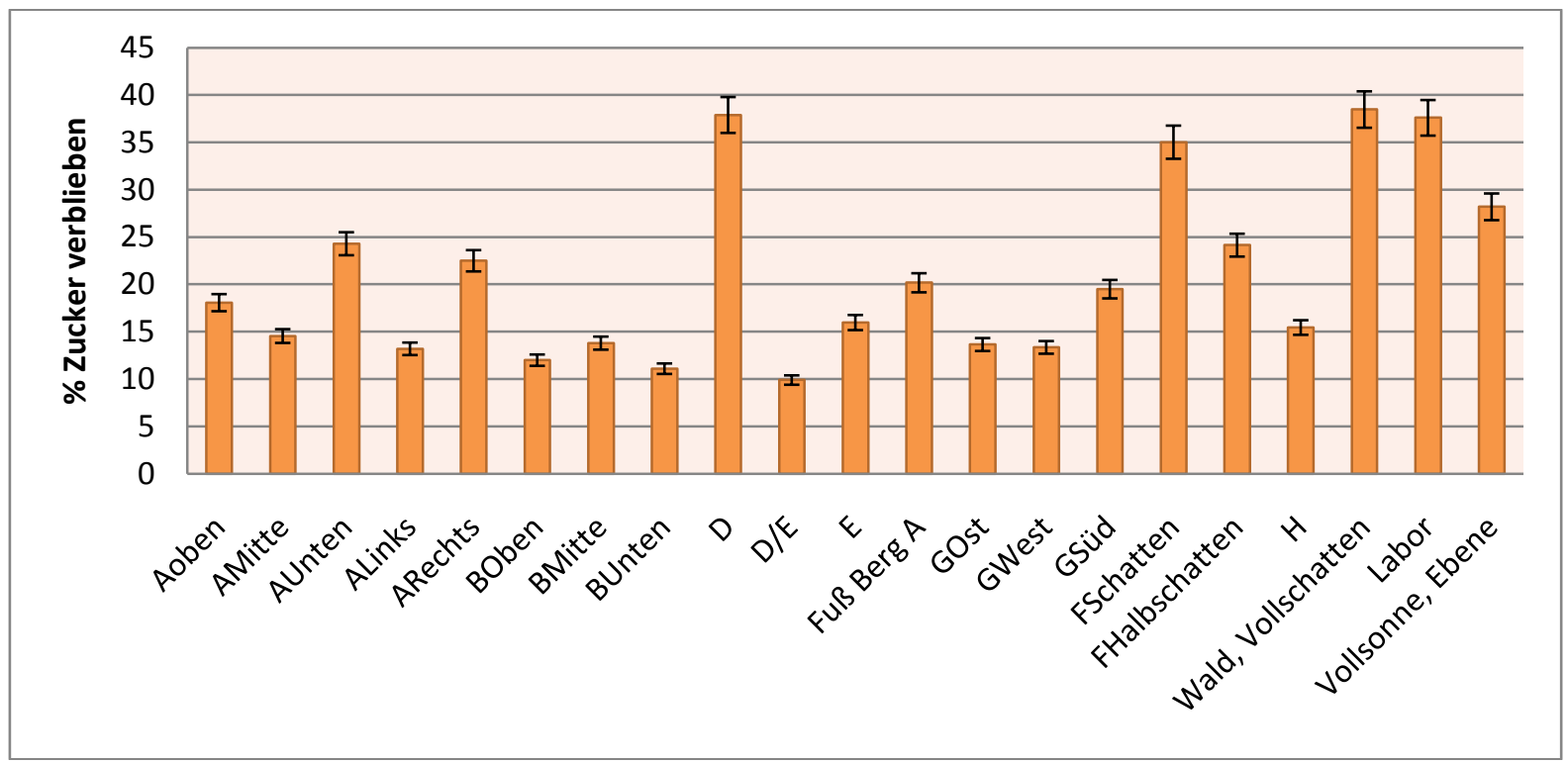

Abb. 4.2: Durch die Pallmann- Methode (Pallmann et al., 1940) ermittelte GlucoseInversionsraten. Die Fehlerbalken zeigen den prozentualen Fehler.

Hier sieht man, dass an den kalten Vergleichstandorten Labor und Wald der wenigste Zucker invertiert war, auch der Standort D, ein unbewaldeter Nordhang, an dem sehr 
wenig BSCs vorkommen, bekam recht wenig Wärme. Die „klassischen“ BSC - Standorte Berg, A, B, E und $G$ waren sogar noch wärmer als der ganztägig unbeschattete Sonnenvergleichsstandort im Tal. Auffällig ist auch, dass die Wärmemengen an einem einzelnen Standort in Abhängigkeit von Exposition und Reliefposition beträchtlich schwanken (siehe Werte für A und B).

\subsubsection{Minimale und maximale Bodenoberflächentemperaturen}

Es wurde vermutet, dass sich die Bodenoberflächentemperaturen an den BSC-Standorten in Abhängigkeit von Exposition, Inklination und Bewuchs sehr kleinräumig ändern. Dieses sollte mit einigen Messreihen belegt werden. Hierfür wurde in kurzen Zeitabständen die Bodenoberflächentemperatur an je 12 verschiedenen Stellen innerhalb eines Zählquadrates an Berg A gemessen. Die Ergebnisse sind in den Abbildungen 4.3 4.5 dargestellt worden. Hierbei zeigen die Temperaturbereiche innerhalb der Balken das Spektrum vom höchsten bis zum tiefsten Wert. Der gelbe Graph zeigt jeweils den Temperaturmittelwert der zwölf Temperaturen an. Die Abbildungen 4.3 und 4.5 zeigen die vertikalen Achsen der Linientransekte, die Abbildung 4.4 die horizontale Achse. Man sieht Unterschiede der gemessenen Temperaturen von fast $30{ }^{\circ} \mathrm{C}$; in Abbildung 4.4 ist zwischen den Quadraten B14 und D1 ein Temperatursprung zu beobachten. Dieser ist auf den Umschlag der Expositionen von grob südöstlicher zu südlicher Richtung zu erklären. Die Messungen wurden an einem heißen und wolkenlosen Nachmittag im späten August durchgeführt, die Lufttemperatur lag bei $27^{\circ} \mathrm{C}$. Keine der untersuchten Stellen lag im Vollschatten, es gab nur kleinere durch Kräuter verursachte Schattenstellen. 
4 Ergebnisse

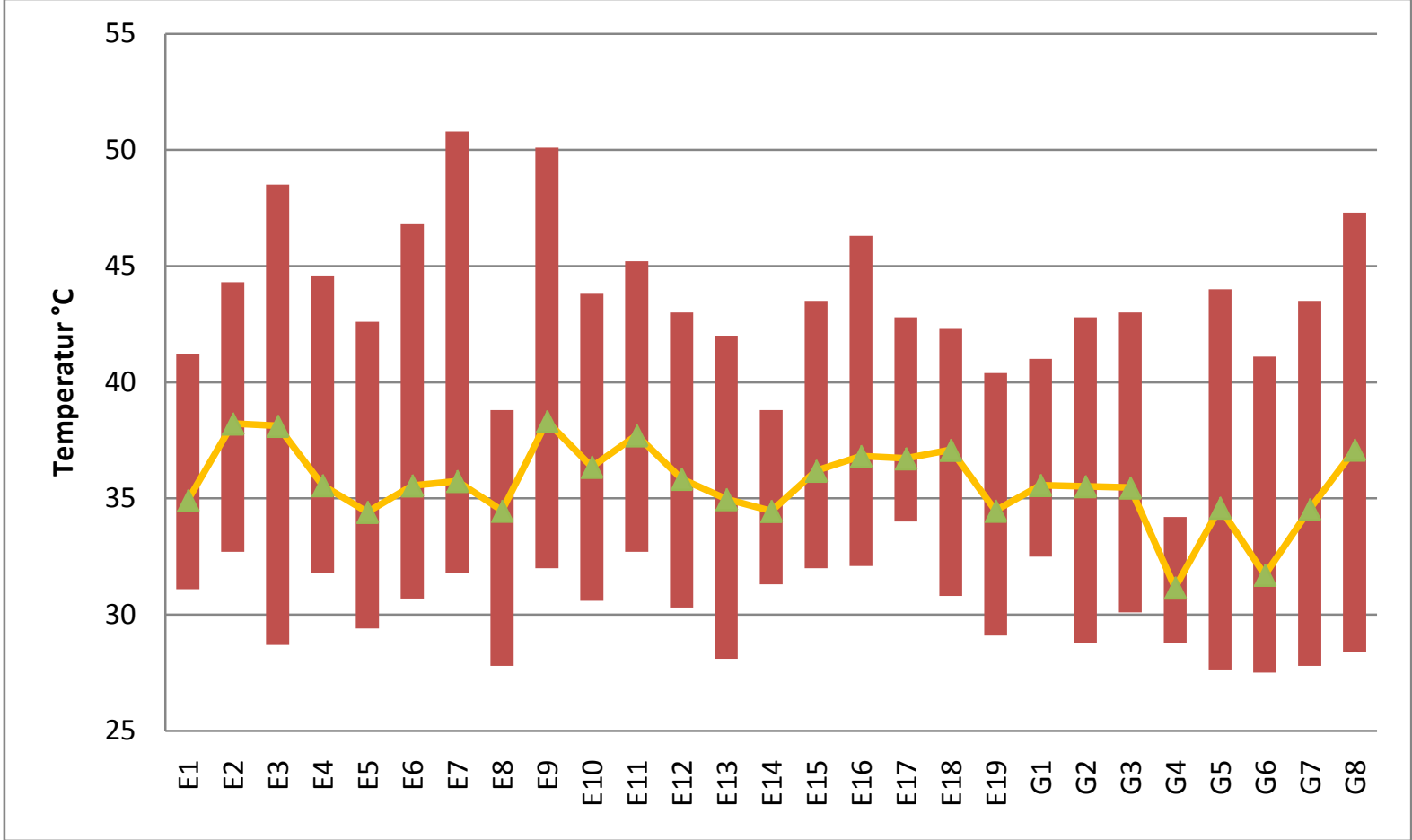

Abb. 4.3: Bodenoberflächentemperaturen von BSC-Standorten, erste Vertikalachse.

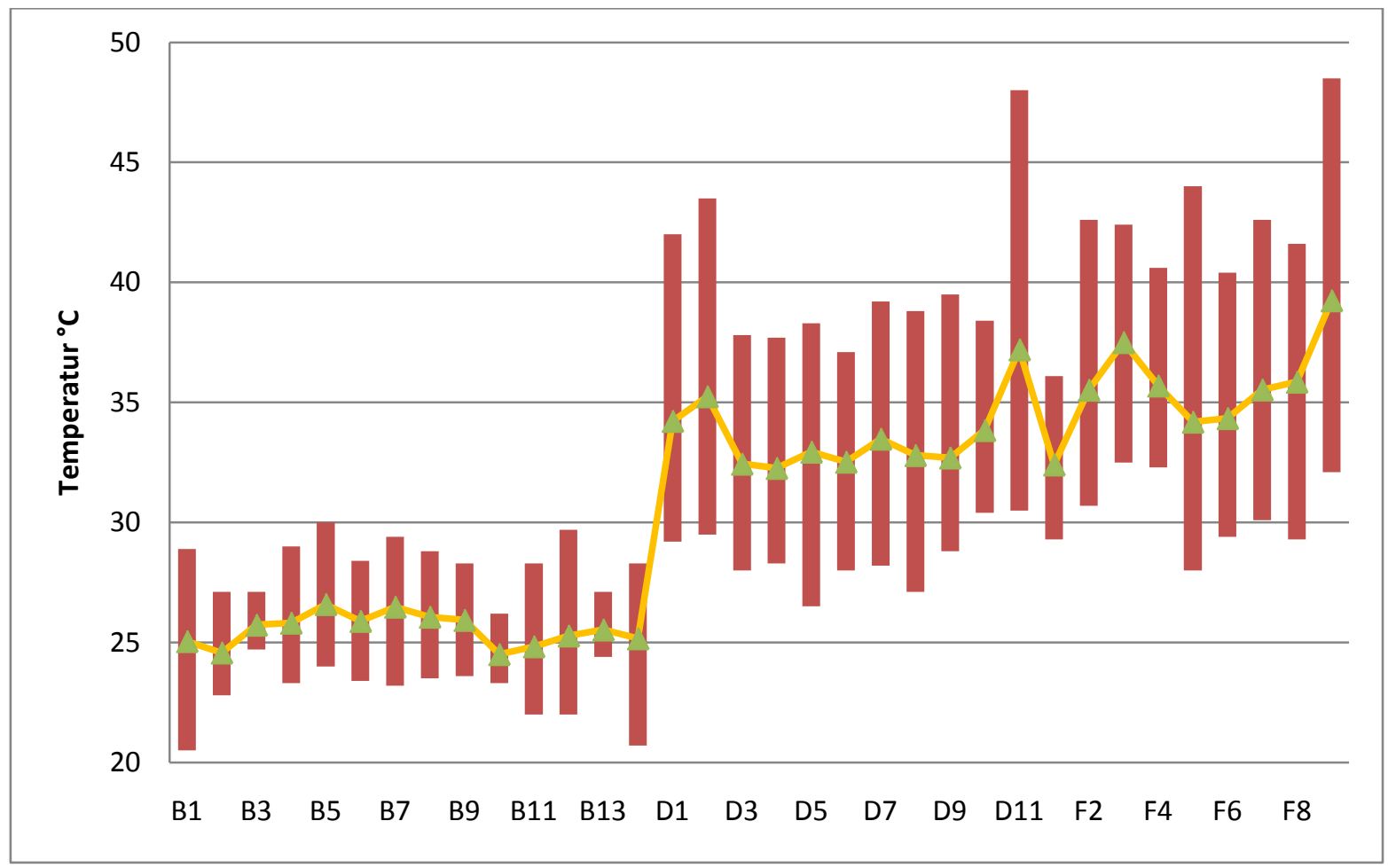

Abb. 4.4: Bodenoberflächentemperaturen von BSC-Standorten, Horizontalachse. 


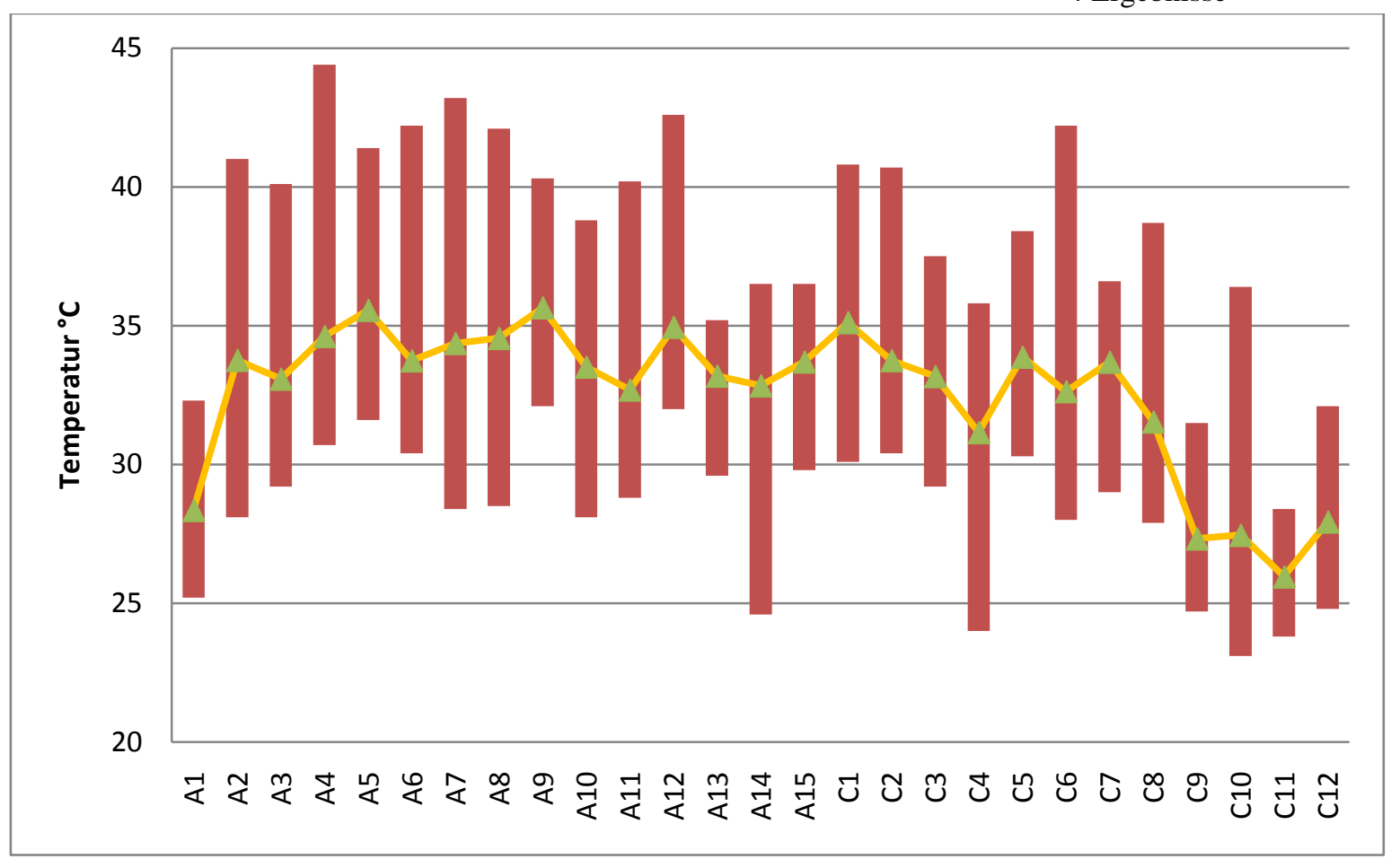

Abb. 4.5: Bodenoberflächentemperaturen von BSC-Standorten, zweite Vertikalachse.

\subsubsection{Bodenanalysen}

\subsubsection{1 pH- Wert des Auflagehorizonts}

Die pH-Werte von Bodensuspensionen der verschiedenen BSC-Standorte wurden zunächst gemessen, dann wurde den Bodensuspensionen noch eine definierte Menge Kaliumchlorid zugegeben. Der danach gemessene $\mathrm{pH}$-Wert sollte Aussagen über die Austauscherfunktion des Bodens zulassen. In Abbildung 4.6 wird deutlich, dass der $\mathrm{pH}$ an allen Standorten nach der Zugabe von $\mathrm{KCl}$ gesunken ist, das heißt, dass in den untersuchten Böden hauptsächlich Kationenaustauscher vorhanden sind (siehe Kap. 3.3.2.2). Die Ausgangs-pH-Werte liegen alle im basischen Bereich. In Abbildung 4.7 ist diese Absenkung des pH-Wertes noch einmal in anderer Form dargestellt. Hier sieht man, dass der Boden mit dem höchsten Ausgangs-pH-Wert, nämlich die Probe von Berg I, die geringste Absenkung des pH-Wertes erfährt. 


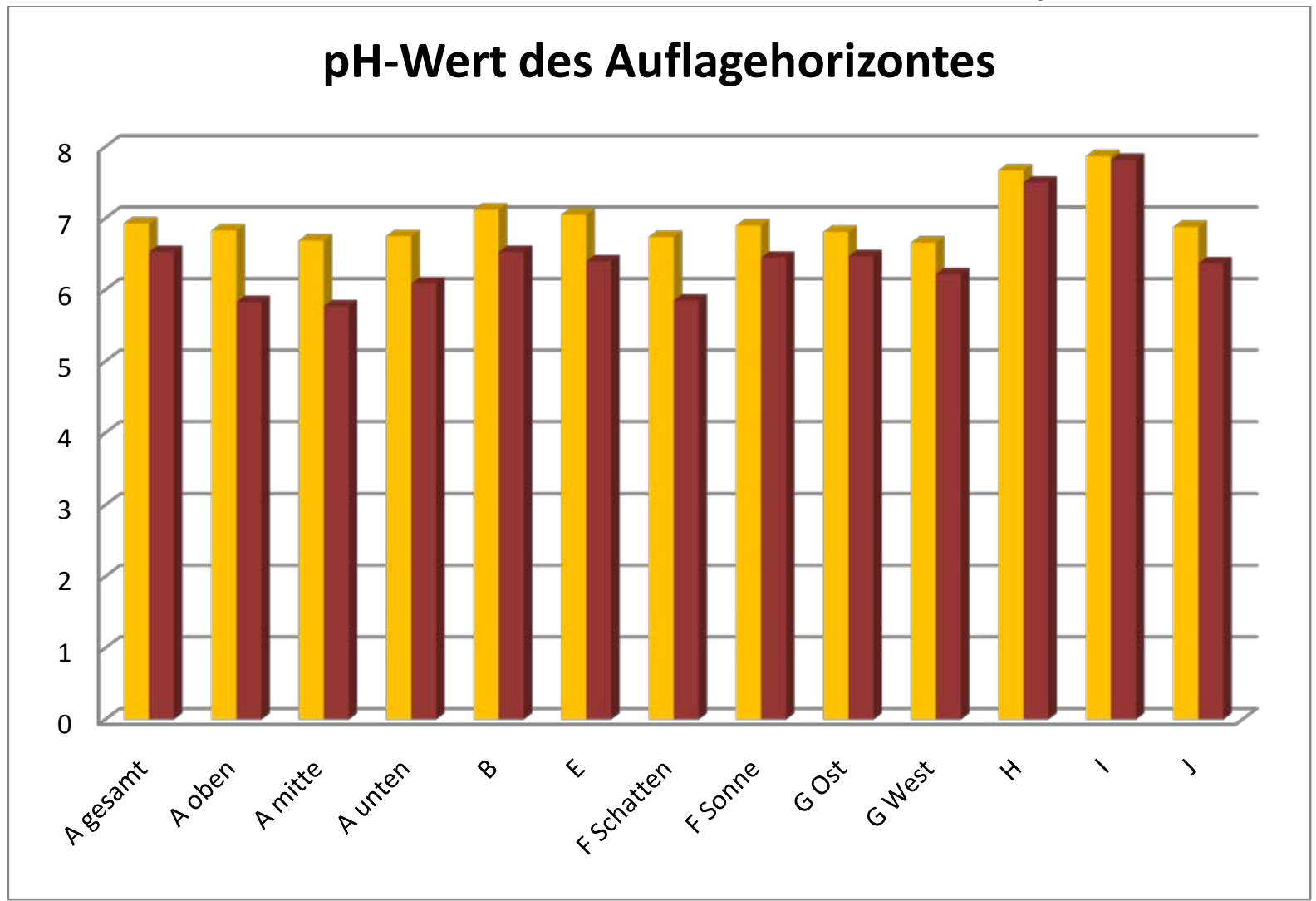

Abb. 4.6: pH-Wert des Auflagehorizontes verschiedener BSC-Standorte. Die gelben Säulen zeigen den Ausgangs- pH- Wert, die roten Säulen den pH-Wert nach Zugabe von Kaliumchlorid.

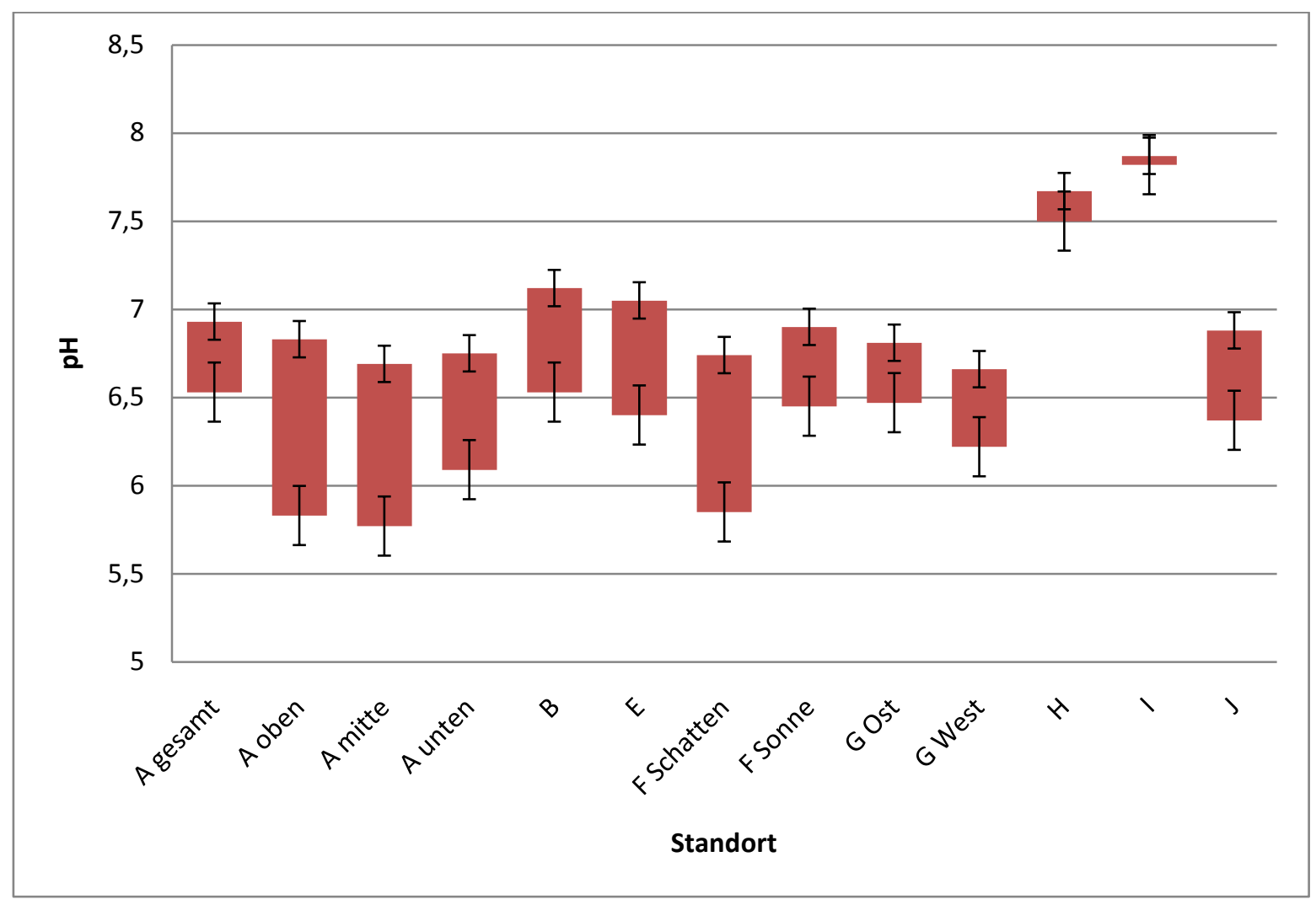

Abb. 4.7: Absenkung des pH-Wertes des Auflagehorizontes verschiedener BSC-Standorte durch die Zugabe von Kaliumchlorid. Die Fehlerbalken zeigen den prozentualen Fehler. 


\subsubsection{Weitere Ergebnisse der bodenchemischen Analysen}

An den Bodenoberflächenproben der verschiedenen Standorte wurden noch verschiedene weitere bodenchemische Analysen durchgeführt (siehe Tabelle 4.1). Dabei ist vor allem augenfällig, dass sich das $\mathrm{C} / \mathrm{N}-$ Verhältnis des Standortes $\mathrm{F}_{\text {Schatten }}$ stark von den anderen Werten unterscheidet.

\begin{tabular}{|l|c|c|c|c|c|}
\hline & $\mathbf{W H K}_{\mathbf{m a x}}$ & $\begin{array}{l}\mathbf{C}_{\text {total }} \\
(\mathbf{m m o l} / \mathbf{g T B})\end{array}$ & $\begin{array}{l}\mathbf{N}_{\text {total }} \\
(\mathbf{m m o l} / \mathbf{g T B})\end{array}$ & $\begin{array}{l}\mathbf{C}_{\text {org }} \\
(\mathbf{m m o l} / \mathbf{g T B})\end{array}$ & $\begin{array}{l}\mathbf{C}_{\text {org }} / \mathbf{N}_{\text {org }} \\
(\mathbf{m o l} / \mathbf{m o l})\end{array}$ \\
\hline $\mathbf{A}_{\text {gesamt }}$ & 0,41 & 2,36 & 0,19 & 2,33 & 12,20 \\
\hline $\mathbf{A}_{\text {oben }}$ & 0,34 & 0,78 & 0,07 & 0,76 & 10,18 \\
\hline $\mathbf{A}_{\text {mitte }}$ & 0,44 & 1,21 & 1,18 & 1,19 & 11,11 \\
\hline $\mathbf{A}_{\text {unten }}$ & 0,54 & 1,66 & 0,15 & 1,64 & 10,98 \\
\hline $\mathbf{B}$ & 0,46 & 1,72 & 0,16 & 1,71 & 10,98 \\
\hline $\mathbf{E}$ & 0,51 & 2,55 & 0,23 & 2,53 & 10,87 \\
\hline $\mathbf{F}_{\text {Schatten }}$ & 0,66 & 2,63 & 0,15 & 2,61 & 17,53 \\
\hline $\mathbf{F}_{\text {Sonne }}$ & 0,65 & 2,66 & 0,23 & 2,64 & 11,63 \\
\hline $\mathbf{G}_{\text {Ost }}$ & 0,54 & 3,28 & 0,28 & 3,26 & 11,61 \\
\hline $\mathbf{G}_{\text {West }}$ & 0,65 & 2,58 & 0,23 & 2,56 & 11,24 \\
\hline $\mathbf{H}$ & 0,60 & 2,20 & 0,19 & 2,09 & 10,98 \\
\hline $\mathbf{I}$ & 0,40 & 1,35 & 0,10 & 1,23 & 11,73 \\
\hline $\mathbf{J}$ & 0,54 & 2,06 & 0,18 & 2,04 & 11,19 \\
\hline
\end{tabular}

Tab. 4.1: Bodenchemische Analysen des Oberbodens. Weitere Analyseergebnisse befinden sich im Anhang. 
4.2 Vergleichende Morphologie Biologischer Bodenkrusten

4 Ergebnisse

\subsubsection{Makroskopische Untersuchungen}

\subsubsection{Beteiligte Kryptogamen}

Es wurden in den Biologischen Bodenkrusten aller Sammelorte insgesamt 21 Flechtenarten, fünf Laubmoosarten, eine Lebermoosart und eine Art makroskopisch sichtbarer Cyanobakterienlager gefunden. Die häufigsten Arten sind in den Abbildungen 4.7 - 4.9 dargestellt. Abbildung 4.7 (A-C) zeigt verschiedene Vertreter der Cyanoflechtengattung Collema, so sieht man auf Bild A Collema tenax (Sw.) Ach., Bild B zeigt Collema crispum (Huds.) F.H. Wigg. und Bild C Collema limosum (Ach.) Ach.. Aus dieser Gattung wurde außerdem noch Collema coccophorum Tuck. gefunden.

Bild C zeigt die parasitisch auf Cladonia siedelnde Diploschistes muscorum (Scop.) R. Sant. Sie ist an den schwarzen eingesenkten Apothecien gut zu erkennen.

Bild D zeigt Peltigera lepidophora (Vain.) Bitter, welche ebenfalls Cyanobakterien als Photosymbionten besitzt.

Die auf Abb. 4.8 gezeigten Flechten beherbergen Grünalgen als Photosymbionten. Bild A zeigt Cladonia pyxidata (L.) Hoffm., Bild B die sehr auffällige aber auch variationsreiche Psora luridella (Tuck.) Fink. Diese Flechte ist ebenfalls noch auf Bild D gezeigt, hier ist sie im Spätsommer aufgenommen worden und ihre obere Thallusrinde ist durch die starke Sonneneinstrahlung ausgebleicht. Es wird vermutet, dass diese Flechte sehr schnell wächst. So waren wiederholt aus dem Gefüge gelockerte BSCs mit dieser Flechte gefunden worden, die sowohl auf der Ober-, als auch auf der Unterseite Thalli der Flechte trugen. Auch auf der Unterseite waren die Thalli meist noch intakt. Bild E zeigt eine Oberseite, die Thalli auf der Unterseite waren meist ausgeprägter. Psora luridella war auch die Flechte, die die größten BSCs bildete. Es wurden $15 \mathrm{~cm}$ hohe und oft bis zu $25 \mathrm{~cm}$ im Durchmesser zählende Thalli gefunden. Bild B zeigt außerdem einen Vertreter der Xanthoparmeliae (hellgrüne Laubflechte am Bildrand), hier ist es Xanthoparmelia camtschadalis (Ach.) Hale., die im Untersuchungsgebiet aus ihrer Gattung am häufigsten gefunden wurde. Bild C zeigt Cladonia ochrochlora Flörke und auf Bild F ist Catapyrenium lachneum (Ach.) R. Sant. zu sehen. 
Nicht gezeigt werden die Flechtenarten Cladonia stricta (Nyl.) Nyl., Cladonia cariosa (Ach.) Spreng., Collema coccophorum Tuck., Heppia lutosa (Ach.) Nyl.,Xanthoparmelia vagans (Nyl.) Hale, Xanthoparmelia conspersa (Ehrh. Ex. Ach.) Hale und die häufig gefundenen Lager eines Cyanobakteriums aus der Gattung Nostoc. Diese bilden Flechtenlagern ähnliche Gallertlager aus, welche im Querschnitt blättrig sind, sich aber zu kugeligen Knäueln einrollen. Sie grenzen sich zu den Flechten durch die fehlende Strukturierung im Thallusquerschnitt und natürlich durch das Fehlen von Mykobionten ab.

Ebenfalls nicht gezeigt werden einige sehr seltene Flechtenarten, die aufgrund ihrer Seltenheit nur bis zur Gattung bestimmt werden konnten, da verwertbare Merkmale wie Sporen nicht in ausreichender Menge gefunden werden konnten. Es waren Vetreter der Gattungen Gyalidea (evtl. geoica), Buellia, Atalamia, Lepraria, Sqamarina und Stereocaulon gefunden worden. Die Substratansprüche der gefundenen Flechten werden, soweit bekannt, in Tab. 4.2 gezeigt. Die Informationen entstammen Wirth (1995) und beziehen sich auf im Wesentlichen auf in Deutschland gefundene Flechten.

Abb. 4.9 zeigt die im Untersuchungsgebiet gefundenen Moose, die allerdings nicht alle bestimmt werden konnten, da meist die zur Bestimmung erforderlichen Fortpflanzungsorgane fehlten. Bild A zeigt ein Lebermoos der Gattung Riccia sp. Diese oft in Trockengebieten vorkommenden Organismen rollen bei Trockenheit ihre Thalli ein (siehe Bild B) und überdauern so bis zum nächsten Niederschlagsereignis. Bild C zeigt Tortula ruralis (Hedw.) Gärtn. und Bild D Bryum argenteum Hedw. Tortula ruralis kann mit Hilfe seiner Glashaare, die als Kondensationspunkt für Licht dienen, mit erhöhten Strahlungsmengen umgehen. Bild E zeigt das Laubmoos Rhytidium rugosum (Hedw.) Kindb. 
4 Ergebnisse

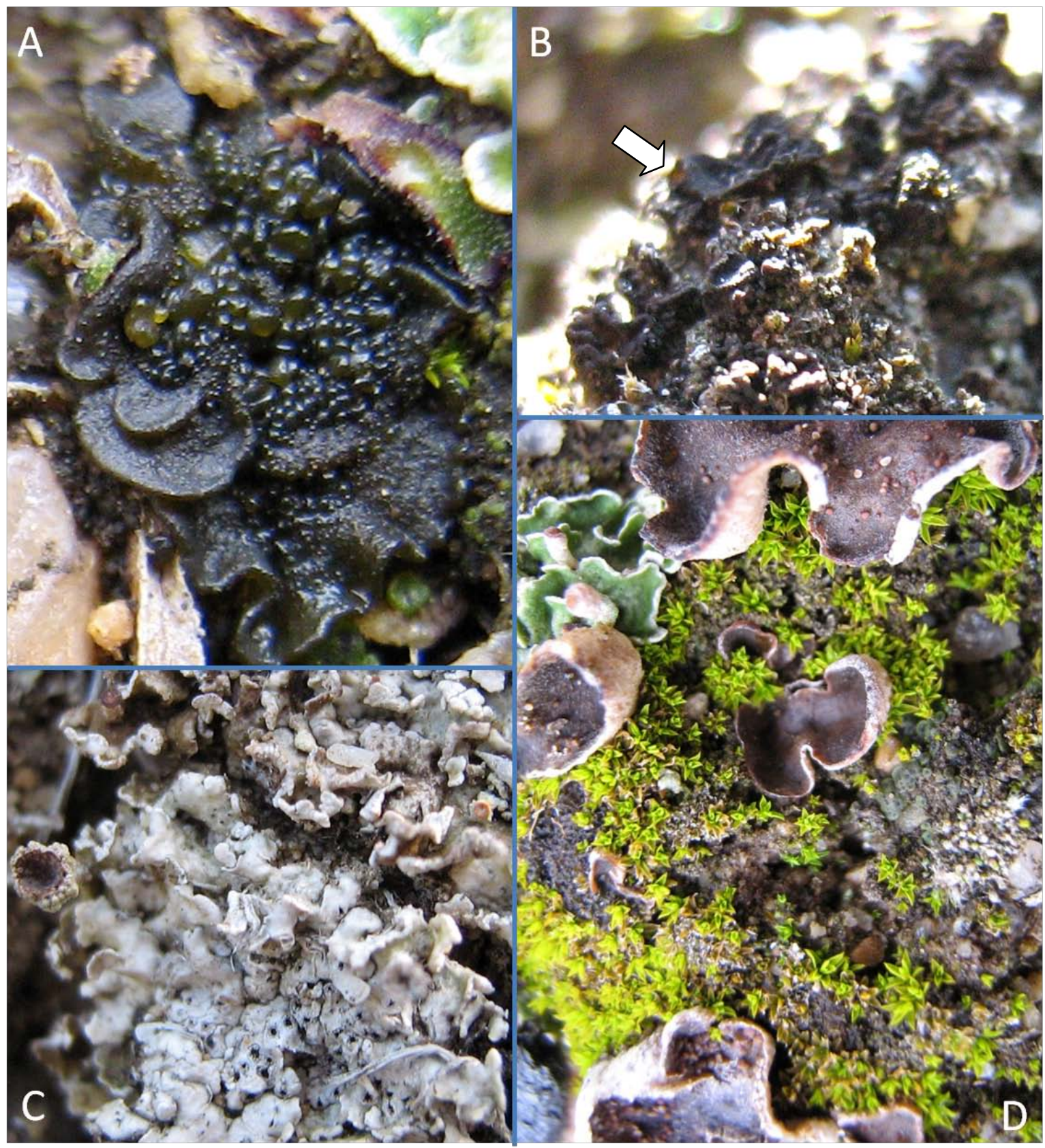

Abb. 4.7: In den BSCs vorkommende Flechtenarten I. A: Collema tenax (Sw.) Ach., B: Collema crispum (Huds.) F.H. Wigg., C: Diploschistes muscorum (Scop.) R. Sant., D: Peltigera lepidophora (Vain.) Bitter. 
4 Ergebnisse

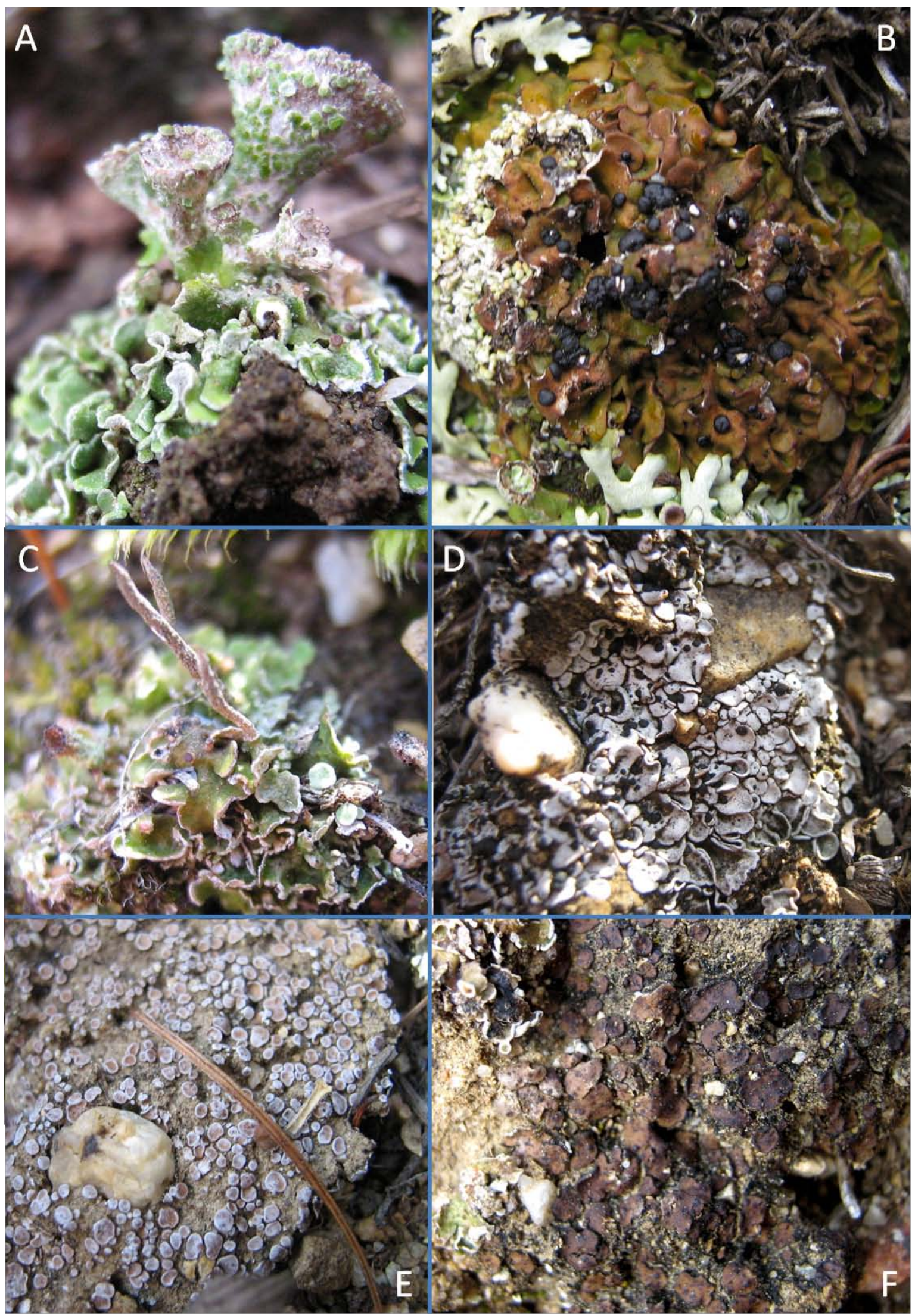

Abb. 4.8: In den BSCs vorkommende Flechtenarten II. A: Cladonia pyxidata (L.) Hoffm., B: Psora luridella (Tuck.) Fink und Xanthoparmelia camtschadalis (Ach.) Hale, C: Cladonia ochrochlora Flörke, D: Psora luridella (Tuck.) im ausgebleichten Zustand, E: Psora luridella (Tuck.), frisch bewachsene Unterseite, F: Catapyrenium lachneum (Ach.) R. Sant. 
4 Ergebnisse

\begin{tabular}{|c|c|c|c|c|c|c|}
\hline Flechte & Substrat & $\mathrm{pH}$ & $\begin{array}{l}\text { Feuchtigkeit } \\
\text { des } \\
\text { Substrats }\end{array}$ & $\begin{array}{l}\text { Lichtbedin } \\
\text { gungen }\end{array}$ & Höhenstufen & Arealdiagnose \\
\hline $\begin{array}{l}\text { Catapyrenium } \\
\text { lachneum (Ach.) } \\
\text { R. Sant. }\end{array}$ & $\begin{array}{l}\text { kalkhaltige oder } \mathrm{SiO}_{2} \\
\text { arme Silikatböden, } \\
\text { meist basenreich }\end{array}$ & $\begin{array}{l}\text { neutroph./ } \\
\text { basiph. }\end{array}$ & & photoph. & bis alpin & $\begin{array}{l}\text { arkt-mieur.alp } \\
\text { (-med.alp) }\end{array}$ \\
\hline $\begin{array}{l}\text { Cladonia cariosa } \\
\text { (Ach.) Spreng. }\end{array}$ & $\begin{array}{l}\text { basenreiche, kalkfreie } \\
\text { oder oberflächlich } \\
\text { entkalkte, durchlässige } \\
\text { Böden }\end{array}$ & $\begin{array}{l}\text { m.(z.)acid } \\
\text { oph.- } \\
\text { neutroph. }\end{array}$ & trocken & sonnig & $\begin{array}{l}\text { kollin bis } \\
\text { submontan, } \\
\text { montan }\end{array}$ & $\begin{array}{l}\text { arkt- } \\
\text { smed.mo(- } \\
\text { med.mo) }\end{array}$ \\
\hline $\begin{array}{l}\text { Cladonia } \\
\text { pyxidata (L.) } \\
\text { Hoffm. }\end{array}$ & $\begin{array}{l}\text { kalkreiche oder } \\
\text { kalkfreie aber } \\
\text { basenreiche Böden }\end{array}$ & $\begin{array}{l}\text { m.basiph.- } \\
\text { m(z.)acido } \\
\text { ph. }\end{array}$ & $\begin{array}{l}\text { trocken und } \\
\text { frisch }\end{array}$ & & $\begin{array}{l}\text { kollin bis } \\
\text { submontan }\end{array}$ & arkt-med \\
\hline $\begin{array}{l}\text { Collema } \\
\text { coccophorum } \\
\text { Tuck. }\end{array}$ & $\begin{array}{l}\text { tonig-lehmiger bis } \\
\text { lehmig-sandiger, } \\
\text { nährstoffreicher Boden. }\end{array}$ & $\begin{array}{l}\text { subneutro } \\
\text { ph. }\end{array}$ & shygroph. & lichtreich & $\begin{array}{l}\text { kollin bis } \\
\text { submontan }\end{array}$ & bor-med \\
\hline $\begin{array}{l}\text { Collema crispum } \\
\text { (Huds.) F.H. } \\
\text { Wigg. }\end{array}$ & $\begin{array}{l}\text { kalkhaltige Böden und } \\
\text { Gesteine }\end{array}$ & basiph. & shygroph. & zphotoph. & $\begin{array}{l}\text { kollin bis } \\
\text { submontan }\end{array}$ & $\begin{array}{l}\text { mieur(sub- } \\
\text { atl)-med }\end{array}$ \\
\hline $\begin{array}{l}\text { Collema } \\
\text { limosum (Ach.) } \\
\text { Ach. }\end{array}$ & $\begin{array}{l}\text { tonig-lehmige, sandig- } \\
\text { lehmige, kalkhaltige } \\
\text { Böden }\end{array}$ & $\begin{array}{l}\text { mbasiph - } \\
\text { sub } \\
\text { neutroph }\end{array}$ & shygroph. & $\begin{array}{l}\text { z-s. } \\
\text { photoph. }\end{array}$ & $\begin{array}{l}\text { kollin bis } \\
\text { montan }\end{array}$ & $\begin{array}{l}\text { (bor-)mieur- } \\
\text { submed (- } \\
\text { med) }\end{array}$ \\
\hline $\begin{array}{l}\text { Collema tenax } \\
\text { (Sw.) Ach. }\end{array}$ & $\begin{array}{l}\text { tonig-lehmige bis } \\
\text { sandig- humose +/-- } \\
\text { kalkhaltige Böden }\end{array}$ & $\begin{array}{l}\text { basiph.- } \\
\text { subneutro } \\
\text { ph. }\end{array}$ & frisch & sphotoph. & bis montan & arkt-med \\
\hline $\begin{array}{l}\text { Diploschistes } \\
\text { muscorum } \\
\text { (scop.) R. Sant. }\end{array}$ & $\begin{array}{l}\text { häufig Jugendstatium } \\
\text { auf Cladonia pyxidata, } \\
\text { später basenreiche } \\
\text { Böden }\end{array}$ & $\begin{array}{l}\text { m.acidoph } \\
\text {. m. } \\
\text { basiph. }\end{array}$ & $\begin{array}{l}\text { trocken bis } \\
\text { humid }\end{array}$ & $\begin{array}{l}\text { z-s. } \\
\text { photoph. }\end{array}$ & bis alpin & bor-med \\
\hline $\begin{array}{l}\text { Heppia lutosa } \\
\text { (Ach.) Nyl. }\end{array}$ & kalkreiche Feinerde & $\begin{array}{l}\text { subneutro } \\
\text { ph. - } \\
\text { m.basiph. }\end{array}$ & z.xeroph. & lichtreich & $\begin{array}{l}\text { bis } \\
\text { hochmontan }\end{array}$ & mieur-med \\
\hline $\begin{array}{l}\text { Peltigera } \\
\text { lepidophora } \\
\text { (Vain.) Bitter }\end{array}$ & basenreiche Rohböden & $\begin{array}{l}\text { subneutro } \\
\text { ph. - } \\
\text { m.basiph. }\end{array}$ & & & $\begin{array}{l}\text { hochmontan } \\
\text { bis alpin }\end{array}$ & $\begin{array}{l}\text { arkt- } \\
\text { mieur(alp) }\end{array}$ \\
\hline
\end{tabular}

Tab. 4.2: Standortansprüche der gefundenen Flechtenarten und Arealdiagnose (soweit bekannt). Nach Wirth (1995). 


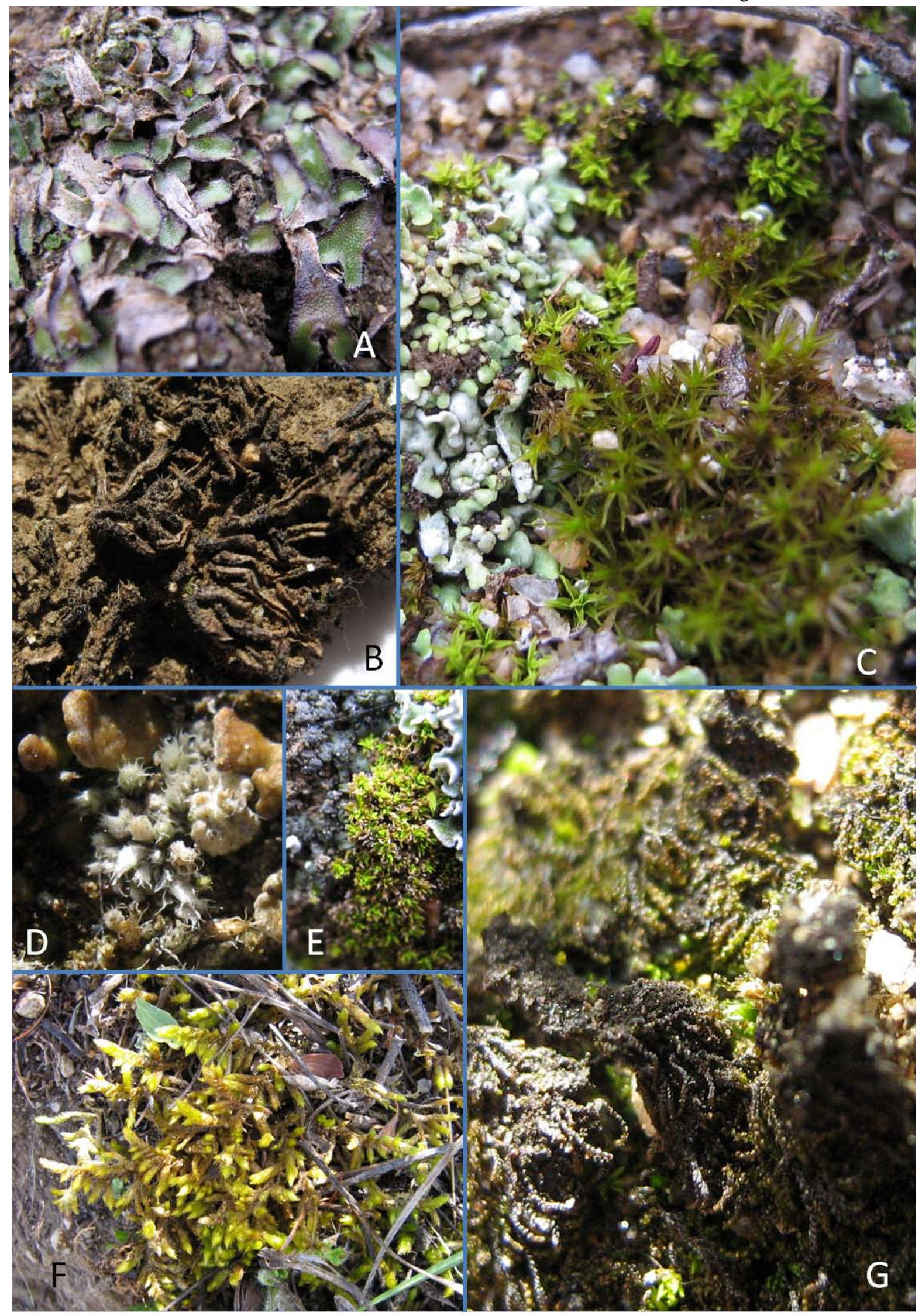

Abb. 4.9: In den BSCs vorkommende Moosarten. A: Riccia sp. (L.), B: Riccia sp. (L.) im ausgetrockneten Zustand, C: Tortula ruralis (Hedw.) Gärtn., D: Bryum argenteum Hedw., E: Rhytidium rugosum (Hedw.) Kindb. 


\subsubsection{BSC-Typen}

\subsection{Mikroskopische Untersuchungen}

Es wurden die verschiedenen BSC-Typen von verschiedenen Standorten mikroskopiert. Hierbei wurden einmal die Freilandproben selbst mikroskopiert, indem kleine Krustenpartikel herauspräpariert und von mineralischen Bestandteilen so weit wie möglich befreit wurden, und weiterhin auf Festmedium angezogene Algen mikroskopiert. Die Ergebnisse sind in den Abbildungen 4.10 - 4.12 und in Tabelle 4.3 dargestellt Die Abbildung 4.10 zeigt einige Übersichtsaufnahmen. In Bild A sieht man dunkle Flechtenthalli, dazwischen ragen Cyanobakterien der Ordnung Oscillatoriales, eventuell der Gattung Phormidium heraus. Auf Bild B sind Cyanobakterien der Gattung Coleodesmium zu sehen. Bild C zeigt eine Autofluoreszensaufnahme einer BSC-Flocke. Chlorophyll zeigt hier eine rote Autofluorezenz, man kann also davon ausgehen, dass es sich bei allen rot leuchtenden Strukturen um photosynthetisch aktive Organismen handelt. Die gelb leuchtenden Strukturen sind hier mineralischer Natur. Auf Bild D sieht man eine Flocke, die zu einem großen Teil aus dem Cyanobakterium Phormidium besteht. Diese sind durch die Präparation aus ihrem natürlichen Gefüge gerissen und ragen so hervor. Auf Bild E kann man sehen, dass einige BSCs zu einem großen Teil aus Pilzhyphen bestehen. Ob diese Teile einer Flechte sind oder frei vorkommen, kann man nicht immer beurteilen. Bild F zeigt einen Mineralpartikel. Das Präparat wurde mit Safranin angefärbt. Nach der Färbung wurden Bakterienkolonien sichtbar. Ob diese auf der Oberfläche wachsen, in Mikronischen oder innerhalb (krypotoendolithisch), konnte nicht eindeutig bestimmt werden.

Abbildung 4.11 zeigt einige Detailaufnahmen von Cyanobakterien und Grünalgen aus BSCs. Auf Bild A ist ein Faden der Gattung Phormidium zu sehen. Diese Gattung zeichnet sich dadurch aus, dass sie im Gegensatz zu Microcoleus (siehe Bild C und E) zu je einem Faden in der Gallerthülle wachsen. Bild B zeigt einen weiteren Vertreter der Oscillatoriales innerhalb des BSC-Verbands. Die Cyanobakterien bilden ausgedehnte Schichten aus EPS (Extrazellulären Polysaccharide, auch Gallerthülle genannt), auf denen sich andere Organismen ansiedeln können und verschiedene Überlebensvorteile genießen, auf die später noch einzugehen sein wird. Bild C zeigt einen Vertreter der Gattung Microcoleus. Er wurde auf Festmedium angezogen und zeigte schon bald die charakteristische Wuchsform. 
Makroskopisch wachsen die Filamente dieser Cyanobakterien lockenartig. Auf Bild E sieht man, dass die Filamente Stränge bilden und zu mehreren von einer Scheide umgeben sind. Bild D zeigt eine Grünalge, einen Vertreter der Chroococcales. Diese Algen sind auch häufig als Photobionten in Flechten vorhanden. In diesem Fall handelt es sich aber um freie, ebenfalls auf Festmedium kultivierte Algen.

Abbildung 4.12 zeigt einige Autofluoreszenz-Detailaufnahmen verschiedener Cyanobakterien. Auf Bild A sind kugelige Cyanobakterien der Gattung Chroococcus zu sehen. Auch diese wurden zuvor auf Festmedium angezogen. Bild B zeigt einen Angehörigen der Gattung Tolypothrix in seiner Gallertscheide. Eine Scheide und der sich darauf ansiedelnde Bewuchs sind auch auf Bild C zu sehen. Außerdem sieht man dort einen Strang unbestimmter Oscillatoriales. Auf Bild D wird ein auf Festmedium gewachsener Strang von Microcoleus gezeigt, auf Bild E einige Filamente der Gattung Lyngbya. Man sieht neben den autofluoreszierenden Fäden eine leere Gallerthülle. Lyngbya ist neben einigen anderen Cyanobakterien zu gleitender Bewegung in der Scheide befähigt und so scheint diese Scheide verlassen worden zu sein. Auf Bild F ist ein Vertreter der mit ihnen eng verwandten Gattung Leptolyngbya zu sehen. 


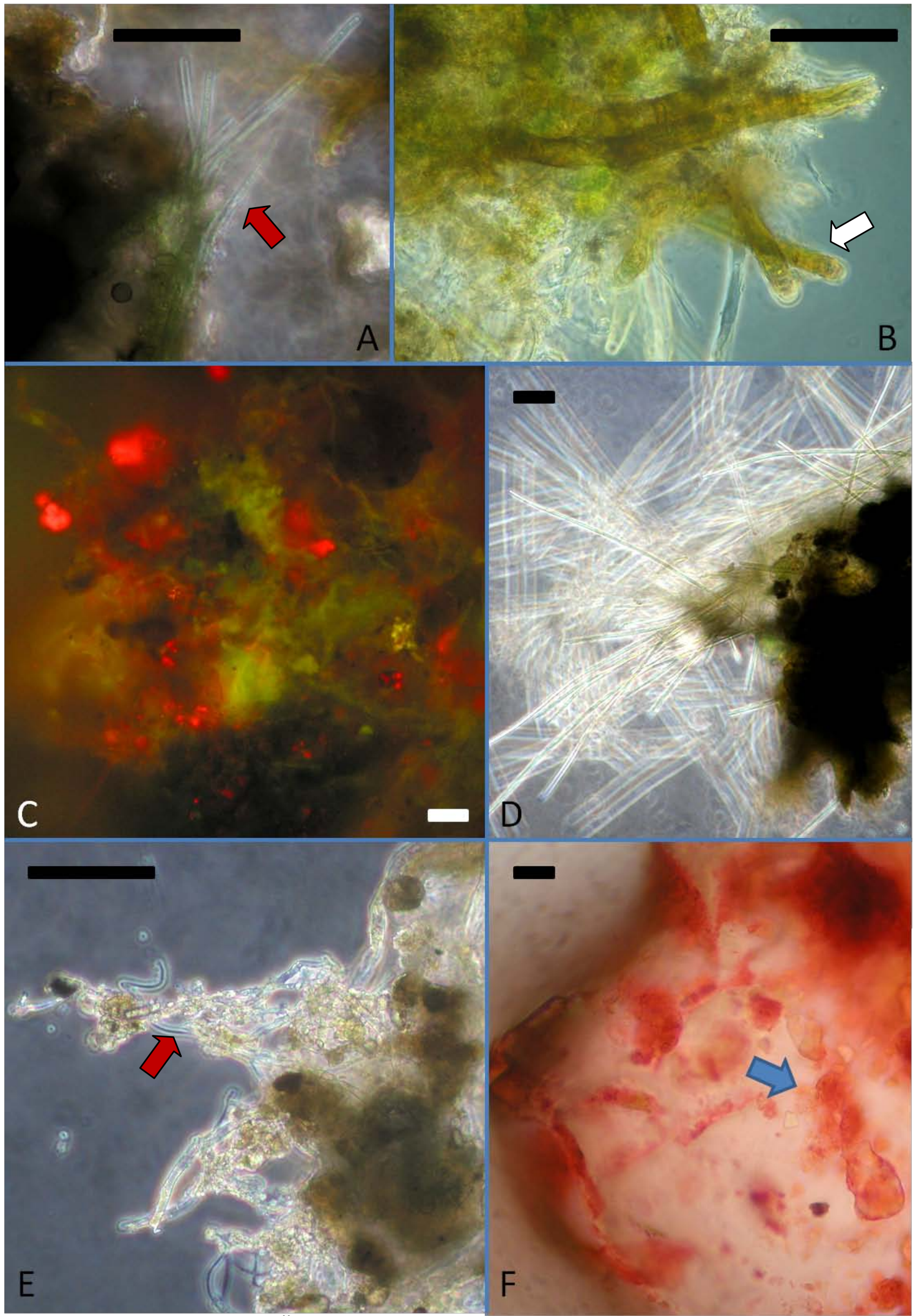

Abb. 4.10: Mikroskopische Übersichtsaufnahmen von BSCs. A: Übersicht mit heraus ragenden Oscillatoriales (roter Pfeil), Übersicht mit Coleodesmium sp. (weißer Pfeil), C: Übersicht einer BSCProbe (Autofluoreszenz) D: Übersicht mit Phormidium sp., E: Übersicht mit Pilzhyphen (roter Pfeil), F: Aufwuchs oder Kryptoendolithenwachstum eines Quarzkristalls, der blaue Pfeil deutet auf eine Bakterienkolonie (angefärbt mit Safranin). Die Balken zeigen die Distanz von $5 \mu \mathrm{m}$ an. 


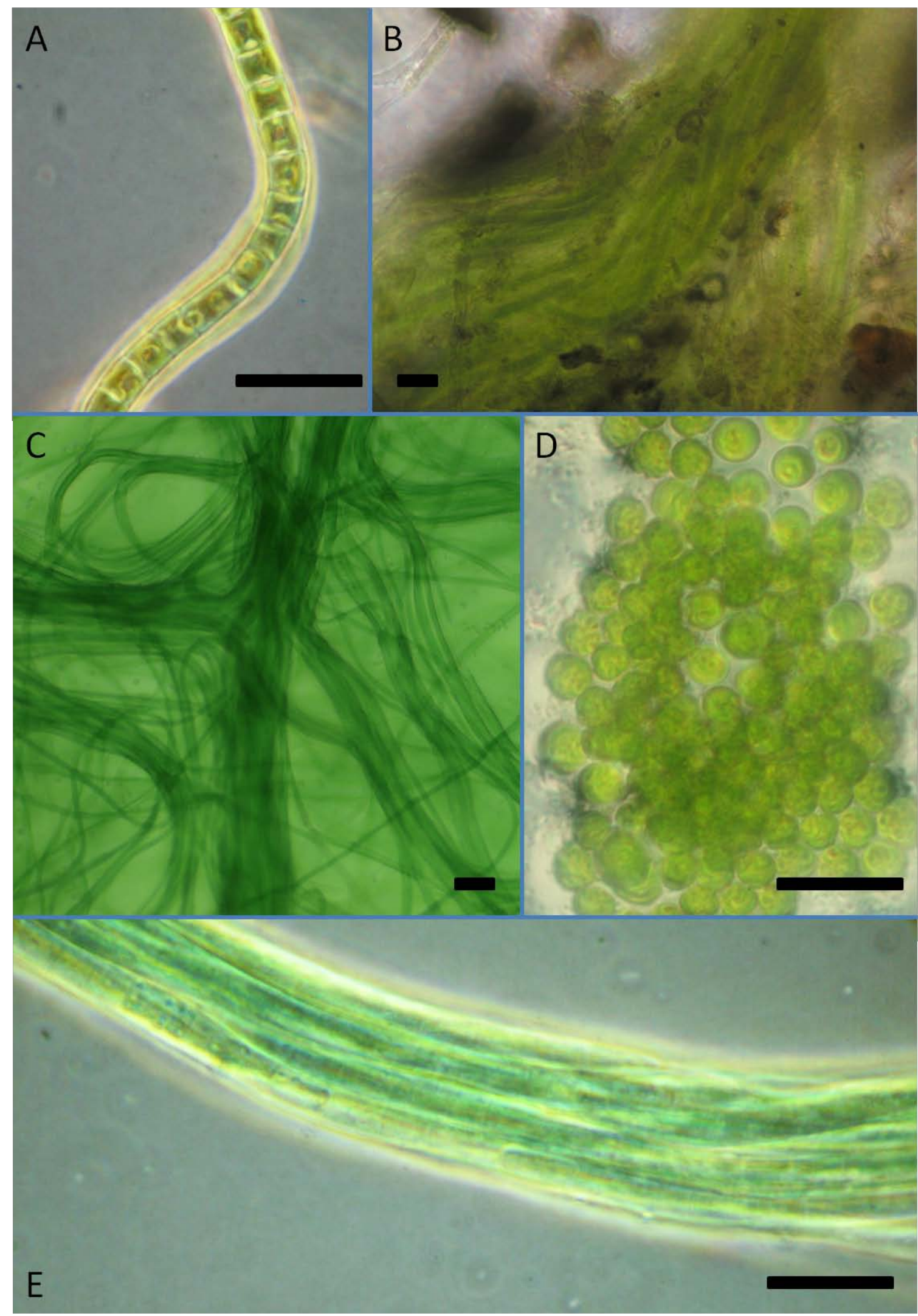

Abb. 4.11: Mikroskopische Detailaufnahmen von BSCs. A: Phormidium sp. (L.), B: Oscillatoriales in bewachsener Gallertscheide, C: Microcoleus sp. (Wachstum auf Festmedium), D: Chlorella-artige Grünalge (Wachstum auf Festmedium), E: Microcoleus sp. in typischer Wuchsform. Die Balken zeigen die Distanz von $5 \mu \mathrm{m}$ an. 


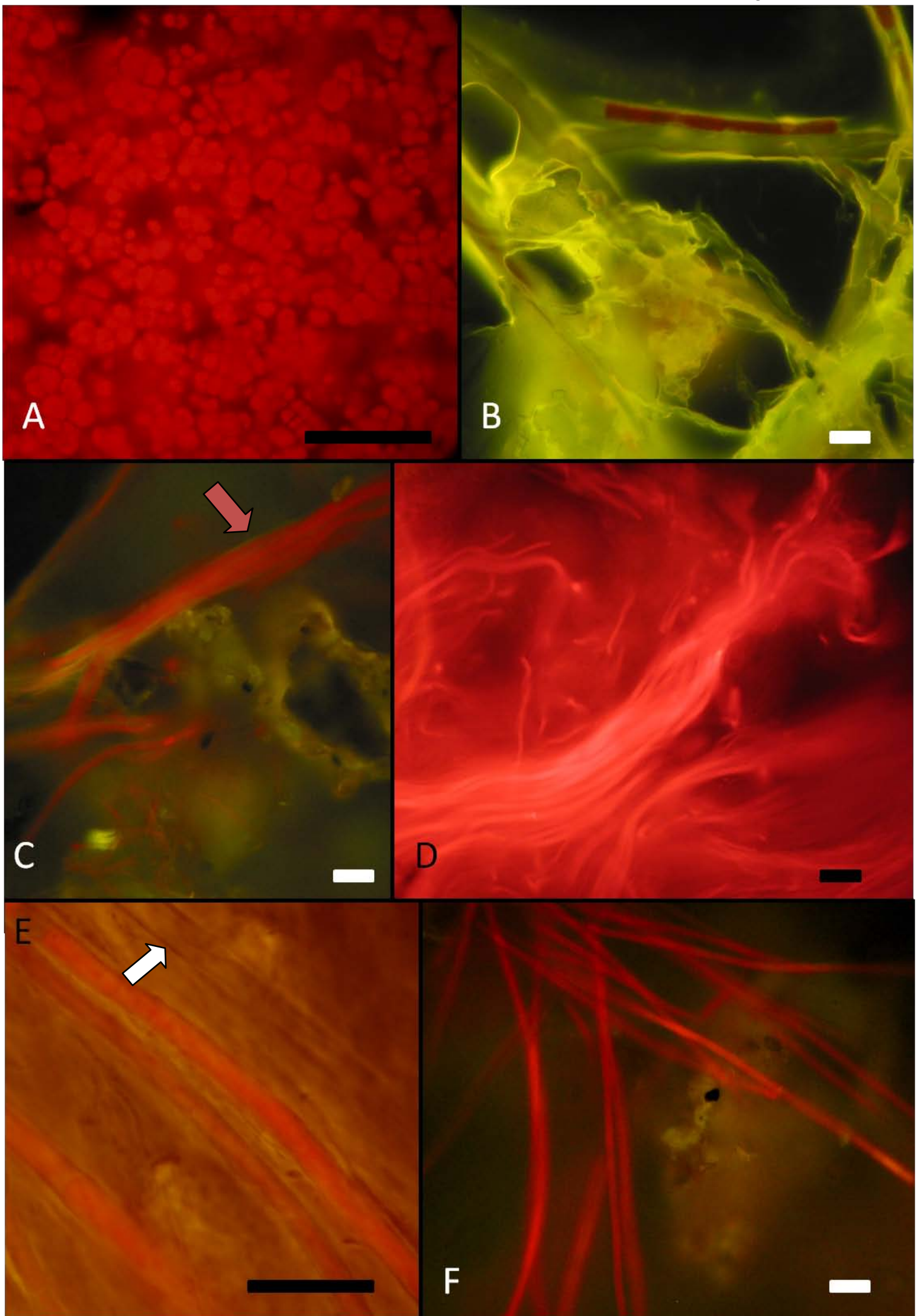

Abb. 4.12: Mikroskopische Autofluoreszenzaufnahmen von BSCs. A: Chroococcus sp. (Wachstum auf Festmedium), B: Tolypothrix sp. in Gallertscheide, C: Oscillatoriales (Pfeil), D: Microcoleus sp. (Wachstum auf Festmedium), E: Lyngbya sp. in Gallertscheide (eine leere Scheide wird durch den Pfeil markiert), F: Leptolyngbya sp. Die Balken zeigen die Distanz von $5 \mu \mathrm{m}$ an. 


\subsection{Makroskopische Untersuchungen}

4 Ergebnisse

Es war grundsätzlich möglich, dass jede der gefundenen makroskopisch sichtbaren Kryptogamenarten, also Moose und Flechten, mit jeder anderen zusammen gefunden werden konnte. Es stellte sich jedoch heraus, dass einige Kombinationen besonders häufig waren. Diese wurden nun mikroskopisch auf das Vorhandensein von Algen geprüft und mit Erkenntnissen aus der Untersuchung im Freiland verknüpft. Hierbei konnte man die Tendenz erkennen, dass dünnere BSCs oft höhere Algenanteile enthalten. Größere Flechten wie Cladonia und Psora bilden oft geschlossene Flächen, so dass in den von ihnen gebildeten BSCs oft keine Möglichkeit besteht, dass Algen überleben können, da diese ja auf das Sonnenlicht angewiesen sind. Die vermutete Position innerhalb der Sukzessionsreihe ist ein im nächsten Kapitel zu diskutierender Faktor, der auf der Annahme beruht, dass BSCs sich von reinen dünnen Algenkrusten $\mathrm{zu}$ komplexen aus Organismen aller Reiche zusammengesetzten Klimaxkrusten entwickeln. In Abb. 4.13 sind einige BSCs gezeigt, wobei hier nicht nur häufige Typen gezeigt werden.

In Bild A sieht man verschiedene Cyanoflechten-Moos-Algen-Krusten mit Heppia und Catapyrenium. Diese Flechten wachsen oft lückig und bieten somit Algen Lebensraum. Bild B zeigt eine gemische Kruste mit Moos, Collema coccophorum, Cladonia, Catapyrenium und Peltigera. Dieser Krustentyp steht nach oben genannter Einschätzung etwa in der Mitte bis am Ende der Klimaxreihe, wohingegen die auf Bild C gezeigte angefeuchtete Kruste mit Peltigera, Collema und Moos eher einen Klimaxzustand darstellen dürfte, weil weder Algen noch Pflanzen zwischen einem derart dichten Bewuchs Ansiedlungsmöglichkeiten haben. Ebenso ist die auf Bild D gezeigte Psora-Cladonia-Moos-Kruste im oberen Bereich der Sukzessionsreihe anzusiedeln. Bild E zeigt eine gemischte Kruste mit lückigem Wuchs und Collema crispum, Cladonia, Diploschistes und Moos. Diese ist zwar komplex aufgebaut, besitzt aber genug Lücken für andere Organismen. Ihr Status ist später zu diskutieren. Die in Bild F abgebildete Cladonia-Kruste ist ein Beispiel für eine BSC mit nur einer makroskopischen Kryptogamenart und bietet Algen wenig Lebensraum. Bild G zeigt wieder eine gemischte Kruste mittlerer Sukzessionsstufe mit junger Psora, Cladonia, Collema, Moos und einem Gefäßpflanzensämling, der sich zwischen den Flechten angesiedelt hat. 


\begin{tabular}{|c|c|c|c|c|c|c|c|c|}
\hline BSC-Typ & Dicke & Flechten & Moose & Wuchsform & $\begin{array}{l}\text { Algen } \\
\text { innerhalb der } \\
\text { Krustenfläche }\end{array}$ & $\begin{array}{l}\text { Algen } \\
\text { am } \\
\text { Rand }\end{array}$ & $\begin{array}{l}\text { Wachstum } \\
\text { höherer } \\
\text { Pflanzen } \\
\text { beobachtet }\end{array}$ & $\begin{array}{l}\text { Vermutete } \\
\text { Position innerhalb } \\
\text { der } \\
\text { Sukzessionsreihe }\end{array}$ \\
\hline $\begin{array}{l}\text { Reine } \\
\text { Algenkrusten }\end{array}$ & $-4 \mathrm{~mm}$ & -- & -- & $\begin{array}{l}\text { dünner } \\
\text { Aufwuchs }\end{array}$ & ja & ja & ja, selten & I \\
\hline $\begin{array}{l}\text { Algen-Moos- } \\
\text { Krusten }\end{array}$ & $-10 \mathrm{~mm}$ & -- & ja & lückig & ja & ja & ja & I \\
\hline $\begin{array}{l}\text { Algen-Moos- } \\
\text { Collema*- } \\
\text { Krusten } \\
\end{array}$ & $-15 \mathrm{~mm}$ & ja & ja & lückig & ja & ja & ja & $\mathrm{I}$ \\
\hline $\begin{array}{l}\text { Algen- Collema } \\
\text { - Krusten }\end{array}$ & Ø $10 \mathrm{~mm}$ & ja & oft & lückig & ja & ja & selten & I -M \\
\hline $\begin{array}{l}\text { Cladonia-Moos } \\
\text { - Krusten }\end{array}$ & $\begin{array}{c}\text { Ø } 10 \mathrm{~mm}, \\
\text { bis zu } 35 \\
\mathrm{~mm}\end{array}$ & ja & ja & $\begin{array}{l}\text { manchmal } \\
\text { lückig }\end{array}$ & selten & ja & ja & $\mathrm{M}$ \\
\hline $\begin{array}{l}\text { Catapyrenium - } \\
\text { Collema - } \\
\text { Krusten }\end{array}$ & $\begin{array}{c}\varnothing 7-10 \\
\text { mm }\end{array}$ & ja & oft & oft lückig & oft & ja & selten & $\mathrm{M}$ \\
\hline $\begin{array}{l}\text { Cladonia- } \\
\text { Catapyrenium - } \\
\text { Krusten }\end{array}$ & $\begin{array}{c}\varnothing 15-20 \\
\mathrm{~mm}\end{array}$ & ja & oft & $\begin{array}{l}\text { manchmal } \\
\text { lückig }\end{array}$ & selten & ja & selten & $\mathrm{M}$ \\
\hline $\begin{array}{l}\text { Peltigera - } \\
\text { Cladonia - } \\
\text { Moos -Kruste }\end{array}$ & Ø $15 \mathrm{~mm}$ & ja & ja & oft lückig & oft & ja & ja & $\mathrm{M}-\mathrm{K}$ \\
\hline $\begin{array}{l}\text { Cladonia-Psora } \\
\text { - Krusten }\end{array}$ & $\begin{array}{c}\varnothing 15-20 \\
\mathrm{~mm}\end{array}$ & ja & oft & oft lückig & oft & ja & ja & $M-K$ \\
\hline $\begin{array}{l}\text { Gemischte } \\
\text { Krusten** }\end{array}$ & $\begin{array}{c}\varnothing 15-20 \\
\mathrm{~mm}\end{array}$ & ja & ja & lückig & ja & ja & oft & $\mathrm{M}-\mathrm{K}$ \\
\hline $\begin{array}{l}\text { Cladonia- } \\
\text { Krusten }\end{array}$ & $\begin{array}{l}\text { Ø } 10 \mathrm{~mm}, \\
\text { bis zu } 35 \\
\mathrm{~mm}\end{array}$ & ja & nein & $\begin{array}{c}\text { meist } \\
\text { geschlossen }\end{array}$ & nein & ja & selten & $\mathrm{K}$ \\
\hline Psora-Krusten & $\begin{array}{l}\varnothing 15 \mathrm{~mm} \text {, } \\
\text { bis zu } 10 \\
\text { cm }\end{array}$ & ja & nein & geschlossen & nein & oft & nie & $\mathrm{K}$ \\
\hline $\begin{array}{l}\text { Psora - } \\
\text { Xanthoparmelia } \\
\text { - Krusten } \\
\end{array}$ & $\begin{array}{l}\varnothing 15 \mathrm{~mm}, \\
\text { bis zu } 30 \\
\mathrm{~mm}\end{array}$ & ja & selten & geschlossen & nein & oft & nie & $\mathrm{K}$ \\
\hline $\begin{array}{l}\text { Cladonia - } \\
\text { Xanthoparmelia } \\
\text { - Krusten }\end{array}$ & $\begin{array}{l}\varnothing 10 \mathrm{~mm}, \\
\text { bis zu } 35 \\
\mathrm{~mm}\end{array}$ & ja & selten & $\begin{array}{c}\text { meist } \\
\text { geschlossen }\end{array}$ & nein & ja & selten & $\mathrm{K}$ \\
\hline
\end{tabular}

Tab. 4.3: Ergebnisse der mikroskopischen Analysen der häufigsten BSC-Typen.* hier meist

Collema coccophorum Tuck., **= keine dominierende Art feststellbar. 
4 Ergebnisse

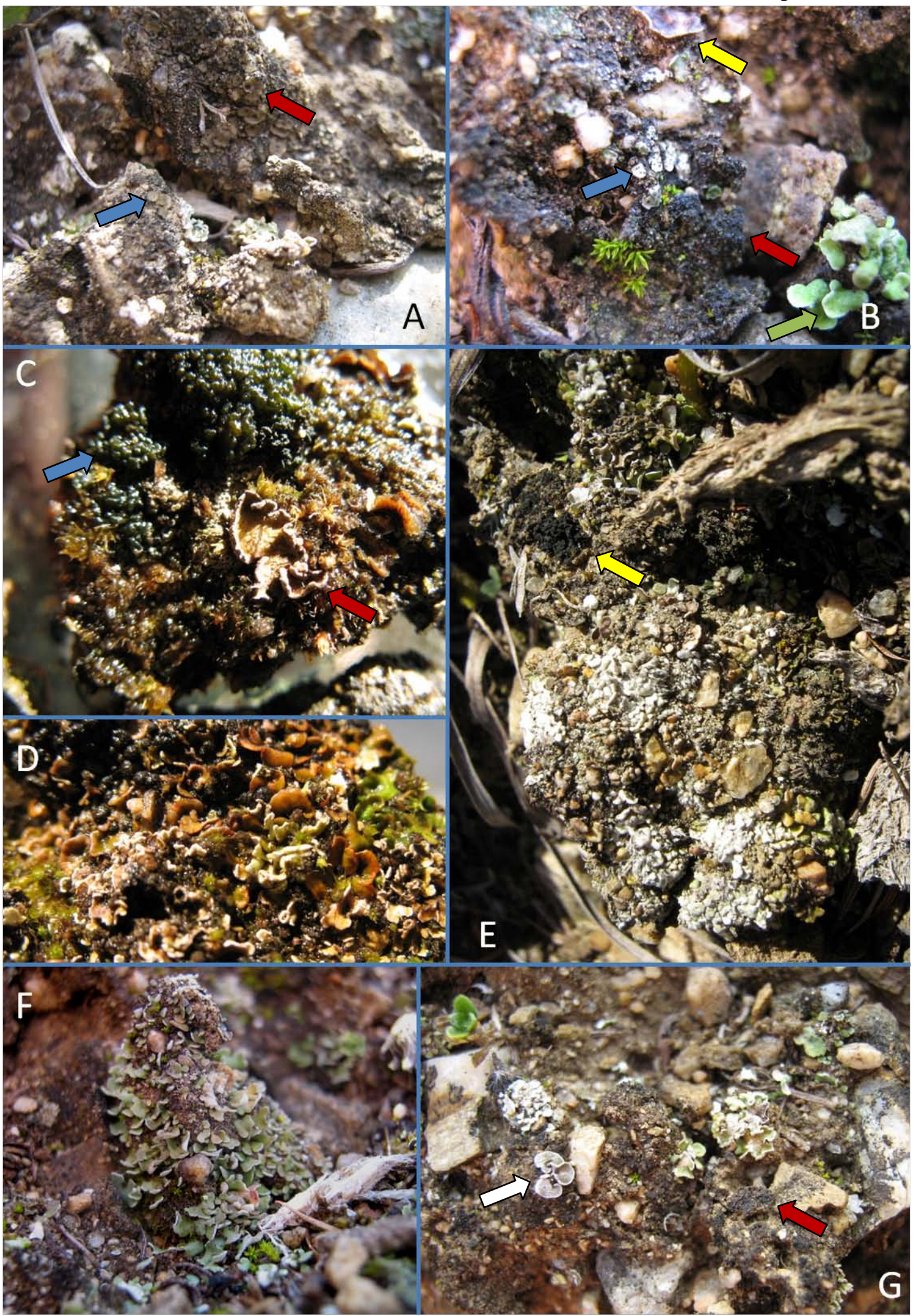

Abb. 4.13: BSC-Typen. A: verschiedene Cyanoflechten-Moos-Algen-Krusten mit Heppia (roter Pfeil) und Catapyrenium (blauer Pfeil), B: gemische Kruste mit Moos, Collema coccophorum (roter Pfeil), Cladonia (grüner Pfeil), Catapyrenium (blauer Pfeil) und Peltigera (gelber Pfeil), C: angefeuchtete Kruste mit Peltigera (roter Pfeil), Collema (blauer Pfeil) und Moos, D: PsoraCladonia-Moos-Kruste, E: gemischte Kruste mit lückigem Wuchs und Collema crispum (gelber Pfeil), Cladonia, Diploschistes und Moos, F: Cladonia-Kruste G: gemischte Kruste mit junger Psora (weißer Pfeil), Cladonia, Collema (roter Pfeil), Moos und Gefäßpflanzensämling. 
[Geben Sie den Titel des Dokuments ein]

4 Ergebnisse

\subsection{Maximale Wasserspeicherungskapazität (WHKmax) verschiedener BSC- Typen}

An verschiedenen BSC-Proben und Vergleichsproben (Flechten, Moose, eine sukkulente Gefäßpflanze und reines Substrat) wurde die maximale Wasserspeicherungskapazität gravimetrisch bestimmt. Die Ergebnisse sind in Abbildung 4.14 dargestellt worden. Hier sieht man, dass das reine Substrat die niedrigste $\mathrm{WHK}_{\max }$ hat, während die Laubflechte Cladonia furcata gefolgt einer weiteren unbestimmten Cladonia und einem Angehörigen der Gattung Cladina die höchsten Werte aufweisen. Diese drei Flechten sind nicht Bestandteil von BSCs, sondern wachsen auf feuchteren Standorten. Die BSC-Proben befinden sich mit den Moosproben und der Gefäßpflanze Orostachys malacophylla im unteren Feld der Grafik.

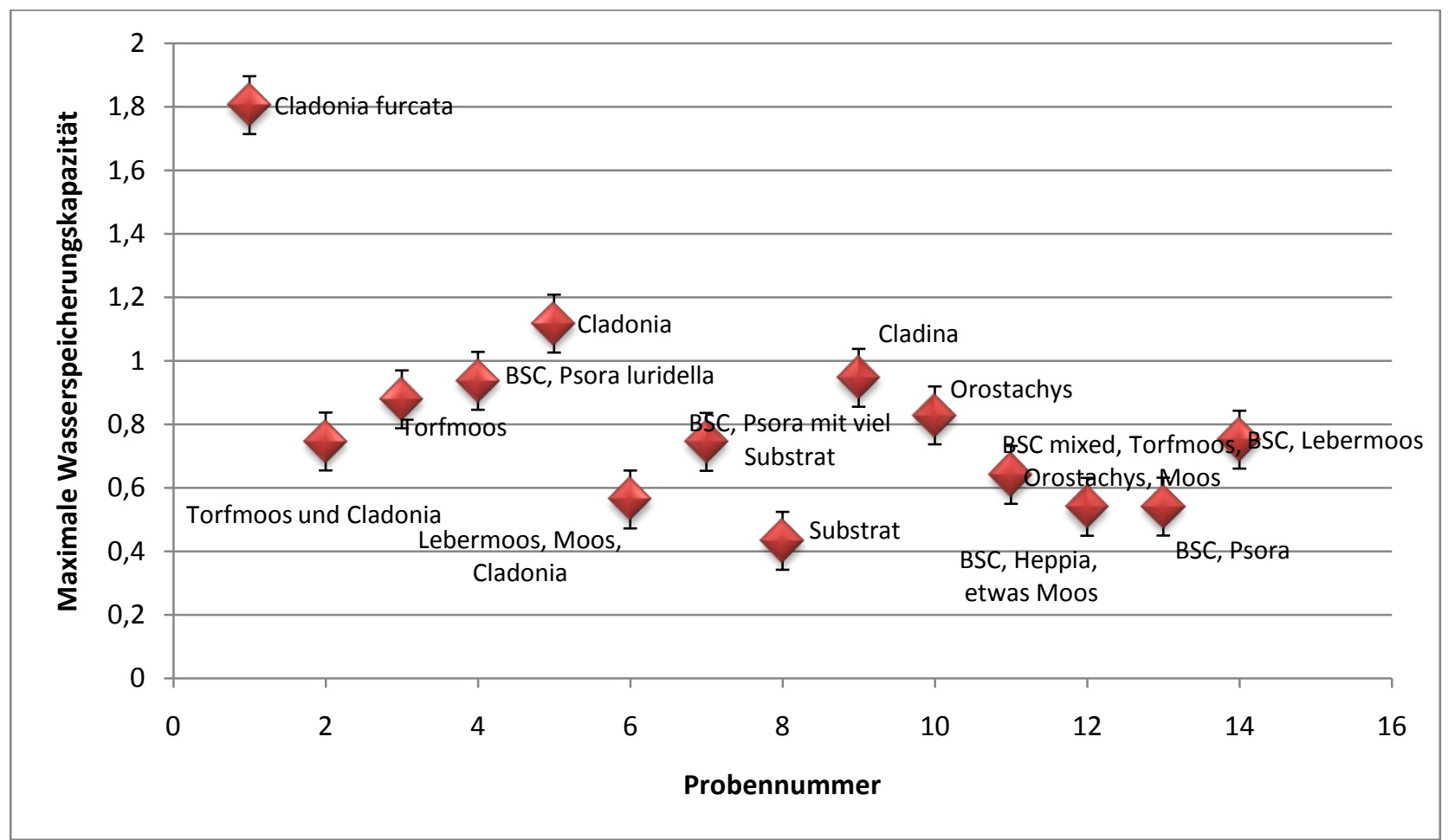

Abb. 4.14: Maximale Wasserspeicherungskapazität verschiedener Bodenkrusten. Die Fehlerbalken zeigen den prozentualen Fehler. 


\subsection{Der Einfluss verschiedener Standortfaktoren auf das Auftreten Biologischer Bodenkrusten und ihre Zusammensetzung}

In diesem Kapitel soll zunächst die Kombination verschiedener Standortfaktoren auf die Bedeckung mit Biologischen Bodenkrusten und auf die in ihnen vertretenen Kryptogamenarten dargestellt werden. Anschließend werden der Einfluss der Gefäßpflanzen allgemein und verschiedener morphologischer Gefäßpflanzengruppen auf die Bedeckung mit BSCs und der Einfluß der Inklination und der Exposition auf die Anzahl der Kryptogamenarten beschrieben. Abschließend soll noch die Auswirkung von Schädigung der BSCs durch Tritt demonstriert werden.

\subsubsection{Analyse der Standortfaktoren}

An Standort A wurde durch das Anlegen verschiedener Linientransekte und die Installation von Zählquadraten eine genaue Aufnahme der Faktoren BSC-Bedeckung, Anzahl der Kryptogamenarten, Pflanzenbedeckung, Anzahl der Pflanzenarten, Exposition, Inklination, Wölbung, Abstand zum Bergrücken und Bedeckung mit Stein ermöglicht. Die Pflanzen- und Kryptogamenarten wurden namentlich erfasst und die Pflanzenarten wurden anschließend auf ihre Indikatorfunktion für verschiedene Vegetationstypen klassifiziert (nach Dulamsuren, 2004). So konnte zu jedem Zählquadrat ermittelt werden, welche Vegetationstypen hier rein oder gemischt vorlagen und für die Multiple Regression wurden diese Gruppen aufgrund dieser Einteilung getrennt voneinander betrachtet.

Zu jedem Vegetationstyp wurde so die Korrelation der verschiedenen Faktoren untereinander durch Spearmans Rangkorrelation ermittelt. Eine Übersicht der miteinander korrelierenden oder auch nicht korrelierenden Faktoren konnte in einem sog. Matrix-Scatterplot dargestellt werden.

Es werden hier die Ergebnisse der Vegetationstypen Artemisia frigida-Gebirgstrockensteppe, Artemisia frigida-Pulsatilla ambigua- Gebirgstrockensteppe und Pulsatilla ambiguaGebirgstrockensteppe gezeigt. Weiterhin kamen noch vor: die Artemisia frigida-Festuca 
lenensis - Gebirgstrockensteppe, die Artemisia frigida- Festuca lenensis- Pusatilla ambiguaUlmus pumila-Gebirgstrockensteppe, die Artemisia frigida-Pulsatilla ambigua-Ulmus pumila-Gebirgstrockensteppe, die Artemisia frigida-Ulmus pumila-Gebirgstrockensteppe, die Pulsatilla ambigua-Ulmus pumila-Gebirgstrockensteppe und schließlich das reine Ulmus pumila-Offene Waldgebiet. Diese Gruppen waren aber sehr spärlich besetzt und so konnten keine Korrelationen ermittelt werden.

\subsubsection{Artemisia frigida-Gebirgstrockensteppe}

Diese zeichnete sich an diesem Standort durch die Charakterarten Alyssum lenense, Orostachys malacophylla, Chamaerodes erecta, Patrinia sibirica, Koeleria cristata und Polygala tenuifolia in veränderlichen Anteilen aus. 21 Zählquadrate ließen sich diesem Vegetationstyp überwiegend zuordnen. Die Inklination reichte von 25 bis $42^{\circ}$, die Exposition von 242 bis $279^{\circ}$, die BSC-Bedeckung von 3 - 55 \% und die Pflanzenbedeckung von 15$75 \%$. Wie in der Abbildung 4.15 und Tabelle 4.3 zu sehen, ergab die Korrelationsanalyse für diesen Vegetationstyp signifikante Abhängigkeiten zwischen der Anzahl der Pflanzenarten mit der Bedeckung mit Gestein $(r=-0,49)$, der Entfernung vom Bergrücken $(r=0,47)$ und der Pflanzenbedeckung ( $\mathrm{r}=0,53)$. Außerdem korrelierte die Pflanzenbedeckung mit der Anzahl der Kryptogamenarten $(r=-0,41)$ und die Anzahl der Kryptogamenarten wiederum mit der Entfernung vom Bergrücken $(r=-0,47)$. Aus Abbildung 4.16 wird für die Entfernung zum Bergrücken und die Anzahl der Kryptogamenarten jedoch ersichtlich, dass die Streuung der Werte recht hoch ist, so ist das Bestimmtheitsmaß der Ausgleichskurve auch nur mit 0,25 angegeben. Auch die Anzahl der Kryptogamenarten mit der Pflanzenbedeckung ergibt keine anschauliche Verteilung (siehe Abb. 4.17). Hier ist das Bestimmtheitsmaß mit 0,17 angegeben. 
4 Ergebnisse
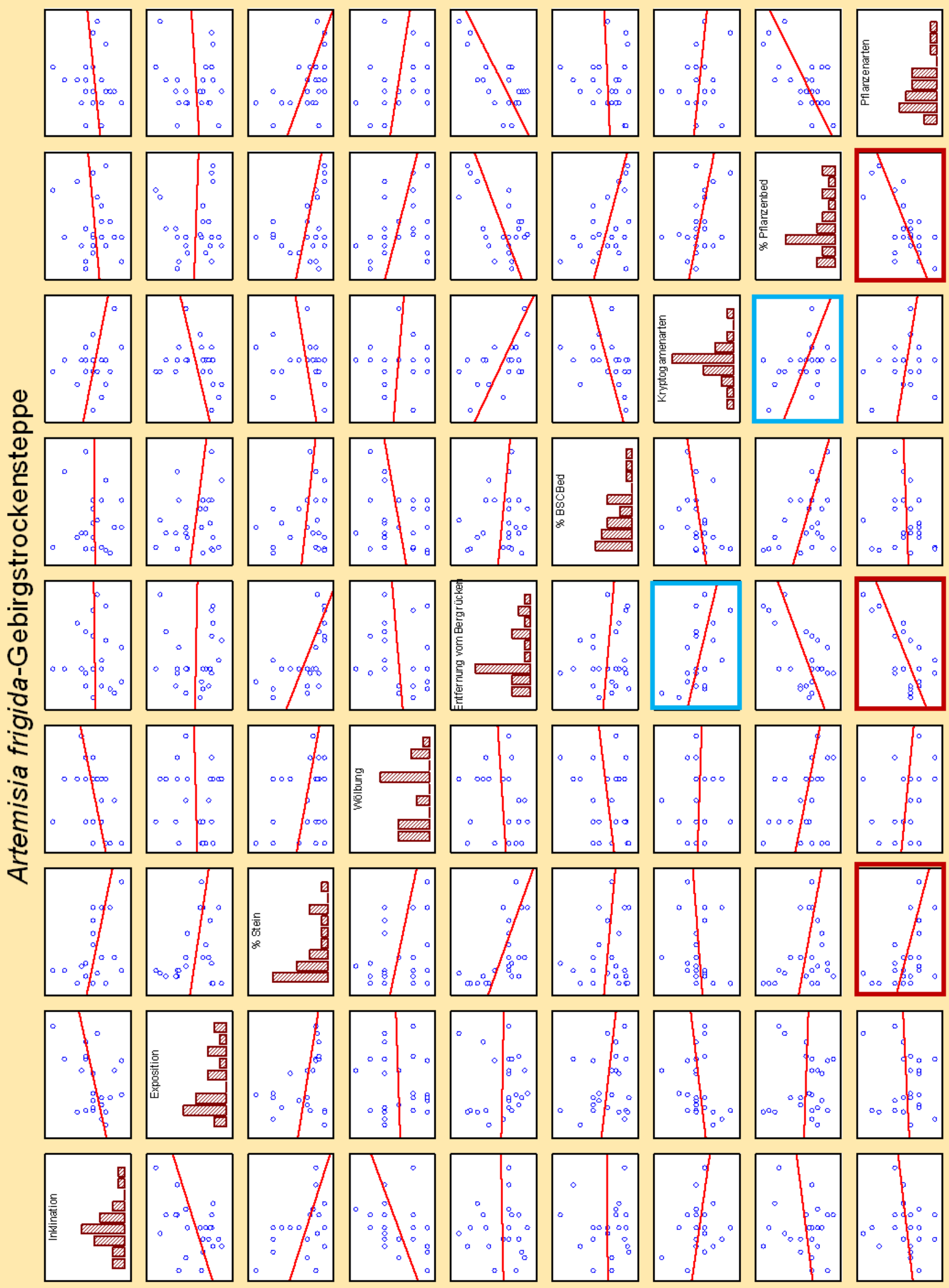

Abb. 4.15: Matrix-Scatterplot für die Artemisia-frigida-Gebirgstrockensteppe. Die blau markierten Plots zeigen BSCs betreffende Korrelationen an, die rot markierten Plots zeigen weitere Korrelationen. 


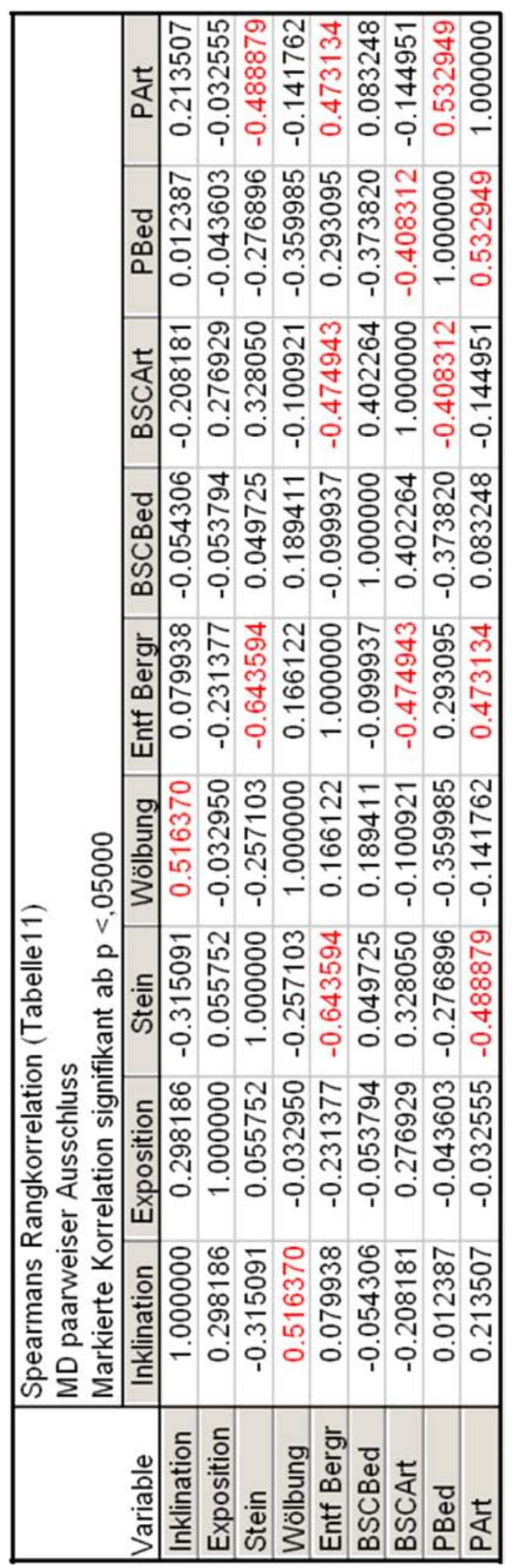

Tab. 4.4: Spearmans Rangkorrelation für die Artemisia frigida-Gebirgstrockensteppe. Die rot markierten Ziffern geben signifikante Korrelationen an. 
4 Ergebnisse

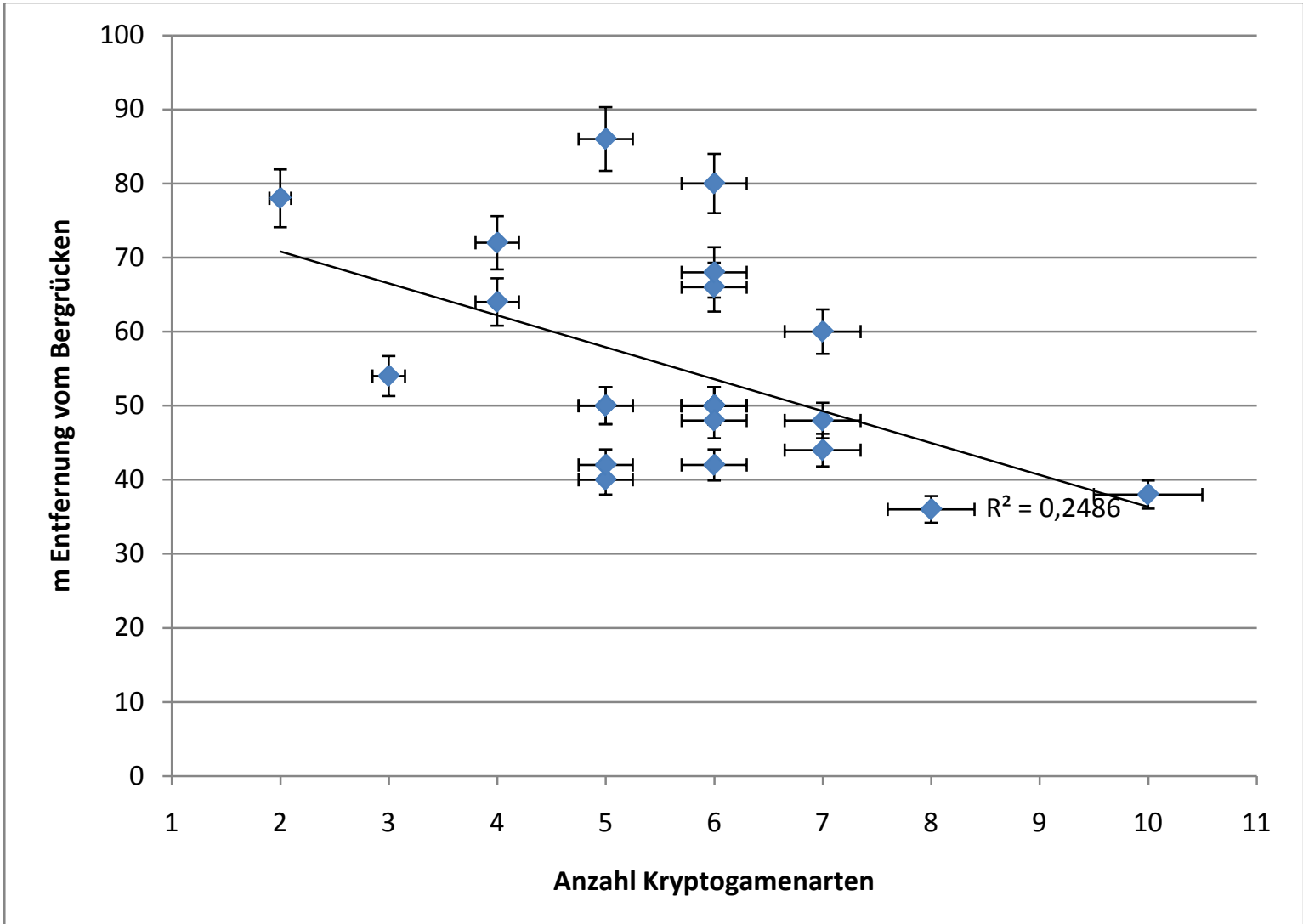

Abb. 4.16: Lineare Regression von der Anzahl der Kryptogamenarten und der Entfernung vom Bergrücken. Die Fehlerbalken geben den prozentualen Fehler an.

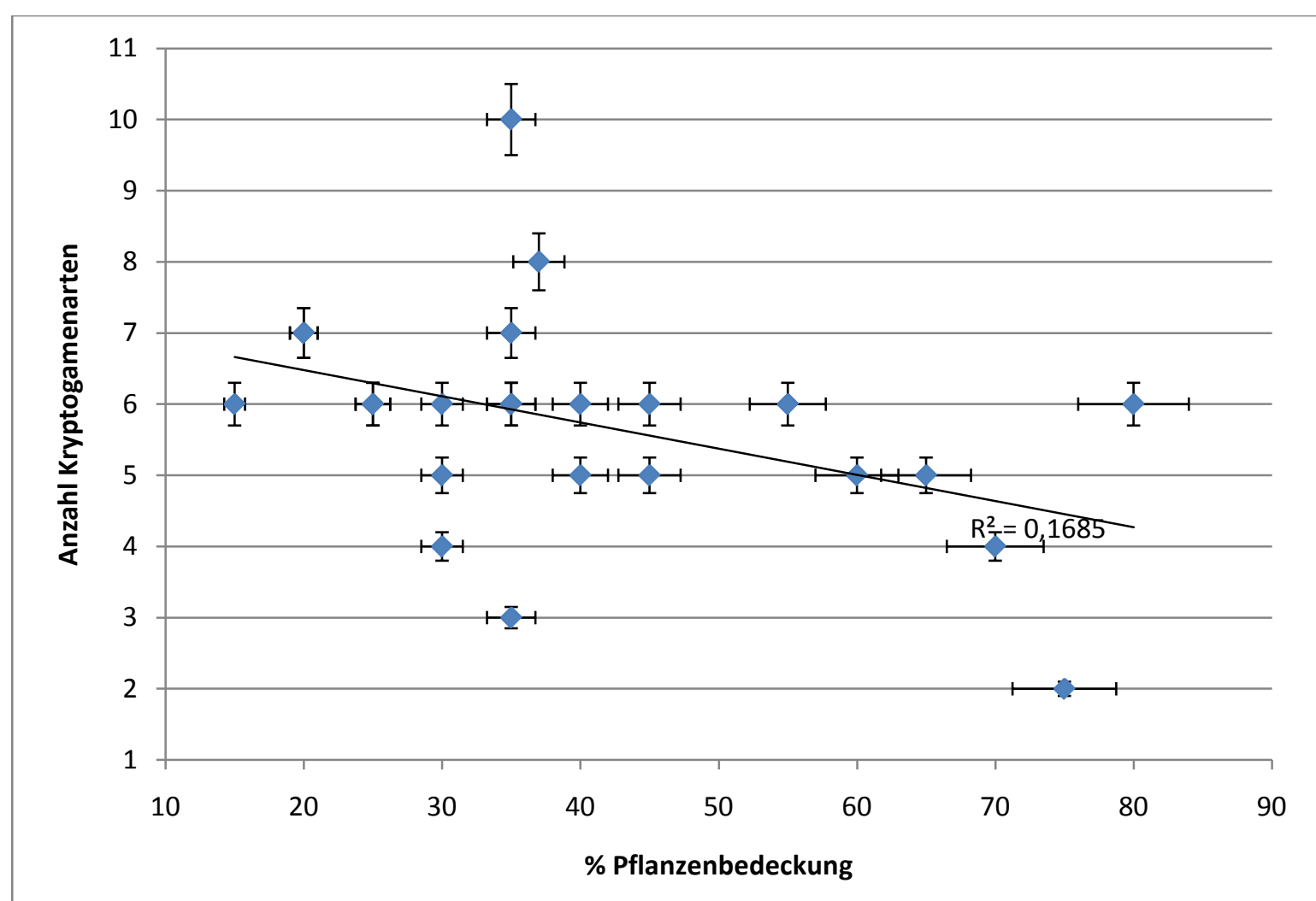

Abb. 4.17: Lineare Regression von der Anzahl der Kryptogamenarten und der Pflanzenbedeckung. Die Fehlerbalken geben den prozentualen Fehler an. 


\subsubsection{Artemisia frigida-Pulsatilla ambigua-Gebirgstrockensteppe}

Die Artemisia frigida-Gebirgstrockensteppe zeichnete sich an diesem Standort durch die Charakterarten Alyssum lenense, Orostachys malacophylla, Chamaerodes erecta, Patrinia sibirica, Koeleria cristata und Polygala tenuifolia in veränderlichen Anteilen aus. Die Pulsatilla ambigua-Gebirgstrockensteppe wurde durch die Charakterarten Bupleurum bicaule und Poa botryoides vertreten. 30 Zählquadrate ließen sich diesem Vegetationstyp überwiegend zuordnen. Die Inklination reichte von 18 bis $42^{\circ}$, die Exposition von 208 bis $290^{\circ}$, die BSC-Bedeckung von 1 - 60 \% und die Pflanzenbedeckung von 4 bis 55 \%. Wie in der Abbildung 4.18 und Tabelle $4.4 \mathrm{zu}$ sehen, ergab die Korrelationsanalyse für diesen Vegetationstyp signifikante Abhängigkeiten zwischen der Bedeckung mit Pflanzen und der Anzahl der Pflanzenarten ( $r=0,42)$, der Anzahl der Pflanzenarten und der Enfernung zum Bergrücken ( $r=0,54)$, der Anzahl der Pflanzenarten und der Exposition $(r=0,37)$ und der Pflanzenbedeckung und der Entfernung zum Bergrücken ( $\mathrm{r}=0,43)$. Außerdem korrelierte die Bedeckung mit BSCs mit der Anzahl der Kryptogamenarten $(r=0,60)$ und die Anzahl der Kryptogamenarten wiederum mit Bedeckung mit Gestein ( $\mathrm{r}=$ 0,62). Wie aus Abbildung 4. 19 für die Anzahl der Kryptogamenarten gegen die prozentuale Bedeckung mit Gestein ersichtlich wird, ist auch hier die Streung der Werte recht groß. Das Bestimmtheitsmaß liegt hier bei 0,26. Für die Anzahl der Kryptogamenarten gegen die Bedeckung mit BSCs sieht die Abhängigkeit mit $\mathrm{R}^{2}=0,32$ etwas besser aus (siehe Abb. 4.20), die Anzahl der Kryptogamenarten gegen die Pflanzenbedeckung aufgetragen ergibt jedoch nur $\mathrm{R}^{2}=0,13$ (siehe Abb. 4.21). 
4 Ergebnisse
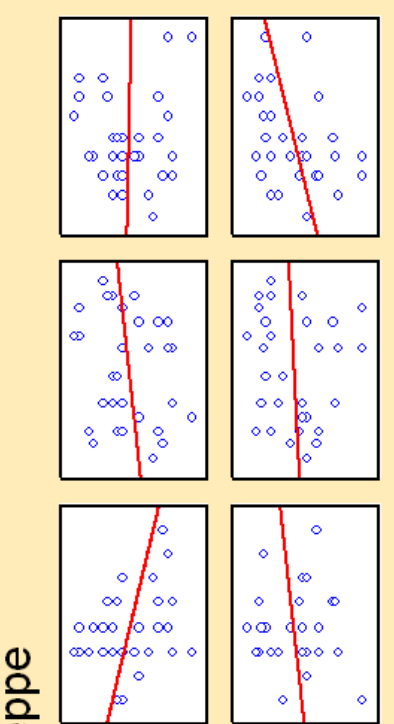

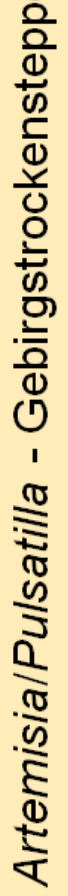
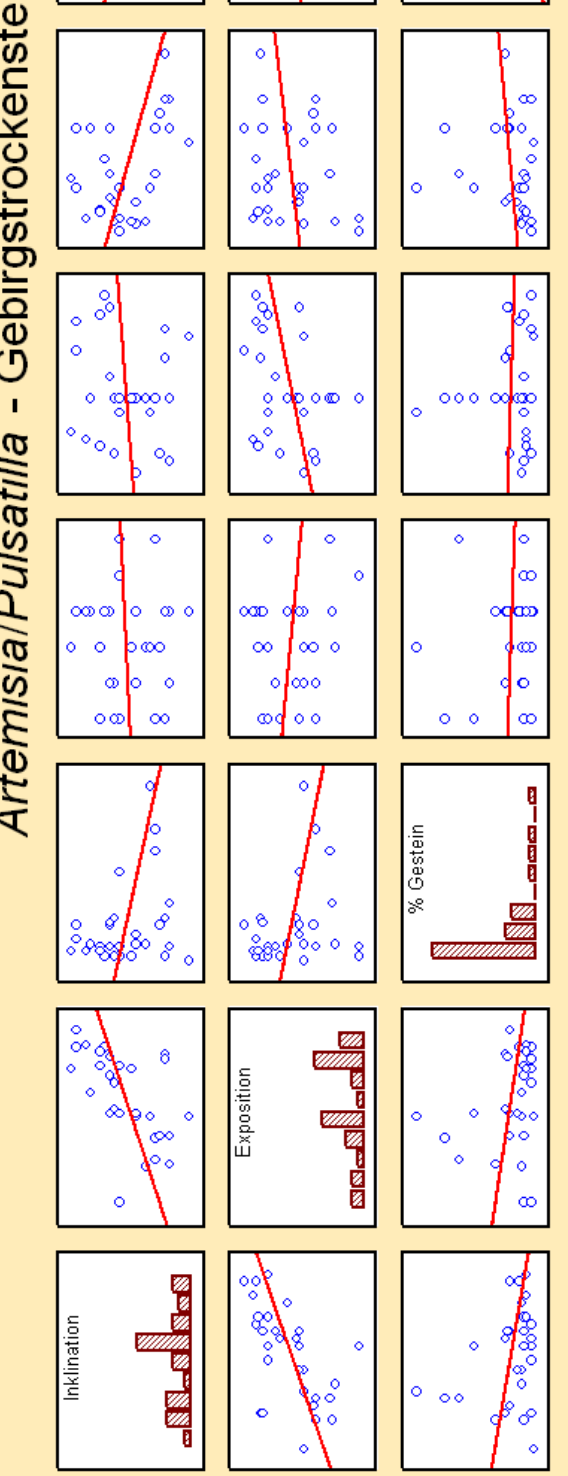
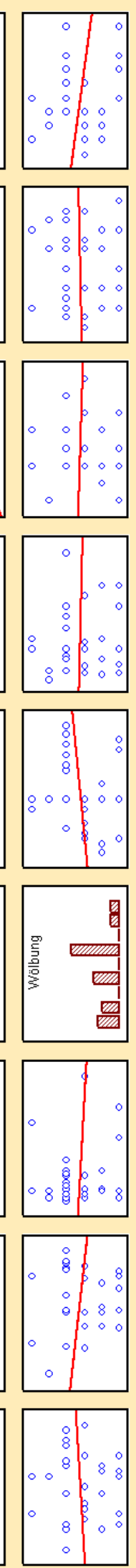
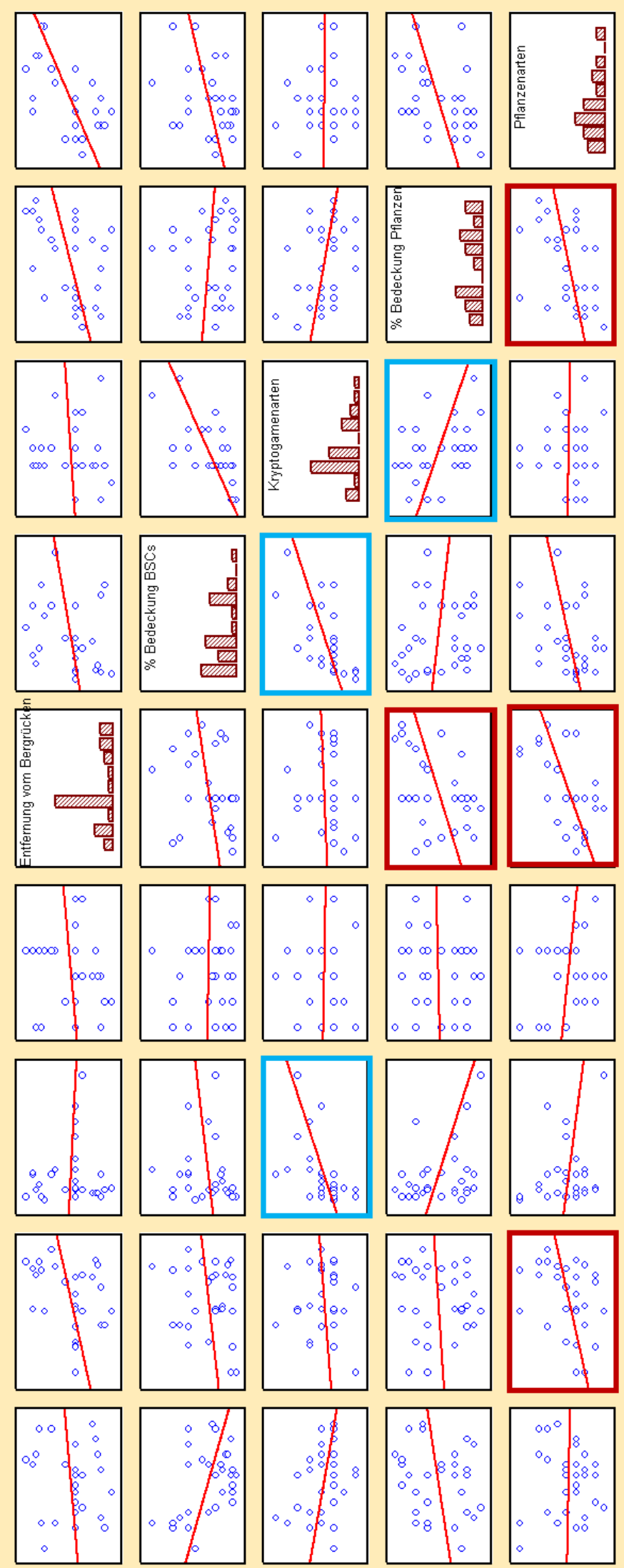

Abb. 4.18: Matrix-Scatterplot für die Artemisia-frigida-Pulsatilla ambiguaGebirgstrockensteppe. Die blau markierten Plots zeigen BSCs betreffende Korrelationen an, die rot markierten Plots zeigen weitere Korrelationen. 


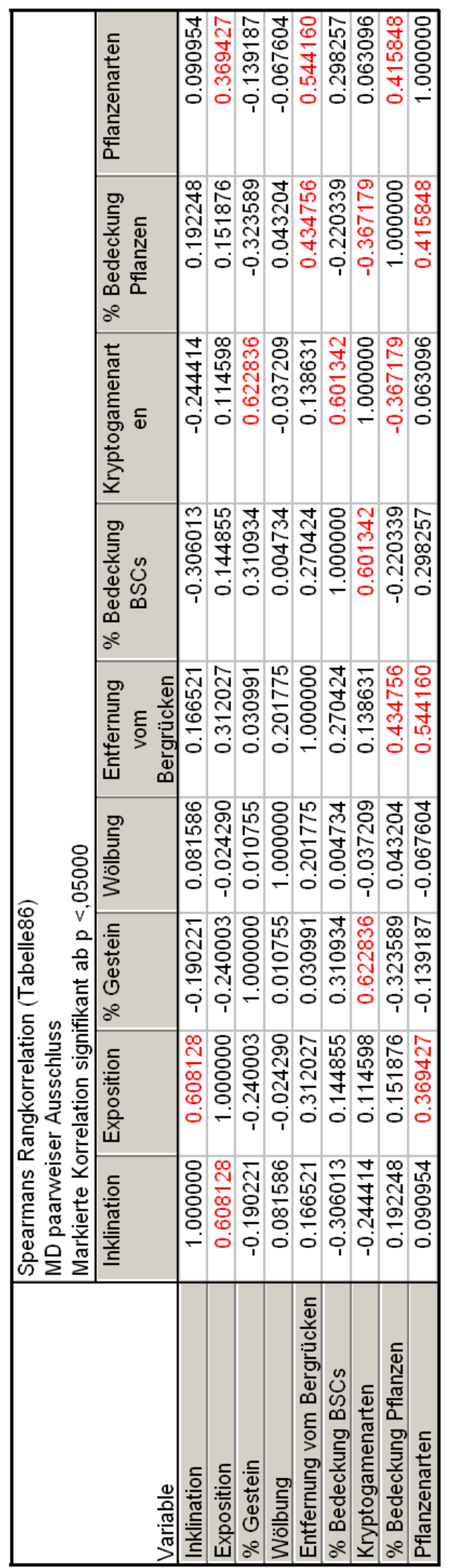

Tab. 4.5: Spearmans Rangkorrelation für die Artemisia frigida-Pulsatilla ambiguaGebirgstrockensteppe. Die rot markierten Ziffern geben signifikante Korrelationen an. 
4 Ergebnisse

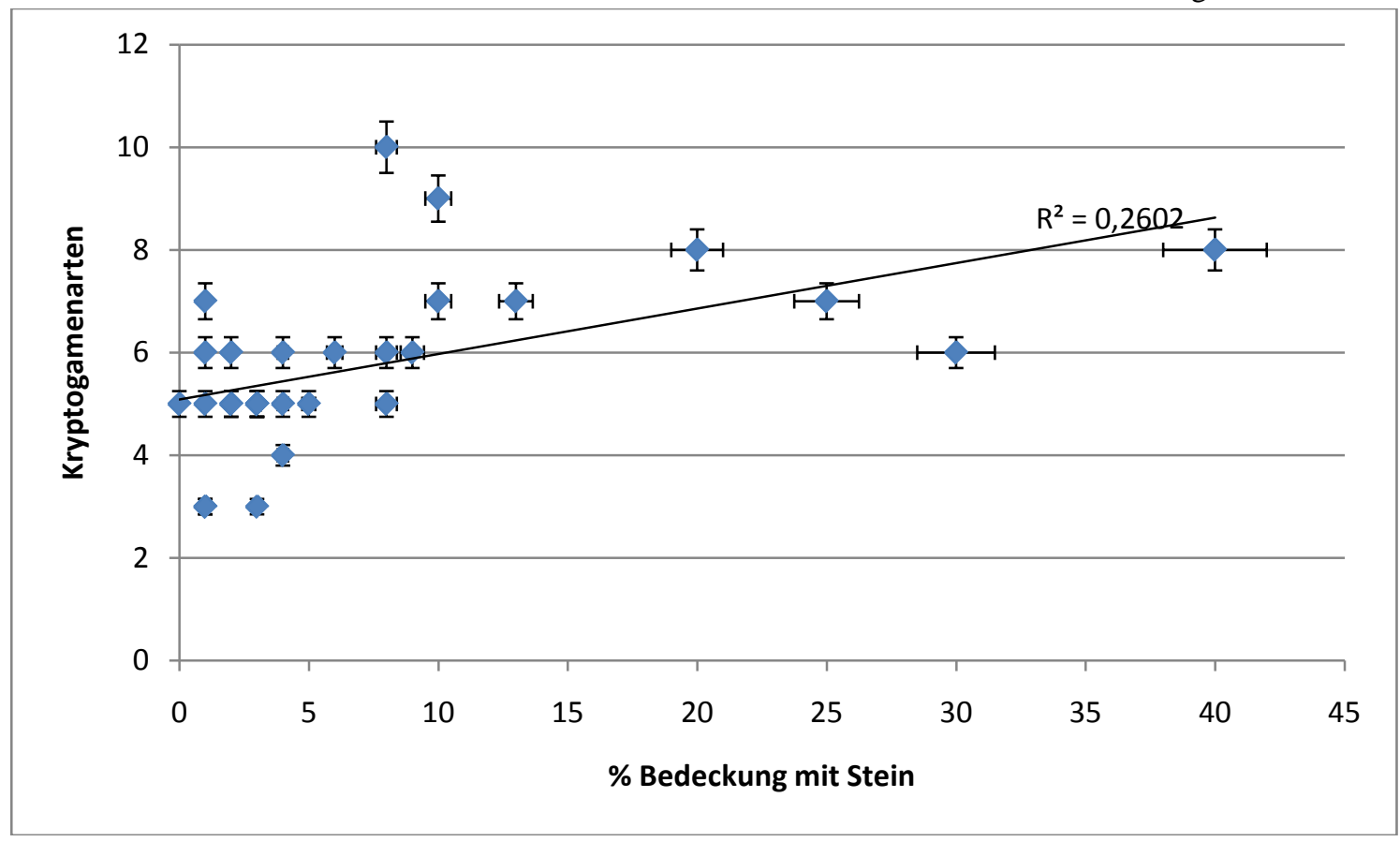

Abb. 4.19: Lineare Regression von der Anzahl der Kryptogamenarten und der Bedeckung mit Stein. Die Fehlerbalken geben den prozentualen Fehler an.

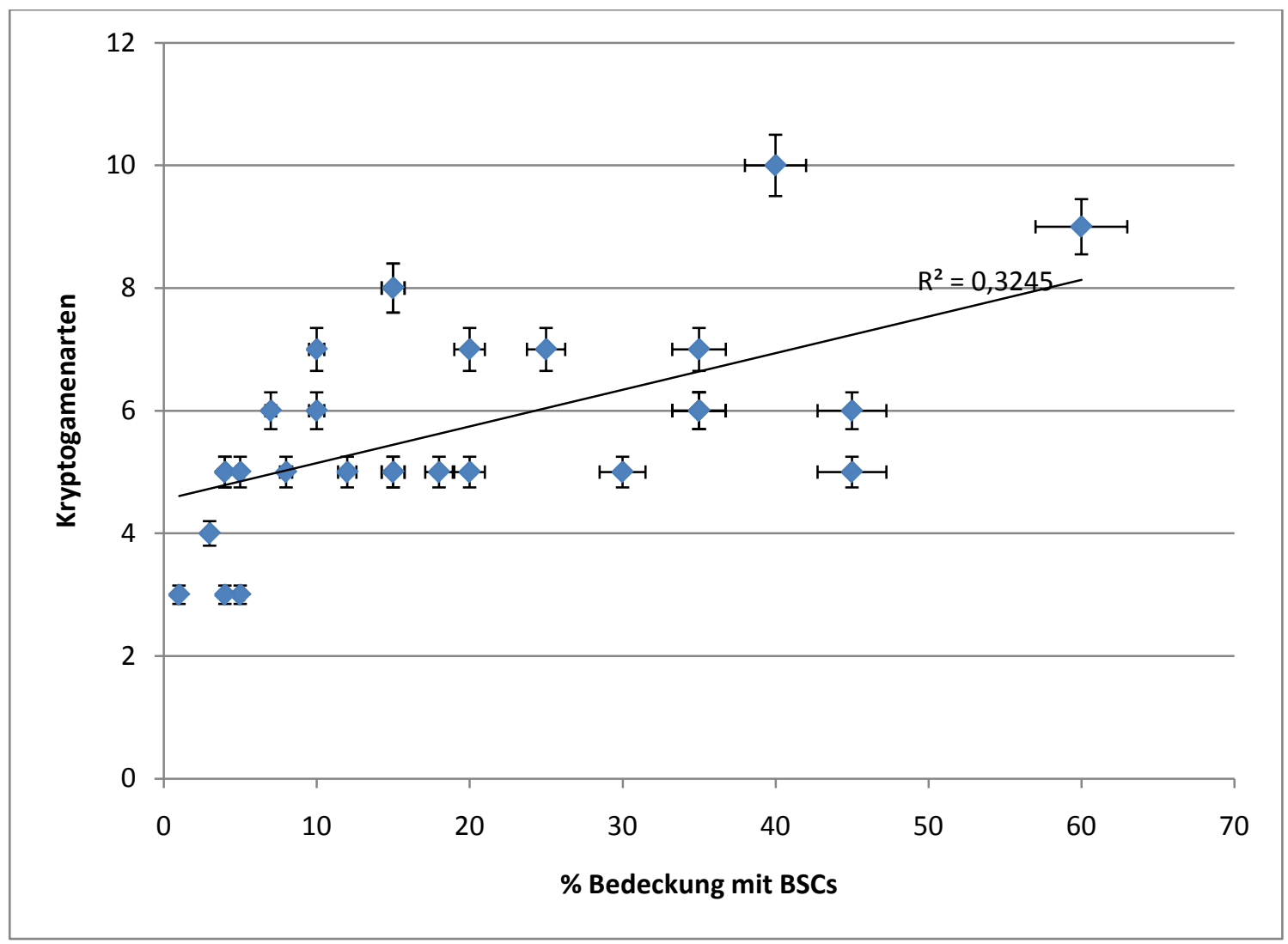

Abb. 4.20: Lineare Regression von der Anzahl der Kryptogamenarten und der Bedeckung mit BSCs. Die Fehlerbalken geben den prozentualen Fehler an. 
4 Ergebnisse

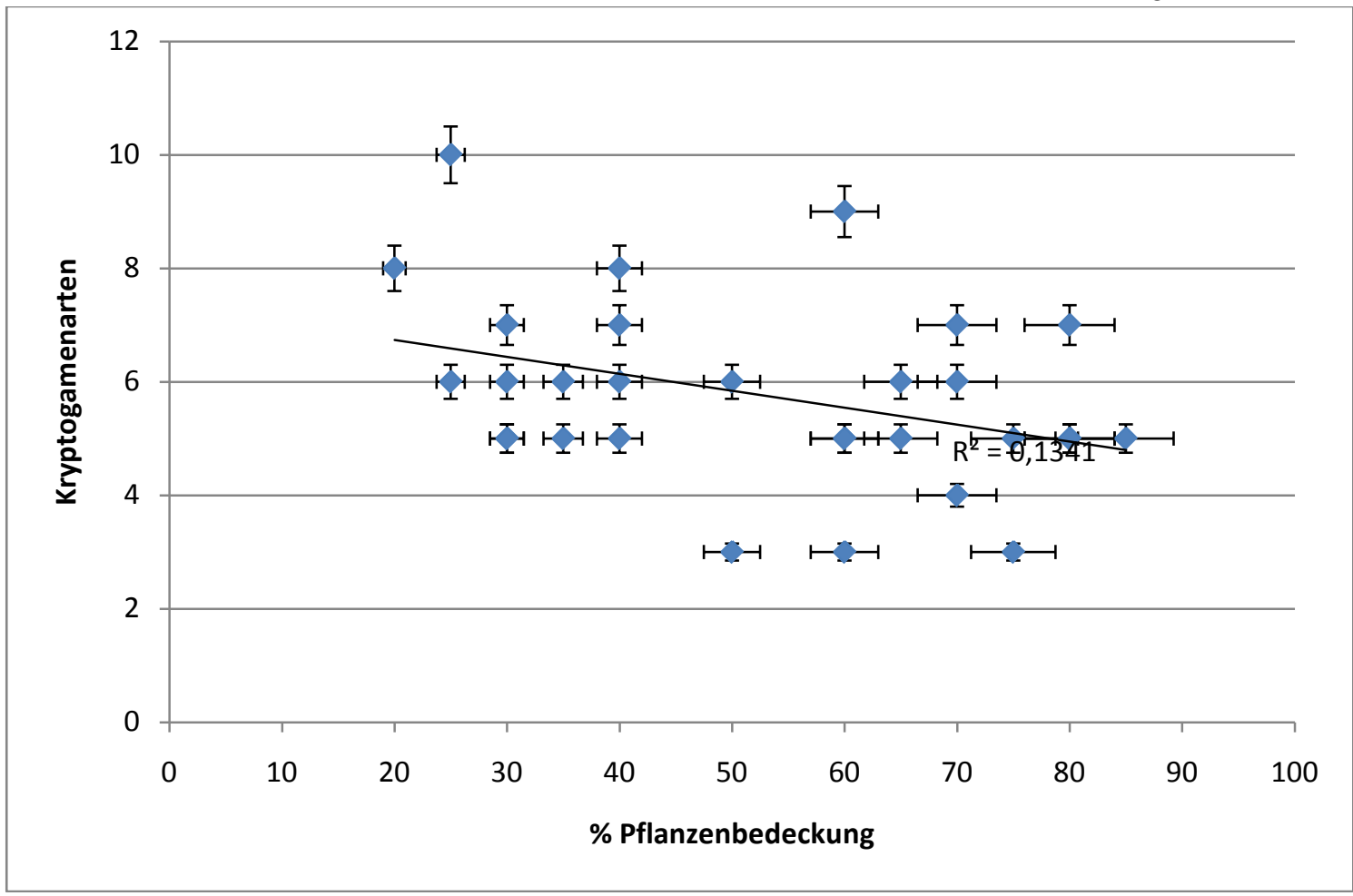

Abb. 4.21: Lineare Regression von der Anzahl der Kryptogamenarten und der Pflanzenbedeckung. Die Fehlerbalken geben den prozentualen Fehler an.

\subsubsection{Pulsatilla ambigua - Gebirgstrockensteppe}

Die Pulsatilla ambigua-Gebirgstrockensteppe wurde durch die Charakterarten Bupleurum bicaule und Poa botryoides vertreten. 12 Zählquadrate ließen sich diesem Vegetationstyp überwiegend zuordnen. Die Inklination reichte von 19 bis $38^{\circ}$, die Exposition von 215 bis $280^{\circ}$, die BSC-Bedeckung von 2 - 45 \% und die Pflanzenbedeckung von 25 bis $85 \%$. Wie in der Abbildung 4.22 und Tabelle $4.5 \mathrm{zu}$ sehen, ergab die Korrelationsanalyse für diesen Vegetationstyp signifikante Abhängigkeiten zwischen der Anzahl der Pflanzenarten und der Entfernung zum Bergrücken $(\mathrm{r}=0,85)$ und der Anzahl der Pflanzenarten und der Exposition $(\mathrm{r}=0,58)$. Außerdem korrelierte die Anzahl der Kryptogamenarten mit der prozentualen Bedeckung mit BSCs $(r=0,68)$. Auch hier war, wie in Abb. 4.23 ersichtlich, die Streuung recht groß. Das Bestimmtheitsmaß ist mit 0,25 angegeben. 
4 Ergebnisse
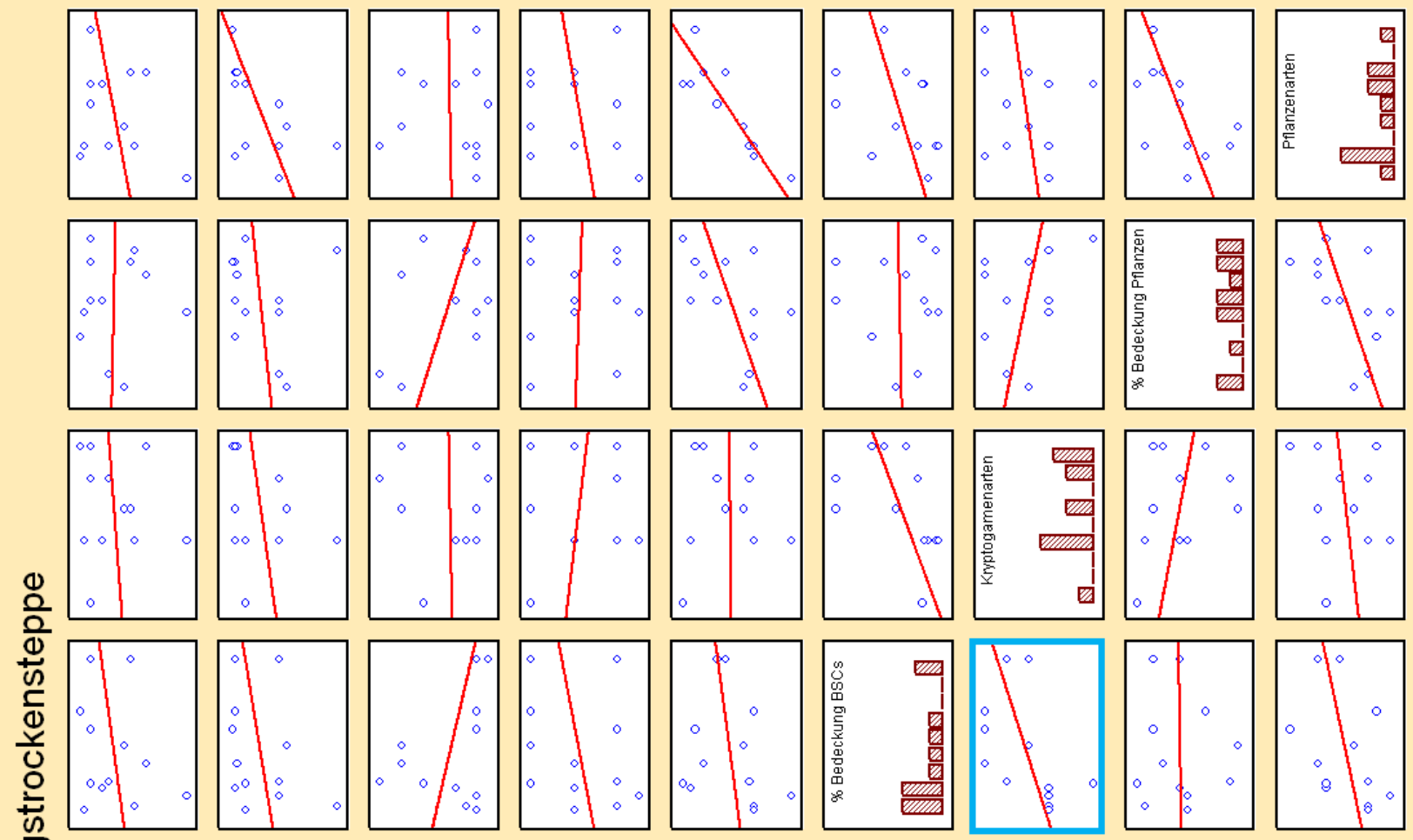

:
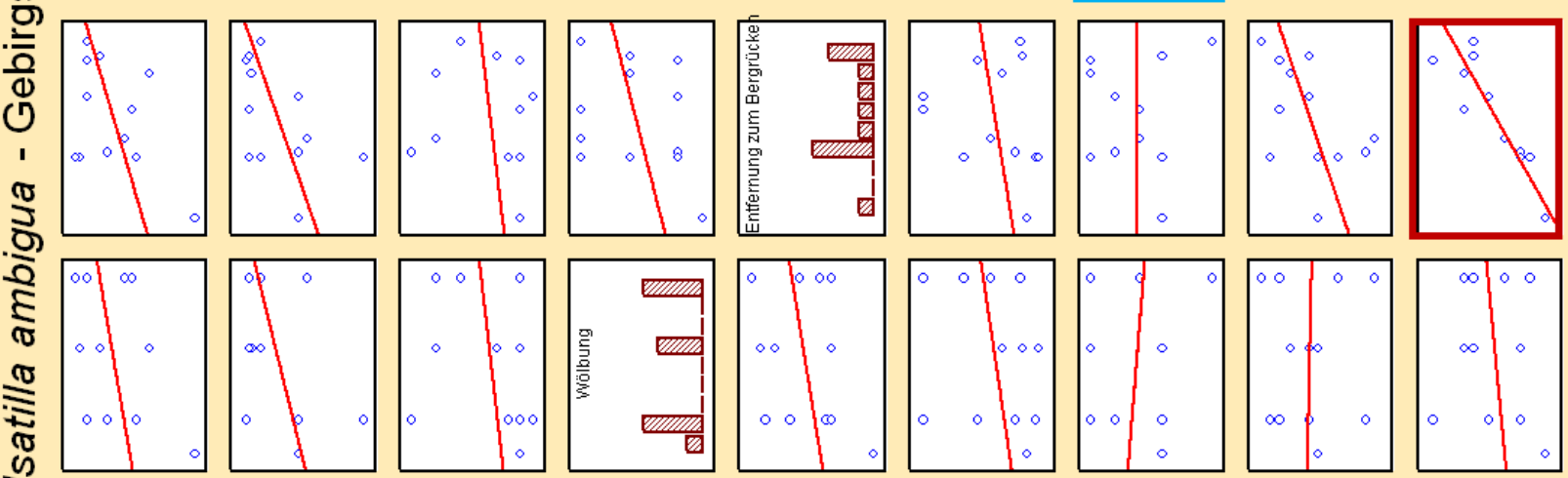

年
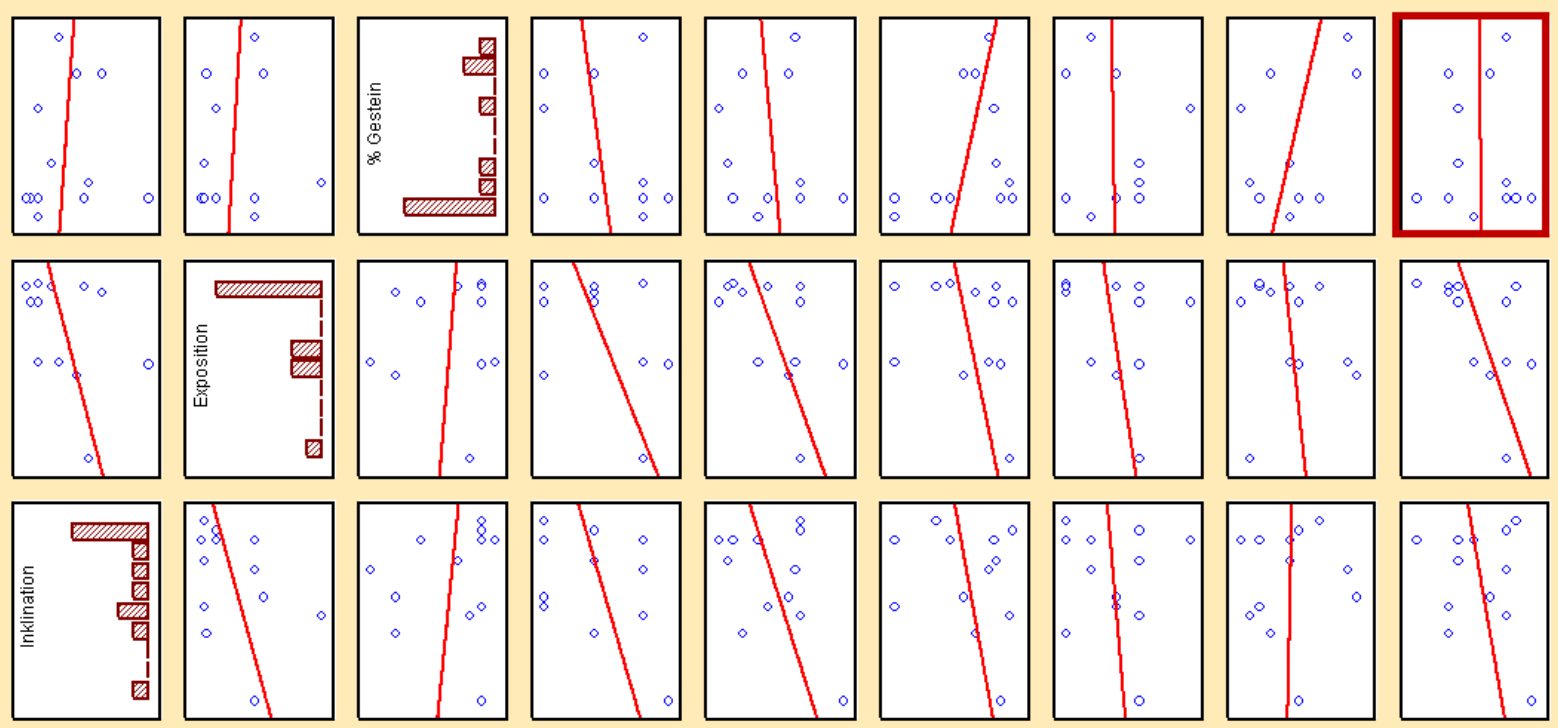

Abb. 4.22: Matrix-Scatterplot für die Pulsatilla ambigua-Gebirgstrockensteppe. Die blau markierten Plots zeigen BSCs betreffende Korrelationen an, die rot markierten Plots zeigen weitere Korrelationen. 


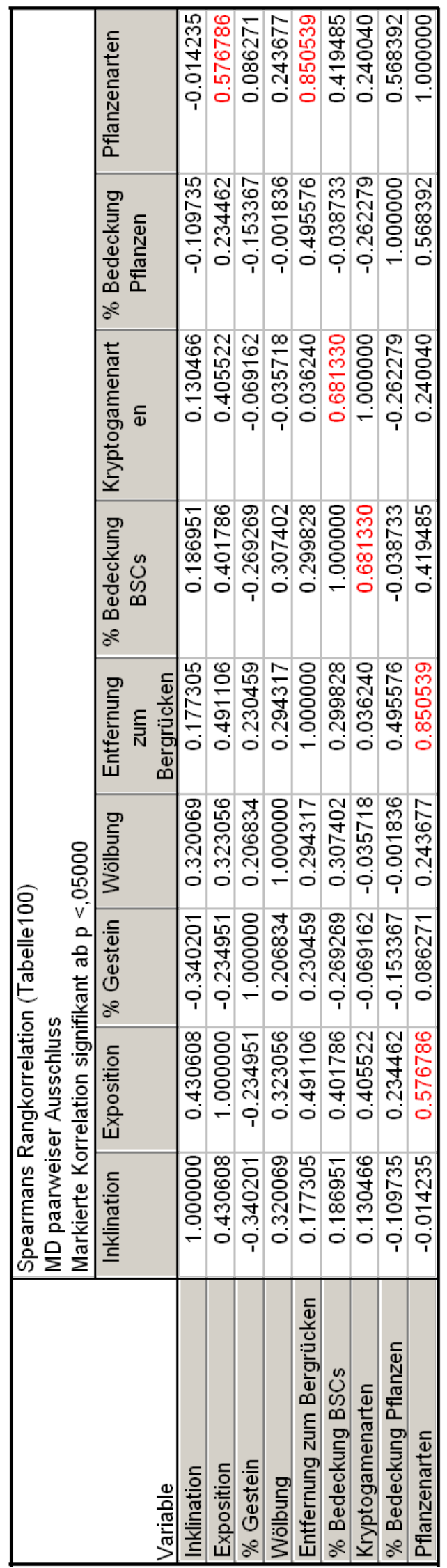

Tab. 4.6: Spearmans Rangkorrelation für die Pulsatilla ambigua-Gebirgstrockensteppe. Die rot markierten Ziffern geben signifikante Korrelationen an. 
4 Ergebnisse

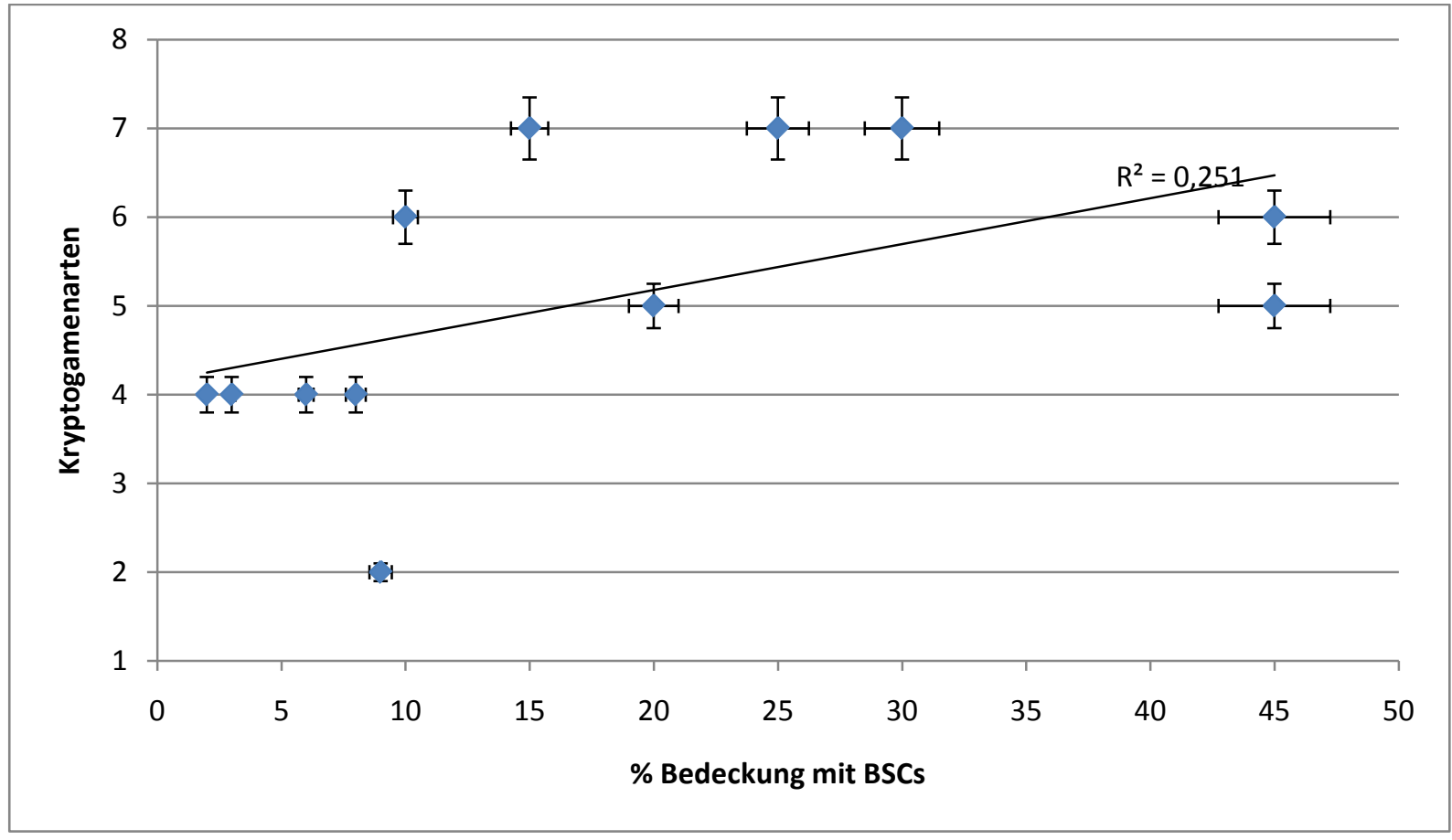

Abb. 4.23: Lineare Regression von der Anzahl der Kryptogamenarten und der Bedeckung mit BSCs. Die Fehlerbalken geben den prozentualen Fehler an. 


\subsubsection{PCA (Hauptkomponentenanalyse) aller Vegetationstypen zusammen}

Es wurde mit Canoco for Windows ${ }^{T M}$ eine Hauptkompenentenanalyse berechnet, um unabhängig von den einzelnen Vegetationstypen etwaige Zusammenhänge und Muster zu erkennen. Diese Analyse ist in Abbildung 4.24 dargestellt worden. Da auf den ersten Blick keine Muster erkennbar waren, wurden die einzelnen Punkte noch ihrem Vegetationstyp entsprechend farblich markiert. Auch hier wurden keine Muster augenfällig.

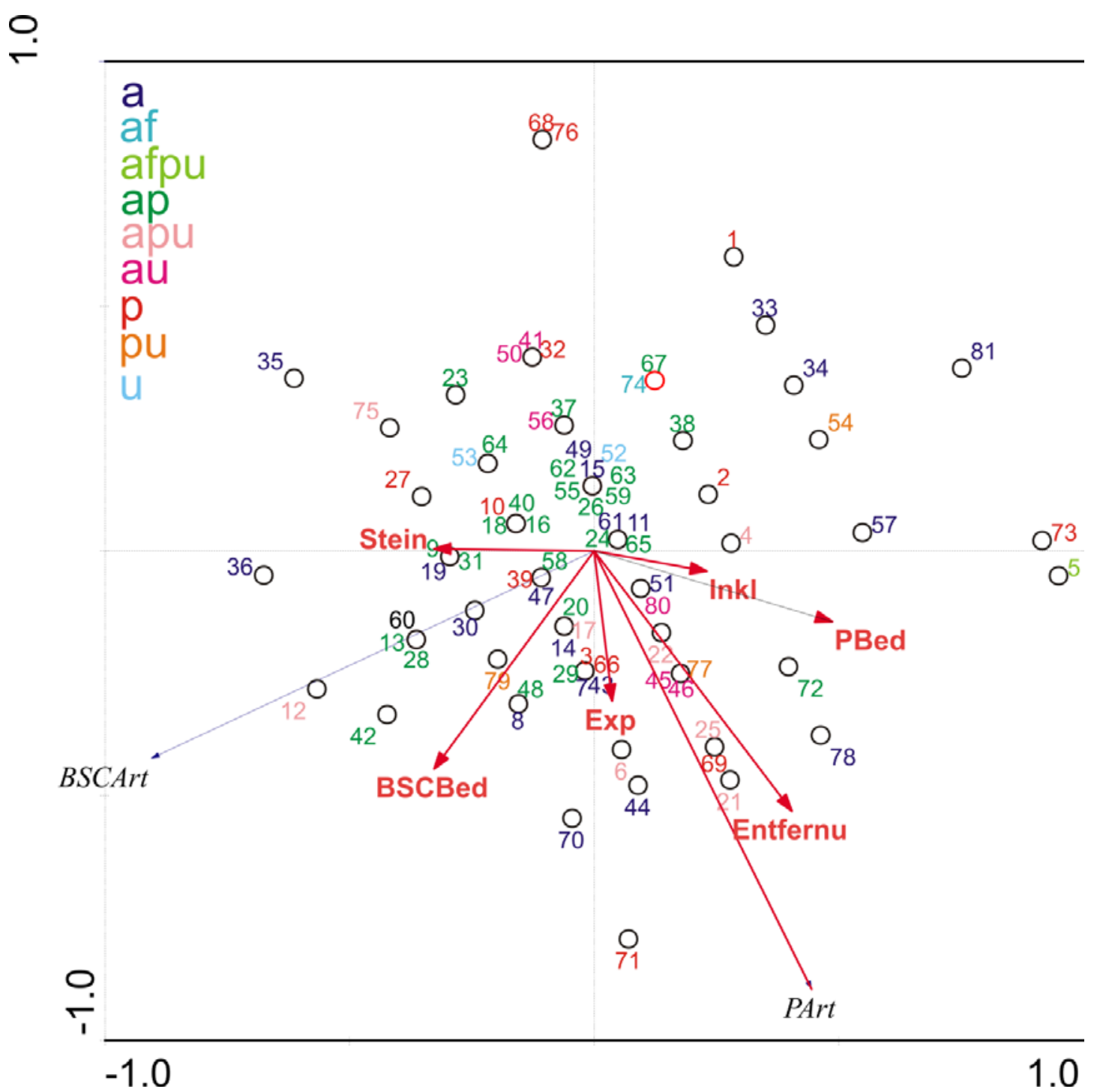

Abb. 4.16: Hauptkomponentenanalyse (PCA) aller Vegetationstypen zusammen. $\mathrm{a}=$ Artemisia frigida-GTS, $\mathrm{f}=$ Festuca lenensis-GTS, $\mathrm{p}=$ Pulsatilla ambigua-GTS, $\mathrm{u}=$ Ulmus pumila-OWG, die mehrbuchstabigen Kürzel stellen die entsprechenden Mischtypen dar. 


\subsubsection{Einfluss der Gefäßpflanzen auf die Bedeckung mit biologischen Bodenkrusten und deren Zusammensetzung}

Die Ergebnisse der vorhergehenden Analyse machen keine starken Korrelationen zwischen dem Auftreten von BSCs und Pflanzen nachweisbar. Der „Berg A“, der Gegenstand der Analyse war, ist in Abb. 4.25 und 4.26 dargestellt. Hier ist die ungefähre Lage der Zählquadrate verzeichnet, was aufgrund der räumlichen Verzerrung der Darstellung nur schematisch verstanden werden kann. Es war auffällig, dass zur Mitte des Hanges hin die Pflanzenbedeckung spärlicher wird (siehe Abb. 4.25). Auch wurde eine leichte Tendenz zu mehr BSC zu eben dieser Mitte hin beobachtet (siehe Abb. 4.26), diese konnte aber nicht belegt werden. Um diese Zusammenhänge näher zu beleuchten, wurde also eine weitere Studie durchgeführt, die auch auf die möglichen Einflüsse verschiedener Klassen von Pflanzen eingehen sollte. Diese Klassifizierung unterschied zwischen Gräsern, der oft reichlich vorhandenem Potentilla acaulis, der Alyssum-Klasse, den „mittleren Kräutern“ und der Pulsatilla - Klasse. Die Klasse der Gräser enthielt außerdem noch stark beschattende Kräuter. Potentilla acaulis wächst kriechend und sehr niedrig. Es wirft nicht sehr viel Schatten, bietet dafür aber theoretisch Schutz gegen Erosion, es wurde also ein positiver Effekt auf die BSCs vermutet. Die Alyssum - Klasse teilte sich Alyssum lenensis mit anderen unter 15 cm hohen Kräutern mit wenig Schattenwurf, wie z.B. den verschiedenen ThymusArten. Die Pulsatilla-Klasse zeichnete sich durch einen im Basalbereich recht breiten Wuchs, aber geringer Pflanzenhöhe aus und die „mittleren Kräuter“ waren basal eher schmal, dafür aber höher als $15 \mathrm{~cm}$ und warfen allgemein auch eher wenig Schatten. Hier waren Pflanzen wie z.B. Veronica incana oder Leontopodium leontopodioides zu finden.

Die Ergebnisse dieser Regressionsanalyse sind in Abbildung 4.27 und Tabelle 4.6 jeweils in der Übersicht dargestellt. Es haben sich signifikante Korrelationen zwischen der Pflanzenbedeckung mit der Erosionsstufe ( $r=-0,45)$, der Anzahl der Grasarten $(r=0,48)$, der Bedeckung mit Gras ( $\mathrm{r}=0,81)$, der Bedeckung der Potentilla-Klasse $(\mathrm{r}=0,24)$, der Bedeckung mit „mittleren Kräutern“ $(r=0,44)$ und der Bedeckung mit Kräutern der Pulsatilla-Klasse $(\mathrm{r}=0,25)$ ergeben. Die Anzahl der Grasarten korrelierte außerdem mit der Erosionsstufe $(r=-0,41)$, der Grasbedeckung $(r=0,51)$, der Bedeckung der Potentilla- Klasse ( $r=0,26)$, der Bedeckung mit „mittleren Kräutern“ ( $r=0,35)$ und der Bedeckung mit Kräutern der Pulsatilla-Klasse $(\mathrm{r}=0,25)$. Die Bedeckung mit Gras korrelierte zudem mit der Bedeckung mit Kräutern der Alyssum-Klasse $(\mathrm{r}=$-0,36) und der Bedeckung mit „mittleren Kräutern“ $(r=0,43)$. Für die Bedeckung mit BSCs stellten sich Korrelationen mit der 
Pflanzenbedeckung ( $\mathrm{r}=-0,57)$, der Grasbedeckung $(\mathrm{r}=-0,46)$ und der Bedeckung mit „Mittleren Kräutern“ ( $r=-0,28)$ ein. Diese Korrelationen wurden in den Abbildungen 4.28 4.30 dargestellt. Für die Korrelation der Pflanzenbedeckung mit der BSC-Bedeckung ergibt sich ein Bestimmtheitsmaß von 0,29, die Werte sind stark gestreut (siehe Abb. 4.28). Dies trifft auch auf die Abhängigkeit der BSC-Bedeckung von der Grasbedeckung $\left(\mathrm{R}^{2}=0,12\right.$; siehe Abb. 4.29) und von der Bedeckung mit „mittleren Kräutern“ $\left(R^{2}=0,10\right.$; siehe Abb. 4.30) zu. 
4 Ergebnisse

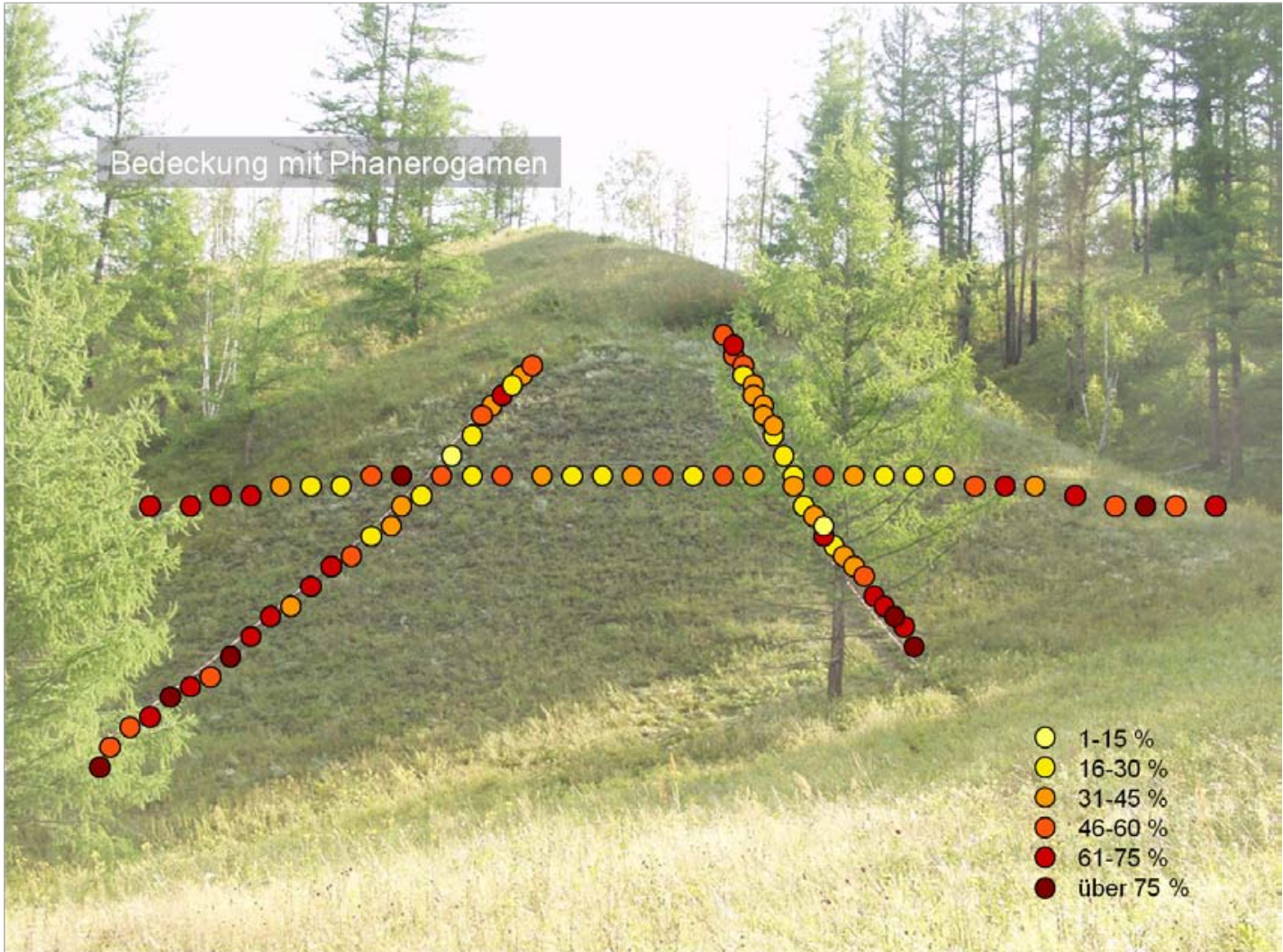

Abb. 4.25: Bedeckung mit Pflanzen auf den Linientransekten des Berges A.

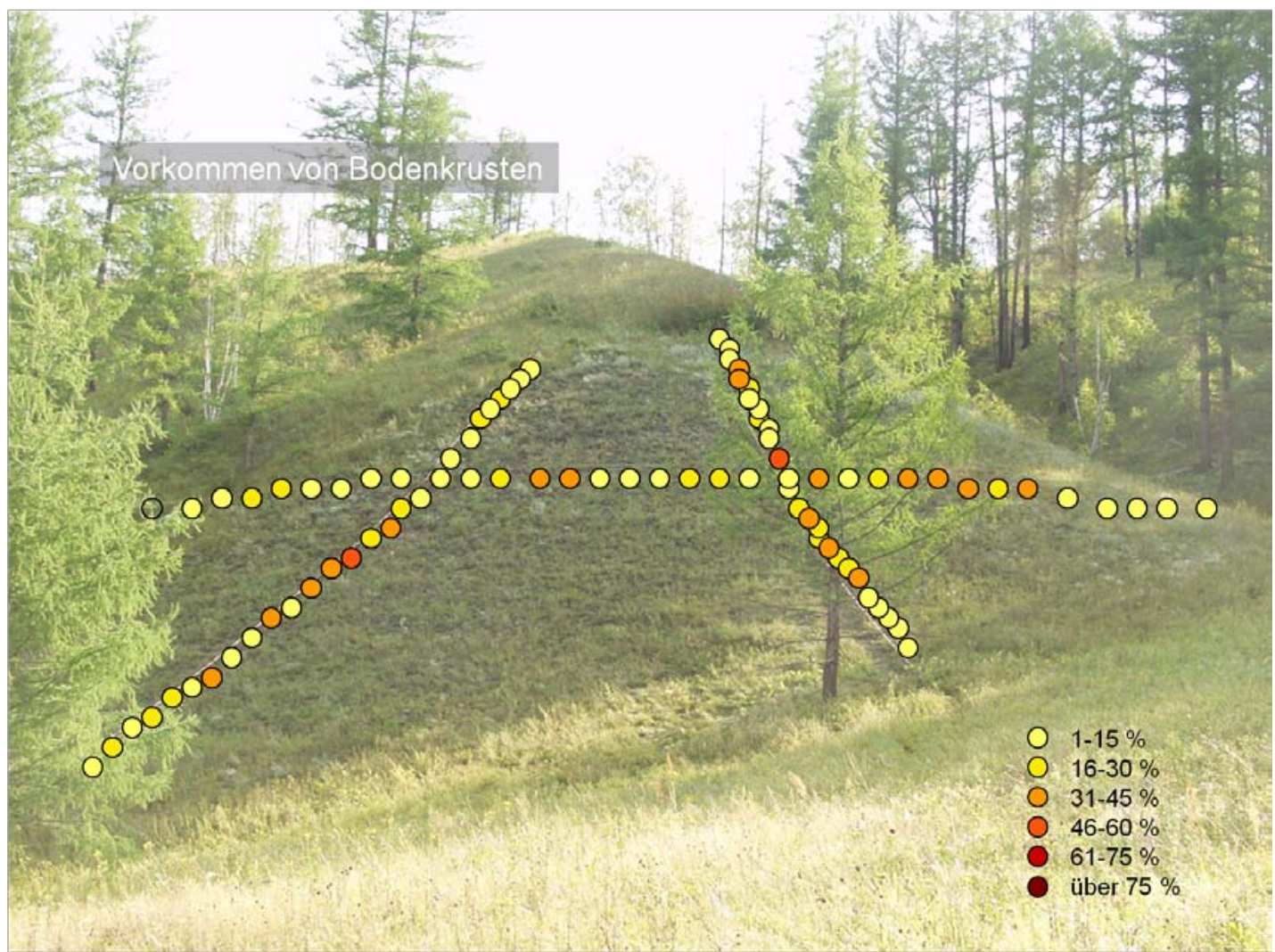

Abb. 4.25: Bedeckung mit BSCs auf den Linientransekten des Berges A. 
4 Ergebnisse
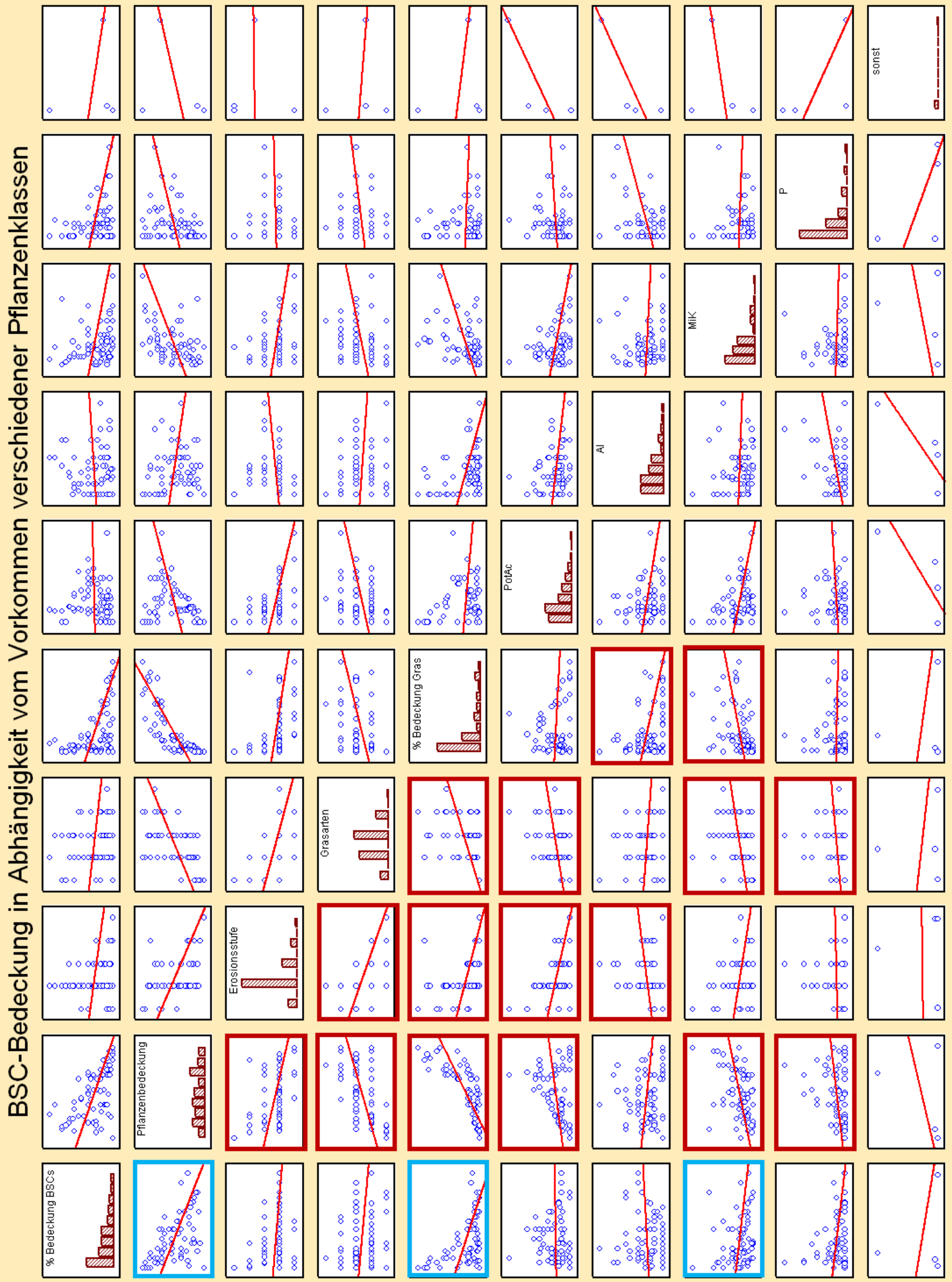

Abb. 4.27: Matrix-Scatterplot für die Abhängigkeiten zwischen BSC-Bedeckung und dem Vorkommen von Pflanzen. Die blau markierten Plots zeigen BSCs betreffende Korrelationen an, die rot markierten Plots zeigen weitere Korrelationen. 


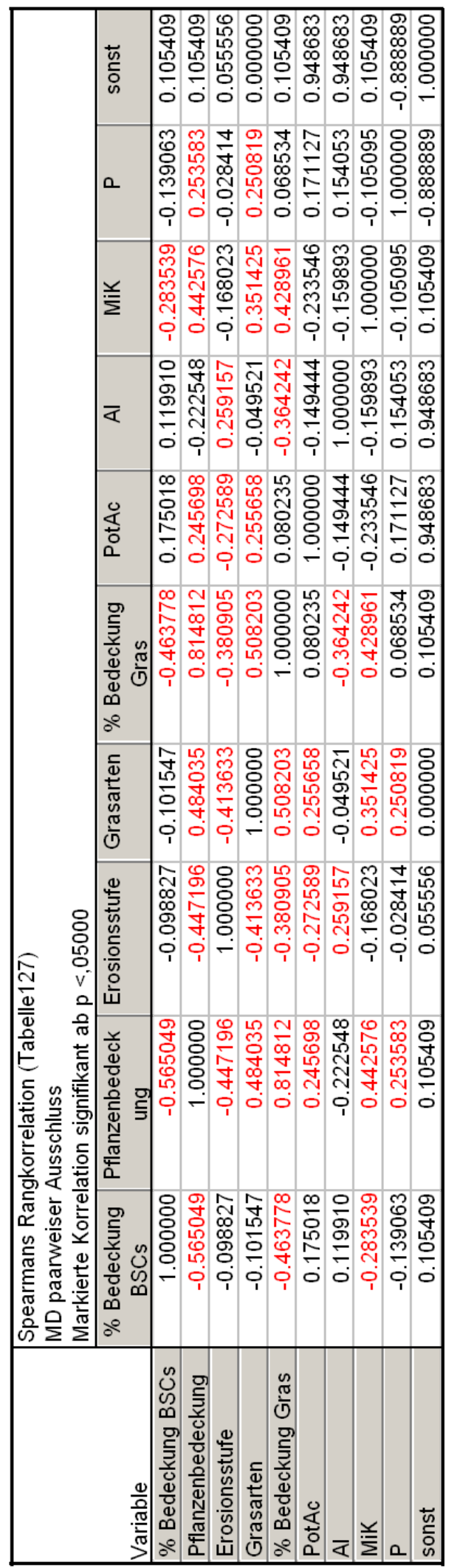

Tab. 4.7: Spearmans Rangkorrelation für die Abhängigkeiten zwischen BSC-Bedeckung und dem Vorkommen von Pflanzen. Die rot markierten Ziffern geben signifikante Korrelationen an. 
4 Ergebnisse

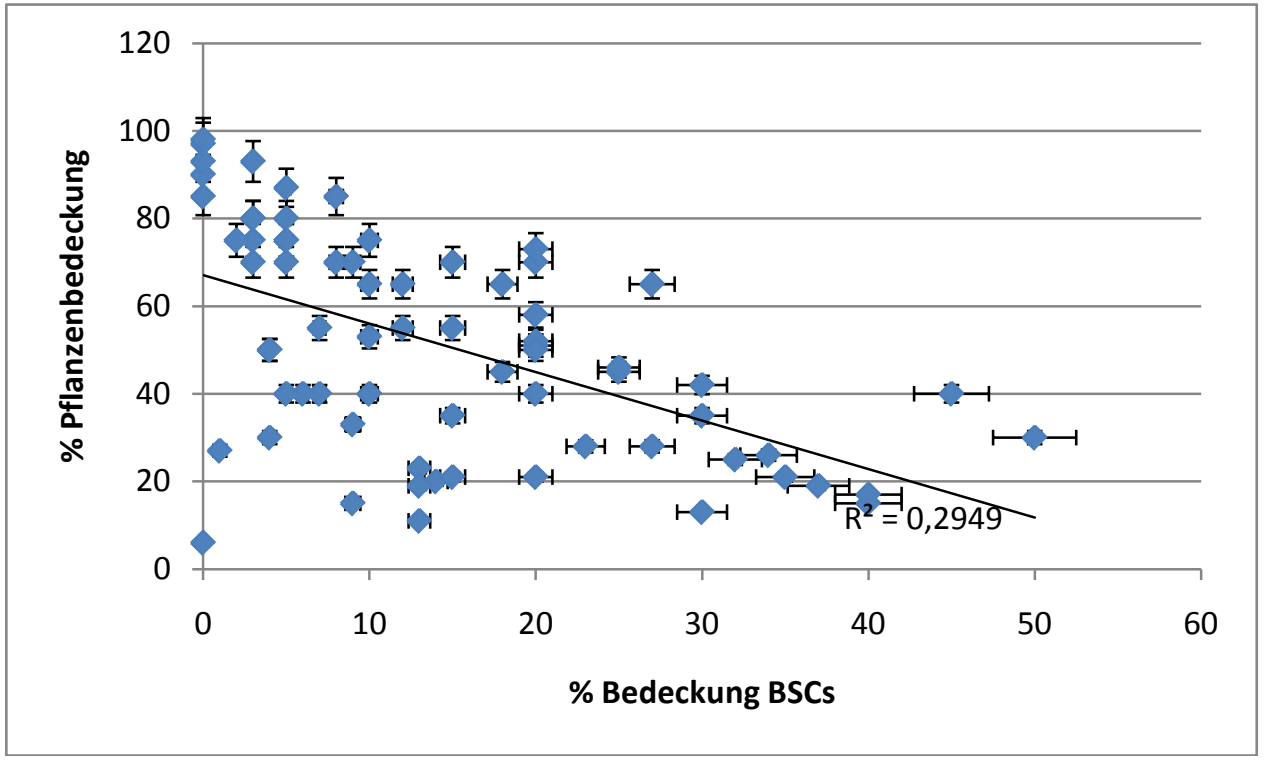

Abb. 4.28: Lineare Regression von der Pflanzenbedeckung und der Bedeckung mit BSCs. Die Fehlerbalken geben den prozentualen Fehler an.

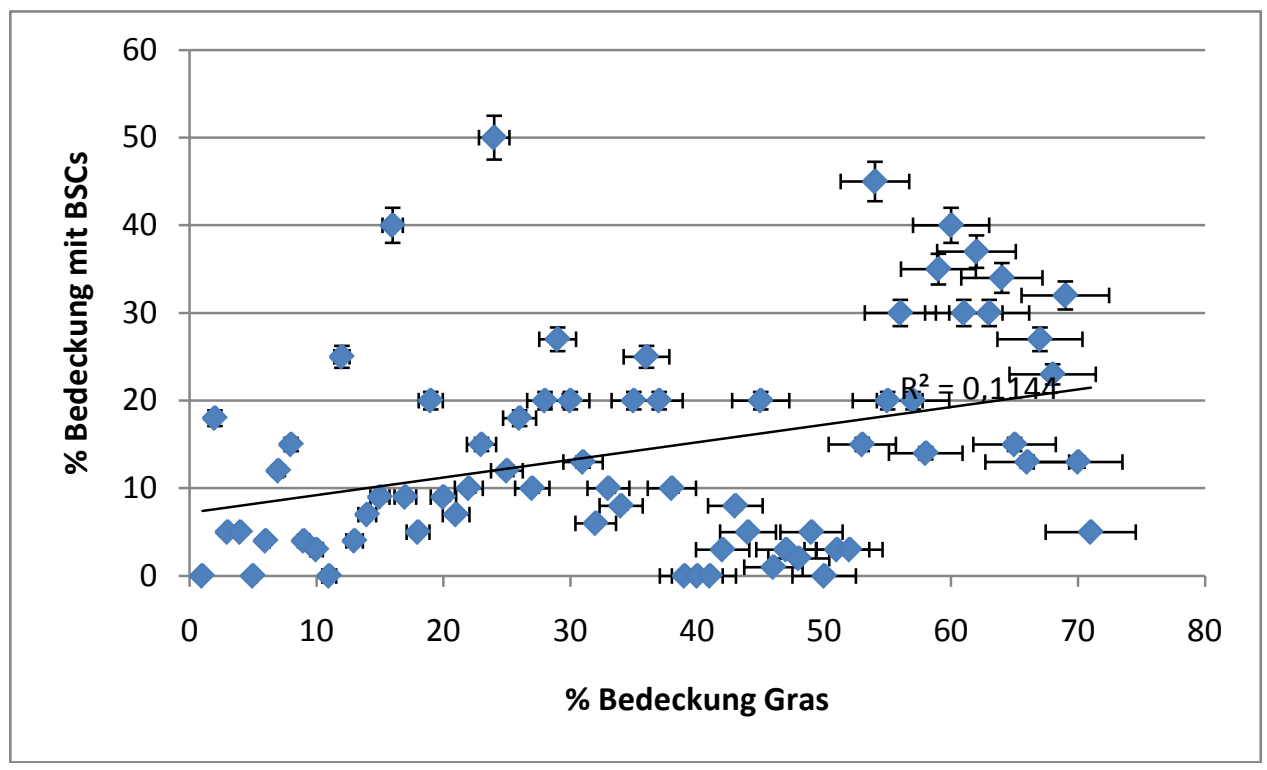

Abb. 4.28: Lineare Regression von der Bedeckung mit BSCs und der Bedeckung mit Gras. Die Fehlerbalken geben den prozentualen Fehler an. 
4 Ergebnisse

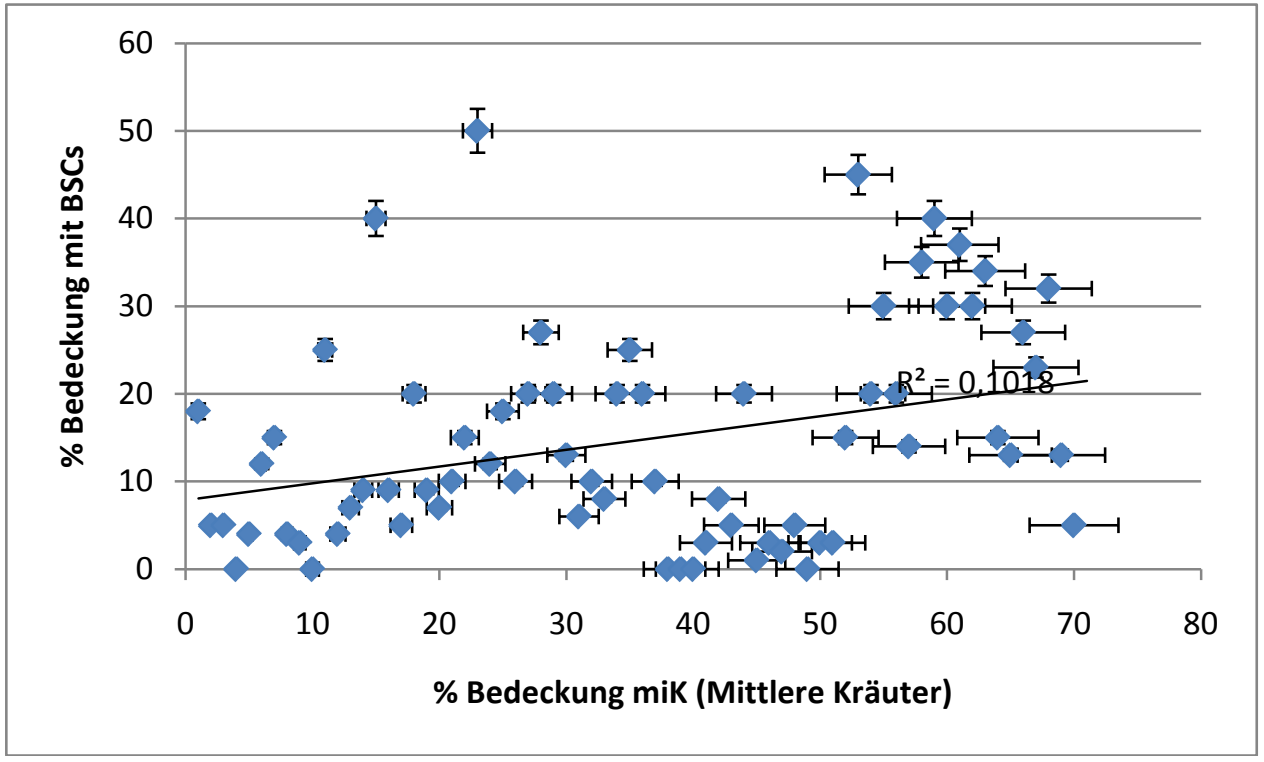

Abb. 4.28: Lineare Regression von der Bedeckung mit BSCs und der Bedeckung mit „mittleren Kräutern“. Die Fehlerbalken geben den prozentualen Fehler an. 


\subsubsection{Einfluss von Exposition und Inklination auf die Anzahl von Kryptogamenarten}

Dieser Versuch wurde an mehreren Bergketten an langen Linientransekten durchgeführt, wobei hier alle $5 \mathrm{~m}$ das Zählquadrat ausgelegt wurde. Dieses Vorgehen schloss eine Vielzahl von unterschiedlichen Expostions- und Inklinationsverhältnissen ein. Die Ergebnisse der Regressionsanalyse sind in Abbildung 4.31 und Tabelle 4.7 in der Übersicht dargestellt. Für die Abhängigkeit der Kryptogamenzahl von der Exposition ergab sich eine Korrelation von $r=0,25$ und von der Inklination war sie $r=-0,29$. Die Abbildung 4.32 zeigt eine polynomale Regression zweiten Grades der Anzahl der Kryptogamenarten in Abhängigkeit von der Exposition. Auch hier sind die Werte stark gestreut und das Bestimmtheitsmaß mit $R^{2}=0,22$ relativ gering. Es wurde eine polynomale Regression gewählt, da hier eine lineare Abhängigkeit nicht zu erwarten war, weil die Exposition eine zirkuläre Variable ist. Man erkennt ein Minimum bei etwas über $200^{\circ}$. Auch bei der linearen Regression der Anzahl der Kryptogamenarten gegen die Inklination ist eine starke Streuung zu sehen, die den sehr niedrigen Wert $\mathrm{R}^{2}=0,07$ erklärt.

Die Abbildung 4.34 zeigt die Anzahl der Kryptogamenarten in Abhängigkeit von Inklination und Exposition gleichzeitig, wobei die Blasengröße die Anzahl der Arten symbolisiert. Man sieht eine Tendenz zu größeren Blasen (= mehr Arten) ab $220^{\circ}$ aufwärts, das heißt in südwestlicher bis westlicher Richtung. Eine weitere Tendenz könnte in die Richtung zeigen, dass bei etwa $25^{\circ}$ die größten Artenzahlen gefunden wurden. 
4 Ergebnisse

Die Anzahl von Kryptogamenarten in Abhängigkeit von Exposition und Inklination
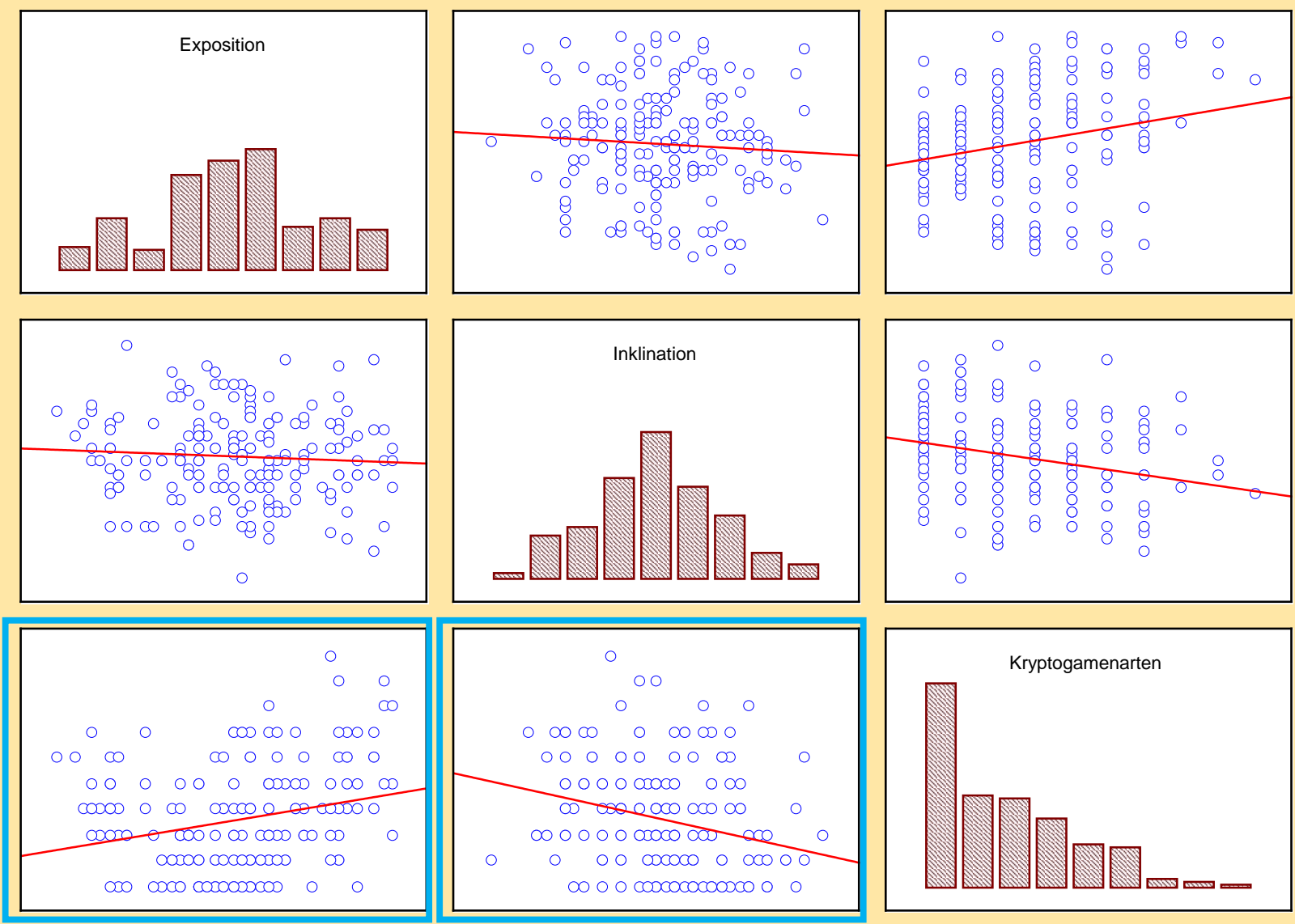

Abb. 4.31: Matrix-Scatterplot für die Anzahl der Kryptogamenarten in Abhängigkeit von Exposition und Inklination. Die blau markierten Plots zeigen BSCs betreffende Korrelationen an.

\begin{tabular}{|l|r|r|r|}
\hline \multirow{4}{*}{ Variable } & \multicolumn{3}{|l|}{$\begin{array}{l}\text { Spearmans Rangkorrelation (Tabelle132) } \\
\text { MD paarweiser Ausschluss } \\
\text { Markierte Korrelation signifikant ab } \mathrm{p}<, 0500 \text { ( }\end{array}$} \\
\cline { 2 - 4 } & Exposition & Inklination & $\begin{array}{c}\text { Kryptogamenart } \\
\text { en }\end{array}$ \\
\hline Exposition & 1,000000 & $-0,065863$ & 0,245541 \\
\hline Inklination & $-0,065863$ & 1,000000 & $-0,292541$ \\
\hline Kryptogamenarten & 0,245541 & $-0,292541$ & 1,000000 \\
\hline
\end{tabular}

Tab. 4.8: Spearmans Rangkorrelation für die Anzahl der Kryptogamenarten in Abhängigkeit von Exposition und Inklination. Die rot markierten Ziffern geben signifikante Korrelationen an. 
4 Ergebnisse

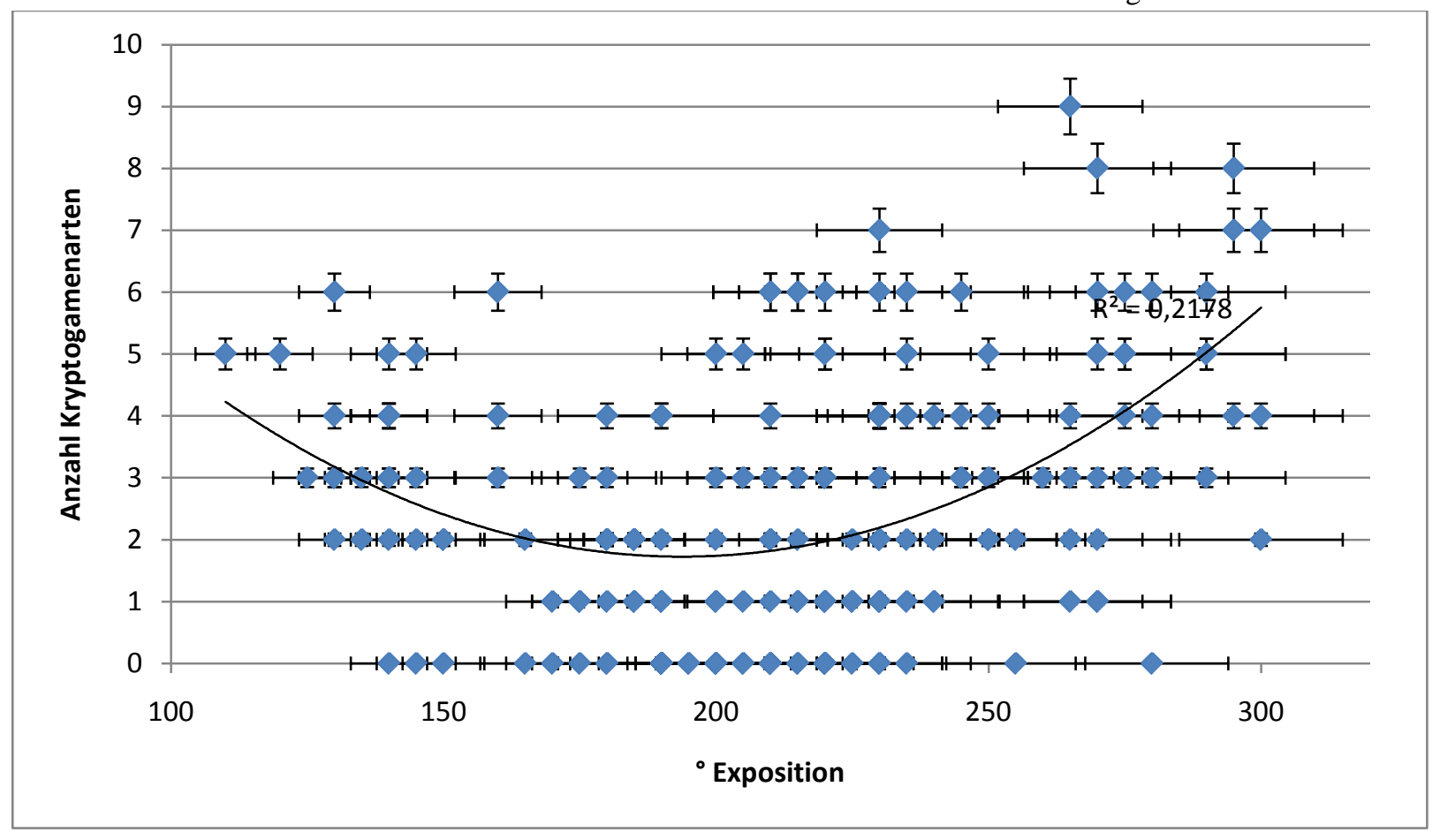

Abb. 4.32: Polynomale Regression (zweiten Grades) von der Anzahl der Kryptogamenarten und der Exposition. Die Fehlerbalken geben den prozentualen Fehler an.

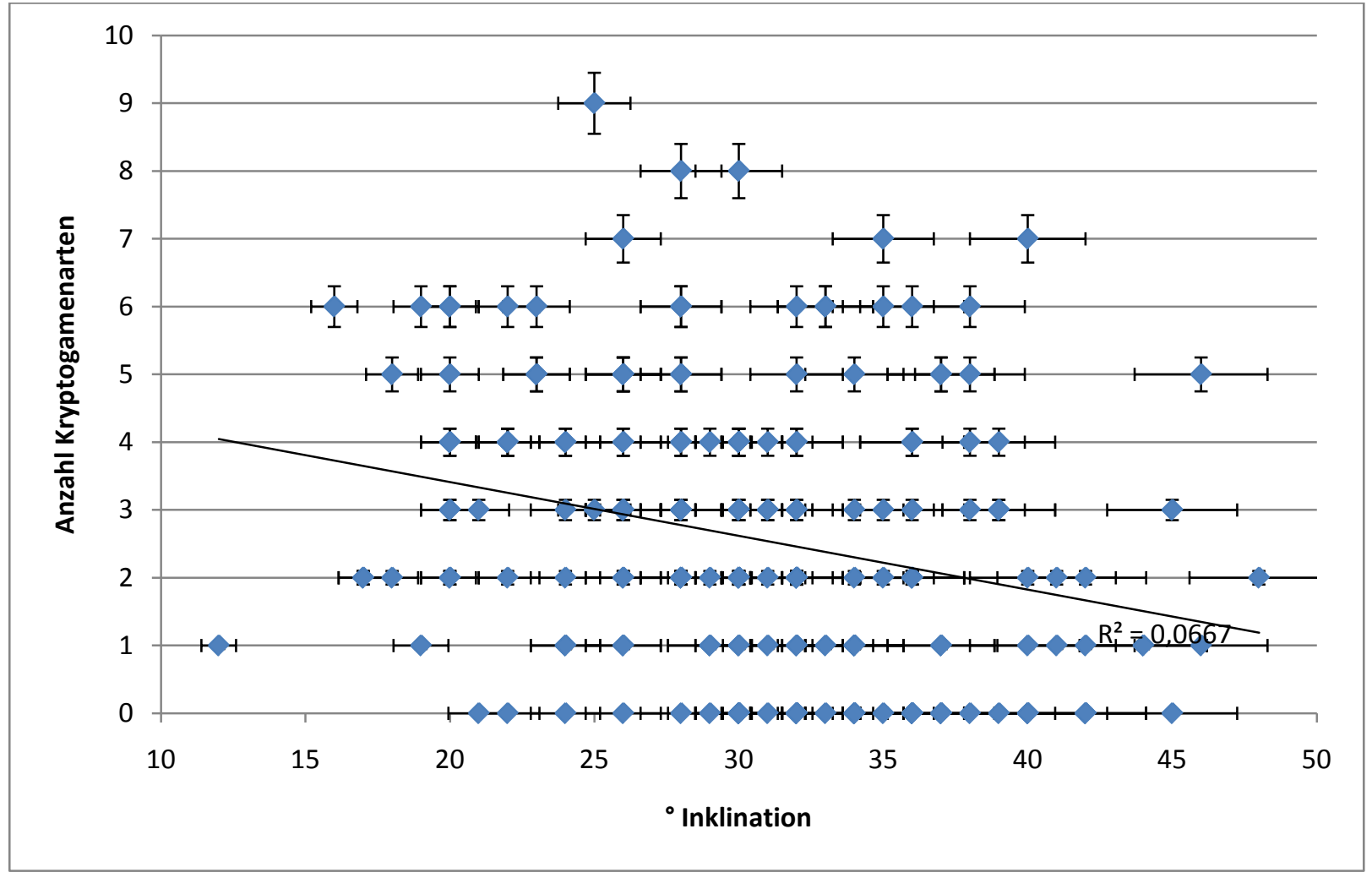

Abb. 4.33: Lineare Regression von der Anzahl der Kryptogamenarten und der Inklination. Die Fehlerbalken geben den prozentualen Fehler an. 


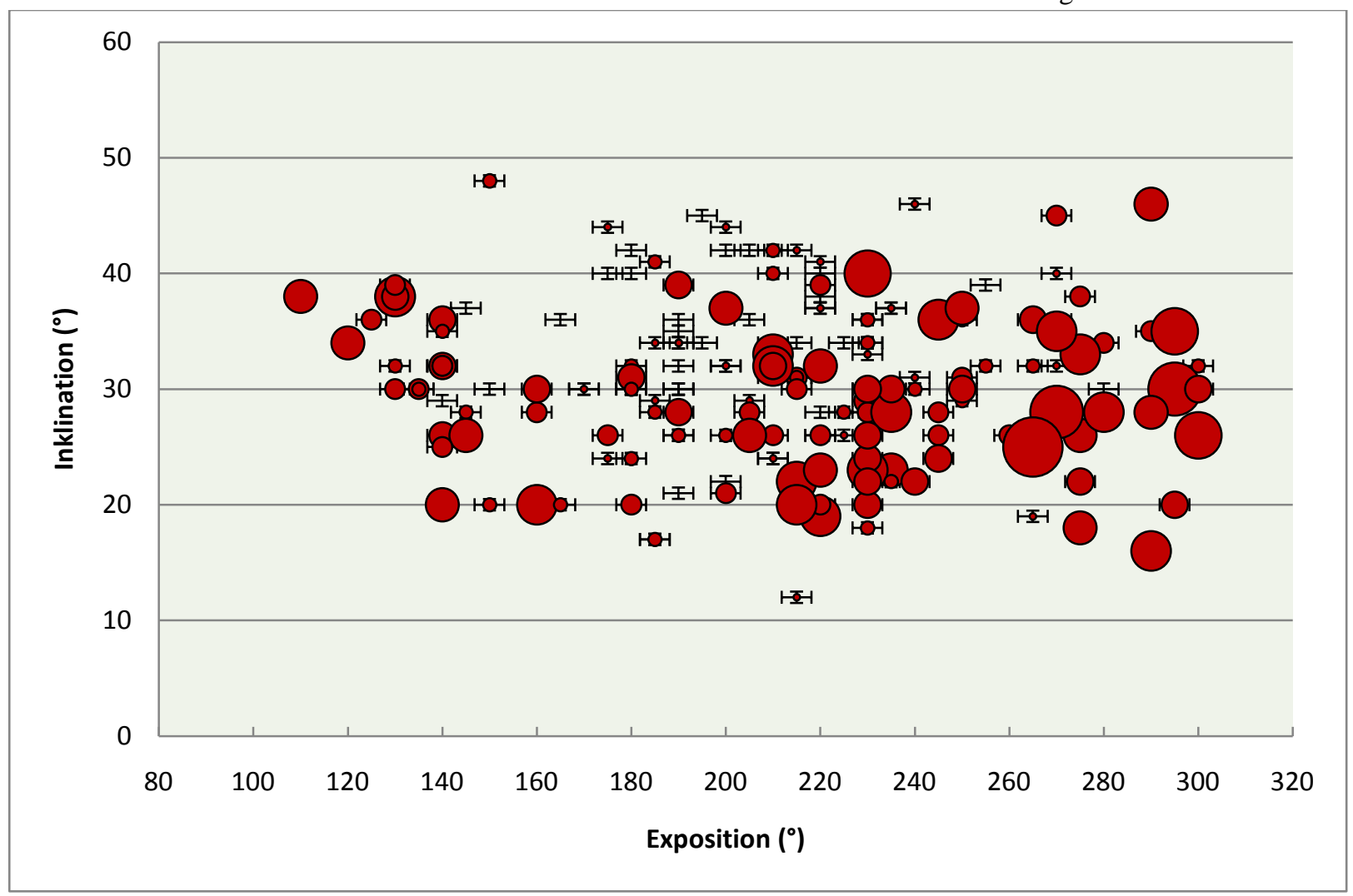

Abb. 4.34: Blasendiagramm von der Anzahl der Kryptogamenarten gegen die Exposition und die Inklination. Hierbei stellt die Blasengröße die Anzahl der gefundenen Kryptogamenarten dar. Die Fehlerbalken geben den prozentualen Fehler an. 


\subsubsection{Die Auswirkungen von Trittbelastung auf die Bedeckung mit BSCs und Pflanzen}

Dieser Versuch wurde ebenfalls an Berg A durchgeführt, und zwar wurde auf den 2006 benutzten Trittwegen neben den Linientransekten 2007 ein weiteres Linientransekt angelegt. Daneben wurden zwei Vergleichstransekte angelegt, die im Vorjahr nicht betreten worden waren. Die Ergebnisse dieses Versuches sind in den Abbildungen 3.35 und 4.36 dargestellt. Man sieht sowohl in der Pflanzendedeckung (siehe Abb. 4 35) wie auch in der Bedeckung mit BSCs (siehe Abb. 4.36) einen starken Rückgang nach der Schädigung.

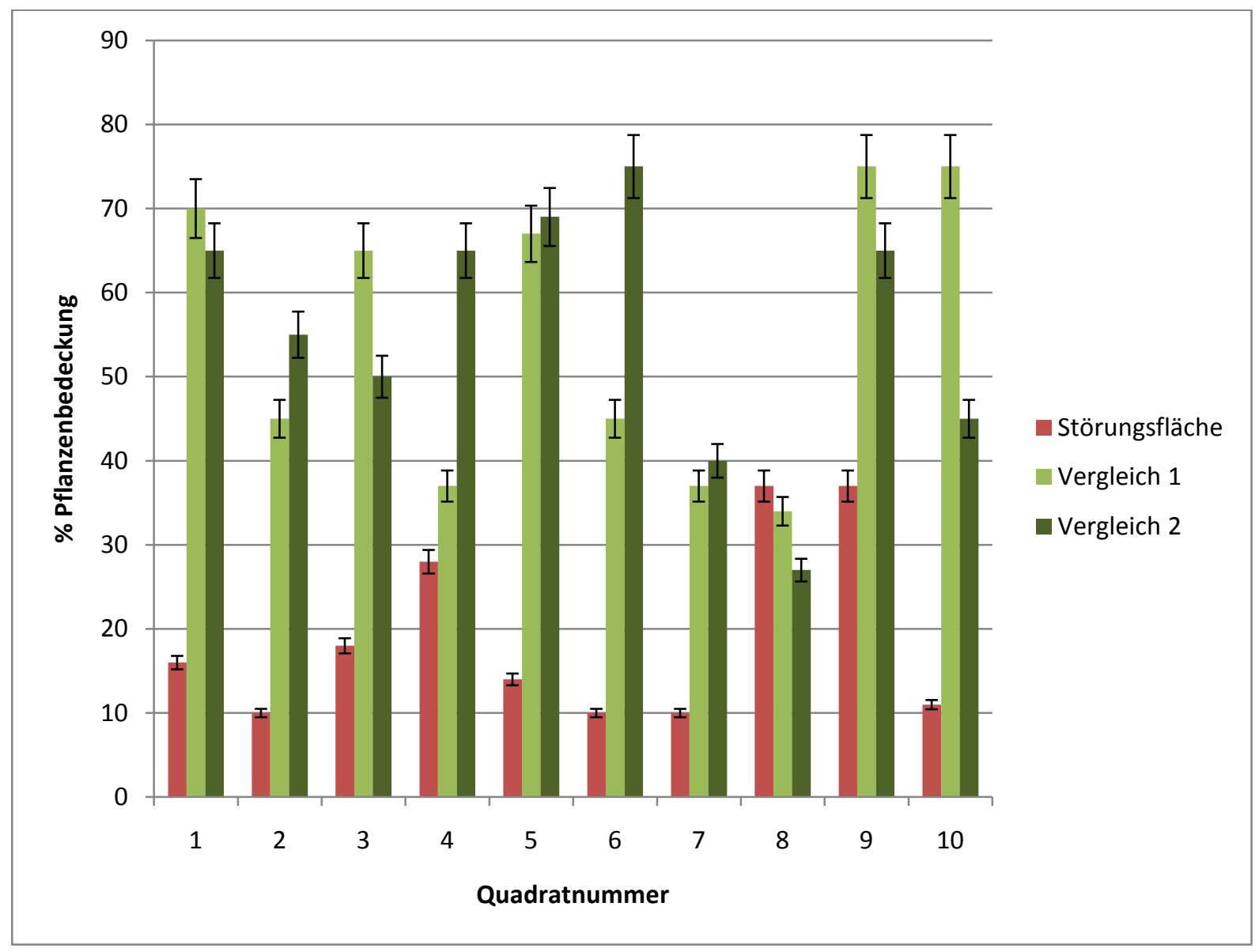

Abb. 4.35: Die Pflanzenbedeckung ein Jahr nach starker Trittbelastung. Die Fehlerbalken geben den prozentualen Fehler an. 
4 Ergebnisse

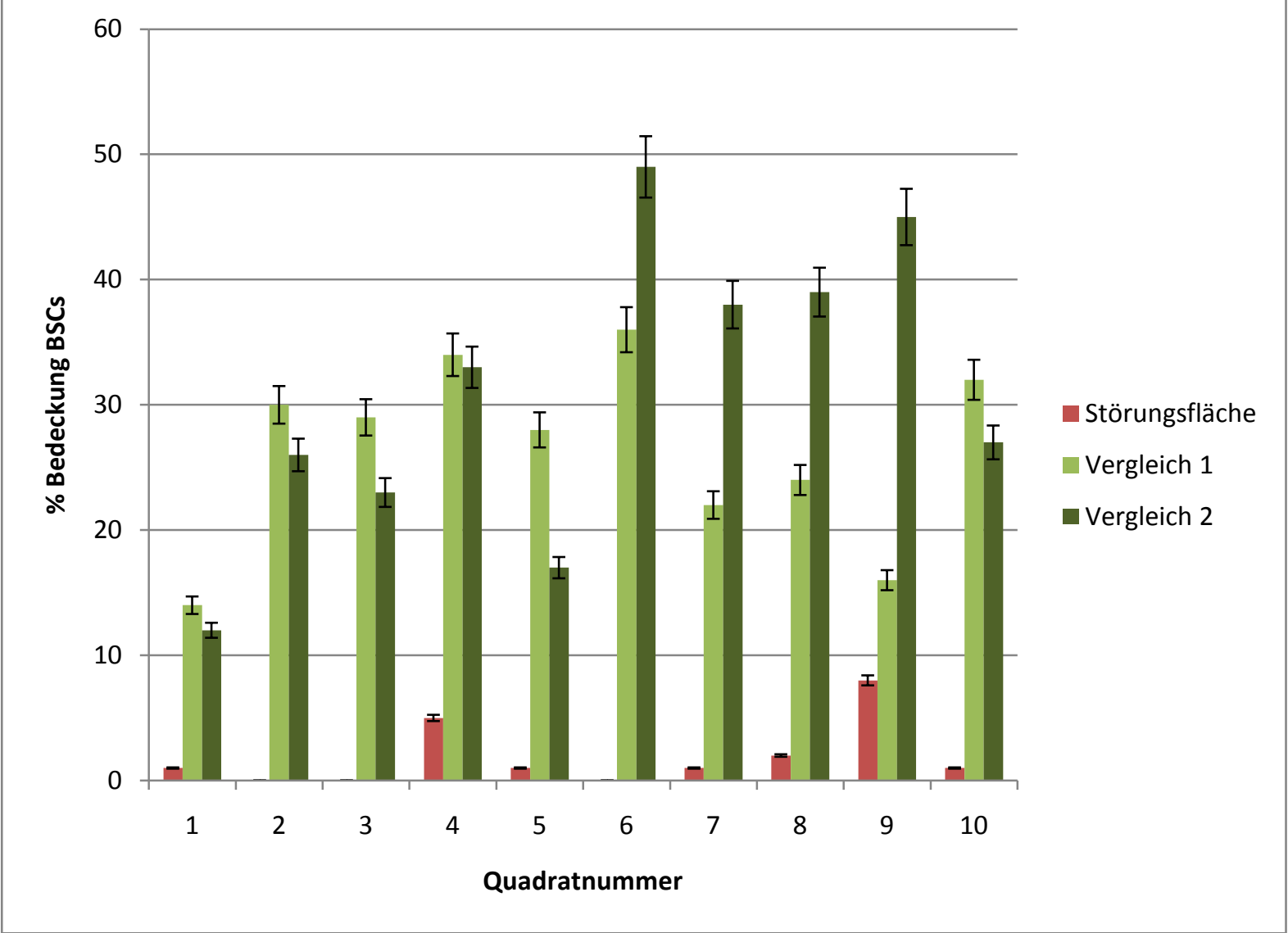

Abb. 4.36: Die Bedeckung mit BSCs ein Jahr nach starker Trittbelastung. Die Fehlerbalken geben den prozentualen Fehler an. 
4.4 Analyse der mikrobiellen Diversität in Biologischen Bodenkrusten über die Konstruktion von 16S rDNA-Genbanken

Es sollten zwei möglichst verschiedene BSC-Standorte bezüglich der Zusammensetzung ihrer bakteriellen Flora miteinander verglichen werden. Ausgewählt wurden die Standorte G und H. Diese unterscheiden sich, wie aus Tabelle 4.9 ersichtlich wird, unter anderem durch ihre Exposition. Berg G zeigt ein sehr großes Spektrum verschiedener Expositionen (südöstlich bis südwestwestlich), er ist auf drei Seiten BSC-Standort. Die Exposition des Berges H ist ausschließlich süd- bis südwestlich ausgerichtet, dieser Hang ist auch durchschnittlich steiler. Die kryptogame Artenzusammensetzung und die durchschnittliche Bedeckung mit BSCs unterscheiden sich ebenfalls sehr.

\begin{tabular}{|c|c|c|}
\hline & Berg G & Berg H \\
\hline Lage & UTM: 48U0667396 5438800 & UTM: 48U0666979 5440021 \\
\hline Höhe & $1002 \mathrm{~m}$ üNN & $954 \mathrm{~m}$ üNN \\
\hline Exposition & $135-240^{\circ}$ & $180-220^{\circ}$ \\
\hline Inklination & $25-40^{\circ}$ & $30-50^{\circ}$ \\
\hline Lage in der Landschaft & $\begin{array}{c}\text { Am Fuß des Berges } \\
\text { bewaldet, jedoch keine } \\
\text { Beschattung im BSC - Feld }\end{array}$ & $\begin{array}{l}\text { Ganz frei mit Ausrichtung } \\
\text { ins Flusstal }\end{array}$ \\
\hline \multicolumn{3}{|l|}{ Charakterarten } \\
\hline Artemisia frigida -GTS & 4 & 2 \\
\hline $\begin{array}{l}\text { Carex amgunensis - } \\
\text { GTS }\end{array}$ & - & - \\
\hline Festuca lenensis- GTS & 1 & 1 \\
\hline $\begin{array}{l}\text { Pulsatilla ambigua - } \\
\text { GTS }\end{array}$ & - & - \\
\hline Ulmus pumila- OWG & 2 & 2 \\
\hline $\begin{array}{l}\text { Pflanzenbedeckung } \\
\text { innerhalb des BSC - Feldes }\end{array}$ & $60-95$ & $10-40$ \\
\hline $\begin{array}{l}\text { BSC -Typ dominierend, } \\
\text { Mischung aus: }\end{array}$ & $\begin{array}{l}\text { Xanthoparmelia spec., } \\
\text { Cladonia spec., Psora } \\
\text { luridella, Catapyrenium } \\
\text { lachneum }\end{array}$ & $\begin{array}{c}\text { Catapyrenium lachneum, } \\
\text { Collema spec., Moos, } \\
\text { Initialkrusten }\end{array}$ \\
\hline BSC - Bedeckung & $10-70 \%$ & $0-10 \%$ \\
\hline Kryptogamenarten & 18 & 6 \\
\hline
\end{tabular}

Tabelle 4.9: Vergleich verschiedener Parameter der Standorte G und H. Bodenanalysen siehe Tab. 4.1. GTS = Gebirgstrockensteppe, OWG = Offenes Waldgebiet. 
Die Analyse der mikrobiellen Diversität innerhalb der Bodenkrusten der zwei Standorte erfolgte durch eine Isolierung der Gesamt-DNA und eine anschließende selektive Amplifikation der 16S-rDNA mit anschließender Sequenzierung. Die Bearbeitung der Rohsequenzen und eine weitere Analyse der Datensätze mittels DOTUR (Schloss und Handelsmann, 2005), über verschiedene Tools des Ribosomal Database Project (Maidak et al., 1994) und schließlich MEGA4.0 (Kumar et al., 2008) führten zur Ableitung von Stammbäumen. Es ergab sich so eine Übersicht über die Vielfalt der an diesen beiden Standorten vertretenen Bakterien.

Es wurden für Standort G insgesamt 351 und für Standort H insgesamt 306 verwertbare Sequenzen erhalten. Von diesen wurden die nächsten Verwandten über die Datenbanken von NCBI und RDP bestimmt. Die Identifikation von Chimären erfolgte über Mallard (Ashelford et al., 2006) und Bellerophon (Huber et al., 2004). Potentielle Chimären wurden entfernt. Tabelle 4.10 gibt deren Anteile an den gesamten Sequenzen wieder.

\begin{tabular}{|l|l|l|}
\hline & G01 & H01 \\
\hline Chimären & $92 / 351=\mathbf{2 6 , 2 1} \%$ & $48 / 306=\mathbf{1 5}, \mathbf{7 4} \%$ \\
\hline
\end{tabular}

Tab. 4.10: Chimären in den Standortgenbanken G01 und H01, detektiert durch Mallard und Bellerophon.

Die Anzahl der durch DOTUR-Analyse detektierten OTUs (operational taxonomical units) bei den Distanzen 0,03 (mind. $97 \%$ Übereinstimmung der Sequenzen) und 0,2 (80 \% Übereinstimmung) ist in Tabelle 4.11 angegeben. Hier finden sich auch die ebenfalls durch die DOTUR-Analyse errechneten Werte des abundance based coverage etimator (ACE) und des Chao1 (nichtparametrischer Häufigkeitsschätzer auf Basis von ein- und zweielementigen Mengen), welche angeben, wie viele OTUs an diesem Standort zu erwarten gewesen wären. Bei Standort G01 und einer Distanz von 0,03 sind das für den ACE 304 und für den Chao1 282 gegen 104 tatsächlich gefundene OTUs. Das entspricht also einer Ausschöpfung von 34,21 beziehungsweise 36,88 \%. Für eine Distanz von 0,2 stehen 26 erwartete OTUs für den ACE und für den Chao1 25 gegen 23 tatsächlich gefundene und beschreiben so also eine Ausbeute von 88,46, beziehungsweise 92 \%. Für den Standort H01 und einer Distanz von 0,03 sind das für den ACE 483 und für den Chao1 494 gegen 168 tatsächlich gefundene OTUs. Das entspricht einer Ausschöpfung von 34,78 beziehungsweise 34,01 \%. Für eine 
Distanz von 0,2 stehen 33 erwartete OTUs für den ACE und für den Chao1 30 gegen 26 tatsächlich gefundene und beschreiben so also eine Ausbeute von 78,79, beziehungsweise $86,67 \%$.

Der Shannon-Wiener-Index (siehe Tabelle 4.11) beschreibt die Biodiversität von einem Datensatz ausgehend. Er beschreibt die Vielfalt betrachteter Daten. Dabei werden sowohl die Anzahl der Datenkategorien als auch die Abundanz, das heißt die Anzahl der Individuen je Art berücksichtigt. Aussagekräftig sind hier vor allem die Werte für die Artebene, d.h. die Distanz von 0,2. Die beiden Genbanken überschreiten hierbei mit 3,93 (für G01) und 4,93 (für H01) sogar die von Magurran (1988) für Umweltproben angegebene Bandbreite des Index von 1,5 bis 3,5 .

\begin{tabular}{|l|c|c|c|c|c|}
\hline Standort & Distanz & $\begin{array}{l}\text { Anzahl der } \\
\text { OTUs }\end{array}$ & ACE* & Chao1 $\neq$ & Shannon-Wiener $\boldsymbol{~}$ \\
\hline G01 & 0,03 & 104 & 304 & 282 & 3.93 \\
\hline & 0,2 & 23 & 26 & 25 & 2.12 \\
\hline H01 & 0,03 & 168 & 483 & 494 & 4.93 \\
\hline & 0,2 & 26 & 33 & 30 & 2.64 \\
\hline
\end{tabular}

Tab. 4.11: Tatsächlich gefundene OTUs (operational taxonomical units) im Vergleich mit Schätzwerten und der Shannon-Weaver-Index für die Genbanken der Standorte G und $\mathbf{H}$.

* abundance based coverage estimator (ACE), nicht parametrischer Häufigkeitsschätzer auf Basis von Häufigkeit $(>10)$ und Seltenheit $(<10)$ von OTUs.

‡ nichtparametrischer Häufigkeitsschätzer auf Basis von ein- und zweielementigen Mengen.

† Shannon-Wiener-Index der Diversität; je höher, desto diverser.

Weiterhin konnten durch DOTUR Rarefaction-Kurven berechnet werden. Diese beruhen auf dem Prinzip, dass beim Sequenzieren alle OTUs einer Umweltprobe gefunden wurden, wenn jede Sequenz mindestens zweimal vorhanden war. So wird ausgehend von der festgestellten Arten-Abundanz-Verteilung berechnet, wie viele Arten bei einer standardisierten Individuenzahl zu erwarten wären. Je höher die Individuenzahl, desto steiler die Kurve. Da Artenreichtum und Artabundanz in die Berechnung eingehen, gelten die Kurven bei vergleichenden Ansätzen als bessere Alternative zu Diversitätsindices (Achziger et al., 1992). Durch randomisierte Wiederbeprobungen zur Extrapolation konnten so Artenakkumulationskurven (siehe Abb. 4.37 und 4.38) erstellt werden (Colwell et al., 1994). Ebenfalls wurden vom Programm Konfidenzintervalle ausgegeben, diese stellen den 
4 Ergebnisse

Vertrauensbereich des Schätzwertes dar und werden durch die in den Abbildungen 4.37 und 4.38 gezeigten Fehlerbalken dargestellt. Für den Standort H01 zeigen diese Kurven auf Phylaebene eine Sättigung, für die Artebene ist selbst bei 270 untersuchten Sequenzen keine Sättigung in Sicht (siehe Abb. 4.37). Ähnlich sieht das Bild für G01 aus, hier sind die Kurven lediglich etwas flacher (siehe Abb. 4.38).

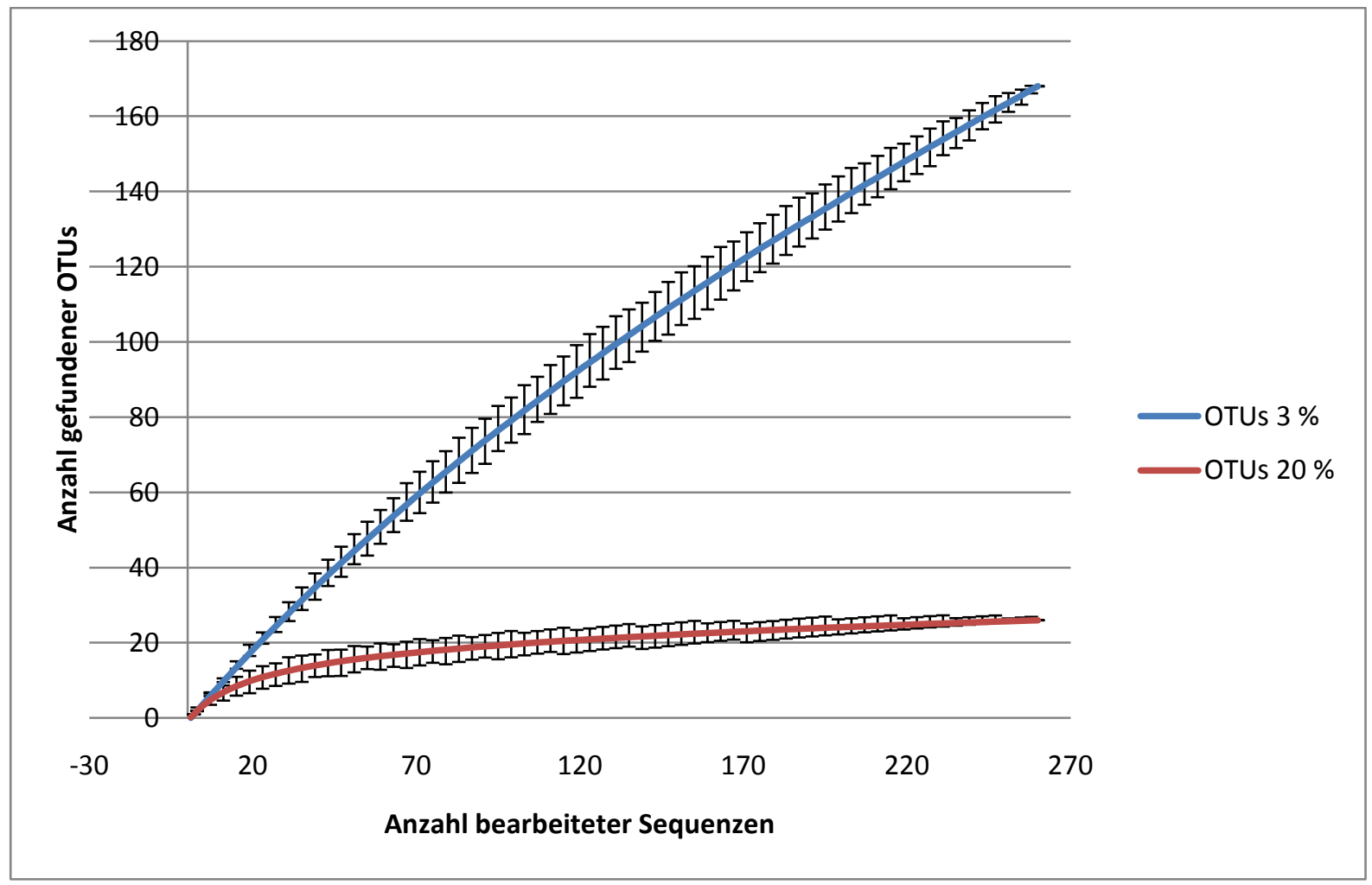

Abb. 4.37: Rarefaction für H01. 


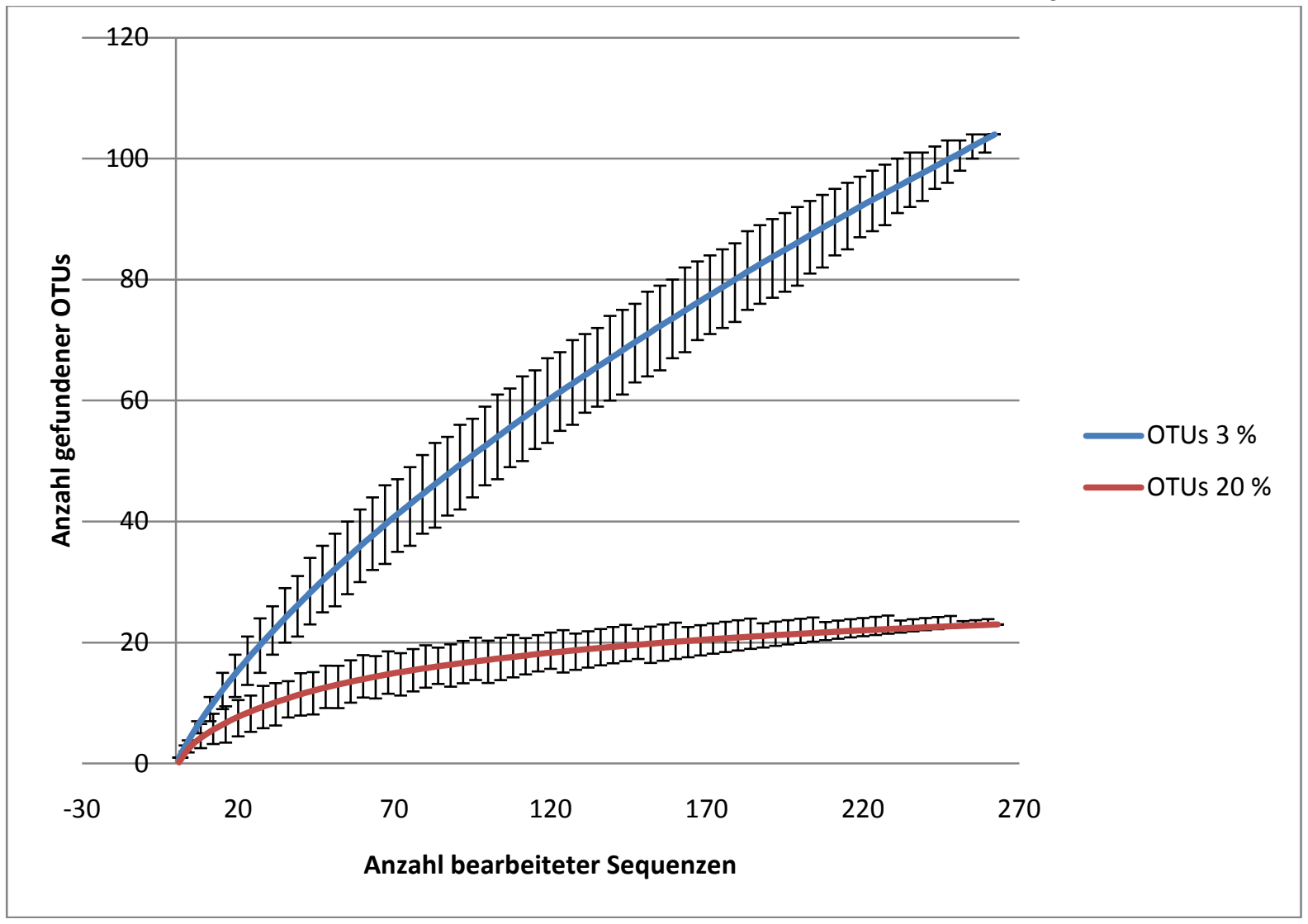

Abb. 4.38: Rarefaction für G01.

Eine andere Möglichkeit, die Sequenzen den unterschiedlichen Phyla zuzuordnen zeigt der Classifier vom Ribosomal Database Project (Maidak et al., 1994). Alle Sequenzen, exclusive der Chimären wurden hierfür dem Projekt beigeladen. Die Ergebnisse der daraus hervorgehenden Klassifizierung sind als prozentualer Anteil an der Gesamtartenzahl in der Abbildung $4.39 \mathrm{zu}$ sehen. Auf den ersten Blick ersichtlich ist es, dass es an Standort H mehr Phyla gibt als an Standort G. So sind zusätzlich an diesem Standort die Gemmatimonadetes mit 3,6 \%, die Firmicutes mit 0,6 \% und die Planctomycetes mit 0,6 \% vorhanden. Nitrospira dagegen kommt mit 1,9 \% nur an G01 vor. Die Chloroflexi sind bei H01 mit 3 \% vorhanden, bei G01 mit 1,9 \%, Bacteroidetes machen bei H01 18,6 \% aus, während sie bei G01 nur 9,6 \% darstellen. Die Actinobacteria sind mit 6,6 \% bei H01 und 8,7 \% bei G01 relativ gleich verteilt, während für Cyanobacteria (9 \% bei H01 gegen $24 \%$ bei G01) der Unterschied größer ist. Die Acidobacteria sind mit 14,4 \% (H01) und 10,6 \% (G01) wieder recht ähnlich verteilt, ebenso die Verrucomicrobia mit 3,3 \% (H01) und 1,9 \% (G01). Die Proteobacteria machen bei H01 nur ein Viertel aus (25,3 \%), während sie bei G01 ein Drittel der Sequenzen stellten (33,7 \%). Nicht klassifiziert werden konnten bei H01 13,8 \% und bei G01 7,7 \%. 
4 Ergebnisse

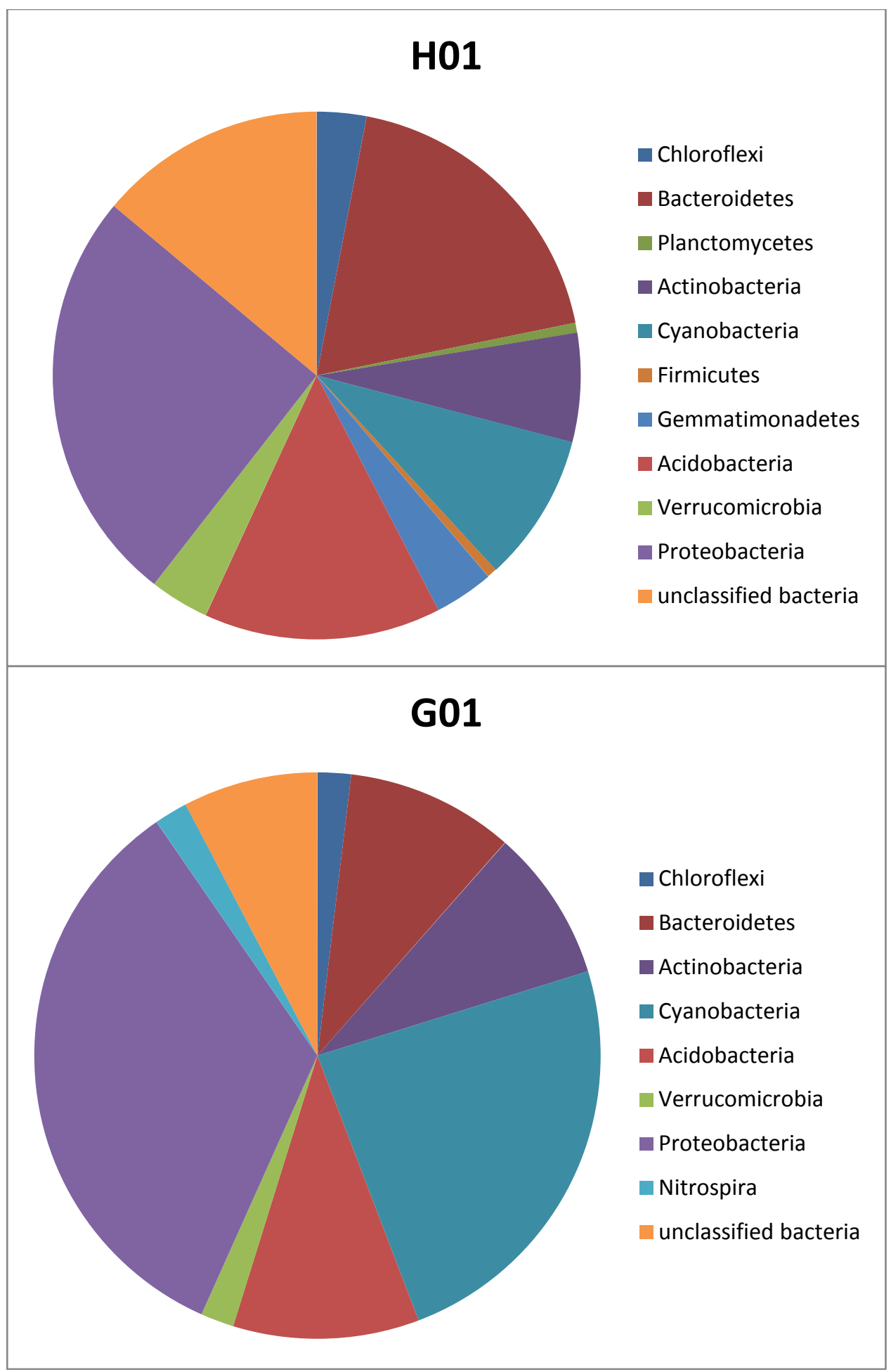

Abb. 4.39: Phylaverteilung der 16S rDNA-Genbanken der Standorte G01 und H01. Auf Grundlage der Einteilung durch den RDP Classifier (Maidak et al., 1994).

Die Sequenzstammbäume sind in Abbildung 4.40 über mehrere Seiten dargestellt. Der erste Baum (Bild A) zeigt die Proteobakterien des Standortes G01. Zu den Proteobakterien 
konnten insgesamt 35 OTUs gezählt werden. Der größte Teil davon, nämlich 27 OTUs entfiel auf die Alphaproteobacteria. Es wurden außerdem sieben Betaproteobakterien und ein Gammaproteobakterium gefunden. Die meisten nächsten Verwandten waren unkultivierte Bakterien, einige konnten jedoch Taxa oder sogar Arten zugeordnet werden, so wurden die Alphaproteobakterien Chelatococcus asaccharovorans, Bosea thiooxidans, Roseomonas gilardii und die Gattungen Phyllobacteriaceae, Brevundimonas, Caulobacter und Sphingomonas als nächste Nachbarn der untersuchten Sequenzen durch BLAST-Analyse ermittelt. Das Gammaproteobakterium hatte ein unkultiviertes Bakterium als nächsten Nachbarn, bei den Betaproteobakterien wurde ein Hinweis auf die Gattung Variovorax gefunden. Die Cyanobacteria, Chloroflexi und Actinobacteria von Standort G01 werden zusammen in einem Stammbaum auf Bild E gezeigt. Bei den Cyanobakterien, zu denen 25 OTUs gehörten, fanden sich ebenfalls viele unkultivierte nächste Nachbarn. Es wurden die Taxa Pseudanabaenaceae, Nostocales, Coleodesmium, Tolypothrix und Leptolyngbya gefunden und eine Sequenz konnte sogar der Art Phormidium pristleyi zugeordnet werden. Die Chloroflexi waren nur durch zwei Sequenzen vertreten, hier konnte die genauere Verwandschaft zu bekannten Gattungen nicht ermittelt werden, da der nächste Nachbar ebenfalls ein unkultiviertes Bakterium war. Zu den Actinobacteria konnten 9 OTUs gezählt werden. Hier fanden sich neben unkultivierten Bakterien die Taxa Frankiaceae, Blastococcus, Dactylosporangium und Lentzea. Auf Bild C sind die Stammbäume der Bacteroidetes und von den Acidobacteria, Nitrospira und Verrucomicrobia zusammen zu sehen. $\mathrm{Zu}$ den Bacteroidetes wurden 10 Sequenzen gezählt, diese konnten durch die Ergebnisse des RDP-Classifiers im Wesentlichen in Chitinophagaceae (fünf Sequenzen), Cytophagaceae (drei Sequenzen) und zwei anderweitig klassifizierten Sequenzen eingeteilt werden. Die Chitinophagaceae und Cytophagaceae enthielten nur unkultivierte Bakterien als nächste Nachbarn, die anderweitig klassifizierten einen Vertreter der Gattung Hymenobacter. Die Acidobacteria enthielten 11 OTUs und konnten nicht weiter unterteilt werden. Es finden sich keine Hinweise auf Gattungen oder gar Arten. Das gleiche gilt für Nitrospira (zwei OTUs) und Verrucomicrobia (2 OTUS).

Auf Bild E ist der Stammbaum der Proteobacteria des Standortes H01 dargestellt. Er enthält die Sequenzen von 44 OTUs samt denen der zugehörigen nächsten Nachbarn. Die Alphaproteobakterien stellten auch hier mit 30 OTUs den größten Anteil. Diese ließen sich aufgrund des hohen Anteils unkultivierter Bakterien als nächste Nachbarn nicht weiter unterteilen, es wurden aber verhältnismäßig viele Sequenzen denen von bekannten Arten 
zugeordnet, so etwa Sphingomonas japonica, Sphingomonas oligophenolica, Phenylobacterium immobile, Chelatococcus asachharovorans (der auch schon in G01 gefunden wurde) und Belnapia moabensis. Neben der Gattung Sphingomonas, die zahlreich vertreten war, wurden noch Devosia und Roseomonas gefunden. Eine Sequenz konnte den Gammaproteobakterien zugeordnet werden, Hinweise auf niedrigere Taxa ergeben sich nicht. Fünf Sequenzen hatten als nächste Verwandte Betaproteobakterien. Neben Azoarcus buckelii waren das jedoch nur nicht kultivierte Bakterien. Im Unterschied zu der Genbank des Standortes G01 findet sich hier noch das Taxon der Deltaproteobakterien, dem acht OTUs zugeordnet wurden. Hier finden sich neben nicht kultivierten Bakterien zwei Myxococcales als nächste Verwandte. Bild E zeigt die Cyanobacteria des Standortes H01. Diese lassen sich in Nostocales, Oscillatoriales und die Mitochondrien von Chlorophyta (Grünalgen) einordnen. Die Nostocales enthielten sechs OTUs, hier ließen sich die Taxa Tolypothrix und Rivularia neben unkultivierten Bakterien finden. Die Oscillatoriales enthielten sieben OTUs und es wurde neben Microcoleus paludosus ein Hinweis auf das Taxon Phormidiaceae gefunden. Zwei OTUs waren mit Mitochondrien verwandt. Bild F zeigt einen Stammbaum der Bacteroidetes für H01, die in Chitinophagaceae, Sphingobacteriaceae, Cytophagaceae und Hymenobacter unterteilt werden konnten. Insgesamt enthält er die Sequenzen von 31 OTUs samt derer ihrer nächsten Nachbarn. Die Chitinophagaceae, die mit 15 enthaltenen OTUs die größte Gruppe darstellten, ließen aufgrund der überwiegend unkultivierten nächsten Nachbarn keine weitere Unterteilung zu. Es wurden die Taxa Segetibacter und Chitinophaga gefunden. Zu den Sphingobacteriaceae gehörten 2 OTUs, diese gehörten dem Taxon Pedobacter an. Zu den Cytophagaceae konnten neun OTUs gezählt werden. Hier fand sich eine Verwandschaft zu Spirosoma panaciterrae und zu den Taxa Flexibacteriaceae und Dyadobacter. Vier OTUs gehörten zu den Hymenobacteriales. Zwei Verwandtschaften zu bestimmten Arten konnten festgestellt werden und zwar zu Hymenobacter daecheongensis und Hymenobacter roseosalivarius. Die Acidobacteria von H01 sind auf Bild G dargestellt worden. Hierzu konnten 24 OTUs gezählt werden. Sämtliche nächsten Verwandten sind unkultivierte Bakterien und so lassen sich keine weiteren Unterteilungen vornehmen. Auf Bild $\mathrm{H}$ ist ein gemeinsamer Stammbaum der vertreterarmen Actinobacteria, Gemmatimonadetes, Chloroflexi, Planctomycetales und Verrucomicrobiales dargestellt. Zu den Actinobacteria, die allesamt den Actinomycetales zugeordnet werden können, wurden 11 OTUs gerechnet. Hier fand sich ein OTU, das Actinoplanes auranticolor und eines das Microlunatus panaciterreae (wie schon in G01) als nächsten Verwandten hatte. Weitere Verwandtschaftsverhältnisse zu bestimmten Arten oder Gattungen konnten nicht hergestellt 
werden. Die Gemmatomonadetes waren mit sechs OTUs vertreten. Hier konnte nicht weiter klassifiziert werden, ebenso wie bei den Chloroflexi, die mit fünf OTUs verteten waren. Ein OTU war den Planctomycetales, genauer Planctomycetacia zuzuordnen. Die Verrucomicrobia enthielten sechs OTUs, die ebenfalls nur unkultivierte Bakterien als nächste Nachbarn hatten, hier konnte also nicht weiter unterteilt werden.

\section{Abb. 4.40: Evolutionäre Beziehungen der 16S rDNA- Genbanken der Standorte G und $H$.}

Die evolutionäre Entwicklung wurde mit Hilfe der neighbor joining-Methode (Saitou und Nei, 1987) abgeleitet. Es wird der idealisierte Stammbaum gezeigt. Der prozentuale Anteil der Replikatstammbäume, in denen die assoziierten Taxa während des bootstrap Tests (1000 Replikate) einem Cluster zugeordnet wurden, wird neben den Abzweigungen angegeben (Felsenstein, 1985). Der Stammbaum wird maßstabsgerecht wiedergegeben, die Einheit der Astlängen entspricht derjenigen der evolutionären Distanzen, welche benutzt wurden, um den Stammbaum abzuleiten. Die evolutionären Distanzen wurden mit Hilfe der Maximum Composite Likelihood-Methode (Tamura et al., 2004) errechnet und werden als Anzahl der Basenaustausche pro site angegeben. Alle Positionen die gaps und fehlende Daten enthalten, wurden aus dem Datenset eliminiert. Die phylogenetischen Analysen wurden mit MEGA4 (Tamura et al., 2007) vorgenommen.

A= G01, Proteobakterien

B= G01, Cyanobakterien, Chloroflexi und Actinobakterien

C= G01, Bacteroidetes; G01, Acidobakterien, Nitrospira und Verrucomicrobia

$\mathrm{D}=\mathrm{H} 01$, Proteobakterien

$\mathrm{E}=\mathrm{H} 01$, Cyanobakterien

$\mathrm{F}=\mathrm{H} 01$, Bacteroidetes

$\mathrm{G}=\mathrm{H} 01$, Acidobakterien

H= H01, Actinobakterien, Gemmatimonadetes, Chloroflexi, Planctomyceten und Verrucomicrobia. 


\section{Ergebnisse}

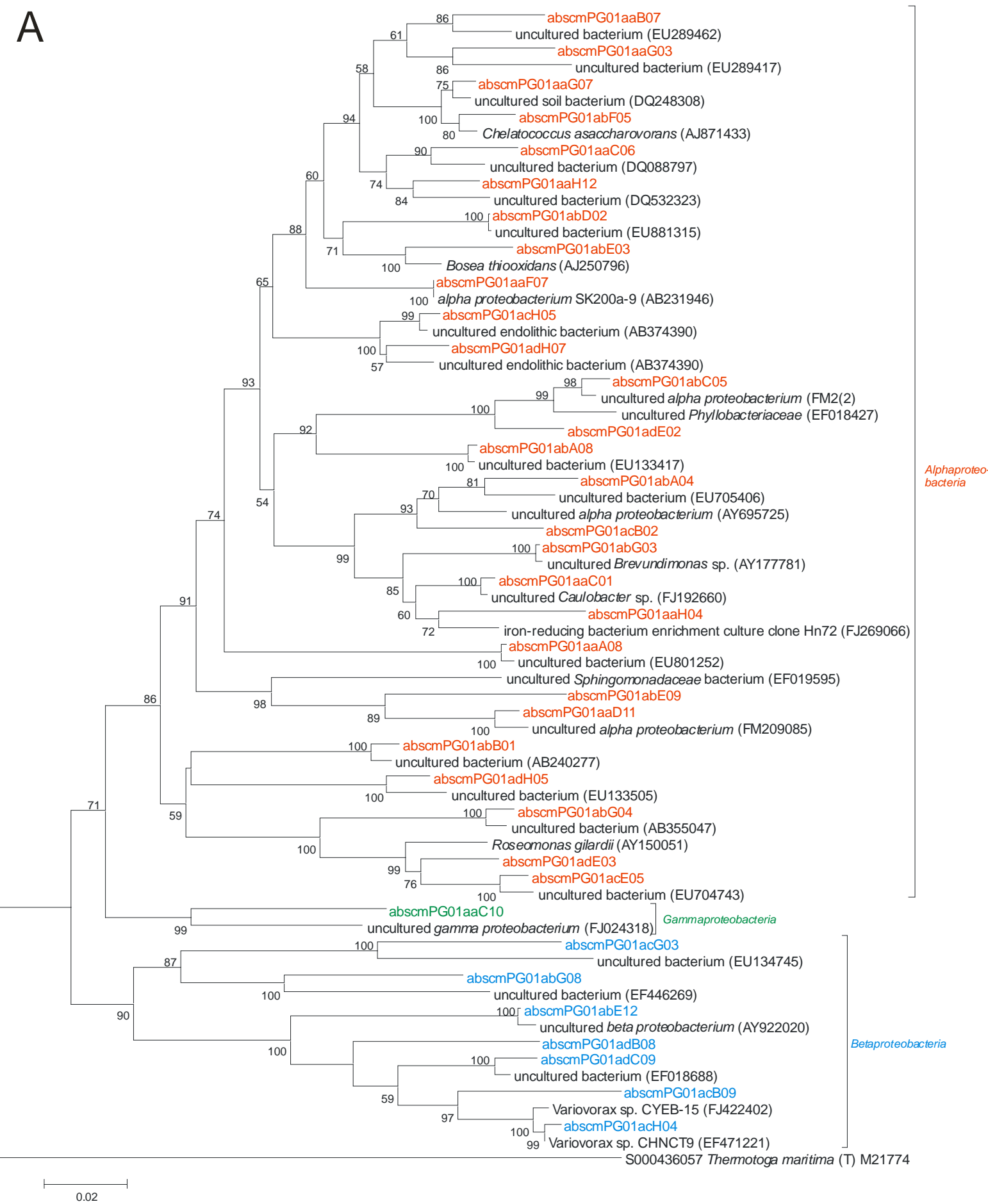


4 Ergebnisse

B

51

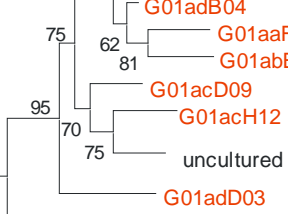

uncultured bacterium (EF516628)

Ergerisse

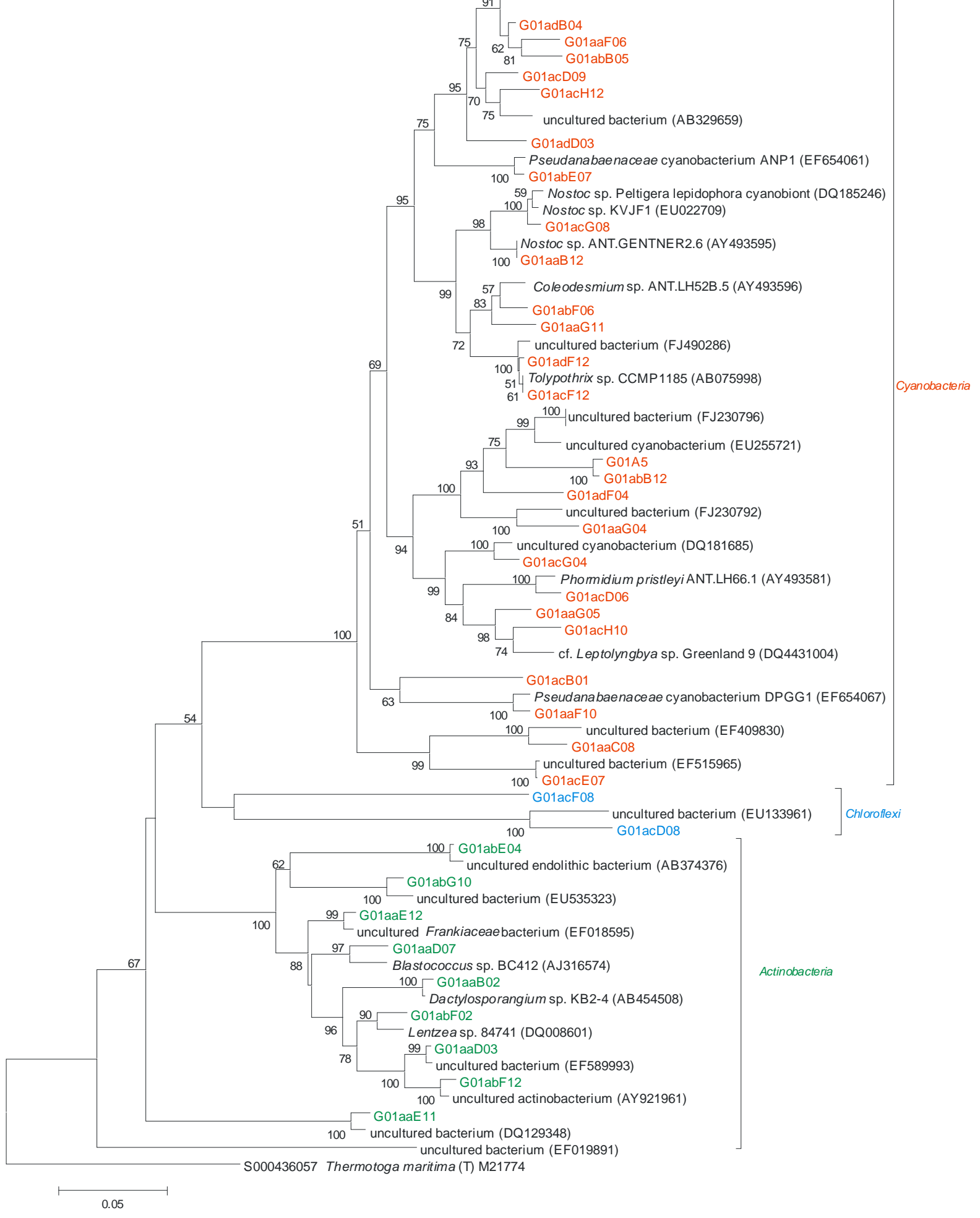



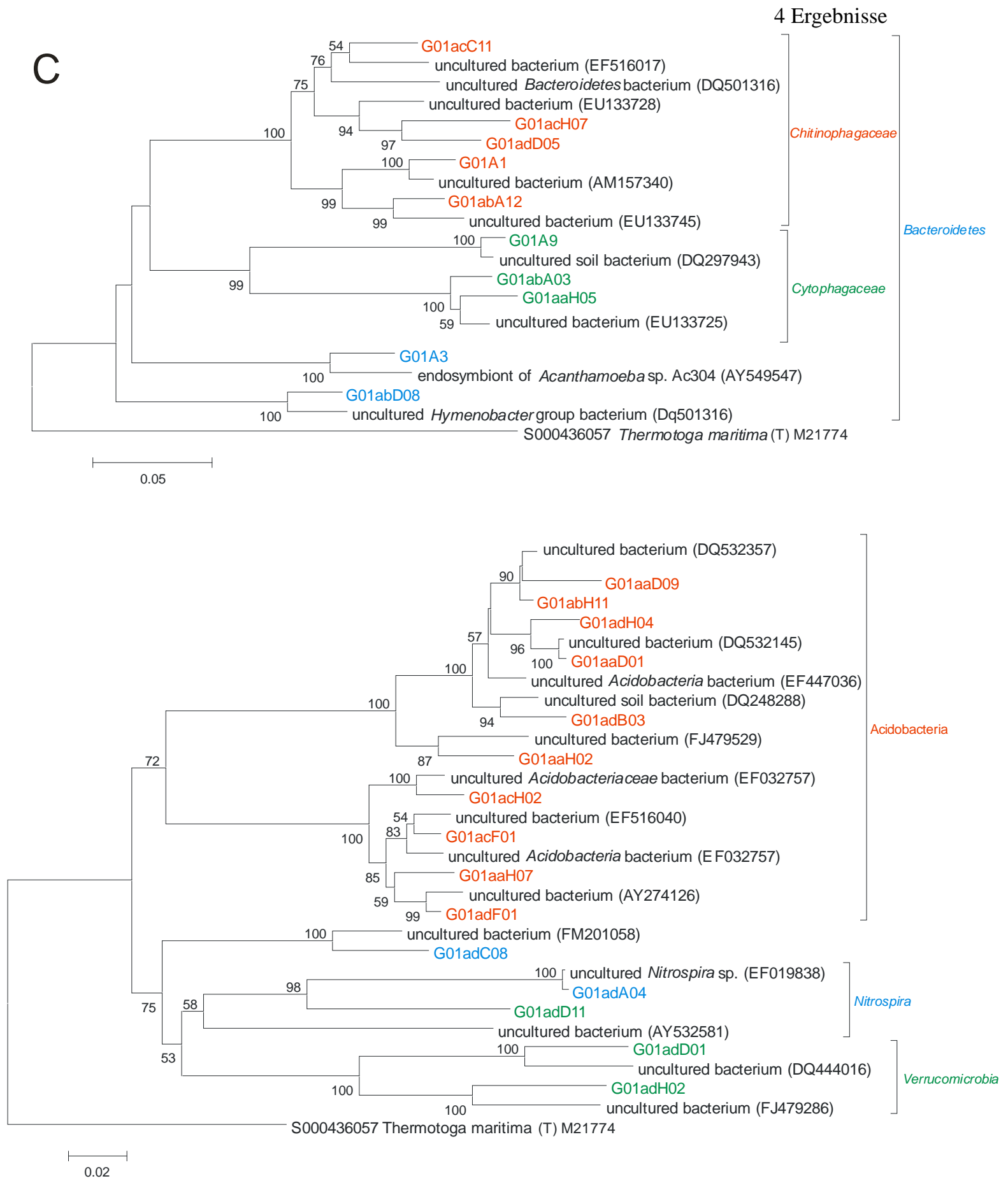


\section{Ergebnisse}

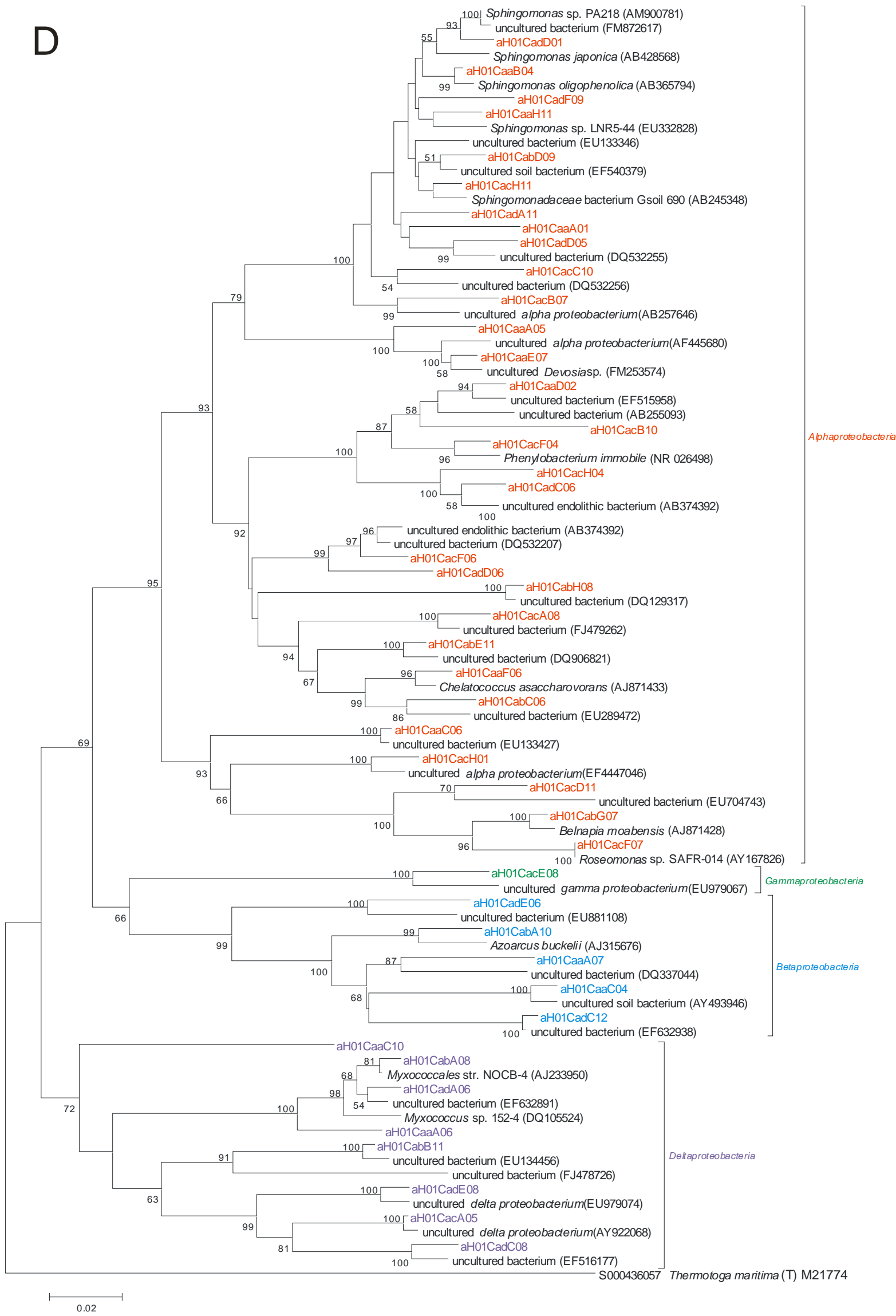




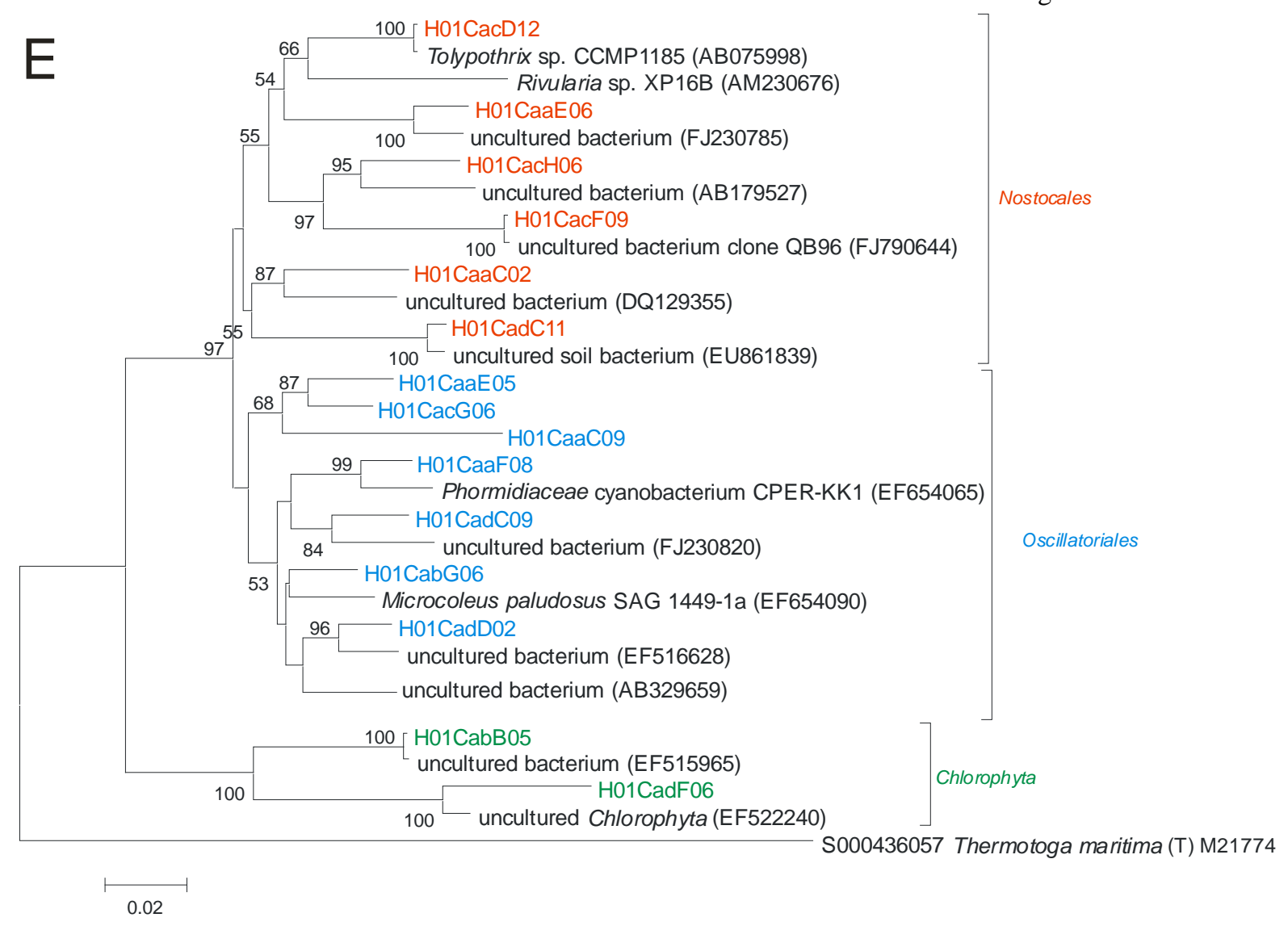




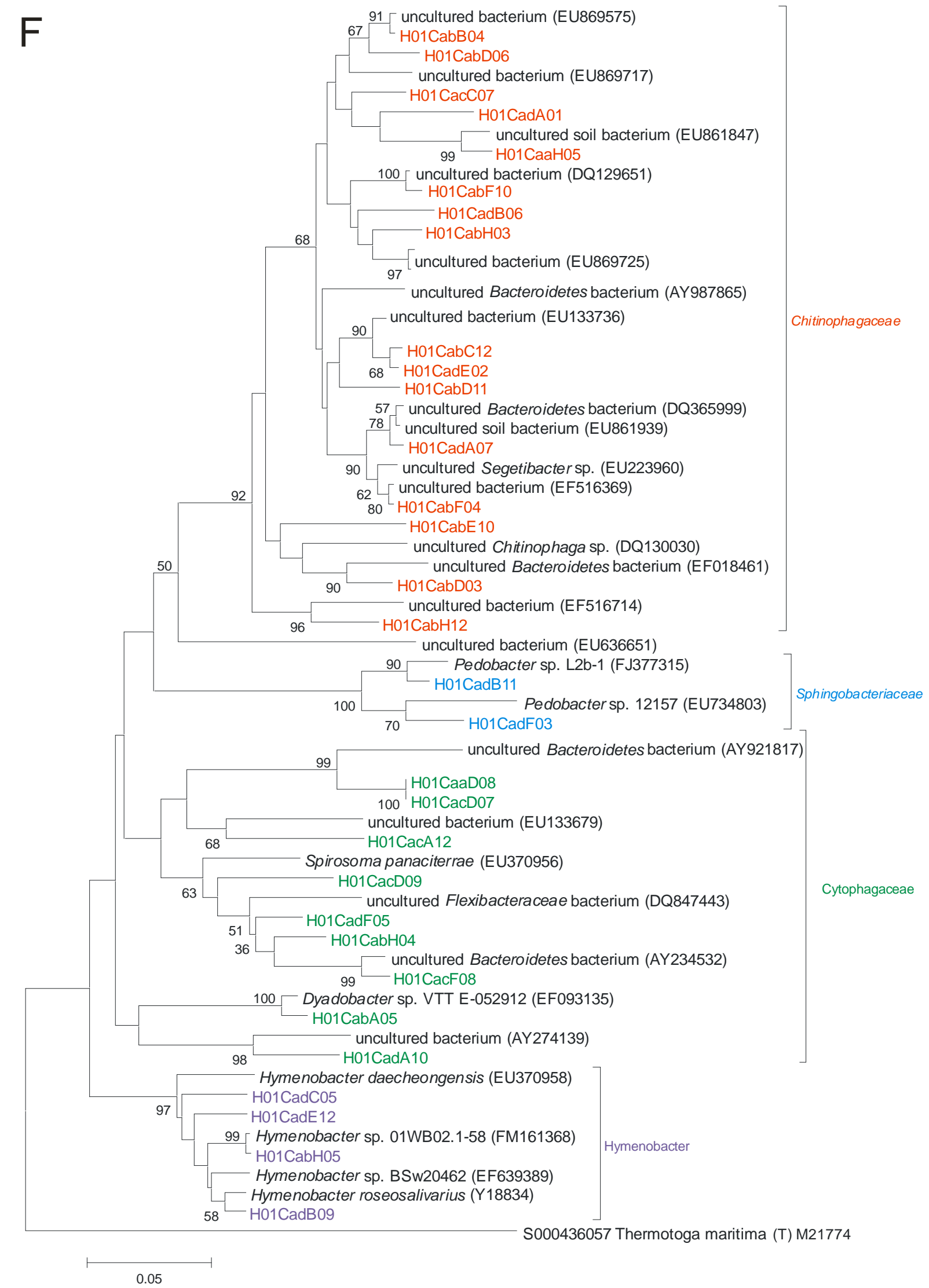

4 Ergebnisse 
4 Ergebnisse

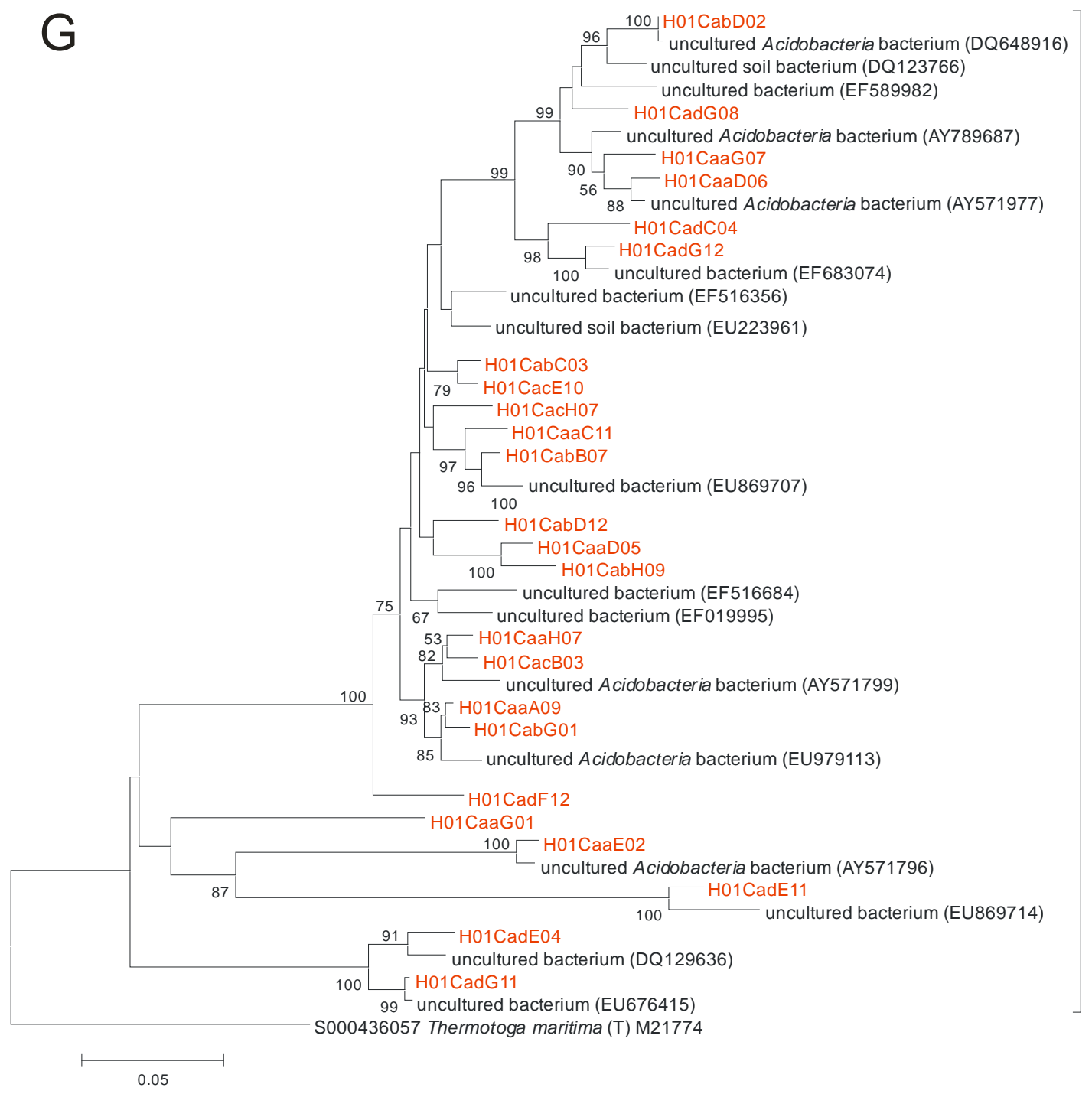

Acidobacteria 


\section{Ergebnisse}

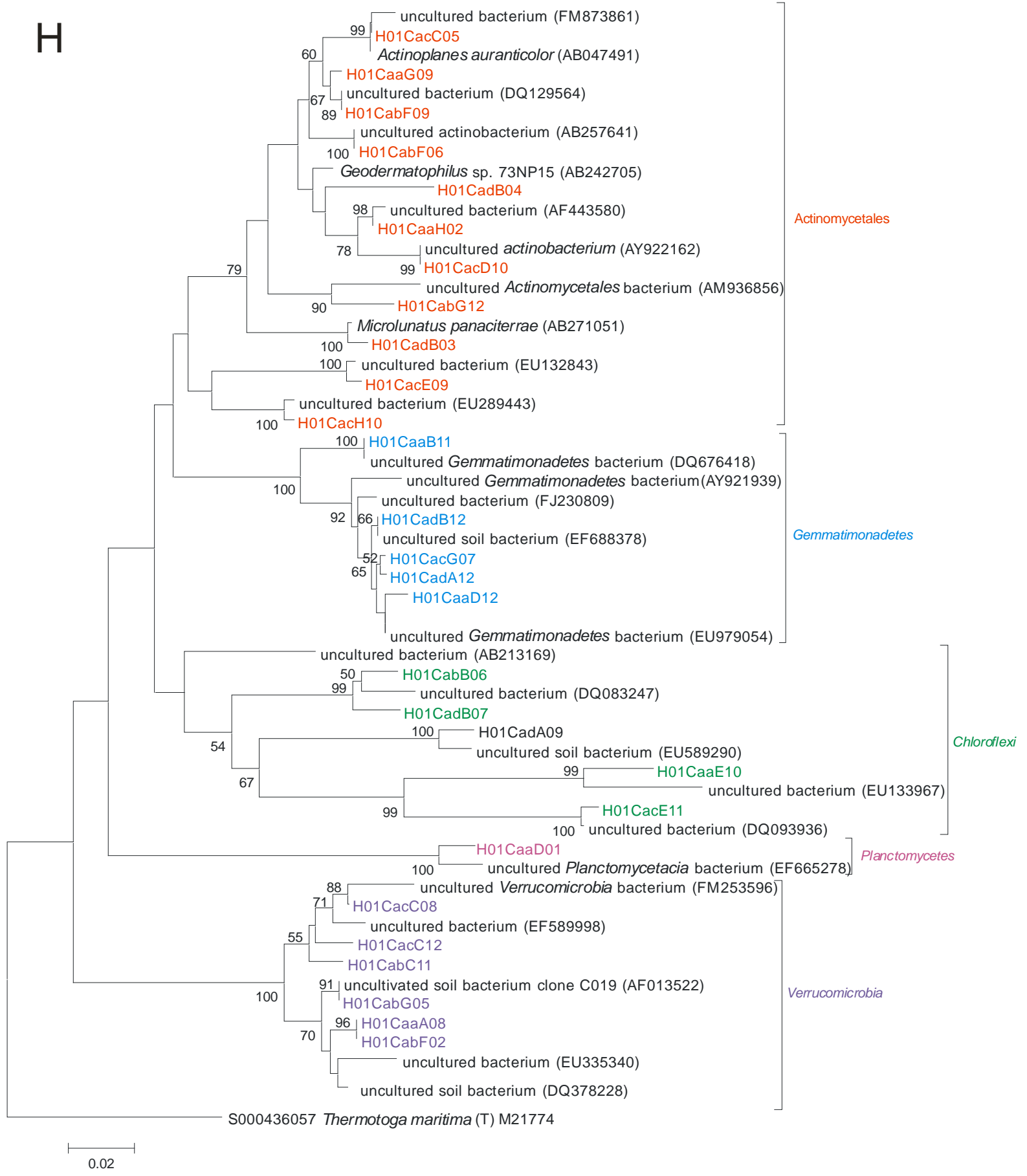




\subsection{Sonstige Ergebnisse}

\subsubsection{Archaeen -DGGE (denaturing gradient gel electrophoresis)}

An Sammelproben der Standorte wurde zunächst die gesamte genomische DNA isoliert, dann wurde mit für die 16S-rDNA von Archaeen spezifischen Fragmente gezielt vervielfältigt. Es erfolgte eine nested PCR zur Erhöhung der Ausbeute, außerdem wurde in diesem Schritt die für die DGGE notwendige GC-Klammer angehängt. Es wurden aus den Proben von den Standorten A01, D01, G01 und H01 verwertbare Banden gewonnen. Die Banden wurden aus dem DGGE-Gel ausgeschnitten, reamplifiziert und sequenziert. Die erhaltenen Sequenzen wurden mit Pregap und Gap4.0 bearbeitet und anschließend einer BLAST-Analyse unterzogen. Die Ergebnisse sind in Tabelle 4.12 dargestellt. Die BLAST-Analyse ergab nur unkultivierte Archaeen als nächste Nachbarn, deshalb wurde noch eine Klassifizierung über RDP (Maidak et al., 1994) vorgenommen, deren Ergebnisse in Tabelle 4.13 dargestellt werden. Hierbei stellte sich heraus, dass alle Archaeen, den Crenarcheota, genauer, Thermoprotei, Desulforococcales angehörten. Vier Archaeen der Standorte A01, G01 und D01 gehörten weiterhin dem Genus Pyrolobus an, eine vom Standort H01 dem Genus Ignisphaera. 
4 Ergebnisse

\begin{tabular}{|c|c|c|c|c|c|c|}
\hline Sequenz & $\begin{array}{l}\text { Blast- } \\
\text { länge }\end{array}$ & Organismus & Gruppe & $\begin{array}{c}\text { Max. } \\
\text { Identity }\end{array}$ & Literatur & $\begin{array}{c}\text { Accession } \\
\text { Nr. }\end{array}$ \\
\hline A01_1 & 843 & $\begin{array}{l}\text { Uncultured archaeon } \\
\text { clone } \\
\text { Elev_16S_arch_674 }\end{array}$ & $\begin{array}{l}\text { Archaea; } \\
\text { environmental } \\
\text { samples }\end{array}$ & 97 & $\begin{array}{l}\text { Environ. } \\
\text { Microbiol. } 10 \text { (4), } \\
\text { 926-941 (2008) }\end{array}$ & EF022814 \\
\hline A01_2 & 794 & $\begin{array}{c}\text { Uncultured archaeon } \\
\text { clone byn222 }\end{array}$ & $\begin{array}{l}\text { Archaea; } \\
\text { environmental } \\
\text { samples }\end{array}$ & 95 & $\begin{array}{l}\text { Direct Submission } \\
\text { Submitted (30- } \\
\text { JUN-2009) } \\
\text { School of } \\
\text { Biological } \\
\text { Sciences, The } \\
\text { University of } \\
\text { Hong Kong, } \\
\text { Pokfulam Road, } \\
\text { Hong Kong, SAR, } \\
\text { China }\end{array}$ & GQ395290 \\
\hline D01_1 & 850 & $\begin{array}{l}\text { Uncultured archaeon } \\
\text { clone FR2_c11a }\end{array}$ & $\begin{array}{l}\text { Archaea; } \\
\text { environmental } \\
\text { samples }\end{array}$ & 97 & $\begin{array}{l}\text { Direct Submission } \\
\text { Submitted (21- } \\
\text { OCT-2009) } \\
\text { Institute for } \\
\text { Microbiology and } \\
\text { Archaea } \\
\text { Center, University } \\
\text { of Regensburg, } \\
\text { Universitätsstr. } \\
\text { 31, Regensburg }\end{array}$ & GU126497 \\
\hline G01_1 & 848 & $\begin{array}{c}\text { Uncultured archaeon } \\
\text { clone W5P2-E15 }\end{array}$ & $\begin{array}{l}\text { Archaea; } \\
\text { environmental } \\
\text { samples }\end{array}$ & 97 & $\begin{array}{l}\text { Direct Submission } \\
\text { Submitted (04- } \\
\text { SEP-2009) } \\
\text { Eastern Cereal \& } \\
\text { Oilseed Research } \\
\text { Centre, } \\
\text { Agriculture \& } \\
\text { Agri-Food } \\
\text { Canada, 960 } \\
\text { Carling Ave., } \\
\text { Ottawa, ON K1A }\end{array}$ & GQ871419 \\
\hline H01_1 & 854 & $\begin{array}{c}\text { Uncultured } \\
\text { crenarchaeote }\end{array}$ & $\begin{array}{l}\text { Archaea; } \\
\text { Crenarchaeota; } \\
\text { environmental } \\
\text { samples }\end{array}$ & 97 & $\begin{array}{l}\text { Environ. } \\
\text { Microbiol. } 4 \text { (10), } \\
603-611 \text { (2002) }\end{array}$ & AJ496176 \\
\hline
\end{tabular}

Tab. 4.12: Blast-Analyse der Archaeen-DGGE.

\begin{tabular}{|c|c|c|c|l|l|}
\hline Sequenz & Phylum & Kategorie & \multicolumn{1}{c|}{ Ordnung } & \multicolumn{1}{c|}{ Familie } & \multicolumn{1}{c|}{ Genus } \\
\hline A01_1 & Crenarchaeota & Thermoprotei & Desulfurococcales & Pyrodictiaceae & Pyrolobus \\
\hline A01_2 & Crenarchaeota & Thermoprotei & Desulfurococcales & Pyrodictiaceae & Pyrolobus \\
\hline D01_1 & Crenarchaeota & Thermoprotei & Desulfurococcales & Pyrodictiaceae & Pyrolobus \\
\hline G01_1 & Crenarchaeota & Thermoprotei & Desulfurococcales & Pyrodictiaceae & Pyrolobus \\
\hline H01_1 & Crenarchaeota & Thermoprotei & Desulfurococcales & Desulfurococcaceae & Ignisphaera \\
\hline
\end{tabular}

Tab. 4.13: RDP-Classifying der Archaeensequenzen. 


\subsubsection{Heuschreckenfraß}

4 Ergebnisse

Im Hochsommer wurde augenfällig, dass besonders an den schwarzen Apothecien von Psora luridella starke Fraßspuren auftraten. Es gelang leider nicht, den Verursacher in flagrante delicto zu beobachten. Da aufgrund der Größe der Spuren nur Heuschrecken in Frage kamen, wurde ein Fraßexperiment durchgeführt. Die Ergebnisse sind in Tabelle 4.14 aufgeführt.

\begin{tabular}{|l|l|l|l|}
\hline & Art & abgelehnt & gefressen \\
\hline 1. & $\begin{array}{l}\text { Gampsodeis } \\
\text { sedakovii }\end{array}$ & $\begin{array}{l}\text { Achillea, Potentilla, Vicia, Artemisia, } \\
\text { Fisch, tote und lebende Primnoa primnoa, } \\
\text { Psora-Kruste, Cladonia-Kruste }\end{array}$ & Kartoffelschalen \\
\hline 2. & $\begin{array}{l}\text { Calliptamus } \\
\text { abbrivatus }\end{array}$ & $\begin{array}{l}\text { Psora-Kruste, Cladonia-Kruste, } \\
\text { Kartoffelschalen }\end{array}$ & Achillea, Potentilla, Vicia, Artemisia \\
\hline 3. & $\begin{array}{l}\text { Primnoa } \\
\text { primnoa }\end{array}$ & $\begin{array}{l}\text { Psora-Kruste, Cladonia-Kruste, } \\
\text { Kartoffelschalen }\end{array}$ & Achillea, Potentilla, Vicia, Artemisia \\
\hline 4. & $\begin{array}{l}\text { Primnoa } \\
\text { primnoa }\end{array}$ & $\begin{array}{l}\text { Psora-Kruste, Cladonia-Kruste, } \\
\text { Kartoffelschalen }\end{array}$ & Achillea, Potentilla, Vicia, Artemisia \\
\hline 5. & Arcyptera fusca & Kartoffelschalen & $\begin{array}{l}\text { Achillea, Potentilla, Vicia, Artemisia, } \\
\text { Psora-Kruste, Cladonia-Kruste }\end{array}$ \\
\hline 6. & $\begin{array}{l}\text { Chorthippus } \\
\text { fallax }\end{array}$ & $\begin{array}{l}\text { Achillea, Potentilla, Vicia, Artemisia, } \\
\text { Fisch, tote und lebende Primnoa primnoa, } \\
\text { Psora-Kruste, Cladonia-Kruste, } \\
\text { Kartoffelschalen }\end{array}$ & $\begin{array}{l}\text { - (wurde deshalb vor Ablauf der Zeit } \\
\text { freigelassen) }\end{array}$ \\
\hline 7. & $\begin{array}{l}\text { Celes } \\
\text { skabzubovii } \\
\text { tuberculatum }\end{array}$ & $\begin{array}{l}\text { Psora-Kruste, Cladonia-Kruste } \\
\text { Psora-Kruste, Cladonia-Kruste }\end{array}$ & Achillea, Potentilla, Vicia, Artemisia, \\
\hline Psora-Kruste, Cladonia-Kruste & Achillea, Potentilla, Vicia, Artemisia, \\
\hline
\end{tabular}

Tab. 4.14: Nahrungsspektrum der gefangenen Heuschreckenarten

Eine weitere Art der Gattung Tetrix, die in Verdacht steht, sich von Flechten zu ernähren, konnte nicht gefangen werden. 


\section{Diskussion}

\subsection{Diskussion der Einzelergebnisse}

\subsubsection{Standorte Biologischer Bodenkrusten und abiotische Faktoren}

Biologische Bodenkrusten kommen meistens unter extremen Klima- und Lichtbedingungen vor, so sind sie meistens in ariden oder semiariden Klimaten, beziehungsweise in lokal ariden Mikrohabitaten anderer Klimazonen zu finden (Büdel, 2001). Letzteres ist auch für die in dieser Arbeit untersuchten Standorte der Fall. Die Mongolei gehört der borealen Nadelwaldzone der kaltgemäßigten Klimazone an. In Untersuchungsgebiet in der nördlichen Mongolei wurden Biologische Bodenkrusten so nur an unbewaldeten Süd-, z.T. auch an Ostund Westhängen gefunden. Im Tal oder auch auf Bergkämmen waren sie nicht zu finden. Dies deckt sich mit Beobachtungen aus Deutschland, wo BSCs oft an sog. Trockenrasenstandorten oder auch Xerothermfluren als Lückenbesiedler auftreten. Hier nennt man sie auch „Bunte Erdflechtengesellschaften“ (Fulgensietum fulgentis), welche folgend als „BEG“ abgekürzt wird. Die in der Mongolei gefundenen Arten decken sich hierbei nicht mit den Kennarten der BEG, weisen aber viele ökologische und phylogenetische Gemeinsamkeiten auf, was im Kapitel über die Morphologie von BSCs näher beleuchtet werden soll. Dass die Xerothermrasen in Deutschland vergleichsweise jung sind, kann man daran erkennen, dass es laut Nagel (1975) keinerlei sub- oder semispezifischen Differenzierungen unter von ihm untersuchten Insektenarten gibt, die sich auf diese Gebiete beschränken. Ellenberg (1996) nimmt an, dass sich dieses auch auf die meisten Phanerogamen und Kryptogamen übertragen lässt. Er geht auch davon aus, dass die BEG Stellen besiedelt, die durch Erosion oder Viehtritt unbesiedelt sind, nennt also ganz klar anthropogene Einflüsse als Ursachen des Wachstums von BSCs. Für die Entstehung und die Erhaltung der Xerothermrasen selbst nimmt er ebenfalls einen sehr großen Anteil anthropogener Einflüsse an, wobei deren Ausprägung durch klimatische und edaphische Faktoren beeinflusst wird. Besonderen Stellenwert misst er der Gründigkeit des Bodens bei. 
5 Diskussion

Für die Gebirgstrockensteppenstandorte des Khentej nehmen Dulamsuren et al. (2005) hingegen an, dass diese natürlich waldfrei sind. Dieses wird dadurch begründet, dass sich die Vegetation der Übergangsstandorte zwischen bewaldeten und unbewaldeten Flächen von diesen und diese untereinander so stark unterscheiden, dass angenommen wird, dass diese durch eine Kombination natürlicher Faktoren wie geringe Wasserverfügbarkeit und hohe Bodentemperaturen entstanden sind. Außerdem merken die Autoren an, dass der anthropogene Einfluss im westlichen Khentej gering sein dürfte, weil dieses Gebiet traditionell von nomadischen Viehhaltern eher gemieden wurde und bis heute werde, da der Druck durch Großraubtiere wie dem Europäischen Braunbären (Ursus arctos arctos) und dem Eurasischen Wolf (Canis lupus lupus) zu groß sei, um eine ertragreiche Tierhaltung zu betreiben.

Die nordostasiatischen Steppen gehören zu den klimatisch extremsten Habitaten der borealen Zone. Die untersuchten Südhänge in der Mongolei zeigen, wie in Abbildung 4.1 zu sehen ist, eine merklich höhere (in diesem Fall kumulierte) Temperatur als die bewaldeten, aber auch unbewaldeten Vergleichsstandorte nördlicher Exposition. Auch Vipper (1968) stellte für ähnliche Standorte in Nordostasien neben einer größeren Sonneneinstrahlung höhere Sommertemperaturen fest. Dulamsuren und Hauck (2008) haben die Mikroklimate zweier südexponierter Hänge miteinander verglichen und dabei neben der photosynthetisch nutzbaren Strahlungsmenge und der Temperatur noch die Präzipitation gemessen. Sie fanden heraus, dass die photosynthetisch aktive Strahlung sich an verschiedenen waldfreien Hängen durchaus voneinander unterscheidet und die Bodentemperatur stark vom Vegetationstyp abhängt. Der Boden, gemessen in einem Zentimeter Tiefe war in der offenen Steppe am wärmsten. Dort wurden Maximaltemperaturen von $58^{\circ} \mathrm{C}$ gemessen. Die relative Feuchtigkeit unterschied sich zwischen den untersuchten Standorten nicht wesentlich.

Diese Ergebnisse werden durch die in den Abbildungen 4.3 bis 4.5 dargestellten Erkenntnissen ergänzt, wo nach sich die Bodenoberflächentemperaturen kleinräumig sehr stark unterscheiden können. So sieht man häufig innerhalb eines 50 x $50 \mathrm{~cm}$ umfassenden Quadrates Unterschiede von über $20^{\circ} \mathrm{C}$. Zum Verständnis dieser Ergebnisse ist es wichtig, dass Bodenoberflächentemperaturen durchaus auch auf BSCs genommen wurden, da es darum ging, die direkt auf sie einwirkende Temperatur zu erfassen. Wie auch Quin et al. (2005) feststellten, können sich diese Temperaturen noch wesentlich von denen unbedeckten Bodens unterscheiden. Sie untersuchten die Oberflächentemperaturen durch 
5 Diskussion

satellitengestützte Analysen in einem Wüstengebiet und stellten für Gebiete, die stark mit BSCs bewachsen waren eine durchschnittlich um $3{ }^{\circ} \mathrm{C}$ höhere kinetische Oberflächentemperatur fest als für jene, die nicht bewachsen waren.

Der Vergleich der bodenchemischen Parameter (siehe Abbildungen 4.6 und 4.7 und Tabelle 4.1) ergab keine sehr großen Unterschieden der verschiedenen BSC-Standorte. Der in wässriger Bodensuspension gemessene $\mathrm{pH}$ wurde durch die zwischen den Bodenaustauschern und der Bodenlösung im Gleichgewicht befindlichen wasserlöslichen Säuren (Mineralsäuren und organische Säuren) und $\mathrm{pH}$-neutral reagierenden Kationen bestimmt. Die direkte Wirkung von Protonen auf das Wachstum verschiedener Organismen ist einerseits artspezifisch sehr unterschiedlich und hat andererseits in der Regel erst bei pH-Werten unter 3,8 direkten Einfluss auf die Nährstoffaufnahme durch die Wurzeln. Es werden aber viele chemische und biologische Bodenprozesse durch den $\mathrm{pH}$ beeinflusst wie z.B. die Löslichkeiten verschiedener Kationen. So ist beispielsweise die Verfügbarkeit von Eisen und Mangan im neutralen bis schwach sauren Milieu wegen mangelnder Wasserlöslichkeit stark reduziert. In stärker sauren Böden wäre die Verfügbarkeit von Magnesium, Calcium und teilweise Phosphat behindert, außerdem nähme unter diesen Bedingungen die Konzentration potentiell toxischer Elemente wie Aluminium, Eisen und Mangan stark zu. Auch das Kohlenstoff/Stickstoff-Verhältnis und besonders die überwiegende Stickstoffform (im sauren Milieu ist das $\mathrm{NH}_{4}^{+}$) stark pH-abhängig. Wie in Abbildung 6.6 zu sehen ist, bewegen sich die pH-Werte an den verschiedenen BSC-Standorten im Bereich 6,9 bis 7,8, also im neutralen Bereich, an Standort $\mathrm{H}$ und I sind die $\mathrm{pH}$-Werte geringfügig höher als an den übrigen Standorten.

Der $\mathrm{pH}_{\mathrm{H} 2 \mathrm{O}}$ gibt die Azidität der Bodenlösung wieder, so wie ihr die Pflanze, die Flechte, Alge oder Bakterium unter natürlichen Bedingungen ausgesetzt ist. Die Zugabe von $\mathrm{KCl}$ dagegen bewirkt, dass an die mineralischen oder organischen Austauscher gebundene Protonen oder Al-Ionen abgelöst werden und in die Bodenlösung übergehen, wo sie direkt oder indirekt pHwirksam werden und somit der $\mathrm{pH}_{\mathrm{KCl}}$ ein $\mathrm{Maß}$ für die potentielle Azidität des Bodens darstellt. Wie man in Abbildung 4.7 sehen kann, ist bei den beiden Standorten mit den höchsten $\mathrm{pH}-$ Werten die Absenkung des $\mathrm{pH}$-Wertes durch Zugabe von $\mathrm{KCl}$ am geringsten, hier ist also die potentielle Azidität geringer.

Auch die maximale Wasserhaltekapazität der Böden unterscheidet sich nicht sehr stark, wie man in Tabelle 4.1 sehen kann. Die maximale Wasserhaltekapazität der organischen 
Bestandteile des Bodens (WHK $\mathrm{Wax}_{\max }$ ) hängt von der Weite der Poren (Verdichtungsparameter) und somit auch von der Korngröße ab. Je feinkörniger das Material, umso größer kann die aufgenommene und gehaltene Wassermenge sein (Bossel, 1997). Durchaus interessant sind die Unterschiede, die an verschiedenen Stellen eines Standortes gemessen wurden. So nimmt die $\mathrm{WHK}_{\max }$ an Standort A von oben nach unten ab. Dieses ist vermutlich dadurch bedingt, dass die Erosion (Abschwemmung und Herunterfallen von Material) dafür gesorgt hat, dass weiter unten das Substrat stärker verdichtet ist und somit weniger Wasser aufnehmen kann. Die Werte von Standort F (Schatten und Sonne) unterscheiden sich nicht, wohingegen der Ost- und der Westhang von Berg G geringe Unterschiede zeigten. Am Westhang war die Wasserspeicherungskapazität etwas höher, was ebenfalls mit verändertem Erosionsdruck durch Regen und Regenschatten zusammenhängen kann.

Das C/N-Verhältnis eines Bodens stellt einen Indikator für die Bodenfruchtbarkeit dar. Es lässt auf die Verfügbarkeit von Stickstoff im Boden schließen, je kleiner die Zahl ist, desto besser ist die Stickstoffverfügbarkeit. Über dieses Verfahren kann auch der Humfizierungsgrad eines Bodens bestimmt werden. Bei der Zerstzung wird $\mathrm{CO}_{2}$ freigesetzt und Stickstoff zu einem großen Teil in die mikrobielle Biomasse eingebaut. Dadurch wird das C/N-Verhältnis kleiner, was für eine fortgeschrittene Humifizierung spricht. Wie in Tabelle $4.1 \mathrm{zu}$ sehen ist, liegen die Werte der untersuchten Standorte Biologischer Bodenkrusten relativ nah beieinander. Merklich höher ist nur der C/N-Wert für den Standort

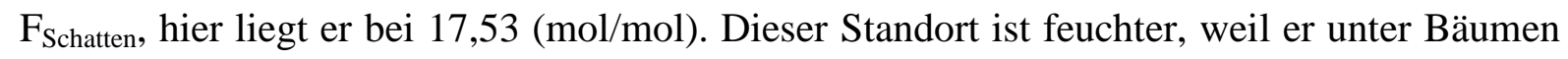
liegt und die Erde zum Teil mit einer Streuschicht bedeckt ist. Dieses fördert die Humifizierung. Referenzwerte für das C/N-Verhältnis sind: etwa 11 für Grünland, etwa 14 für Ackerboden und für Wälder etwa 28-50 (Scheffer und Schachtschabel, 1984). Liengen und Olsen (1997) stellten fest, dass die Stickstoffixierung von Cyanobakterien positiv mit dem C/N-Verhältnis korreliert ist. 


\subsubsection{Vergleichende Morphologie Biologischer Bodenkrusten}

\subsubsection{BCS-Organismen}

Viele der in den BSCs gefundenen Flechtenarten besitzen eine große ökologische und geographische Amplitude. So ist beispielsweise Cladonia pyxidata (L.) Hoffm. in BSCs eines eher sauren Sandstandortes in Brandenburg (Hoppert et al., 2004), an carbonatreichen alpinen Standorten (Türk und Gärtner, 2001), in Artemisia-Steppen in Idaho (Kaltenecker und Wicklow-Howard, 1994) und einem steppenählichem Graslandhabitat in British Columbia (Marsh et al., 2006) gefunden worden. Für Psora luridella (Tuck.) Fink. wurden als Fundorte beispielsweise Colarado, New Mexico, Nevada und Utah angegeben (St. Clair et al., 1993), auch in Idaho wurde sie gefunden (Kaltenecker und Wicklow-Howard, 1994). Außerhalb von Nordamerika wird sie als Bestandteil Biologischer Bodenkrusten nicht erwähnt. Diploschistes muscorum (Scop.) R. Sant. hingegen kommt in BSCs weltweit vor. Sie ist für die Alpen (Türk und Gärtner, 2001), New South Wales in Australien (Eldridge, 1996), Oregons Gebüschsteppen (Ponzetti und McCune, 2001) und der Inneren Mongolei (Zhang, 2005) gefunden worden. Sie ist ebenso Bestandteil der BEG in Deutschland (Büdel, 2005). Catapyrenium lachneum (Ach.) R. Sant. ist in BSCs an carbonatreichen Standorten der Alpen (Türk und Gärtner, 2001), in Artemisia-Steppen in Idaho (Kaltenecker und WicklowHoward, 1994), New South Wales in Australien (Eldridge, 1996) und sogar an einem hochgelegenen äquatorialen Andenstandort (Pérez, 1997) und in Grönland (Hansen, 2001). Neben den Funden in Asien (Büdel, 2001b; Holst et al., 2009, Hauck et al., 2007, Guilan et al., 1995)) wurde Xanthoparmelia camtschadalis (Ach.) Hale noch in Nordamerika (Rosentreter und Belnap, 2001) gefunden. Peltigera lepidophora (Vain.) Bitter kommt in BSCs der Alpen (Türk und Gärtner, 2001), in British Columbia (Marsh et al., 2006) und Grönland (Hansen, 2001) vor, zeigt also eine Präferenz für kältere Gebiete. Heppia lutosa (Ach.) Nyl. zeigt hingegen eher ein verstärktes Auftreten in Hitzewüsten und heißen Steppengebieten, so wurde sie in BSCs in Australien (Eldridge und Koen, 1998), Idaho (Kaltenecker und Wicklow-Howard, 1994), Südafrika (Büdel et al., 2009) und in der Chihuahua-Wüste in Mexiko (Housman et al., 2006) gefunden. Collema tenax (Sw.) Ach. hat ihren Verbreitungsschwerpunkt in BSCs in den nordamerikanischen Wüstengebieten. Sie wurde vornehmlich in den Wüsten des Colorado-Plateaus, aber auch in der Negev-Wüste in Israel (Eldridge et al., 2000) und in den Alpen (Türk und Gärtner, 2001) gefunden. 
5 Diskussion

Es gibt im Untersuchungsgebiet etwas mehr Grünalgenflechtenarten als Cyanobakterienflechtenarten. Lange (2003) erklärt das Vorkommen von beiden damit, dass Grünalgenflechten besser Tau als Wasserquelle nutzen können und sogar allein mit höher Luftfeuchtigkeit und ohne einen Tropfen Wasser ihren Stoffwechsel reaktivieren können, während Cyanobakterienflechten Niederschläge benötigen. Beide können allerdings länger im ausgetrockneten Zustand überdauern. Da die Untersuchungen für diese Arbeit größtenteils in den regenreichen Monaten Juni bis August stattfanden, ist es nicht verwunderlich, dass auch viele aktive Cyanobakterienflechten gefunden wurden. Tabelle 4.2 zeigt die Standortansprüche einiger häufiger Flechtenarten. Auffällig sind die Hinweise auf kalk- oder basenreiche Böden und die hohen Lichtansprüche der meisten Flechten. Die Ansprüche an die Feuchtigkeit des Substrates schwanken allerdings, so benötigen die Collema-Arten einen feuchteren Standort. Einerseits können sie aber, wie oben erwähnt, ihr Wachstum hauptsächlich auf die Sommermonate konzentrieren, außerdem könnten sie von den anderen BSC-Organismen profitieren. Dieser Punkt wird unten noch detaillierter diskutiert werden.

Moose haben einen noch höheren Wasserbedarf als Flechten (Lange, 2003). Die im Untersuchungsgebiet in BSCs vorkommenden Moose besitzen allerdings Anpassungsmechanismen an die häufige Trockenheit und starke Strahlung. Hierbei sind die Strategien, der Moose eher passiver Art, d.h. sie meiden oder tolerieren Austrocknung (Frey und Kürschner, 1998), statt sich aktiver Mechanismen wie ausgeprägter Sukkulenz zu bedienen. Die Lebermoosgattung Riccia zum Beispiel rollt bei Trockenheit die Thalli ein, um sie nach Wiederbefeuchtung nach kürzester Zeit wieder auszurollen und photosynthetische Aktivität aufzunehmen. Die Einrollung der Thalli verzögert auch die Austrocknung (Frey und Kürschner, 1998). Außerdem zeigt das Lebermoos eine Vorstufe von Sukkulenz. Die schmalen Thalli sind dick und besitzen ein Wasserspeichergewebe. Im „Trockenschlaf“ können sie bei nahezu still gelegtem Stoffwechsel mehrere Jahre überdauern. Riccia wird häufig in Australien gefunden (z.B. Eldridge und Koen, 1998), aber auch in der israelischen Negev-Wüste (Shem-Tov et al., 1999) und an Präriestandorten in Idaho wurde sie nachgewiesen (Bowker et al., 2004). Das Laubmoos Bryum argenteum ist ubiquitär verbreitet. In BSCs wird es häufig in der Inneren Mongolei (z.B. Zhang, 2005), aber auch in anderen Wüstengebieten weltweit gefunden (Eldridge und Koen, 1998; Kaltenecker und Wicklow-Howard, 1994; Ponzetti und McCune, 2001). Bryum argenteum ist an trockene Standorte mit hoher Strahlung angepasst. Bei Austrocknung sterben die äußeren Zellen ab und dienen nun als Isolationsschicht, wobei die Zellen Luft enthalten. Diese brechen das 
5 Diskussion

einfallende Licht. So ist auch das silbrig glänzende Aussehen des Mooses zu erklären. Tortula ruralis scheint in BSCs seinen Verbreitungsschwerpunkt in Nordamerika zu haben (Bowker, 2007, Hilty et al., 2004). Dieser Eindruck kann aber auch täuschen, denn aus den USA sind einfach sehr viel mehr Studien über die Zusammensetzung von BSCs bekannt als aus anderen Gebieten. Das auch in Deutschland häufige Moos besitzt Glashaare, mit Hilfe derer es eine hohe Toleranz gegenüber Austrocknung und hohe Temperaturen gewinnt. Das Glashaar fungiert hierbei als Reflektionspunkt für die Strahlung, außerdem kann das Moos hierüber bereits ab 30 \% relativer Luftfeuchte Wasserdampf aufnehmen (Strasburger, 2002). Außerdem schaffen Glashaare rund um das Moos einen windstillen Raum; dadurch wird die Verdunstung um 20-30 \% gesenkt (Proctor, 1982).

Interessanterweise scheinen BSC-Organismen öfters zwar in unterschiedlichen Spezies, aber mit einer Kombination aus vergleichbaren Gattungen aufzutreten, so ist für die Gurbantunngut-Wüste in der Inneren Mongolei berichtet worden, dass dort Diploschistes muscorum neben Collema tenax, Psora decipiens, Xanthoparmelia desertorum, Tortula desertorum, Bryum argenteum und Tortula muralis vorkommen (Zhang, 2005).

\subsubsection{BCS-Typen}

\subsection{2.1 Sukzession}

Als Klimaxstadium wird das jeweilige Endstadium der natürlichen Vegetationsentwicklung für eine Vegetationseinheit entsprechend ihrer Klima- und Bodenbedingungen bezeichnet (Ellenberg, 1996). Im Ursprung wird die Klimaxhypothese auf Pflanzengesellschaften angewendet, soll aber im Rahmen dieser Arbeit analog auf Artenzusammensetzungen biologischer Bodenkrusten verwendet werden. Um Aussagen über die Stellung der verschiedenen Typen von BSCs innerhalb einer möglichen Sukzessionsreihe zu treffen, wurden ein Initialstadium (I), ein mittleres Stadium (M) und ein Klimaxstadium (K), sowie deren Übergangsstadien angenommen (siehe Tabelle 4.3). Man weiß inzwischen, dass die Entwicklung Biologischer Bodenkrusten mit der Ansiedlung von Cyanobakterien beginnt, während sich Grünalgen, Moose und Flechten später erst einfinden. Die Fähigkeit von Cyanobakterien wie Microcoleus sp. zur gleitenden Bewegung und ihre Toleranz gegen hohe 


\section{Diskussion}

Temperaturen, Strahlung und Trockenheit spielen bei der Ausbreitung eine große Rolle (Friedmann und Galun, 1974; Belnap, 1993). Man weiß außerdem, dass sie Polysaccharide produzieren, die von heterotrophen Organismen als Substrat genutzt werden können und diese auch in gewissem Maße vor schädlichen Umwelteinflüssen wie zum Beispiel Austrocknung bewahren können; durch ihre starke Quellbarkeit sind sie in der Lage, innerhalb von kurzer Zeit viel Wasser aufzunehmen und einige Zeit zu speichern (Hoppert et al., 2004; Kemmling et al., 2004). Diese Polysaccharide stabilisieren außerdem die Erdoberfläche gegen Verwehung und Abschwemmung des Substrats (Evans und Johansen, 1999). Die als Pioniere siedelnden Cyanobakterien reichern außerdem den Boden mit für das Wachstum höherer Organismen essentiellen Mineralen an (Harper und Pendleton, 1993) und manche von ihnen sind in der Lage Luftstickstoff $\mathrm{zu}$ fixieren und erhöhen damit die Fruchtbarkeit des Bodens, was wiederum die Ansiedlung von höheren Organismen an manchen Standorten erst möglich macht (Metting, 1981). Freie Cyanobakterien zeigen außerdem wie Grünalgenflechten die Fähigkeit, ohne Niederschlag bei sehr hohen Luftfeuchtigkeiten Photosynthese zu betreiben (Mazor et al., 1996) und somit Biomasse für die Entstehung eines Ökosystems zu erzeugen. Zusammen mit den austrocknungsverzögernden Eigenschaften ihrer Polysaccharidscheiden macht sie dieses zu guten Erstbesiedlern arider Standorte.

Die weitere Sukzession von BSCs wird durch physikalische Einflüsse wie Bodenstruktur, Strahlungsstärke, topographische Faktoren wie die Exposition und Inklination und die Wasserverfügbarkeit beeinflusst (West, 1990). Mit der Zeit bildet sich eine Mikrozonierung aus, es können anaerobe Zonen entstehen, die auch anaeroben Organismen Möglichkeiten geben, sich anzusiedeln und Aufgaben in der komplexen Ökologie der Bodenkrusten zu übernehmen (z.B. Garcia-Pichel und Belnap, 1996). Die organismische Diversität nimmt allgemein zu.

Moose benötigen für ihr Wachstum ein (z.B. durch Cyanobakterien) stabilisiertes Substrat, da ihr Lebenszyklus mit der Sporenkeimung und eines sich daraus entwickelnden Protonemageflechtes beginnt (Scott, 1982), was ihm Rahmen dieser Arbeit bei der Anzucht auf Festmedien oft zu beobachten war. Dieses Protonema ist sehr zerbrechlich und eine Bewegung des Substrates würde es beschädigen und das Wachstum verzögern. Die Entwicklung eines Flechtenthallus muss unter noch definierteren Bedingungen stattfinden. So darf die Feuchtigkeit nicht zu groß, aber auch nicht zu niedrig sein (Schwendener, 1872) und 
5 Diskussion

die Nährstoffkonzentration sollte ebenfalls in einem relativ engen und eher niedrigen Toleranzbereich liegen (Geitler, 1933, 1934, 1937, 1938). Die Standorteinflüsse müssen hier sowohl mit den Ansprüchen des Photobionten wie auch des Mykobionten korrespondieren. Die sexuelle Reproduktion ist nur dem Mykobionten möglich und erfolgt über Sporen. Der Mykobiont ist dann darauf angewiesen, den Algenpartner vor Ort zu finden. Die vegetative Vermehrung der Flechten erfolgt über Isidien oder Soredien. Hierbei werden diese vegetativen Vermehrungseinheiten verbreitet, die dann über die Stufe der Prothalli zu Thalli auswachsen können. Es ist anzunehmen, dass für diesen Prozess die physikochemischen Voraussetzungen nicht ganz so streng sind wie bei der von Geitler beschrienenen Lichenisierung, ein stabilisiertes Substrat dürfte jedoch auch hier Voraussetzung sein, zumal das Wachstum sehr langsam stattfindet.

Die Einteilung der BSC- Typen in die verschiedenen Sukzessionsklassen (siehe Tabelle 4.3) erfolgte unter Berücksichtigung dieser Annahmen. Die erste Initialstufe, die reine Algenkruste war sehr dünn und vor allem in trockenem Zustand nur schwer auszumachen. Häufiger gefunden wurden Algenkrusten mit einem Moosanteil. Wie oben erwähnt wurde, benötigen Moose zum Siedeln ein stabilisiertes Substrat. Trotzdem wurde dieser Typ den Initialkrusten zugeordnet, weil er häufig an gestörten Standorten auftrat (siehe auch nächste Kapitel). Auch Algenkrusten mit Moos und Collema coccophorum wurden an gestörten Standorten häufiger gefunden.

Der mikroskopisch detektierbare Algenanteil innerhalb einer BSC nahm tendenziell mit zunehmendem Sukzessionsgrad ab. Am Rand eines BSC-Patches wurden fast immer Algen gefunden, wenn nicht die Flechten oder Moose zu überhängendem Wuchs neigten. In der Mitte jedoch waren sie nur zu finden, wenn die Lücken zwischen den Moosen und Flechten groß genug waren, um Licht an die Erdoberfläche gelangen zu lassen, was vornehmlich bei Mischkrusten, die aus mindestens drei verschiedenen Flechten- und Moosarten mit verschiedenen Wuchsformen bestanden, der Fall war. Dies verdeutlicht noch einmal, dass Algen für die Art im Untersuchungsgebiet gefundener BSCs hauptsächlich als Primärbesiedler von Bedeutung sind. Auch das Wachstum von Sämlingen höherer Pflanzen scheint ähnlichen Regeln wie die Besiedlung mit Algen zu folgen. Sie benötigen einerseits für die Keimung ausreichend lange Feuchtigkeit, andererseits für das Wachstum auch genügend Licht. Krustenflechten mit geschlossener Oberfläche schließen sie außerdem vom Substrat ab. Die „gemischten Krusten“ sind nicht ganz einfach einer Sukzessionsklasse 
5 Diskussion

zuzuordnen. Einerseits sind sie artenreich, was einigen gängigen Definitionen über den Klimaxzustand entspricht, andererseits bieten sie auch Raum für Weiterentwicklung, was den Definitionen widersprechen würde. An diesem Beispiel verdeutlicht sich die generelle Problematik der Klimaxhypothese, zumindest wenn man diese $\mathrm{zu}$ eng versteht. Als praktikabel hat sich die Ergänzung von Remmert (1985) erwiesen, der postuliert, dass ein Klimaxzustand sich aus einem Mosaik verschiedener Gesellschaften zusammensetzt, die jeweils eigenen Zyklen unterworfen sind. Manche dieser Zyklen sind artenarm, manche sind artenreich. Andererseits ist es sehr unwahrscheinlich, dass sich ein Ökosystem tatsächlich in einem konstanten Gleichgewicht befindet, da es niemals gänzlich unbeeinflusst von verändernden Außenfaktoren bleibt. Es ist also anzunehmen, dass dieser Klimaxzustand eher ein theroretisches Konstrukt ist, auf das sich ein Ökosystem hinzu bewegen kann, den es aber niemals erreicht.

\subsection{Der Einfluss von Störung auf Biologische Bodenkrusten}

Anthropogene Störungen der Biologischen Bodenkrusten können durch Tritt, Beweidung, Luftverschmutzung, Herbizide oder durch Fahrzeuge auftreten. Besonders gefährdet sind sie an vielen Orten durch militärische Fahrzeuge, da viele Standorte auf Truppenübungsplätzen liegen. Nicht anthropogene Störungen treten durch Erosion durch Wind, Wasser und Gravitationsprozesse auf.

Die Störanfälligkeit der Bodenkrusten hängt von verschiedenen Faktoren wie Bodenbeschaffenheit, Klima und der Zusammensetzung der Kruste ab. Bodenkrusten sind im ausgetrockneten Zustand mehr in Gefahr, durch mechanische Störungen, welche aus der Einwirkung von Kompressions- und Scherkräften bestehen, beschädigt zu werden (Harper und Marble, 1988). Da die die BSCs bildenden Organismen nur in feuchtem Milieu metabolische Aktivität zeigen (Lange, 2001), ist eine Erholung der Kruste in ausgetrocknetem Zustand nicht möglich.

Störungen resultieren oft in einem Verlust des Artenreichtums, von der Bedeckung mit Bodenkrusten und Biomasse (Belnap und Eldrigde, 2001; Eldridge and Koen, 1998), wobei die letzten beiden Punkte die einzelnen Organismengruppen in unterschiedlichem Maße betreffen. Man konnte feststellen, dass Störungen eine Veränderung der Zusammensetzung 
bewirken, noch bevor Veränderungen der Biomasse oder Flächenbedeckung beobachtet wurden (Eldrigde, 1996). Die Erholungsraten nach einer Störung unterliegen ähnlichen Regeln, d.h. es kann eine Regeneration ausschließlich der feuchten Kruste stattfinden, sind aber in noch stärkerem Maße vom Klima abhängig. Hier sind die jährlichen durchschnittlichen Zeiten metabolischer Aktivität entscheidend, jedoch spielt auch hier die Zusammensetzung der Bodenkruste und die Art der Störung eine Rolle (Belnap und Eldridge, 2001). Es gibt, besonders für Australien und den Mittelwesten der USA zahlreiche Studien, die sich mit den Auswirkungen der Störung nicht nur auf die Funktion der Bodenkrusten und deren Physiologie, sondern auch mit ökologischen Prozessen wie dem Verlust der Bodenstabilisierung und auf hydrologische Prozesse beschäftigen (Eldridge, 2001; Warren, 2001; Belnap, 1993 und 2001b). Die Regenerationsfähigkeit der BSCs variierte hier mit der Art und Jahreszeit und der organismischen Zusammensetzung.

Die in Abbildung 4.36 dokumentierte Störung geschah im Juli und August, also in der feuchten Jahreszeit. Trotzdem waren ein Jahr danach dramatisch weniger BSCs zu finden (=Biomasseverlust). Es kann vermutet werden, dass die „natürlichen“ Störungen, die durch die Hanglage bedingt sind, also der erhöhte Erosionsdruck eine Wiederausbreitung der BSCs noch erschweren.

Eine Störung durch Feuer hat in erster Linie Verlust von Biomasse, Bedeckung und Artenreichtum zur Folge (Belnap, 2001b). Auch hier ist der Grad der Schädigung und die Regenerationsfähigkeit von der Zusammensetzung der Krusten abhängig und außerdem von der Zusammensetzung und Verbreitung der phanerogamen Vegetation, der Feuerintensität und der Häufigkeit der Brände (Hawkes und Flechtner 2002; Johansen et al., 1982, 1993 und 2001). Bowker et al. (2003) fanden im östlichen Oregon in einer Prärielandschaft, die regelmäßig von weniger intensiven natürlichen Feuern betroffen ist, BSCs, die durch diese Feuer wenig beeinträchtigt werden. Ihre Zusammensetzung aus Moosen und Flechten war ein Jahr nach dem Brand ähnlich wie zuvor, ihre Biomasse war allerdings geringer. Außerdem wurde - wahrscheinlich dadurch bedingt - ein Verlust der Bodenoberflächen-stabilität festgestellt. Es wird vermutet, dass die BSCs nur deswegen relativ wenig beeinträchtigt werden weil die Feuer nicht sehr intensiv sind, da zwischen ihnen wenig höhere Pflanzen wachsen, die dem Feuer Nahrung geben könnten. 
Es reagieren nicht alle Kryptogamenarten gleich auf Störungen. Johansen (1994) demonstrierte, dass die Cyanoflechte Collema tenax und das Moos Pterygeneurum ovatum bereits zwei Jahre nach einem Wildfeuer wieder vollständig hergestellt waren. Dies führten sie auf die häufige Sporenproduktion des Mooses und die asexuelle Vermehrungsstrategie der Flechte durch Wind- und Wasserverbreitung von Thallusbruchstücken zurück. Eldridge und Rosentreter (1999) schlugen darauf hin ein Denkmodell vor, nachdem mit dem Komplexitätsgrad einer Flechte ihre Fähigkeit zur Regeneration abnimmt. Des Weiteren seien Flechten im Vorteil, die neben der sexuellen Vermehrung auch noch die Möglichkeit der vegetativen Reproduktion besäßen. Dieses Modell würde Cyanobakterien und Cyanoflechten als gut regenerationsfähig ansehen, Moose, Lebermoose und Krustenflechten wären mäßig regenerationsfähig und Strauch- und Laubflechten seien durch Störung stärker gefährdet.

Dieses Denkmodell kann durch eigene Erkenntnisse gestützt werden. Der Standort Berg H ist sehr steil und exponiert, es sind viele Spuren wetterbedingter Erosion wie Einbrüche und Hangrrutschungen zu finden. Die Pflanzenbedeckung ist wie die Bedeckung mit BSCs sehr gering. Hier wurden ausschließlich Collema und weniger Catapyrenium lachneum (eine Krustenflechte) sowie Moos gefunden. Berg G hingegen liegt wie Berg $F$ hinter einem Waldgebiet. Er ist nicht ganz so steil, dürfte aber wegen der Lage zwischen zwei Bergrücken und der mangelnden Attraktivität seiner phanerogamen Bedeckung von Pferden nicht besonders häufig frequentiert werden. Pferde meiden - wenn möglich - schlecht zu überblickendes Terrain, weil sie dort gegenüber ihren Prädatoren stark im Nachteil sind. Von allen untersuchten Standorten waren Xanthoparmelia- Arten (eine komplexe Laubflechte) nur hier häufig. Die anderen untersuchten Standorte lagen zwischen den beiden beschriebenen. Meist waren hier Psora und Cladonia dominant, aber auch Collema wurde häufig gefunden. Es war aber auch erkennbar, dass letzteres eher an kürzlich gestörten Stellen zutraf. 


\subsubsection{Der Einfluss verschiedener Standortfaktoren auf das Auftreten Biologischer Bodenkrusten und ihre Zusammensetzung}

\subsubsection{Abiotische Faktoren}

Die hier untersuchten abiotischen Faktoren sind im Wesentlichen die Exposition und die Inklination. Die Feuchtigkeit und die Temperatur konnten nicht direkt bestimmt werden. Wenn man die von Vipper (1953) geäußerte These zugrunde legte, dass die Feuchtigkeit mit dem Abstand zum Bergrücken abnimmt und die Temperatur zunimmt, sind diese Faktoren im gemessenen „Abstand zum Bergrücken“ enthalten. Auch die Wölbung ist indirekt ein Maß für die Wasserverfügbarkeit, da diese die Abflussgeschwingigkeit des Wassers stark beeinflusst.

Für die Artemisia frigida- GTS konnte eine schwache Korrelation zwischen der Entfernung vom Bergrücken und der Anzahl der Kryptogamenarten gefunden werden. Dieser Zusammenhang ist schwach und allenfalls als Hinweis zu sehen, da er für die anderen Vegetationstypen fehlt.

Die Wölbung schien keinen Einfluss auf Auftreten und Zusammensetzung von BSCs zu haben.

Die Exposition und die Inklination zeigen jeweils eine ebenfalls schwache Korrelation mit der Anzahl der Kryptogamenarten (siehe Abbildungen 4.32 und 4.33). Durch die Wahl einer polynomischen Ausgleichskurve, die durch die radiale Natur der Daten notwendig ist, sieht man ein Minimum der Artenzahlen bei $180^{\circ}$. Die Korrelation ist aber auch hier aufgrund der starken Streuung sehr klein.

Auf Abbildung 4.34 kann man sehen, dass es zumindest optisch einen Hinweis darauf gibt, dass um 180 bis $200^{\circ}$ die Artenzahlen geringer sind. Große Blasen (= große Artenzahlen) kommen hingegen um 220 und $280^{\circ}$ vor. Dieses wäre darauf zurückzuführen, dass bei von Süden abweichenden Expositionen auch weniger photo- und thermotolerante Kryptogamenarten vorkommen können. 
Andere Studien haben für ähnliche Standorte festgestellt, dass das Mikroklima und insbesondere Temperatur einmal direkt und indirekt über die mikroklimatische Veränderung von Bodenparametern phanerogame und kryptogame Vegetation beeinflussen (z.B. Becker, 1999 für Xerothermrasen in Sachsen-Anhalt). Auch der Wind hatte einen Einfluss auf die Trockenheit der Standorte, die ihrerseits wieder die Vegetation beeinflusste.

\subsubsection{Biotische Faktoren}

Zahlreiche Untersuchungen, welche meist im Kontext der Fragestellungen zur Desertifikation stehen, belegen, dass biologische Bodenkrusten oft einen entscheidenden Einfluss auf die Besiedlung arider Habitate mit Phanerogamen besitzen. So können sie z.B. durch Veränderung des Mikroreliefs die Keimwahrscheinlichkeit und die Überlebenschancen von Gräsern erhöhen (Eckert et al., 1986; Harper und Pendleton, 1993), sie können die Textur von Böden in ähnlichem Maße beeinflussen wie deren Chemie. Es wurden bislang Hinweise auf einen gewissen Einfluss der Bodenkrusten auf die Verhältnisse von Stickstoff, Kohlenstoff und organischen Materials gefunden (West, 1990; Belnap, 2001; Belnap und Harper, 1995). Die Krusten enthalten oft viele Expolysaccharidbildner. Die von ihnen oft in großer Menge ausgeschiedenen Polysaccharide (EPS) führen neben der allgemeinen Stabilisierung der Böden oft $\mathrm{zu}$ veränderten Verhältnissen in der Wasser- und Nährstoffzugänglichkeit, die auch Phanerogamen zu Gute kommt, wie sich daran zeigt, dass das Vorhandensein von Bodenkrusten oft positiv mit der Phytodiversität korreliert ist (z.B. Beymer und Klopatek, 1992). Dies ist allerdings nicht immer der Fall. In einigen Studien gab es auch eine negative Korrelation (z.B. Eldridge, 1993; Prasse, 1999). Man nimmt an, dass dies einerseits von der Pflanzenart und deren Keimungsverhalten, aber auch von der Mikrotopographie der Kruste abhängt. So waren die von Prasse (1999) beschriebenen BSCs sehr glatt und fest. Andere BSCs wirkten sich aufgrund der Schutzfunktion gegen Wind und Wasser eher förderlich auf die Samenkeimung aus (Beymer und Klopatek, 1992).

Der Einfluss der phanerogamen Vegetation auf biologische Bodenkrusten wird von einigen Autoren noch wesentlich stärker bewertet. BSCs treten an manchen Stellen nur auf, wenn eine Störung der höheren Vegetation deren Wachstum verhindert oder verzögert (z.B. Lukešová, 2001). Dies kann durch anthropogen bedingte temporäre Störungen ebenso wie 
durch ungünstige Standortverhältnisse (z.B. geringe Wasserverfügbarkeit als Niederschlag) bedingt sein. Als ein nahe liegender Grund wären die unterschiedlichen Wachstumsgeschwindigkeiten $\mathrm{zu}$ nennen. Gerade gegen einjährige Gräser sind Bodenkrusten, welche zur vollen Ausprägung oft Jahrzehnte benötigen, eindeutig im Nachteil. Ist die Krautschicht erst einmal etabliert, bleiben für das Krustenwachstum nur Vegetationslücken ausreichender Größe, da die Algenbestandteile der Krusten eine ausreichende Lichtmenge für eine effektiv betriebene Photosynthese benötigen.

Kuske et al. (2002) zeigten für drei Gräser, welche den invasiven Neophyten zugerechnet werden, dass diese jeweils einen unterschiedlichen Einfluss auf die Zusammensetzung der sie umgebenden Gemeinschaft der Bodenbakterien ausüben. Es ist nahe liegend anzunehmen, dass es einen derartig gerichteten Einfluss auch auf die Zusammensetzung der Bodenkrusten gibt, zumindest wenn diese Kontakt mit den BSCs haben. Diese Vermutung wird durch die von Stohlgren et al. (2001) gemachten Beobachtungen gestützt. Sie beschäftigten sich im Rahmen der Invasionsforschung mit Bodenkrusten und fanden heraus, dass bereits gestörte Krusten empfindlicher auf Invasoren reagieren, die mit diesen in direkte Konkurrenz um Siedlungsraum treten.

Die eigenen Ergebnisse können diese Erkenntnisse weder eindeutig stützen noch widerlegen, da auch hier die Streuung der Werte sehr hoch war. Für die Artemisia frigida-GTS wurde eine schwache negative Korrelation zwischen der prozentualen Pflanzenbedeckung und der Anzahl der Kryptogamenarten gefunden (siehe Abbildung 4.15), für die Artemisia frigidaPulsatilla ambigua-GTS ebenso (siehe Abbildung 4.18). Für die Pulsatilla ambigua-GTS allein deuteten die Ergebnisse nicht darauf hin (siehe Abbildung 4.22). Dieses Ergebnis lässt sich leicht verstehen. Je höher die Bedeckung mit Pflanzen, desto weniger Spielraum gibt es für die Kryptogamenentwicklung. Es können hier nur die Arten überleben, die mit den mit einer hohen Pflanzenbedeckung verbundenen Umständen (Beschattung, verändertes Mikroklima) umgehen können.

In einem weiteren Versuch wurde die Bedeckung mit BSCs mit der Bedeckung mit Pflanzen insgesamt und mit der Bedeckung verschiedener Klassen von Pflanzen in Beziehung gesetzt (siehe Abbildung 4.27). Die Gesamtpflanzenbedeckung war hier negativ mit der BSCBedeckung korreliert, ebenso die Bedeckung mit Gras und die Bedeckung mit „mittleren Kräutern“. Zu den „mittleren Kräutern“ gehörten die Arten Veronica incana oder 
Leontopodium leontopodioides mit basal eher schmalem Wuchs und wenig Schattenwurf. Für die übrigen Klassen konnten keine Korrelationen festgestellt werden. Auch diese Zusammenhänge sind nicht sehr stark und allenfalls als Hinweise zu werten. Zwischen Gräsern und BSCs war vor Versuchsbeginn eine Konkurrenz vermutet worden, weil die nicht quantifizierte Beobachtung gemacht worden war, dass in der Mitte des Berghanges die BSCBedeckung höher und die Grasbedeckung niedriger war. Zwischen Potentilla acaulis und BSCs war eine eher mutualistische Beziehung vermutet werden. Potentilla acaulis hat eine kriechende Wuchsform und ist an mehreren Stellen mit dem Boden verankert. Es waren häufig gut entwickelte BSCs zwischen den Trieben dieser Pflanze gefunden worden, die die BSC am Platz hielten und anscheinend vor Erosion schützten, aber kaum beschatteten. Diese Vermutungen konnten weder belegt noch eindeutig widerlegt werden.

\subsubsection{Weitere Einflüsse}

Wie in den letzten beiden Unterkapiteln zu sehen, sind keine sehr großen Korrelationen zwischen den untersuchten abiotischen und biotischen Standortfaktoren und der Bedeckung mit BSCs oder der Anzahl von Kryptogamenarten gefunden worden. Dieses lässt darauf schließen, dass es noch einen oder mehrere andere, schwer zu überblickende Faktoren gibt, die in dieser Studie nicht erfasst werden konnten. Ein Problem war, dass innerhalb eines Berghanges mehrere Vegetationstypen, die Artemisia frigida-GTS, die Festuca lenensisGTS, die Pulsatilla ambigua-GTS und das Ulmus pumila-OWG wechselnd und nebeneinander vorkommen können. Dieses wirkt sich auch sehr stark auf die Erdflechtenvegetation aus (Hauck et al., 2007). Diesem Problem wurde dadurch begegnet, indem zu jedem untersuchten Quadrat die gefundenen Pflanzenarten erfasst wurden. Die Charakterarten der einzelnen Vegetationstypen wurden gezählt, so dass es schließlich möglich wurde, jedes Quadrat einem oder mehreren Vegetationstypen zuzuordnen. Schwierigkeiten gab es hierbei bei der Gewichtung, da viele Quadrate Charakterarten aller vier Vegetationstypen enthielten. Waren Charakterarten eines Vegetationstypus vorherrschend wurde das Quadrat diesem zugeordnet. Es ist aber nicht auszuschließen, dass es einen Einfluss der anderen Vegetationstypen gab. Eine Analyse der Daten ohne die Einteilung in die Vegetationstypen ergab noch etwas schlechtere Korrelationen, so dass angenommen werden kann, dass diese tatsächlich einen Einfluss auf die 
Erdflechtenvegetation, bzw. die Besiedlung mit BSCs haben. Wie groß dieser aber ist, konnte nicht ermittelt werden.

Es konnte außerdem nicht an jedem Messpunkt, bzw. in jedem Zählquadrat eine genaue Bodenanalyse stattfinden. Die Untersuchung der verschiedenen Standorte und mehrerer Punkte einiger Standorte ergab zwar, dass der Unterschied nicht sehr groß war (siehe Tabelle 4.1), es kann jedoch nicht ausgeschlossen werden, dass es innerhalb der Transekte kleinräumig größere Unterschiede in der Bodenchemie gab. Dies könnte einen Einfluss darauf haben, dass sich zum Beispiel eine Flechtenart, die diesen $\mathrm{pH}$-Wert favorisiert sehr stark ausbreitet und andere Arten unterdrückt. Wenn dieses eine schnell wachsende Flechte ist, kann das neben dem Einfluss auf die Artenzahl auch einen Einfluss auf die Bedeckung mit BSCs haben.

Auch die Temperatur direkt konnte nicht erfasst werden. Es wurden dafür andere Faktoren erfasst wie die Exposition, die Inklination, die Entfernung zum Bergrücken und das Mikrorelief, die ihrerseits einen Einfluss auf die Temperatur haben. Auch die Bedeckung und Höhe der Phanerogamenvegetation hat natürlich Auswirkungen auf die Temperatur. Die in den Abbildungen 4.3 bis 4.5 dokumentierten Unterschiede in den Bodenoberflächentemperaturen können nur einen Hinweis darauf geben, wie groß diese Unterschiede sein können. Da diese aber vom Sonnenstand und der Lufttemperatur abhängig sind und sich nicht nur tages- sondern auch jahreszeitlich ständig ändern, kann dieses nur eine Momentaufnahme sein. Der in Abbildung 4.1 dokumentierte Vergleich der akkumulierten Temperaturen kann nur die Unterschiede der Durchschnittstemperaturen der verschiedenen Standorte demonstrieren, eine vergleichbare kleinräumigere Analyse wäre logistisch nicht möglich gewesen, da die Messungen zu vergleichender Standorte ja praktisch gleichzeitig oder zumindest innerhalb kürzester Zeit hätte stattfinden müssen.

Ein weiterer, schwer zu dokumentierender Faktor war die Erosion oder auch Störung durch Huftritt. Im Gelände sind häufig Abbruchkanten oder auch Hufspuren und dadurch aus ihrer Verankerung gelöste oder zerstörte Bodenkrusten gefunden worden, es erwies sich jedoch als schwierig, diese Störungen zu quantifizieren. Es wurde der Versuch gemacht, Störungsklassen (von $0=$ nicht gestört bis $I V=$ stark gestört) einzuführen und diese Störungsklassen getrennt zu bewerten. Dieses hat sich allerdings als nicht praktikabel erwiesen, da ein weiterer hier nicht gezeigter Versuch keinen Zusammenhang zwischen der 
5 Diskussion

Störungsklasse und der Bedeckung mit BSCs ergeben hat. Das mag daran liegen, dass die gestörten Stellen wesentlich kleiner sind als ein Zählquadrat. Die Störung bezieht sich also nur auf einen Teil des Zählquadrates, während der größte andere Teil anderen Beeinflussungen unterliegt. Der Störungsversuch, welcher in der Abbildung 4.36 dokumentiert wurde, ist also vermutlich nur deshalb aussagekräftig, weil hier nachweislich der Bewuchs des ganzen Quadrates zerstört wurde.

Ein weiterer Einfluss nehmender Faktor ist die Nähe der untersuchten Punkte zueinander. Diese können niemals statistisch unabhängig sein. Ein Beispiel für die Auswirkung dieses Problems ist die Ausbreitung von verschiedenen Arten. Wenn also z.B. in Quadrat A1 Diploschistes muscorum wächst, ist die Wahrscheinlichkeit, dass es dort ebenfalls diese Art gibt, für Quadrat A2 wesentlich höher als für D12. Insbesondere auf Quadrate hangabwärts dürfte dies in besonderem Maße zutreffen. Dieses Problem ließ sich aus verschiedenen Gründen nicht vermeiden. Erstens vermehren sich viele Kryptogamen durch Sporen. Einen Standort ganz außerhalb der Reichweite des anderen zu finden ist praktisch unmöglich, denn dann hätten sich Vegetation und Mesoklima schon wieder so weit verändert, dass eine Vergleichbarkeit nicht mehr gegeben wäre. Zweitens spielte ein Mangel an geeigneten Standorten eine Rolle. Es war nicht immer klar ersichtlich, warum es an manchen oberflächlich dafür geeigneten Standorten keine oder nur wenig BSCs gab. Es wurden anthropogene Störungen dafür angenommen, über deren Art und Intensität aber nichts bekannt war, deshalb wurden solche Standorte eher gemieden.

Ein weiterer, sicherlich sehr hoch zu bewertender Faktor ist Feuer. Wie sich erst lange nach Abschluss der Geländearbeiten herausstellte, hatte es an den Standorten A, B, D, F und G 1996 und 2002 gebrannt (Oyunsanaa Byambasuren, persönliche Mitteilung). Das Feuer im Jahr 1996 war flächendeckend und von mittlerer Intensität, während das Feuer im Jahr 2002 von geringer Intensität und lückenhaft war. Es ist sicherlich gut vorstellbar, dass hier die Schädigung der BSCs vor allem davon abhing, ob in ihrer Nähe brennbares Pflanzenmaterial lag oder wuchs, welches das Feuer nähren konnte. Dieses ist tatsächlich mehr oder minder zufällig, wobei man sich natürlich vorstellen kann, dass die Hangmitte des Berges A, wo die Pflanzenbedeckung niedriger war (siehe Abbildung 4.25), das Feuer schneller vorüber gezogen ist, weil es nicht genährt wurde. Die Brennbarkeit der BSCs selbst hängt natürlich davon ab, ob sie zur Zeit des Feuers trocken oder feucht waren. Darüber ist allerdings nichts bekannt. Das letzte Feuer an den Standorten H und I ist aus dem Jahre 1950 bekannt. 
Inzwischen hat es nach Abschluss der Geländearbeiten im Jahre 2009 an allen Standorten mit hoher Intensität gebrannt.

\subsubsection{Analyse der mikrobiellen Diversität in Biologischen Bodenkrusten über die Konstruktion von 16S rDNA-Genbanken}

Die beiden mittels 16S rDNA- Analyse untersuchten Standorte befinden sich an Berg G und Berg H. Tabelle 4.9 gibt einige ihrer Unterschiede wieder, wobei die augenfälligsten sicherlich die Pflanzenbedeckung, die Anzahl der Kryptogamenarten und die Bedeckung mit BSCs sind. Alle diese Werte sind merklich höher bei Berg G. Berg H ist steiler und deshalb stärker erodiert. Der pH-Wert an Berg G liegt zwischen 6,7 und 6,8 und an Berg H bei 7,7 (siehe Abbildung 4.7). Das C/N- Verhältnis liegt an Berg G zwischen 11,24 und 11,64 und an Berg H bei 10,98. Berg G ist also geringfügig nährstoffreicher.

Die DOTUR-Analyse ergab, dass die beiden Standorte auf Artebene zu etwa 35 \% und auf Phylaebene zu 78-92 \% ausgeschöpft wurden (siehe Tabelle 4.11). Die unterschiedlichen Zahlen ergeben sich aus den unterschiedlichen Schätzmethoden ACE (abundances based coverage estimator) und Chao1 (nichtparametrischer Häufigkeitsschätzer auf der Basis von ein und zweielementigen Mengen). Die Rarefaction-Analysen sind in den Abbildungen 4.37 und 4.38 dargestellt. Hier sieht man für beide Standorte, dass die Bakterielle Diversität auf Phylaebene jeweils nahe der Sättigung ist, während die bakterielle Diversität auf Artebene weit entfernt von einer Ausschöpfung ist. Es gilt zu bedenken, dass bei genetischen Distanzen unter 5 \% die Rarefaction-Analysen die bakterielle Diversität eher unterschätzen, während Chao1 diese eher überschätzt (Roesch et al., 2007). Man kann sagen, dass eine weitere Analyse der Standorte mit der gleichen Methode einen hohen materiellen und personellen Aufwand erfordern würde, wenn eine Sättigung auf Artebene erreicht werden soll. Hier wäre eine „schnellere“ Methode wie Pyrosequencing vorzuziehen.

Der Shannon-Wiener-Index für Biodiversität für Standort G betrug für eine Distanz von 3 \% 3,93 und für eine Distanz von 20 \% 2,12. Für den Standort H betrug er für eine Distanz von 3 \% 4,39 und für die Distanz von 20 \% 2,64 (siehe Tabelle 4.11). Je höher dieser Zahlenwert ist, desto diverser ist ein Standort. Der Wert kann für überaus diverse Standorte bis zu einem 
5 Diskussion

Wert von 8 gehen, für die bakterielle Diversität von BSCs hingegen ist ein Wert von 2 bis 5 üblich (z.B. Nagy et al., 2005; Fierer und Jackson, 2006; Bachar et al., 2010; Abed et al., 2010), wobei noch nach der verwendeten Methode unterschieden werden muss. Die meisten Studien, die sich mit der bakteriellen Diversität von BSCs beschäftigen, verwenden DGGE (denaturierende Gradientengelelektrophorese), wo im allgemeinen weniger Sequenzen erhalten werden, da sich die Banden häufig überlagern. Außerdem ist der Shannon-WienerIndex auch von der Zahl der Stichproben abhängig, zum direkten Vergleich sollte diese also annähend gleich groß sein.

Die im Rahmen der nachfolgenden Diskussionen angegebenen Informationen über Taxa entstammen Brenner et al. (2005), sofern nicht anders angegeben. Abbildung 5.1 gibt einen Überblick über die Verwandtschaft der bakteriellen Phyla.

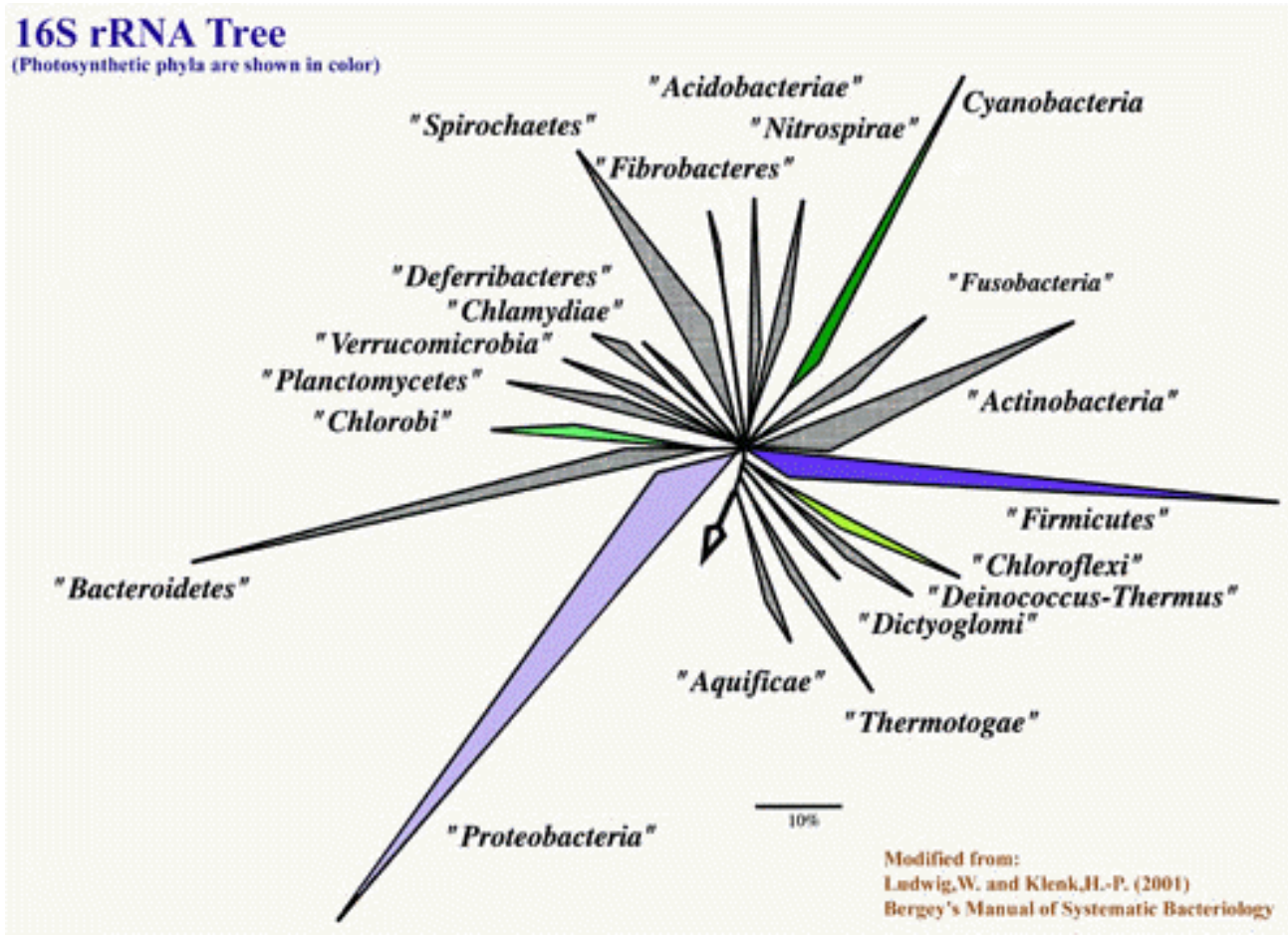

Abb. 5.1: Verwandtschaft der bakteriellen Phyla. Quelle:

http://www.bacterialphylogeny.info/overview.html.

Die Proteobacteria sind eine phylogentetisch reich verzweigte Gruppe gramnegativer typischer Bodenbewohner, sie stellen eines der größten Phyla der Bakterien dar. Die sie 
betreffenden Stammbäume sind in Abbildung 4.40 A (Berg G) und D (Berg H) dargestellt. Sie bestehen aus den Klassen Alphaproteobacteria, Betaproteobacteria, Deltaproteobacteria und Gammaproteobacteria. Innerhalb der Alphaproteobacteria sind die Sphingomonadales anzusiedeln. Einige Arten sind pleomorph, das heißt sie verändern im Laufe der Kultivierung ihre Zellform. Sie sind aerob und chemoorganotroph. An Standort H wurde ein Bakterium gefunden, dessen nächster Nachbar Sphingomonas oligophenolica (siehe Abbildung 4.40 D) in der Lage ist, Phenolsäuren in niedriger Konzentration abzubauen (Ohta et al, 2004). Die Caulobacterales sind aerob und chemoorganotroph. Vertreter hier gefundenen Gattungen Caulobacter und Brevundimonas besitzen einen dimorphen Lebenszyklus. Sie können Stiele ausbilden, mit deren Hilfe sie sich an ein Substrat anheften können. Das andere Stadium ist begeißelt und somit beweglich. Eigentlich sind sie Süßwasserbewohner. Die Gattung Phenylobacterium enthält unbewegliche Stäbchen oder Kokken. Die Rhizobiales enthalten viele Knöllchenbakterien, die in der Lage sind, Luftstickstoff zu fixieren. An beiden Standorten wurde ein Bakterium gefunden, das Chelatococcus asaccarovorans als nächsten Nachbarn hat Dieser ist obligat aerob (Auling et al. 1993). An Standort G scheinen die Rhizobiales häufiger zu finden zu sein. Dort wurden außerdem noch ein Verwandter von Bosea thiooxidans und ein Vertreter der Phyllobacteriaceae gefunden, außerdem als Vertreter der Rhodospirillales ein Nachbar des Humanpathogens Roseomonas gilardii. An Standort H wurde ein Bakterium gefunden, welches sehr nah mit Belnapia moabensis, einem Angehörigen der Rhodospirales, verwandt ist. Dieser Fund ist besonders interessant, weil dieses Bakterium erstmals aus Biologischen Bodenkrusten isoliert wurde (Reddy, 2006). Es ist aerob, fakultativ fermentativ, gramnegativ und rot pigmentiert, enthält allerdings kein Bakteriochlorophyll. Es ist eng mit Roseomonas gilardii verwandt. Die aus der Klasse der Betaproteobacteria gefundenen Bakterien gehören soweit feststellbar im Falle des an Standort G gefundenen Verwandten von Variovorax sp. den Burkholderiales, einer morphologisch und ökologisch stark inhomogenen Ordnung und im Falle des an Standort $\mathrm{H}$ gefundenen Nachbarn von Azoarcus buckelii (welcher der anoxygenen Photosynthese befähigt ist) den Rhodocylales an. An beiden Standorten wurde jeweils ein Vertreter der Gammaproteobacteria, der zurzeit artenreichsten Klasse der Proteobacteria, gefunden, der allerdings nicht näher identifiziert werden konnte. An Standort H wurden sieben Angehörige der Deltaproteobacteria gefunden. Diese Klasse fehlt an Standort G ganz. Die Deltaproteobakteria sind physiologisch eher homogen. Diese gehören laut RDP-Classifier alle der Ordnung Myxococcales an. Die Myxococcales sind vor allem Bodenbewohner. Sie leben in Schwärmen und können sich gleitend über feste Oberflächen fortbewegen, außerdem 
können sie Fruchtkörper bilden. Sie bilden austrocknungsresistente Sporen und leben räuberisch auf anderen Bakterien. Es kann vermutet werden, dass die Mxxococcales deshalb an Standort H so zahlreich vertreten sind, weil hier die BSCs an ihrer Oberfläche eher Raum für die Ausbildung von Fruchtkörpern bieten. Die BSCs des Standortes G sind oft oberseits vollkommen mit Flechten bewachsen, während die gestörten Collema-Mooskrusten ja weitgehend jünger sind.

Die Cyanobacteria, die ursprünglich auch Blaualgen genannt wurden, sind zur oxygenen Photosynthese befähigt, sie sind am nächsten verwandt mit den grampositiven Bakterien mit niedrigem GC-Gehalt, auch wenn der Gramtest bei ihnen meistens negativ ausfällt. An den untersuchten Standorten G (siehe Abbildung 4.40 B) und H (siehe Abbildung 4.40 E) waren in der 16S rDNA-Analyse nur fädige Cyanobakterien aus der Subsektion III (vorher Oscillatoriales) und der Subsektion IV (vorher Nostocales) zuzuordnen. Die Subsektion III ist nicht phylogenetisch kohärent, manche Gattungen sind polyphyletisch, dieses sieht man bei Pseudanabaenaceae von Standort G. Es ist im Stammbaum jeweils ein Vertreter im obersten und im zweiten Zweig von unten zu finden. Die Vertreter der Subsektion III bilden keine Heterocysten, sind also nicht zur Fixierung molekularen Stickstoffs befähigt. Innerhalb der Subsektion unterscheidet man verschiedene Form-Genera. Angehörige des Form-Genus Leptolyngbya können Scheiden produzieren, sind nicht beweglich und besitzen eine sehr hohe genetische Diversität untereinander. Es wurde an Standort H ein Bakterium gefunden, das vermutlich in diesen Form-Genus gehört. Der Form-Genus Microcoleus zeichnet sich dadurch aus, dass mehrere Filamente in einer gemeinsamen Scheide leben, man kann ihre Wuchsform mit Kabelsträngen in einer Verkleidung vergleichen (siehe auch die Abbildungen 4.11 E und 4.12 D). Innerhalb dieser Scheiden sind sie zur gleitenden Bewegung befähigt, Microcoleus besitzt ein reduziertes morphologisches und genetisches Cluster. An Standort G wurde ein naher Verwandter von Microcoleus paludosus gefunden. Dieses Cyanobakterium wurde schon in vielen anderen Biologischen Bodenkrusten entdeckt (Zhang, 2005; Shields et al., 1957; Rivera-Aguilar et al., 2006), scheint also gut an dieses Ökosystem angepasst zu sein. Der Form-Genus Pseudanabaena ist durch eingeschnürte Zellwände von den zuvor beschriebenen zu unterscheiden. Er führt ebenfalls eine gleitende Bewegung aus. Mindestens drei Sequenzen an Standort G können dieser Gruppe vermutlich zugeordnet werden. Phormidium gehört ebenfalls zur Subsektion III. Ein naher Verwandter von Phormidium pristleyi wurde ebenfalls an Standort G gefunden. Über dieses Cyanobakterium ist bekannt, dass es oft hypolithisch, das heißt unterhalb von lichtdurchlässigen Steinen wie zum Beispiel 
Quarzgestein wächst. Dies schützt sie vor zu hoher Strahlung, die Lichtmenge, die durch den Stein noch bei ihnen ankommt, reicht zur Photosynthese aus (Warren- Rhodes et al., 2006). Hypolithisches Wachstum konnte an Quarzgesteinen des Untersuchungsgebietes während der Freilanduntersuchungen auch tatsächlich beobachtet werden. Die Angehörigen der Subsektion IV, den Nostocales bilden Heterocysten, das heißt sie sind in der Lage, elementaren Luftstickstoff zu fixieren und ihn so dem Stickstoffkreislauf ihres Ökosystems zuzuführen, womit sie die Fruchtbarkeit des Bodens erhöhen. Innerhalb der Nostocales gibt es mehrere Form-Genera. Der Form-Genus Nostoc zeichnet sich durch nicht bewegliche Fäden aus, die man leicht an der kugeligen Form ihrer Einzelzellen erkennen kann. Sie können Kapseln bilden und so zum Beispiel Matten in Polarregionen bilden. Sie besitzen eine hohe Austrocknungstoleranz (Scherer und Potts, 1989). Man findet sie auch sehr häufig als Photobionten in Cyanoflechten oder in Form von kugeligen Lagern. Diese Wuchsform wurde im Untersuchungsgebiet ebenfalls beobachtet, die Sequenz G01aab12 könnte eventuell von einem solchen Lager stammen, da die andere diesem Form-Genus zuzuordnende Sequenz auf den Cyanobionten von Peltigera lepidophora hinweist, einer an Standort G häufig gefundenen Flechte. Der Form-Genus Tolypothrix zeigt bewegliche Filamente und wächst in Süßwasser oder auf Boden. Ihm zugehörige Sequenzen gab es in den Proben beider Standorte. Der Form-Genus Coleodesmium hingegen war nur an Standort G mit einer Sequenz vertreten.

Bei den Cyanobakterien gab es Schwierigkeiten beim Konstruieren der Stammbäume aufgrund der genetischen Variabilität der Subsektionen, außerdem waren die nächsten Nachbarn der gefundenen Bakterien fast nur unkultivierte Organismen. Dies führte auch dazu, dass es scheinbar die Subsektionen I (Chroococcales), II (Pleurocapsales) und V (Stigenomatales) an diesen Standorten nicht gibt. Bei den Chroococcales und den Pleurocapsales handelt es sich um kugelige Cyanobakterien, welche wie die mikroskopische Analyse ergab, an den Standorten durchaus vorhanden waren (siehe Abbildung 4.10 C). So sind sicherlich einige der in den Stammbäumen auftauchenden Sequenzen diesen Subsektionen zugehörig, es konnte nur leider nicht ermittelt werden, welche das sind.

Es war auffällig, dass der Cyanobakterienanteil an Standort G mit $24 \%$ gegenüber $9 \%$ an Standort $\mathrm{H}$ erheblich höher ist, obwohl ja durch den lückigen Flechtenwuchs der gestörten BSCs an Standort H mehr Siedlungsfläche für Cyanobakterien zur Verfügung stünde. Das könnte daran liegen, dass Cyanobakterien Austrocknung sehr gut überdauern können und bei 
Taubefeuchtung sogar in geringem Maße Photosynthese betreiben können, sie aber für produktives Wachstum flüssiges Wasser benötigen. Gleitende Cyanobakterien sind zwar in der Lage, im Tagesverlauf von der Krustenoberfläche weiter nach unten zu wanden und so der Austrocknung zu entgehen, Photosynthese ist innerhalb der Kruste jedoch nur eingeschränkt möglich. Standort G ist nicht ganz so steil wie Standort H, was dazu führt, dass das Wasser nicht ganz so schnell abließt, außerdem liegt Standort $\mathrm{H}$ sehr windexponiert, wohingegen Standort H gegenüber eines bewaldeten Hanges liegt, er ist also wahrscheinlich feuchter. Dass die Cyanobakterienbesiedlung stark vom Regenfall abhängt, ist schon länger bekannt (Bowker et al., 2002 und Belnap et al., 2004). Dies führt oft zu einer Saisonalität des Algenanteils, das heißt, dass die Cyanobakterienpopulation in den Übergangsjahreszeiten oder in feuchten Zeiten mit weniger Strahlung stark zunimmt. Die Proben der beiden Jahreszeiten sind allerdings zur selben Zeit (Hochsommer) genommen worden und wurden vor der DNA-Isolierung nicht kultiviert. Es konnte also nur das gefunden werden, was die heiße Zeit überdauert hat. Eine weitere die Variabilität des Algenanteils betreffende interessante Beobachtung ist die von Lukešová (2001) gemachte: stickstofffixierende Cyanobakterien wurden nur in jüngeren Krusten gefunden. Für die Neubesiedlung von stickstoffarmen Böden ist das sehr sinnvoll. In dieser Studie wurden an beiden Standorten stickstofffixierende Nostocales gefunden, obwohl Standort H mehr gestörte BSCs besitzt. Da einerseits diese Nostocales meistens Teil einer Flechte sind, für die andere Regeln gelten dürften und andererseits auch Standort G gestörte Stellen (und Cyanoflechten) beherbergt, ist dieses nicht weiter verwunderlich.

Die Actinobacteria sind einer der artenreichsten Stämme unter den Bakterien. Sie sind oft stäbchenförmig, sind grampositiv und zeichnen sich durch einen hohen GC-Gehalt aus. Viele sind auch mehrzellig und bilden Filamente. Dies ist oft mit der Fähigkeit zur Sporenbildung verbunden. Ihre Stammbäume sind in Abbildung 4.40 B (Standort G) und 4.40 H (Standort H) zu finden. Es wurden verlässliche Hinweise nur auf die Ordnung Actinomycetales gefunden. Die Angehörigen dieser Ordnung leben meist aerob und bilden Sporen. Die meisten bilden ein oft verzweigtes Mycel, welches oberhalb und/oder unterhalb des Substrates liegen kann. Die Angehörigen der zu ihnen gehörenden Actinoplanes produzieren ein feines Mycel, ihre Sporen sind aktiv beweglich. Meist sind sie orange oder rötlich pigmentiert und kommen oft auf pH-neutralen Böden (Nonomura und Takagi, 1977) oft auch in Wüstenböden vor (Couch, 1957), sie dürften also austrocknungstolerant sein. Zum Teil gehören die Chitin abbauenden Bakterien in diese Gattung. Sie sind oft in der Lage, CO zu 
CO2 zu oxidieren. Ein naher Verwandter von Actinoplanes auranticolor lebte an Standort H, ebenso wie ein vermutlich in die Gattung Geodermatophilus gehörendes Bakterium. Diese sind schnell wachsende Actinomyceten mit multilokularen Sporangien und einem Temperaturoptimum bei $10-37^{\circ} \mathrm{C}$. Außerdem werden sie meist aerob lebend in Erde gefunden. Propionibakterien sind im Gegensatz zu den meisten anderen Actinomyceten oft stäbchenförmig, bilden also kein Mycel aus. Sie sind meistens nicht beweglich und bilden auch keine Sporen. Sie ernähren sich chemoorganotroph, ein typisches Fermentationsprodukt ist zum Beispiel Propionsäure. Sie sind typischerweise anaerob bis mikroaerotolerant, ihr Temperaturoptimum liegt bei $30-37^{\circ} \mathrm{C}$. Für Propionibakterien ist eigentlich bekannt, dass sie in erster Linie in Milchprodukten oder auf der menschlichen Haut leben. Der Vertreter Microlunatus panaciterrae hingegen, mit dem ein an Standort H gefundenes Bakterium am engsten verwandt ist, wurde erstmals aus der Erde eines Ginsengfeldes isoliert (An et al., 2008). Dieser ist im Gegensatz zu anderen Propionibakterien allerdings kokkal, beweglich und lebt aerob. Die an Standort G gefundenen Actinobakterien gehören vermutlich den Taxa Frankia, Blastococcus, Dactylosporangium und Lentzea an oder sind zumindest mit diesen eng verwandt. Frankia ist ein langsam wachsender Actinomycet mit multilokularen Sporangien und hat sein Temperaturoptimum bei $10-37^{\circ} \mathrm{C}$. Er ist aerob bis mikroaerophil und wächst auf Erde. Die meisten Frankia-Stämme können Stickstoff fixieren, sie sind oft in Symbiose mit Pflanzen zu finden. Dactylosporangium bildet nur unterirdisches Mycel und wächst trotzdem streng aerob. Das Mycel ist hellorange, dunkelrot bis braun. Dactylosporangium ernährt sich chemoorganotroph und wächst bei $25-37^{\circ} \mathrm{C}$, ihr $\mathrm{pH}-$ Optimum liegt zwischen 6 und 7. Diese Gattung bildet bewegliche Zoosporen.

Die Unterschiede der actinobakteriellen Zusammensetzung der beiden Standorte sind nicht sehr aussagekräftig, da sich aufgrund des hohen Anteils unkultivierter Organismen unter den nächsten Nachbarn kein Muster ergibt. Es kann auch nicht davon ausgegangen werden, dass in der Studie alle Aktinobakterien erfasst werden konnten. Die gewählte Methode hat den Nachteil, dass durch die DNA-Isolierung eher auf gramnegative Bakterien hin selektiert wird, da die grampositive Zelle schwieriger aufzuschließen ist. Dauerstadien wie Sporen können noch schlechter erfasst werden.

Das Phylum Bacteroidetes setzt sich aus den Klassen Bacteroidia, Cytophaga, Flavobacteria und Sphingobacteria zusammen. Ihre Stammbäume sind Abbildung 4.40 C (Standort G) und 4.40 F (Standort H) zu entnehmen. Gefunden wurden an beiden Standorten Angehörige der 
Cytophagales und der Sphingobacteria. Alle Bacteroidetes sind gramnegativ. Die Cytophagales sind nicht photosynthetische, nicht Fruchtkörper bildende gleitende oder unbewegliche Bakterien. Sie leben in Erde oder marin, wo sie oft in großer Individuenzahl vorkommen. Sie leben meist strikt aerob und betreiben einen nichtfermentativen Stoffwechsel. Häufig sind sie gelb pigmentiert, wobei einige auch zu pH-abhängigen Farbveränderungen befähigt sind und im alkalischen Milieu rot bis purpurn verfärben. Da diese Bakterien ganze Zellen zerlegen können, verwundert es nicht, dass es unter ihnen auch fakultativ pathogene Organismen gibt. Sie können viele Arten von biologischen Makromolekülen abbauen, unter anderem gehören dazu Proteine, Stärke und Polysaccharide, auch Chitin. An Standort H wurde eine Vielzahl von Cytophagales gefunden. Auch Spirosoma panaciterrae wurde wie Microlunatus panaciterrae erstmalig aus Erde eines Ginsengfeldes isoliert (Ten et al., 2009). Die Tatsache, dass beide Mikrooganismen von Ginsengfeldern stammen, könnte auf die Tatsache hindeuten, dass in Asien bakterielle Analysen auf der Suche nach Ginsengoide abbauenden Bakterien oft auf Ginsengfeldern durchgeführt werden. Bei beiden Bakterien ist aber eine derartige Stoffwechselleistung nicht gefunden worden und es ist anzunehmen, dass sie einfach in Asien weit verbreitete Bodenbakterien sind. Die Gattung Hymenobacter gehört ebenfalls zu den Cytophagales. Vier Sequenzen waren in diese Gattung einzuordnen, ihre nächsten Verwandten sind Hymenobacter daecheongensis, ein erstmalig in Flusssediment in Südkorea isoliertes Bakterium (Xu et al., 2009) und Hymenobacter roseosalivarius, ein kontinentalantarktisches Bodenbakterium (Hirsch et al., 1998). An Standort G wurde außer einigen nicht kultivierten Angehörigen der Cytophagales ein unkultivierter Angehöriger der Gattung Hymenobacter als nächster Nachbar gefunden. Die Sphingobacteria verdanken ihren Namen der Tatsache, dass sie in der Lage sind, Sphingolipide zu produzieren. Chitinophaga ist eine Gattung innerhalb der Klasse Sphingobacteria. Ihre Angehörigen sind nicht photosynthetische, nicht Fruchtkörper bildende stäbchenförmige bis filamentöse gleitende Bakterien. Sie können Chitin hydrolisieren, sind oxidativ oder fermentativ chemoorganotroph, strikt aerob und ihre optimale Wachstumstemperatur beträgt $23-24^{\circ} \mathrm{C}$, sie können aber auch bis zu einer Maximaltemperatur von $37-40^{\circ} \mathrm{C}$ und einer Minimaltemperatur von $10^{\circ} \mathrm{C}$ wachsen. Ihr $\mathrm{pH}-$ Optimum liegt bei 7, sie können aber in geringeren Teilungsraten auch in einem Bereich von 4 bis 10 wachsen. Es wurden Hinweise auf die Gattung Flexibacter gefunden, der gleitend bewegliche filamentöse Bakterien angehören, die aber auch nicht bewegliche Stadien innerhalb ihres Lebenszyklus durchmachen. Ihre Zellen haben einen Durchmesser von 0,20,6 $\mu \mathrm{m}$ und sind 10-50 $\mu \mathrm{m}$ lang. Sie sind oft pigmentiert, chemoorganotroph, strikt aerob 
oder fakultativ anaerob und verwenden Peptone und Aminosäuren als Stickstoffquelle. Sie werden in Erde und Süßwasser, oft auch in Kläranlagen gefunden.

Die Firmicutes sind das zweite grampositive Phylum, sie besitzen allerdings im Gegensatz zu den Aktinobakterien einen niedrigen GC-Gehalt. Angehörige dieses Phylums wurden nur in sehr geringem Maße und nur an Standort H gefunden (siehe Abbildung 4.39) Sie ernähren sich chemosynthetisch heterotroph. Es gibt aerobe, anaerobe und fakultativ anaerobe, sporulierende und nicht sporulierende Arten. Die Tatsache, dass sie an Standort G nicht gefunden wurden, muss nicht heißen, dass es sie dort nicht gibt. Grampositive Bakterien sind mit dieser Methodik schlechter zu erfassen.

Verrucomicrobia ist ein relativ neu beschriebenes Phylum und enthält nur wenige Arten, die aus Boden und menschlichen Fäkalien isoliert wurden (Hedlund et al., 1997). Auch einige extrem acidophile Arten aus heißen Quellen wurden diesem Phylum zugeordnet. Dieses Phylum trat an beiden Standorten auf, an Standort G mit zwei Sequenzen (siehe Abbildung $4.40 \mathrm{C}$ ) und an Standort H mit sechs Sequenzen (siehe Abbildung 4.40 H). Die nächsten Nachbarn waren aber alles unkultivierte Bakterien, so dass keine näheren Angaben gemacht werden können.

Der bis lang einzige kultivierte Vertreter des Phylums Gemmatimonadetes ist gramnegativ und aerob (Zhang et al. 2003). Gemmatimonadetes wurden nur an Standort H gefunden (siehe Abbildung $4.40 \mathrm{H}$ ). Da man über dieses Phylum noch nicht viel weiß, fällt es schwer, aus ihrer An- oder Abwesenheit Rückschlüsse auf die Ökologie zu ziehen.

Die Chloroflexi sind relativ ursprüngliche Bakterien. Sie treten in Form gramnegativer Filamente mit gleitender Bewegung auf, manche besitzen Bakteriochlorophyll. Sie kommen an beiden Standorten vor (siehe Abbildung 4.40 B für Standort G, 2 Sequenzen und $4.40 \mathrm{H}$ für Standort H, 5 Sequenzen). Da alle Vergleichssequenzen von unkultivierten Bakterien stammen, können keine weiteren Angaben gemacht werden.

Das Phylum Nitrospira enthält relativ ursprüngliche Angehörige der Bacteria. Sie sind gramnegativ, besitzen mehr oder weniger spiralige Zellen und sind metabolisch sehr divers, die meisten Gattungen sind aerob chemolithoautotroh. Außerdem wurden Nitrifizierer, dissimilatorische Sulfatreduzierer und magnetotaktische Bakterien gefunden. Es wurde an 
5 Diskussion

Standort G eine Sequenz detektiert, die diesem Phylum zugeordnet, sonst aber nicht weiter phylogenetisch oder ökologisch klassifiziert werden kann.

Die Acidobacteria sind ein Phylum, das äußerst divers ist. Da erst wenige Vertreter kultiviert werden konnten, ist es schwierig, genaue Aussagen über ihre ökologische Amplitude zu treffen. Es wurden allerdings sehr viele 16S rDNA-Sequenzen in vielen unterschiedlichen Ökosystemen, hauptsächlich aber in Böden gefunden (Barns et al., 2007). Hierbei zeigten sie eine große phylogenetische Varianz, was auf eine ebenso große Varianz ihrer Stoffwechselwege schließen lässt. Aufgrund von Sequenzvergleichen konnten sie in 26 Untergruppen unterteilt werden. In Bodenökosystemen stellen sie oft den Hauptanteil der Bakterien dar (Dunbar et al., 2002). An Standort G wurden 11 Sequenzen gefunden, die den Acidobakterien zugeordnet werden können (siehe Abbildung 4.40 C), das entspricht einem Anteil von 10,6 \%. Dabei gehören sechs Sequenzen zur Untergruppe 4, drei Sequenzen zur Untergruppe 3 und eine Sequenz zur Untergruppe 6. An Standort H wurden 24 Sequenzen gefunden (siehe Abbildung $4.40 \mathrm{G}$ ), die sich auf die Untergruppen 4 (mit 19 Sequenzen), 3 (mit 2 Sequenzen) sowie 6,7 und 16 (mit je einer Sequenz) verteilen. Der Anteil der Acidobacteria an der Gesamtzahl der Sequenzen entspricht 14,4\%. Insgesamt sind die Anteile bei beiden Standorten also nicht signifikant unterschiedlich. Da das Vorkommen von Acidobakterien auch pH-abhängig ist (Jones et al., 2009) und der pH an Standort $\mathrm{H}$ um eine Einheit höher ist, könnten diese Unterschiede dadurch bedingt sein.

Das Phylum Planctomycetes war mit einer Sequenz an Standort H vertreten (siehe Abbildung 4.39). Diese chemoorganotrophen, fakultativ aeroben Bakterien bilden auch filamentöse Formen.

Die von der Domäne Bacteria klar zu unterscheidende Domäne Archaea enthält viele an extreme Milieubedingungen angepasste Organismen. So findet man sie häufig an heißen Quellen oder Standorten mit extremen $\mathrm{pH}$-Bedingungen, häufig sind beide Faktoren gleichzeitig vorhanden. Sie gelten als die ursprünglichsten Prokaryoten. Die an den beiden Standorten gefundenen Archaea werden in den Tabellen 4.12 und 4.13 vorgestellt. Alle gefundenen Archaeen gehören der Ordnung Desulforococcales an. Organismen dieser Ordnung gelten als moderat acidophil, ihr pH-Optimum liegt bei 4,5 bis 7. Sie sind hyperthermophil, ihr Wachstumsoptimum liegt bei $85^{\circ} \mathrm{C}$. An Standort H wurde ein Vertreter der Desulfurococcaceae gefunden. Diese besitzen kokkale bis scheibenförmige Zellen, ihr 
5 Diskussion

Temperaturoptimum liegt bei $85-95{ }^{\circ} \mathrm{C}$, sie leben hauptsächlich anaerob und zeigen chemolithoautotrophes Wachstum durch Schwefelreduktion $\mathrm{zu} \mathrm{H}_{2} \mathrm{~S}$, so wie heterotrophes Wachstum durch Schwefelatmung. An Standort G war ein Vertreter der Pyrodiciaceae zu finden. Diese zeichnen sich durch kokkale bis scheibenförmige Zellen, ein Temperaturoptimum bei $108-113{ }^{\circ} \mathrm{C}$, und die Möglichkeit, chemolithoautotroph Stoffwechsel zu betreiben. Angehörige der Gattung Pyrolobus sind fakultativ aerob, obligat chemolithoautotroph und im Allgemeinen druckunempfindlich. Die Anwesenheit dieser Archaeen ist nicht ungewöhlich, auch wenn die untersuchten Standorte weder besonders heiß sind noch unter starken Drücken stehen. Es muss nicht davon ausgegangen werden, dass sie aktiv am Ökosystem der Standorte beteiligt sind. Es wurde während der PCR auf Archaeen selektiert, die im Allgemeinen an solchen Standorten in niedrigen Individuenzahlen vorkommen. Interessant ist dieses Ergebnis insofern, als dass die Anwesenheit der Archaeen ein Beispiel dafür gibt, wie breit die ökologische Amplitude der mikroorganismischen Artengemeinschaft insgesamt ist, was in Falle einer plötzlich eintretenden Milieuveränderung für das - wenn auch veränderte - Fortbestehen des Ökosystems bedeutend ist. Von Beyerinck (1913) stammt das auf Bakterien bezogene Zitat „Everything is -everywhere - but the habitat selects“.

Zusammenfassend ist zu sagen, dass sich die Standorte hinsichtlich der bakteriellen Diversität innerhalb ihrer BSCs deutlich voneinander unterscheiden. Zwar haben sie gemeinsam, dass bei ihnen die Proteobacteria das dominierende Phylum darstellen, aber die Deltaproteobakterien fehlen an Standort G ganz. Während bei Standort G die zweitstärkste Gruppe die Cyanobacteria darstellen ist dies an Standort H das Phylum Bacteroidetes. Die drittstärkste Gruppe stellten bei beiden Standorten die Acidobacteria. Es gibt wenig Studien, mit denen man diese Ergebnisse vergleichen könnte. Bislang wurde für ähnliche Analysen häufiger die DGGE (denaturierende Gradientengelelektrophorese) verwendet, was aber für diese Studie aufgrund der hohen Anzahl erwarteter Sequenzen (die sich ja auch bestätigt hat) verworfen wurde. Kürzlich erschienen ist eine Studie von Abed et al. (2010) über die bakterielle Diversität von BSCs aus einem Wüstengebiet aus dem Oman. Hier ist der Untergrund ebenfalls kalkhaltig und in etwa gleich und etwas höher als im Untersuchungsgebiet. Das Klima ähnelt sich jedoch nicht sehr. Hier wurden die Cyanobakterien als stark dominierend vorgefunden, sie stellten um 80 \% der Sequenzen dar, die Proteobakterien waren die zweitstärkste Gruppe. Bachar et al. (2010) entnahmen ihre Proben in der Negev-Wüste in Israel. Sie untersuchten drei Standorte mit unterschiedlichen 
Wasserverhältnissen und unterschieden sie nach dem Grad ihrer Aridität. Der Anteil der Cyanobakterien nahm hierbei mit zunehmender Aridität zu. An allen drei von ihnen untersuchten Standorten waren jedoch die Actinobakterien dominant, gefolgt von den Proteobakterien und den Acidobakterien. Der pH-Wert war an allen drei Standorten ähnlich wie in dieser Studie als neutral bestimmt worden. Man sieht also, dass sich die Zusammensetzungen der bakteriellen Gemeinschaft an den beiden Standorten dieser Studie ( $\mathrm{G}$ und $\mathrm{H}$ ) sehr viel mehr gegenseitig ähneln als anderen BSC-Standorten. Dieses kann damit erklärt werden, dass Klima und Bodenchemie den hauptsächlichen Einfluss darauf haben. Man kann die von anderen Autoren gemachten Ableitungen, wie zum Beispiel der Hinweis, dass der Anteil der Cyanobakterien mit zunehmender Aridität ansteigt, nur bedingt auf diese Studie anwenden, weil hier noch andere Faktoren Einfluss haben. So sind hier tatsächlich an dem eindeutig feuchteren Standort G mehr verschiedene Cyanobakterien gefunden worden, obwohl an Standort $\mathrm{H}$ deutlich mehr Cyanobakterien mikroskopisch erfassbar waren. Einerseits benötigen Cyanobakterien, wie oben beschrieben, zum produktiven Wachstum flüssiges Wasser, welches an Standort G länger verfügbar ist, andererseits bietet eine wie an Standort G gefundene reichhaltigere Kryptogamen und Phanerogamen vielfältigere Besiedlungsmöglichkeiten und ökologische Nischen für Cyanobakterien. Generell ist die Biodiversität für den Standort H allerdings größer (siehe Tabelle 4.11), was sicherlich zum Teil deshalb der Fall ist, weil dort die Zahl der untersuchten Sequenzen auch größer war.

Wenn man einen Blick auf die nächsten Nachbarn der erhaltenen Sequenzen wirft, so fällt auf, dass viele von ihnen aus den gleichen Veröffentlichungen stammen. So wurden sehr viele durch LaMontagne et al. (2003) entdeckt. In dieser Studie wurden 16S rDNA-Analysen einer bakteriellen Gemeinschaft im kalifornischen Grasland durchgeführt. Elshahed et al. (2008) untersuchten Prärieerde in Oklahoma. Auch Cruz-Martinez et al. (2009) haben ihre Untersuchungen an kalifornischen Graslandproben gemacht LeSaulnier (2008) hingegen unter suchten zwar auch Bodenproben, diese waren allerdings nicht im Grasland entnommen worden. Die Proben von Pointing et al. (2009) entstammten einem hyperariden Standort in der Antarktis. Dies ist einerseits ein guter Querschnitt über die aktuellen Forschungsinteressen, andererseits zeigt dies, dass sich die Standorte ähneln. Fast alle nächsten Nachbarn waren aus Boden isoliert worden, viele aus Prärie- oder Graslandproben. Das zeigt eine Tendenz zur Spezialisierung unter den Bakterien. 
5 Diskussion

Zum Teil waren die ermittelten maximalen Identitäten (als Maß für die Verwandtschaft zweier Sequenzen) im Vergleich der eigenen Sequenzen mit ihrem jeweiligen nächsten Nachbarn nicht sehr hoch (siehe Blasttabellen im Anhang). Die meisten Werte lagen um $98 \%$, was man schon als sehr starke Verwandtschaft ansehen kann. Es wurden bei manchen Paaren aber auch Identitäten von 95 \% und niedriger (selten sogar nur 87 \%) detektiert. Da Chimären ja ausgeschlossen wurden, kann man davon ausgehen, dass von diesen Sequenzen tatsächlich noch keine verwandten Bakterien bekannt sind, es sich also um neue Arten, wenn nicht gar um neue Gattungen oder höhere Taxa handelt. Dies ist nicht unwahrscheinlich, da man davon ausgeht, dass man einen Großteil der Bakterienarten noch nicht entdeckt hat (Amann et al., 1995). Außerdem sind Studien über vergleichbare Standorte selten, einerseits ist die Mongolei noch nicht sehr intensiv beprobt worden und andererseits sind genbankbasierte Analysen über BSCs eher selten. Über die DGGE kann man viele Sequenzen gar nicht detektieren.

Allerdings sind die Möglichkeiten der PCR-basierten 16S-Analyse auch begrenzt. Durch die Wahl der DNA-Isolationsmethode wurde auf gramnegative Bakterien oder besser aufschließbare grampositive Bakterien selektiert. Dies schließt einen Großteil der Grampositiven schon einmal aus. Außerdem werden in der PCR nur die individuenreichsten Gruppen erfasst und somit nur deren DNA vervielfältigt und anschließend in Genbänke kloniert. Dies muss in ökologischen Studien nicht von Nachteil sein, da man im Allgemeinen über die einflussreichsten Organismen berichten möchte. Man muss sich jedoch darüber im Klaren sein, dass diesen noch viele unentdeckte Bakterien gegenüber stehen. 


\subsection{Schlussfolgerungen für den Naturschutz}

\subsubsection{Funktion und „Nutzen“ Biologischer Bodenkrusten}

Da BSCs fest mit dem Boden assoziiert sind, spielen sie eine aktive Rolle in den Ökosystemprozessen ihres Standortes. Von BSCs mancher Wüsten ist zum Beispiel bekannt, dass sie einen entscheidenden Beitrag zum Schutz gegen Wind- und Wassererosion an ihren Standorten leisten (Belnap, 2001).

Der Beitrag der Bodenkrusten zum Stickstoff-, Kohlenstoff- und Wassergehalt des Bodens wurde häufig diskutiert (Belnap, 1995, Eldridge und Greene, 1994, Johansen, 1993). Es wurden Hinweise gefunden, dass Bodenkrusten einen förderlichen Einfluss auf die Bodenfertilität besitzen, da sie die Wasseraufnahme- und Rückhaltekapazität des Bodens erhöhen (Loope und Gifford, 1972). Cyanobakterien erhöhen durch ihre Fähigkeit zur Fixierung atmosphärischen Stickstoffs die Fertilität des Bodens (Hawkes, 2003). Auch organischer Kohlenstoff wird von Krustenorganismen bereitgestellt (Skujins, 1984). Wasser und Nährstoffe können eine gewisse Zeit in der Matrix der Biologischen Bodenkruste, bestehend aus sogenannten EPS (extrazelluläre polymere Substanzen), welche von verschiedenen Organismengruppen in mehr oder weniger großen Anteilen gebildet wird (Hoppert et al. 2004) gespeichert werden. Die EPS, oft sind dieses Polysaccharide, leisten den entscheidenden Beitrag zur Trockenresistenz von Bodenkrusten und anderen Aggregaten mikrobiotischen Ursprungs (Kemmling et al., 2004). Diese Trockenresistenz ist so groß, dass sogar mehrere Jahre trocken aufbewahrte Krustenstücke nach kurzer Rehydratisierung in wenigen Stunden wieder biologische Aktivität zeigen (Scherer et al., 1986).

Die Verbesserung der Wasser- und Nährstoffversorgung könnte Anlass für die Vermutung bieten, dass ein Bewuchs mit BSCs ausschließlich positive Effekte auf die Ansiedlung höherer Pflanzen hat. Dies ist aber nicht immer der Fall, da manche Krustentypen durch Strukturverringerung der Bodenoberfläche eher die Germinationsraten verringern (Prasse, 1999). Wurde allerdings die Bodenkruste verletzt (durch Entfernen oder Zerkleinern), waren erhöhte Keimungsraten bei den untersuchten Grasarten zu beobachten. Eckert et al., (1986) fanden heraus, dass die Keimungsrate von Gräsern durch Zertreten von Bodenkrusten erhöht wird. Im Untersuchungsgebiet konnten weder positive noch negative stark signifikante 
5 Diskussion

Einflüsse der BSCs auf die Phanerogamenvegetation festgestellt werden. Pflanzenwuchs ist hier also nicht durch die Anwesenheit von BSCs bedingt; ein förderlicher Einfluss, insbesondere bei der Neubesiedlung nach starker Störung kann aber nicht ausgeschlossen werden, war jedoch nicht Teil der Untersuchungen.

Außer Frage steht aber, dass BSCs zahlreichen Organismen Lebensraum bieten. Abbildung 5.1 zeigt eine Schemazeichnung, aus welcher ersichtlich wird, welche Gruppen von Organismen ökologisch mit ihnen vernetzt sind.

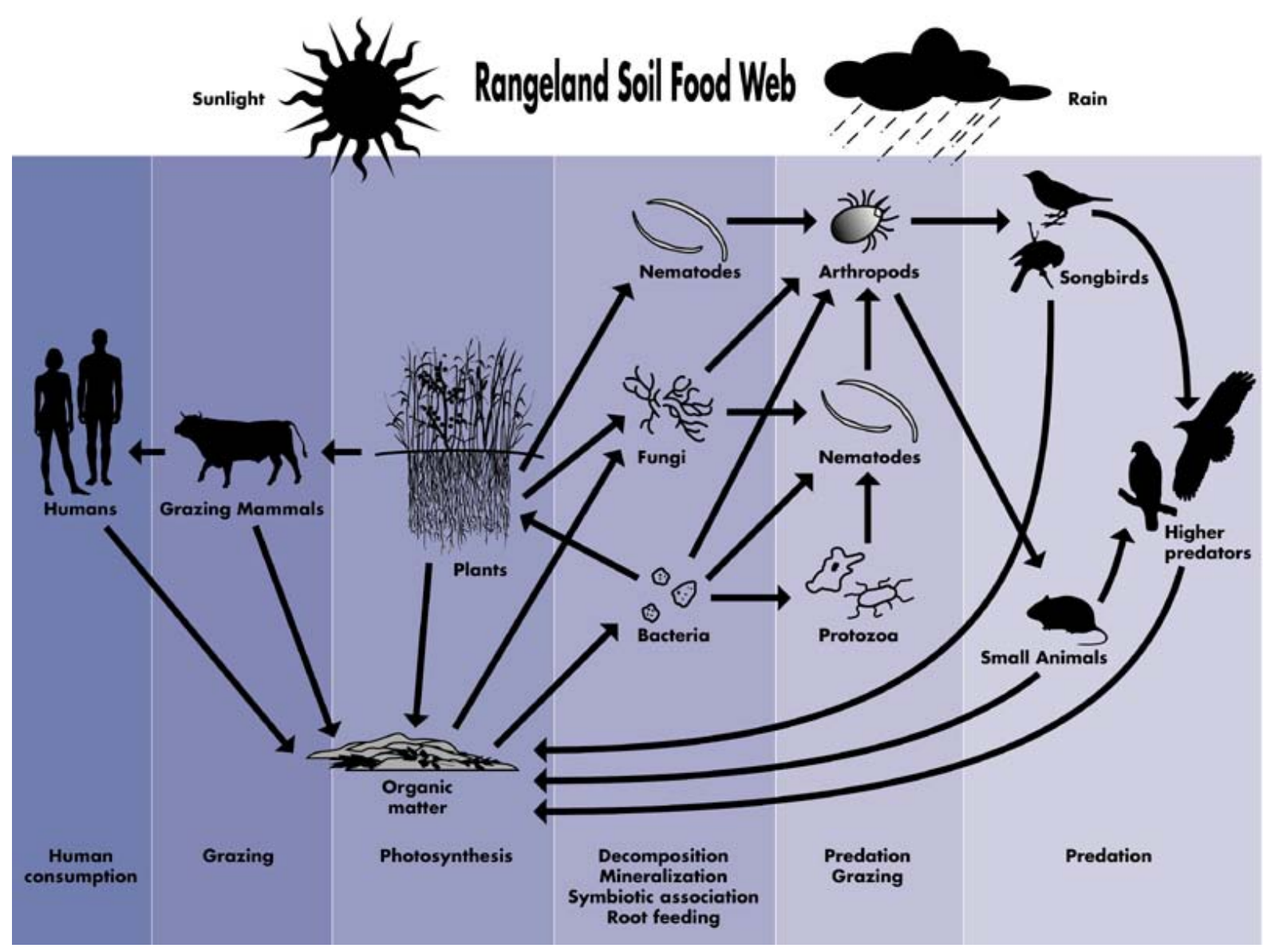

Abb. 5.1: Das Nahrungsnetz Biologischer Bodenkrusten in Weidelandökosystemen. Quelle: http://www.blm.gov/nstc/soil/foodweb/images/FOOD WEB.jpg

Tiere, Protozoen und Pilze waren nicht oder nur eingeschränkt Teil dieser Studie. Während der Freilanduntersuchungen und auch bei mikroskopischen Analysen haben sich jedoch 
5 Diskussion

zahlreiche Hinweise auf ihre Existenz in den BSCs und ihrer näheren Umgebung ergeben.

Heuschrecken wurden beobachtet, wie sie sich von den Flechten ernährten. Es wurden innerhalb der BSCs Milben entdeckt. Nematoden, Diatomeen und Protozoen wurden während mir mikroskopischen Analysen mehrfach beobachtet. Die Abbildung 5.2 zeigt einige in der unmittelbaren Umgebung der BSCs gefundenen Heuschrecken und Höhlen von Erdinsekten.

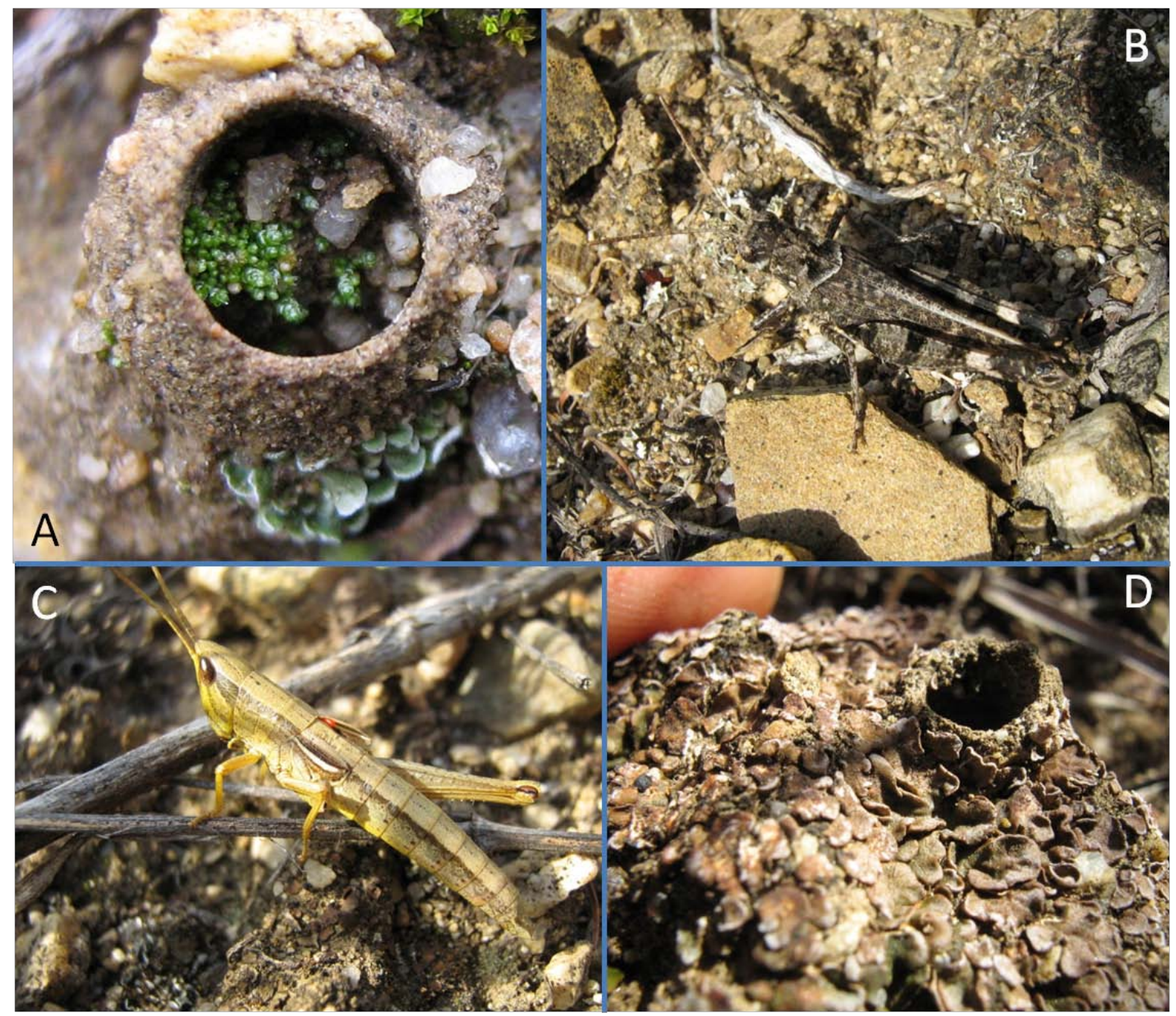

Abb. 5.2: Tiere in der Umgebung von Biologischen Bodenkrusten. $A=$ Wohnhöhle von Hymenopteren. $\mathrm{B}=$ Langfühlerschrecke, $\mathrm{C}=$ Chrysochroan dispar, $\mathrm{D}=$ Eingang zum Erdbau von Hymenopteren. 


\subsubsection{BSCs und ihre Gefährdungssitiation im westlichen Khentej}

Tendenziell ist ein Verlust von Biodiversität mit einem Verlust funktioneller Diversität gleichzusetzen (Petchey und Gaston, 2002), wiewohl es auch vorstellbar ist, dass die Funktion einer ausgestorbenen Art von einer anderen übernommen werden kann. Da eine Art in einem Ökosystem aber auch mehrere Funktionen wahrnehmen kann, ist es wahrscheinlich, dass nicht alle Verluste ausgeglichen werden können. Wenn ganze funktionelle Gruppen aussterben, dann sinkt die funktionelle Diversität natürlich erst recht. Es besteht unter Ökologen Einigkeit darüber, dass für die Funktion eines Ökosystems unter konstanten Bedingungen weniger Arten notwendig sind als für die Stabilität eines Ökosystems unter wechselnden Bedingungen (Loreau et al., 2001).

Die Resilienz bezeichnet die Fähigkeit eines Ökosystems, Störungen zu tolerieren, ohne dass das System derart zusammenbricht, dass langfristig ein qualitativ veränderter Zustand eintritt. Man kann in diesem Zusammenhang auch von der Elastizität eines Ökosystems sprechen (Smith et al., 2009).

Die Stabilität eines Ökosystems hingegen kann verschiedene Ausprägungen haben, die nicht unbedingt bedingen müssen, dass das Ökosystem wieder in den Ausganszustand zurückkehrt. Es kann auch bedeuten, dass ein alternativer stabiler Zustand erreicht wird. Die Frage, ob die Biodiversität und die Stabilität eines Ökosystems miteinander korrelieren, wird kontrovers diskutiert. Da allerdings bei anthropogenen Störungen oft zugleich die Biodiversität und die Stabilität von Ökosystemen beeinflusst werden, ist es nicht immer einfach, diese klar voneinander abzugrenzen (Ives und Carpenter, 2007). Man kann also in solchen Fällen nicht sagen, dass sie miteinander korrelieren.

Man weiß, dass Störungen Biologischer Bodenkrusten oft in einem Verlust des Artenreichtums einhergehen (Belnap und Eldrigde, 2001; Eldridge and Koen, 1998), dass nach einer Störung durch Feuer in resilietenten Ökosystemen aber auch nach einer einige Jahre dauernden Phase der Wiederbesiedlung das Ökosystem wieder hergestellt werden kann (Bowker et al., 2004). Aufgrund des oft langsamen Wachstums der Kryptogamen dauert dies jedoch länger als bei rein phanerogamen Gesellschaften. 
5 Diskussion

Im Untersuchungsgebiet sind Wildfeuer häufig und stellen akut für die Artengemeinschaften eine große Gefahr dar. Langfristig sind diese jedoch daran angepasst, was man daran sieht, dass an den Standorten A, B, G und F, welche nur vier Jahre vorher gebrannt hatten, die Diversität nicht sehr strk von der der anderen Standorte abwich. Vorstellbar wäre sogar, dass für die Gesellschaften die mit den Feuerereignissen verbundene Verjügung langfristig von Vorteil ist.

Eine andere potentielle Gefahr stellt die Beweidung dar. Im Untersuchungsgebiet ist der Beweidungsdruck relativ niedrig. Außerdem findet die Beweidung vor allem im Winter statt, wenn die BSCs gefroren sind. Laut Belnap und Eldridge (2001) sind sie dann robuster und Trittschäden können leichter toleriert werden. In anderen Teilen der Mongolei ist Überweidung jedoch ein großes Problem (Onda et al., 2006). Eigene Beobachtungen in der Landschaft nördlich von Ulaanbaatar zeigten neben eindeutigen Spuren starker Beweidung kaum BSCs. Es wurden an Standorten, die in Exposition und Inklination jenen untersuchten im Khentej ähnelten einige epilithische Flechten gefunden, jedoch selten Algen-und Mooskrusten und fast nie Flechtenkrusten. Nun kann nicht mit Bestimmtheit gesagt werden, dass diese Tatsache der Überweidung allein zuzuschreiben ist, jedoch ist diese sicherlich daran beteiligt. Dass die Überweidung Einfluss auf die Phanerogamenvegetation in den Gebirgsteppen der Mongolei nimmt, zeigten Fernandez-Gimenez und Allen-Diaz (1999). Sie stellten eine Abnahme von Gräsern und eine Zunahme von Stauden, Büschen und einjährigen Unkräutern fest mit zunehmendem Beweidungsdruck fest. In anderen Gebieten der Welt hat man festgestellt, dass ein zu hoher Beweidungsdruck Biologische Bodenkrusten komplett zerstören kann (Belnap und Eldridge, 2001).

Eine weitere potentielle Gefahr ist die Luftverschmutzung. Einige Flechten reagieren sehr empfindlich auf beispielweise Schwefeldioxid. Mann kann Flechten, eingeteilt in Toxitoleranz-Klassen sogar als Indikatoren für Luftverschmutzungen verwenden (Conti und Cecchetti, 2001). Hauck (2008) stellte für die Hauptstadt Ulaanbaatar einen starken Anstieg der Luftverschmutzung anhand epiphytischer Kennarten fest. Noch ist der West-Khentej jedoch nicht davon betroffen. 


\subsubsection{Management Biologischer Bodenkrusten}

Um eine objektive Basis für zukünftige Zustandsaufnahmen zu bekommen, benötigt ein Behandlungskonzept ein tragfähiges und anwendbares Monitoring, welches möglichst über einen langen Zeitraum betrieben wird, da sich BSCs sehr langsam entwickeln.

Zum Monitoring biologischer Bodenkrusten kommen verschiedene Techniken zum Einsatz. So werden fernerkundungsbasierte Multispektralanalysen (Karnieli et al., 2002; Hahn und Kusserow, 1998) ebenso eingesetzt wie Methoden, die über die Bestimmung der Biomasse oder des Chlorophyllgehaltes Rückschlüsse auf die Fitness der Krusten erlauben (z.B. Belnap, 1993). Da die Fitness und die Produktivität der BSCs letztlich über ihre Überlebenswahrscheinlichkeit und die ihres Ökosystems entscheiden, ist es von großer Bedeutung, die Faktoren, die sie beeinflussen, verifizieren zu können. Dies ist insbesondere bei flächenmäßig größeren Ökosystemen, die zu einem großen Teil von der Produktivität von BSCs abhängen, wie viele Wüstenökosysteme, von Vorteil.

Für kleinere Sonderstandorte wie die in dieser Arbeit untersuchten, eignen sich im Prinzip die in dieser Arbeit verwendeten transektbasierten Zählquadratmethoden sehr gut, wobei die Aufnahme der BSC-Bedeckung sehr wichtig ist. Ergänzt werden kann sie sinnvollerweise durch eine Aufnahme der Anzahl der Kryptogamenarten. Da dieses nicht für jeden durchführbar ist, kann man sich auch darauf beschränken, morphologische Gruppen wie Krustenflechten, Moose oder Laubflechten aufzunehmen (Rosentreter et al., 2001). Dies ist auch für Laien leicht erlernbar.

Zum Schutz der Standorte wäre im Idealfall jegliche Störung auszuschließen, wobei kleinere Störungen wie einfaches Betreten toleriert werden können, insbesondere, wenn es in den Wintermonaten stattfindet (Belnap und Eldridge, 2001). Der Beweidungsdruck sollte niedrig gehalten werden und Beweidung sollte nach Möglichkeit nicht im Sommer stattfinden, weil die BSCs im feuchten Zustand leichter zerbrechen. An besonders erhaltenswerten Standorten könnte man zum Schutz der Kryptogamendiversität Ausschlusssysteme für Weidetiere anbringen. Die Unterhaltung dieser Anlagen stellt jedoch ein nicht zu unterschätzendes Problem dar, da menschliche Bauten aufgrund der extremen Wetterbedingungen in der Mongolei nicht besonders lange halten. 
Vor Wildfeuern an besonders erhaltenswerten Standorten könnte ein Schutz durch teilweise Entfernung der sie umgebenden höheren Vegetation erreicht werden. Dieses würde die Feuerintensität abschwächen.

Ein besonderer Einflussfaktor auf die BSCs ist die Erosion. So zeigen unter anderem die Ergebnisse dieser Arbeit, dass steilere und somit stärker erodierte Standorte weniger Flechtenarten aufweisen. Man könnte nun die Erosion zumindest teilweise abschwächen, inden man am Oberhang Befestigungen anbringt, die abschwemmendes Material auffangen. Wie allerdings Warren (2001) bemerkt, sind Ökosysteme an Berghängen stark von den Hangprozessen beeinflusst und deshalb gehören seiner Meinung nach diese Hangprozesse zu den ebenso schützenswerten Prozessen. Das Schlagwort hierbei ist Prozessschutz.

Resümierend kann man sagen, dass die Standorte im Untersuchungsgebiet sehr gut auf die verschiedenen Störungen angepasst sind, sei es Feuer, mäßiger Beweidungsdruck oder Erosion. Ein Ausschluss eines der Faktoren hingegen wäre ein menschlicher Eingriff, der gut überlegt werden sollte. Sollten sich die Faktoren nicht verschärfen oder in ihrer Schärfe durch weitere Faktoren beeinflusst werden, sollten die Standorte ohne jeglichen Eingriff verbleiben. Um Ökosystemprozesse, die sich durch eventuell eintretende Klima- oder Luftqualitätsveränderungen, noch ergeben könnten zu erfassen, sollte aber ein Monitoring in regelmäßigen Abständen betrieben werden. 


\section{Zusammenfassung}

An extrazonalen Gebirgssteppenstandorten im westlichen Khentej in der Nordmongolei sollte das Vorkommen, die Morphologie und die genetische Diversität Biologischer Bodenkrusten untersucht werden.

Im Untersuchungsgebiet grenzt die Sibirische Taiga an die mongolisch-daurische Gebirgswaldsteppe. Daraus entsteht eine einzigartige Mischung von Vegetationstypen der Dunklen Taiga, Hellen Taiga und der Waldsteppe (Dulamsuren, 2004), die durch die Mischung borealer, temperater und daurischer Elemente ist die Gebirgswaldsteppe besonders artenreich ist (Mühlenberg und Samyia, 2002).

Die Standorte der Biologischen Bodenkrusten im westlichen Khentej sind durch ein Zusammenspiel klimatischer und edaphischer Faktoren unbewaldet (Dulamsuren et al., 2005) und lassen sich in die Vegetationstypen Carex amgunensis-, Festuca lenensis-, Pulsatilla ambigua- und die Artemisia frigida-Gebirgstrockensteppe und Ulmus pumila-offenes Waldgebiet einteilen (Dulamsuren, 2004). Für diese Vegetationstypen sollten die Zusammenhänge zwischen dem Auftreten und der Zusammensetzung Biologischer Bodenkrusten und verschiedenen biotischen und abiotischen Faktoren untersucht werden. Dabei ergab sich für die Artemisia frigida-Gebirgstrockensteppe jeweils eine schwache Korrelation zwischen der Entfernung vom Bergrücken, der Inklination und der Exposition und der Anzahl der Kryptogamenarten. Für die Artemisia frigida-Gebirgstrockensteppe und die Artemisia frigida- Pulsatilla ambigua-Gebirgstrockensteppe wurden schwache negative Korrelationen zwischen der prozentualen Pflanzenbedeckung und der Anzahl der Kryptogamenarten gefunden. In einem weiteren Versuch wurde die Bedeckung mit BSCs mit der Bedeckung mit Pflanzen insgesamt und mit der Bedeckung verschiedener Klassen von Pflanzen in Beziehung gesetzt. Die Gesamtpflanzenbedeckung war hier negativ mit der BSCBedeckung korreliert, ebenso die Bedeckung mit Gras und die Bedeckung mit „mittleren Kräutern“. Da die Ergebnisse sehr weit streuen, wird ein weiterer, nicht berücksichtigter Faktor für das Auftreten und die Zusammensetzung Biologischer Bodenkrusten vermutet. 
Des Weiteren sollte die Variation der genetischen Diversität Biologischer Bodenkrusten am Beispiel der Bacteria und Archaea zweier unterschiedlich stark gestörter Standorte gezeigt werden. Hierfür wurden Standortgenbanken der 16S-rDNA der Bakterien angelegt und die archaeelle Diversität durch DGGE (Denaturierende Gradientengelelektrophorese) gezeigt. Aus den Sequenzdaten der Standortgenbanken konnten Stammbäume abgeleitet werden und mittels des Vergleichs mit der RDP II-Datenbank eine Klassifizierung erfolgen. Die beiden Standorte unterschieden sich bezüglich der sie dominierenden Taxa insofern, dass an beiden zwar die Proteobacteria vorherrschten, am weniger gestörten Standort jedoch die Cyanobacteria die zweitstärkste Gruppe bildeten, während am stärker gestörten Standort dies die Bacteroidetes waren. Die drittstärkste Gruppe war an beiden Acidobacteria. Am stärker gestörten Standort waren zusätzlich zu den gemeinsamen die Phyla Firmicutes, Gemmatimonadetes und Planctomycetes, sowie die Klasse Deltaproteobacteria vorhanden, während am weniger stark gestörten Standort zusätzlich das Phylum Nitrospira auftrat.

Eine DOTUR-Analyse ergab, dass die beiden Standorte auf Artebene zu etwa $35 \%$ und auf Phylaebene zu 78-92 \% ausgeschöpft wurden. Die Rarefaction-Analysen zeigen, dass die bakterielle Diversität auf Phylaebene jeweils nahe der Sättigung war, während die bakterielle Diversität auf Artebene nicht ausgeschöpft wurde. Der Shannon-Wiener-Index für Biodiversität für den weniger gestörten Standort betrug für eine Distanz von 3 \% 3,93 und für eine Distanz von 20 \% 2,12. Für den stärker gestörten Standort betrug er für eine Distanz von 3 \% 4,39 und für die Distanz von 20 \% 2,64. 


\section{Literaturverzeichnis}

Achtziger, R., Nigmann, U., Zwölfer, H. (1992). Rarefaction-Methoden und ihre Einsatzmöglichkeiten bei der zooökologischen Zustandsanalyse und Bewertung von Biotopen. Zeitschr Ökol Naturschutz 1: 99-105.

Ahti, T. (2000). Cladoniaceae. Flora Neotropica Monograph 78.

Ahti, T., 1976: The lichen genus Cladonia in Mongolia. - Jour Jap Bot 51: 365 - 373.

Alain, K., Olagnon, M., Desbruyeres, D., Pagé, A., Babier, G., Juniper, S.K., Querellou, J., Cambon-Bonavita, M.A. (2002). Phylogenetic characterization of the bacterial assemblage associated with mucous secretios of the hydrothermal vent polychaete Paravinella palmiformis. FEMS Microbiol Ecol 42: 463-476.

Altschul, S.F., Gish, W., Mier, W., Myers, E.W. und Lipman, D.J. (1990): Basic local alignment search tool. J Mol Biol 215: 403-410.

Amann, R.I., Ludwig, W., Schleifer, K.H. (1995). Phylogenetic identification and in situ detection of individual microbial cells without cultivation. Microbiol Rev 59: 143-169.

An, D., Im, W., Yoon, M. (2008). Microlunatus panaciterrae sp. nov., a $\beta$-glucosidaseproducing bacterium isolated from a ginseng field. Int J Syst Evol Microbiol 58: 2734-2738.

Ashelford, K.E., Chuzhanova, N.A., Fry, J.C., Jones, A.J. und Weightman, A.J. (2006). New Screening software shows that most recent large 16S rRNA gene clone libraries contain chimeras. Appl Environ Microbiol 72(9): 5734-5741.

Auling, G., Busse, H.J., Egli, T., El-Banna, T., Stackebrandt, E. (1993). Description of the gram-negative, obligately aerobic, nitrilotriacetate (NTA)-utilizing bacteria as Chelatobacter heintzii, gen. nov., sp. nov., and Chelatococcus asaccharovorans, gen. nov., sp. nov. Syst Appl Microbiol 16(1): 104-112.

Bachar, A., Al-Ashab, A., Soares, M.I.M., Sklarz, M.Y., Angel, R., Ungar, E.D., Gillor, O. (2010). Soil microbial abundance and diversity along a low precipitation gradient. Microb Ecol DOI: $10.1007 / \mathrm{s} 00248-010-9727-1$.

Bannikova, I.A. (2003). Forest steppe of Interior Asia: structure and function. Trudy Sov RossMong Kompl Biol Eksped 43: 22-38.

Barns, S.M., Cain, E.C., Sommerville, L., Kuske, C.R. (2007). Acidobacteria phylum sequences in uranium-contaminated subsurface sediments greatly expand the known diversity within the phylum. Appl Environ Microbiol 73(9): 3113-3116.

Becker, T. (1999). Die Xerothermrasen-Gesellschaften des unteren Unstruttales und einige ökologische Gründe für ihre Verteilung im Raum. Mitt florist Kart Sachsen-Anhalt 4: 3-29. 
Belnap J, Ojima D, Phillips S, Barger N (1999) Biological soil crusts of inner and outer Mongolia: impacts of grazing and precipitation on nitrogen cycles. In: Eldridge DJ, Tongway D, King G (Ed) Proceedings of the 6th International Rangeland Congress, Townsville, Australia.

Belnap, J. (1993). Recovery rates of cryptobiotic crusts: inoculent use and assessment methods. Great Basin Nat, 53, 89-95.

Belnap, J. (2001a). Factors influencing nitrogen fixation and nitrogen release in biological soil crusts. In: Belnap J, Lange O (Ed.) Ecological studies. Biological soil crusts: structure, function and management. Springer, Berlin Heidelberg New York, pp. 241-261.

Belnap, J. (2001b). Microbes and microfauna associated with Biological Soil Crusts. In: Belnap J, Lange O (Ed) Ecological studies. Biological soil crusts: structure, function and management. Springer, Berlin Heidelberg New York, S. 167-176.

Belnap, J., Harper, K.T. (1995). Influence of cryptobiotic soil crusts on elemental content of tissue of two desert seed plants. Arid Land Research and Management 9 (2), 107-115.

Belnap, J., Phillips, S.L., Miller, M.E. (2004): Response of desert microbiological soil crusts to alterations in precipitation frequency. Oecologica 141(2): 306-316.

Ben-Dov, E., Shapiro, O.H., Siboni, N., und Kushmaro, A. (2006). Advantage of using insosine at the 3 'termini of $16 \mathrm{~S}$ rRNA gene universal primers for the study of microbial diversity. Appl Environ Microbiol 72: 6902-6906.

Beyerinck, M.W. (1913). De infusies en de ontdecking der backteriën. In Jaarboek van de Koninklije Akademis van Wetenschappen. Müller, Amsterdam.

Beymer, R.J., Klopatek, J.M. (1992). Effects of grazing on cryptogamic crusts in pinyonjuniper-woodlands in Grand Canyon National Park. Am Midl Nat, 127, 139-148.

BNatSchG/BUNDESNATURSCHUTZGESETZ vom 20.12. 1976 (BGBL I S 650); zuletzt novelliert als BNatSchGNeuregG vom 25.3. 2002 (BGBl I S. 1193)

Bolortsetseg, B. und Tuvaansuren, G. (1996). The potential impacts of climate change on pasture and cattle production in Mongolia. Water, Air, and Soil Pollution 92: 95-105.

Bonfield, J.K., Beal, K.F., Staden, R. (1995). A new DNA sequence assembly program. Nucleic Acids Research 23(24): 2992-4999.

Bossel, H. (2004). Systemzoo 2: Klima, Ökosysteme und Ressourcen, Volume 2. Books On Demand, Norderstedt.

Bowker, M.A. (2007). Biological soil crust rehabilitation in theory and practice: an underexploited opportunity. Restoration Ecology 15 (1): 13-23.

Bowker, M.A., Belnap, J., Rosentreter, R., Graham, B. (2004). Wildfire resistant biological soil crusts and fire-induced loss of soil stability in Palouse prairies, USA. Applied Soil Ecology 
Bowker, M.A., Reed, S.C., Belnap, J., Phillips, S.L. (2002). Temporal variation in Community Composition, Pigmentation, and Fv/Fm of Desert Cyanobacterial Soil Crusts. Microb Ecol, 43, 13-25.

Brenner, D. J., Krieg, N. R., Garrity, G. M., Staley, J. T., Boone, D. R., Vos, P., Goodfellow, M., Rainey, F. A. und Schleifer, K. (Hrsg.) (2004): Bergey's Manual of Systematic Bacteriology, (5 Bände).

Bergey's Manual Trust. Springer, Berlin Heidelberg.

Bruno, W.J., Socci, N.D. und Halpern, A.L. (2000). Weighted neighbor joining: a likelihoodbased approach to distance-based phylogeny reconstruction. Mol Biol Evol 17: 189-197.

Büdel, B. (1987). Zur Biologie und Systematik der Flechtengattungen Heppia und Peltula im südlichen Afrika. Bibl lich 23.

Büdel, B. (2001a). Synopsis: comparative Biogeography of Soil-Crust Biota. In: Belnap J, Lange O (Ed.) Ecological studies. Biological soil crusts: structure, function and management. Springer, Berlin Heidelberg New York, pp. 241-261.

Büdel, B. (2001b). Biological Soil Crusts of Asia including the Don and Volga region. In: Belnap J, Lange O (Ed.) Ecological studies. Biological soil crusts: structure, function and management. Springer, Berlin Heidelberg New York, pp. 241-261.

Büdel, B. (2005). Microorganisms of biological Soil Crusts on soil surfaces. In: Microorganisms in soils: roles in genesis and functions. Soil Biol 3: 307-323.

Büdel, B., Darienko, T., Deuschewitz, K., Dojani, S., Friedl, T., Mohr, K.I., Salisch, M., Reisser, W., Weber, B. (2009). Southern African Biological Soil Crusts are ubiquitous and highly diverse in drylands, being restricted in rainfall frequency. Microb Ecol 57(2): 229-247.

Cameron, R.E. (1978). The perplexity of desert preservation in a threatening world. In: Schofield, E.A. (Ed.) Earth Care: Global protection of Natural Areas. Westview Press, Boulder, Colorado, pp 411-443.

Casamayor, E.O., Schäfer, H., Baneras, L., Pedros-Alio, C., Muyzer, G. (2000). Identification of and spatio-temporal differences between microbial assemblages from two neighboring sulfurous lakes: comparison by microscopy and denaturating gradient gel electrophoresis. Appl Environ Microbiol 66:499-508.

Christensen, M. (1989). A view of fungal ecology. Mycol 81: 1-19.

Chuluun, T. und Ojima, D. (2002). Land use change and carbon cycle in arid and semi-arid lands of East and Cenral Asia. Science In China C 45: 48-54.

Cogt, U. (1979). Bodenflechten der Mongolischen Volksrepublik. Feddes Repert 90, 421-440.

Colwell, R.K., und Coddington, J.A. (1994). Estimating terrestrial biodiversity through extrapolation. Philosophical Transactions of the Royal Society 345: 101-118. 
Cruz-Martínez, K., Blake Suttle, K., Brodie, E.L., Power, M.E., Andersen' G.L., Banfield, J.F. (2009). Despite strong seasonal responses, soil microbial consortia are more resilient to longterm changes in rainfall than overlying grassland. The ISME Journal 3: 738-744.

Degelius, G. (1974). The lichen genus Collema with special reference to the extra-european species. Acta Universitatis Upsaliensis 20: 2.

Der Rat der europäischen Gemeinschaften (1992). Anlage I zu den FFH-Richtlinien.

DeSantis, T. Z., Hugenholtz, P., Keller, K., Brodie, E.L., Larsen, N., Piceno, Y.N., Phan, R. und G. L. Andersen. (2006). NAST: a multiple sequence alignment server for comparative analysis of 16S rRNA genes. Nucleic Acids Res 34:W394-9.

Doll, R. (1981). Flechten. Ziemsen, Wittenberg.

Dulamsuren, C. (2004). Floristische Diversität, Vegetation und Standortbedingungen in der Gebirgstaiga des West-Khentey, Nordmongolei. Dissertation, University Göttingen. Berichte des Forschungszentrums Waldökosysteme A: 191.

Dulamsuren, C. und Hauck, M. (2008). Spatial and seasonal varation of climate on steppe slopes of the northern Mongolian mountain taiga. Grassland Science 54(4): 217-230.

Dulamsuren, C., Hauck, M., Mühlenberg, M. (2005). Ground vegetation in the Mongolian taiga forest-steppe ecotone does not offer evidence for the human origin of grasslands. Appl Veg Sci 8(2): 149-154.

Dunbar, J.S., Barns, M., Ticknor, L.O., Kuske, C.R. (2002). Empirical and theoretical bacterial diversity in four Arizona soils. Appl Environ Microbiol 68:3035-3045.

Eckert, R.E., Peterson, F.F., Meurisse, M.S., Stephens, L.J. (1986). Effects of soil-surface morphology on emergence and survival of seedlings in big sagebrush communities. $J$ Range Manage, 39, 409-414.

Eldridge, D. J. und Koen, T.B. (1998). Cover and floristics of microphytic soil crusts in relation to indices of landscape health. Plant Ecol 137(1): 101-114.

Eldridge, D. und Rosentreter, R. (1999). Morphological groups: a framework for monitoring microphytic crusts in arid landscapes. J Arid Envir 41: 11-25.

Eldridge, D.J. (1993). Cryptogams, vascular plants and soil hydrological relations: some prelimniary results from the semiarid woodlands of eastern Australia. Great Basin Nat, 53, 4858.

Eldridge, D.J. (1996). Distribution and floristics of terricolous lichens in Soil Crusts in arid and semi-arid New South Wales, Australia. Austr J Bot 44: 581-599.

Eldridge, D.J., Greene, R.S.B. (1994). Microbiotic Soil Crusts: A Review of their Roles in Soil and Ecological Processes in the Rangelands of Australia. Aust J Soil Res 32, 389-415. 
Elenkin, A.A. (1901). Fakul'tativnye lišajniki. Izv SP Bot Sada, 1, 129-154.

Ellenberg, H. (1996). Vegetation Mitteleuropas mit den Alpen. Verlag Eugen Ulmer, Stuttgart.

Elshahed, M.S., Youssef, N.H., Spain, A.M., Sheik, C., Najar, F.Z., Sukharnikov, L.O., Roe, B.A., Davis, J.P., Schloss, P.D, Bailey, V.L., Krumholz, L.R. (2008). Novelty and Uniqueness Patterns of Rare Members of the Soil Biosphere. Appl Env Microbiol 74(17): 5422-5428.

Ettl, H., Gärtner, G. (1995). Syllabus der Boden-, Luft- und Flechtenalgen. Spektrum Akad. Vlg. Hdg., Heidelberg.

Evans, R.D., Johansen, J.R (1999). Microbiotic crusts and ecosystem processes. Crit Rev Plant Sci 18: 183-225.

Evenari, M. (1985). The desert environment. In: Evenari M, Noy-Meyr I and Goodall DW (Ed.), Hot Deserts and Arid Shrublands Vol 12a: Ecosystems of the World. Elsevier, Amsterdam, pp. 1-22.

Felsenstein, J. (1985). Confidence limits on phylogenies: An approach using the bootstrap. Evol 39:783-791.

Fernandez-Gimenez, M.E. und Allen-Diaz, B. (1999). Testing a non-equilibrium model of rangeland vegetation dynamics in Mongolia. J Appl Ecol 36: 871-885.

Fischer S.G. and Lerman L.S. (1980). Separation of random fragments of DNA according to properties of their sequences. Proc Natl Acad Sci USA 77: 4420-4424.

Fischer S.G. and Lerman L.S. (1983). DNA fragments differing by single base-pair substitutions are separated in denaturing gradient gels: Correspondence with melting theory. Proc Natl Acad Sci USA 80: 1579-1583.

Fitter, A.H., Gilligan, C.A., Hollingworth, K., Kleczkowski, A., Twyman, R.M., Pitchford, J.W. and the members of the NERC- Soil Biodiverstity Programme (2005). Biodiversity and ecosystem function in soil. Funct Ecol 19: 369-377.

Frahm, J.P. und Frey, W. (2004). Moosflora. UTB, Stuttgart.

Frey, W. und Kürschner, H. (1998). Wüstenmoose: Anpassungen und Überlebensstrategien im täglichen Kampf mit der Sonne. Biol unserer Zeit 4: 231-240.

Friedmann, E.I, Galun, M. (1974). Desert algae, lichens and fungi. In: Brown, G.W. (Ed.), Desert Biology. Academic Press, London, S. 165-212.

Garcia-Pichel, F., Belnap, J. (1996). Microenvironments and microscale productivity of cyanobacterial desert crusts. J Phycol 32: 774-782.

Geitler, L. (1933). Beiträge zur Kenntnis der Flechtensymbiose I-III. Arch Protistenk 80: 378409. 
Geitler, L. (1934). Beiträge zur Kenntnis der Flechtensymbiose IV-V. Arch Protistenk 82: 5185.

Geitler, L. (1937). Beiträge zur Kenntnis der Flechtensymbiose VI. Arch Protistenk 88: 161179.

Geitler, L. (1938). Beiträge zur Kenntnis der Flechtensymbiose VI. Arch Protistenk 90: 489501.

Goward, Trevor. 1999. The lichens of British Columbia-illustrated keys. Part 2 Fruticose species. Special Report Series 9. Victoria, BC: British Columbia Ministry of Forests; 319 p.

Goward, Trevor; McClure, Bruce; Meidinger, Del. 1994. The lichens of British Columbiaillustrated keys. Part 1 Foliose and squamulose species. Special Report Series 8. Victoria, BC: British Columbia Ministry of Forests; 181 p.

Grubov, V.I. (2000). Key to the vascular plants of Mongolia (with an atlas). Enfield, N. H.: Science Publishers, 2 Bände.

Grubov, V.I., Junatov, A.A. (1952). Osnovnye osobennosti flory Mongol'skoj Naradnoj Respubliki v svjazi s ee rajonirovaniem. Bot Žurn 37, 45-64.

Gyelnik, V. (1930). Lichenologische Mitteilungen. Hedw 68, 20-45.

Hahn, A. und Kusserow, H. (1998). Spatial and temporal distribution of algae in soil crusts in the Sahel of W Africa: Prelimniary results. Willdenow 28: 227-238.

Hale, M.E. (1990). A synopsis of the lichen genus Xanthoparmelia (Vainio) Hale (Ascomycotina, Parmeliaceae). Smith Contr Bot 74: 1-250.

Hanahan, D. (1983): Studies on transformation of Escherichia coli with plasmids. J Mol Biol 166(4): 557-580.

Hansen, E.S. (2001). Lichen-rich Soil Crusts of Arctic Greenland. In: Belnap J, Lange O (Ed.) Ecological studies. Biological soil crusts: structure, function and management. Springer, Berlin Heidelberg New York, S. 241-261.

Harper, K.T., Marble, J.R. (1988). A role for nonvascular plants in management of arid and semi-arid rangelands. In: Tueller, P.T. (Ed) Vegetation science applications for rangeland analysis and management. Kluwer Academic Publishers, Dordrecht, S. 136-169.

Harper, K.T., Pendleton, R.L. (1993). Cyanobacteria and cyanolichens: can they enhance availability of essential minerals for higher plants? Western North American Naturalist 53 (1), 59-72.

Harper, K.T., Pendleton, R.L., (1993). Cyanobacteria and cyanolichens: can they enhance availability of essential minerals for higher plants? Great Basin Nat 53: 59-72.

Hartwig, J.H. (1993). The lichen genus Peltigera, exclusive of the P. Canina-group, in 
Norway. Sommerfelt 15:1-77.

Hauck, M. \& S. Javkhlan, 2006: Additions to the lichen flora of Mongolia: records from Khentey and Khangay. - Willdenow 36: 895 - 912.

Hauck, M. Dulamsuren, C., Mühlenberg, M. (2007). Lichen diversity on steppe slopes in the northern mongolian mountain taiga and its dependence on microclimate. Flora 2002: 530-546.

Hawkes, C.V. (2003). Nitrogen cycling mediated by biological soil crusts and arbuscular mykkhorizal fungi. Ecol 84: 1553-1562.

Hilty, J.H., Eldridge, D.J. Rosentreter, R., Wicklow-Howard, M.C., Pellant, M: (2004). Recovery of biological soil crusts following wildfire in Idaho. Rangeland Ecol Manag 57(1): 89-96.

Hirsch, P., Ludwig, W., Hethke, C., Sittig, M., Hoffmann, B., Gallikowski, C.A. (1998). Hymenobacter roseosalivarius gen. nov., sp. nov. from continental Antartica soils and sandstone: bacteria of the Cytophaga/Flavobacterium/Bacteroides line of phylogenetic descent. Syst Appl Microbiol 21(3): 374-383.

Holst, J., Butterbach-Bahl, K., Liu, C., Zheng, X., Kaiser, A.J. Schnitzler, J.P., ZechmeisterBoltenstern, S., Brüggemann, N. (2009). Dinitrogen fixation by biological soil crusts in an Inner Mongolian steppe. Biol Fertil Soils 45: 679-690.

Hoppert, M., Reimer, R., Kemmling, A., Schröder, A., Günzl, B. und Heinken, T. (2004). Structure and reactivity of a Biological Soil Crust from a xeric sandy soil in Central Europe. Geomicrobiol J 21: 183-191.

Housman, D.C., Powers, H.H., Collins, A.D., Belnap, J. (2006). Carbon and nitrogen fixation differ between sucessional stages of biological soil crusts in the Colorado Plateau and Chihuahuan desert. J Arid Env 66(4): 629-634.

Huber, T., Faulkner, G. Hugenholtz, P. (2004). Bellerophon: a program to detect chimeric sequences in multiple sequence alignments. Bioinf 20 (14): 2317-2319.

Hughes Martiny, J.B., Bohannan, B.J.M., Brown, J.H., Colwell, R.K., Fuhrman, J.A., Green, J.L., Horner-Devine, M.C., Kane, M., Adams Krumins, J., Kuske, C.R., Morin, P.J., Naeem, S., Øvreås, L., Reysenbach, A.-L., Staley, J.T. (2006). Microbial biogeography: putting microorganisms on the map. Nat Rev Microbiol4: 102-112.

Huneck, S., Poelt, J., Ahti, T., Vittikainen, O., Cogt, U. (1984). Zur Verbreitung und Chemie von Flechten der Mongolischen Volksrepublik. Erforsch Biol Ress MVR, 4, 51-62.

Ives, A.R. und Carpenter, S.R. (2007). Stability and diversity of Ecosystems. Sci 317(5834): 58-62.

James, P.W., Hawksworth, D.G., Rose, F. (1977). Lichen communities in the British Isles: a preliminary conspectus. In Seaward MRP (Ed.) Lichen ecology. Academic Press, New York, S. 295-413. 
Johansen, J.R. (1993). Cryptogamic crusts of semiarid and arid lands of North America. $J$ Phycol, 29, 140-147.

Jukes, T.H., Cantor, C.R. (1969). Evolution of protein molecules. In: H.N. Munro (Ed.), Mammalian protein metabolism. Academic Press, New York, USA. S. 21-132.

Junatov, A.A. (1950). Osnovnye čerty rastitel'nogo pokrova Mongol'skoj Naradnoj Respubliki. Trudy Mog Komiss Akad Nauk SSSR 39.

Kaltenecker, J. und Wicklow-Howard, M. (1994). Microbiotic soil crusts in sagebrush habitats of southern Idaho. Report for the U.S. Department of Agriculture Forest Service and U.S. Department of Interior Bureau of Land Management, on file with the Interior Columbia Basin Ecosystem Management Project, Walla Walla, USA.

Karczmarz , K., Swies, F. (1981). Beitrag zur Bryoflora der Mongolei - 1. Laub- und Lebermoose aus dem Chentei- Gebirge. Feddes Repert 92 (9-10): 695-711.

Karnieli, A, Gabai, A., Ichoku, C., Zaady, E., Shachak, M. (2002). Temporal dynamics of soil and vegetation spectral responses in a semi-arid environment. Int J Remote Sensing 23(19): 4073-4087.

Kemmling, A., Kämper, M., Flies, C., Schieweck, O., Hoppert, M. (2004). Biofilms and extracellular matrices on geomaterials. Env Geol 46(3-4): 429-435.

Kumar, S., Dudley, J., Nei, M. und Tamura, K. (2008) MEGA: A biologist-centric software for evolutionary analysis of DNA and protein sequences. Brief Bioinf 9: 299-306.

Kuske, C.R., Ticknor, L.O., Miller, M.E., Dunbar, J.M., Davis, J.A., Barns, S.M., Belnap, J. (2002). Comparison of soil bacterial communities in rhizospheres of three plant species and the interspaces in an arid Grassland. Appl Environ Microbiol, 68, 1854-1863.

LaMontagne, M.G., Schimel, J.P., Holden, P.A. (2003). Comparison of subsurface and surface soil bacterial communities in california grassland as assessed by terminal restriction fragment length polymorphisms of PCR-amplified 16S rRNA genes. Microb Ecol 46 (2): 216-227.

Lange, O.L. (2001). Photosynthesis of Soil Crust Biota as Dependent on Environmental Factors. In: Belnap, J., Lange, O.L. (Ed.) Biological Soil Crusts: Structure, Function and Management. Springer, Berlin, Heidelberg, New York, p. 217-240.

Lange, O.L. (2003). Wenn kleine Organismen große Wirkung zeigen. Forschung 28(4): 14-19.

Lehmkuhl, F., Lang, A. (2001). Geomorphological investigations and luminescence dating in the southern part of the Khangay and the Valley of the Gobi Lakes (Central Mongolia). $J$ Quaternary Sci 16(1): 69-87. 
Lesaulnier, C., Papamichail, D., McCorkle, S., Ollivier, B., Skiena, S., Taghavi, S., Zak, D., Van Der Lelie, D. (2008). Elevated atmospheric $\mathrm{CO}_{2}$ affects soil microbial diversity associated with trembling aspen. Environ Microbiol 10: 926-941.

Li, X.R., Wang, X.P., Li, T, Zhang, J.G. (2002). Microbiotic soil crust and its effect on vegetation and habitat on artificially stabilized desert dunes in Tengger Desert, North China. Biol Fertil Soils 35: 147-154.

Liengen, T. und Olsen, R.A. (1997). Seasonal and site-specific variations in nitrogen fixation in a high arctic area, Ny-Ålesund, Spitsbergen. Can J Microbiol 43(8): 759-769.

Loope, W.L., Gifford, G.F. (1972). Influence of a soil microfloral crust on select properties of soils under pinyon juniper in southeastern Utah. J soil Water Conserv, 27, 164-167.

Loreau, M. (2010). Linking biodiversity and ecosystems: towards a unifying ecological theory. Phil Trans $R$ Soc B 365: 49-60.

Loreau, M., Naeem, S., Bengtsson, J., Grime, J.P., Hector, A., Hooper, D.U., Huston, M.A., Raffaeli, D., Schmid, B., Tilman, D., Wardle, D.A. (2001). Biodiversity and Ecosystem Functioning: Current knowledge and future challenges. Sci 294 (5543): 804-808.

LSPA- Law on Special Protected Areas of 1994. Mongolia. Article 12, Section 1. Article 18, section 1. Article 21, section 2. In: Mongolian Environmental Laws, 1996. Mongolian Ministry of Nature and the Environment, Ulaanbaatar. S. 152 pp.

Lukešová, A. (2001). Soil Algae in brown coal and lignite post-mining areas in Central Europe (Czech Republic and Germany). Restor Ecol 9(4). 341-350.

Lumbsch, T. (1993a). Studien über die Flechtengattung Diploschistes I. Nova Hedwigia 56: 227-236.

Lumbsch, T. (1993b). Studien über die Flechtengattung Diploschistes II. Nova Hedwigia 56: 237-239.

Magurran, A.E. (1988). Ecological diversity and its measurement. Princeton University Press, Princeton, USA.

Maidak, B.L, Larsen, N., McCaughey, M.J., Overbeek, R., Olsen, G.J., Fogel, K., Blandy, J. and Woese, C.R. (1994). The Ribosomal Database project. Nucl Ac Res 22(17): 3485-3487.

Marsh, J., Nouvet, S., Sanborn, P. und Coxson, D. (2006). Composition and function of biological soil crust comminities along topographic gradients in grasslands of central interior British Columbia (Chilcotin) and southwestern Yukon (Kluane). Can J Bot 84: 717-736.

Mazor, G., Kidron, G. J., Vonshak, A., The role of cyanobacterial exopolysaccharides in structuring desert microbial crusts. FEMS Microbiol Ecol 21: 121-130.

Metting, B. (1981). The systematic and ecology of soil algae. Bot Rev 47: 195-312.

Meusel, H., Jäger, E., Weinert, E. (1965). Vergleichende Chorologie der zentraleuropäischen 
Flora, Band 1 (2 Bände). Fischer, Jena.

Mühlenberg, M., Hondong, H., Dulamsuren, C., von Gadow, K. (2004). Large-scale biodiversity research in the southern taiga, Northern Mongolia. For Snow Landsc Res 78: 93118.

Muyzer, G., De Waal, E.C., Uitterlinden, A.G. (1993). Profiling of complex microbial population by denaturing gradient gel electrophoresis analysis of polymerase chain reactionamplified genes coding for 16S rRNA. Appl Environ Microbiol 59: 695-600.

Muyzer, H., Hottenträger, A., Teske, A., Wawer, C. (1996). Denaturing gradient gel electrophoresis of PCR-amplified 16s rDNA - a new molecular approach to analyze the genetic diversity of mixed microbial communities. Akkermann, A.D.L., Van Elsas, J.D., De Bruijn, F.J. (Ed). Molecular Microbial Ecology Manual. Kluwer Academic Publishers, Dordrecht, Niederlande, p. 3.4.4./1-23.

Nagel, P. (1975). Studien zur Ökologie und Chorologie der Coleopteren (Insecta) xerothermer Standorte des Saar-Moosel-Raumes mit besonderer Berücksichtigung der die Bodenoberfläche besiedelnden Arten. Dissertation Universität Saarbrücken, 225 S.

Nash, T.H., Gries, C., Elix, J.A. (1995). A revision of the lichen genus Xanthoparmelia in South America. Bibl Lich 56: 133-144.

Nonomura, H. und Takagi, S. (1977). Distribution of actinoplanetes in soils of Japan. Journal of Ferment Technol 55: 423-428.

Novichkova-Ivanova L.N. (1977). Terrestrial algae of deserts in the Dgungar (Dzungarin) and Zaaltai (Transaltai) Gobi. Bot Zh, 62, 1709-1719. Auf Russisch.

Novichkova-Ivanova, L.N. (1988). Epilithic cenosis of algae of the transaltai Gobi. In Natural Conditions, Plant Cover and Animals of Mongolia. Puschino, pp. 276-282. Auf Russisch.

Novichkova-Ivanova, L.N. 1980. Pochvennye vodorosli fitocenozov Saharo-Gobiiskoi pustynnoi oblasti (Soil algae of Sahara-Gobi desert region). Nauka. Leningrad, pp. 1-256. Auf Russisch.

Onda, Y., Kato, H., Tanaka, Y., Tsujimura, M., Davaa, G., Oyunbaatar, D. (2006). Analysis of runoff generation and soil erosion processes by using environmental radionuclides in semiarid areas of Mongolia. J Hydrol 333(1): 124-132.

Ogorodnikov, A.V. (1981). Soils of mountain forests in Poeple's Republic of Mongolia. Nauka, Novosibirsk 144 pp. Auf Russisch.

Ohta, H., Hattori, R., Ushiba, Y., Mitsui, H., Ito, M., Watanabe, H., Tonosaki, A., Hattori, T. (2004). Sphingomonas oligophenolica sp. Nov., a halo- and orano-sensitive oligotrophic bacterium from paddy soil that degrades phenolic acids at low concentrations. Int J Syst Evol Microbiol 54(6): 2185-2190.

Orlovsky, L., Dourikov, M., Babaev, A. (2004). Temporal dynamics and productivity of biogenic soil crusts in the central Karakum desert, Turkmenistan. J Arid Environm, 56, 579- 
601.

Pallmann, H., Eichenberger, E. und Hasler, A. (1940). Eine neue Methode der Temperaturmessung bei ökologischen und bodenkundlichen Untersuchungen. Ber Schweiz Bot Ges 50: 337-362.

Parkinson, D. (1983). Fuctional relationships between soil organisms. In: Lebrun P, Andre HM, De Medts A, Gregoire-Wibo C, Wauthy G (Ed) Proc VIII In Coll Soil Zoology. DieuBrichart, Louvain-la-Neuve, Belgium, S. 153-165.

Paus, S. (1997). Die Erdflechtenvegetation Nordwestdeutschlands und einiger Randgebiete Bibl Lich 66.

Pérez, F.L. (1997). Microbiotic crusts in the high equatorial Andes, and their influence on paramo soils. Catena 31(3): 173-198).

Petchey, O.L. und Gaston, K.J. (2002). Extinction and the loss of functional diversity. Proc $R$ Soc Lond B 269: 1721-1727.

Peveling, E. (1988). Beziehungen zwischen den Symbiosepartnern in Flechten. Naturwiss 75(2): 77-86.

Poelt, J. (1969). Bestimmungsschlüssel europäischer Flechten. Cramer, Leipzig.

Pointing, S.B., Chan, Y., Lacap, D.C., Lau, M.C.Y., Jurgens, J.A. Farell, R.L. (2009). Highly specialized microbial diversity in hyper-arid polar desert. Proc Nat Acad Sci USA 106(47): 19964-19969.

Ponzetti, J.M., McCune, B.P. (2001). Biotic soil crusts of Oregon's shrub steppe: community composition in relation to soil chemistry, climate, and livestock grazing. Bryol 104(2): 212225.

Prasse, R. (1999). Experimentelle Untersuchungen an Gefäßpflanzenpopulationen auf verschiedenen Geländeoberflächen in einem Sandwüstengebiet. Dissertation. Universitätsverlag Rasch, Osnabrück.

Primack, R.B. (1995). Naturschutzbiologie. Spektrum Akademischer Verlag, Heidelberg.

Proctor, M.C.F. (1982). Physiological ecology: water relations, light and temperature responses, carbon balance. In: A.J.E. Smith (Hrsg.) Bryophyte Ecology, Chapman and Hall, London, New York, 333-381.

Qin, Z., Berliner, P.R. und Karnieli, A. (2005). Ground temperature measurement and emissivity determination to understand the thermal anomaly and its significance on the development of an arid environmental ecosystem in the sand dunes across the Israel-Egypt border. J Arid Environ 60: 27-52.

Rassadina, K.A. (1950). Cetrarija (Cetraria) SSSR Trudy bot. Inst. AN SSSR11/5 Leningrad. 
Remmert, H. (1985). Was geschieht im Klimax-Stadium? Naturwiss 72: 505-512.

Reysenbach, A.-L. und Pace, N.R. (1995): In Archaea: A Laboratory Manual-Thermophiles. Robb, F.T., Place, A.R. (Ed). Cold Spring Harbour Laboratory Press, New York, pp. 101-107.

Rivera-Aguilar, V, Montejano, G., Rodriguez-Zaragoza, S. und Duran-Diaz, A. (2006). Distribution and composition of cyanobacteria, mosses and lichens of the biological soil crusts of the Tehuacán Valley, Puebla, México. J Arid Environm 67(2): 208-225.

Rosentreter, R. (1992). Displacement of rare plants by exotic grass. P. 1-6. Posterpräsentation "Symposium on Ecology, Management and Restoration of Intermountain Annual Rangelands, Boise, Idaho, 18.-22. Mai 1992.

Rosentreter, R. und Belnap, J. (2001). Biological Soil Crusts of North America. In: Belnap J, Lange O (Ed.) Ecological studies. Biological soil crusts: structure, function and management. Springer, Berlin Heidelberg New York, pp. 241-261.

Rosentreter, R., Eldridge, D.J., Kaltenecker, J.H (2001). Monitoring and Management of Biological Soil Crusts. In: In: Belnap J, Lange O (Ed.) Ecological studies. Biological soil crusts: structure, function and management. Springer, Berlin Heidelberg New York. S. 547468.

Sambrook, J., Fritsch, E.F., und Maniatis, T. (1989). Molecular cloning: a laboratory Manual. Cold Spring Harbor Lab Press, New York.

Sanger, F., Nicklen, S. und Coulson, A.R. (1977). DNA sequencing with chain-terminating inhibitors. PNAS 74/12: 5463-5467.

Saitou, N. und Nei, M. (1987). The neighbor-joining method: A new method for reconstructing phylogenetic trees. Mol Biol Evol 4:406-425.

Scheffer, F., Schachtschabel, P. (1984). Lehrbuch der Bodenkunde (11. Aufl.) Enke, Stuttgart.

Scherer, S. und Potts, M. (1989). Novel water stress protein from a desiccation-tolerant cyanobacterium. Purification und partial characterization. J Biol Chem 264: 12546-12553.

Scherer, S., Ernst, A., Chen, T.W., Böger, P. (1984) Rewetting of drought-resistant blue-green algae: Time course of water update and reappearance of respiration, photosynthesis and nitrogen fixation. Oecol 62,418-423.

Schmeil, O., Fitschen, J.(1993). Flora von Deutschland und angrenzender Länder. 89. Aufl., Quelle und Meyer, Heidelberg.

Schneider, G. (1979). Die Flechtengattung Psora sensu Zahlbruckner: Versuch einer Gliederung. Bibl Lich 13: 1-292.

Schubert, R., Klement, O. (1971). Beitrag zur Flechtenflora der Mongolischen Volksrepublik. Feddes Repert, 82, 187-262. 
Schultaz, M., Büdel, B. (2002). Key to the genera of Lichinaceae. Lichenol 34: 39-62.

Schulten, J.A. (1985). Soil aggregation by cryptogams in the sand prairie. American Journal Of Botany 72: 1657-1661.

Schwendener, S. (1872). Erörterung zur Gonidienfrage. Flora N.R. 30: 161-166, 177-182, 193202, 225-234.

Scott, G.A.M. (1982). Desert bryophytes. In: Smith, A.J.E. (Ed.) Bryophyte Ecology. Chapman \& Hall, London, S. 200.

Shem-Tov, S., Zaady, E., Groffmann, P.M., Guttermann, Y. (1999). Soil carbon content along a rainfall gradient and inhibition of germination: a potential mechanism for regulating distribution of Plantago coronopus. Soil Biol Biochem 31(9): 1209-1217.

Shields, L. M., Mitchell,C., Drouet, F. (1957). Alga- and lichen-stabilized surface crusts as soil nitrogen sources. Am J Bot 44(6): 489- 498.

Skujins, J. (1984). Microbial ecology of desert soils. Adv Microbiol Ecol 7: 49-91.

St Clair, L.L., Johansen, J.R., Rushforth, S.R. (1993). Lichens of soil crust communities in the intermountain area of the western United States. Great Basin Nat 53(1): 5-12.

Staden, R., Beal, K.F., Bonfield, J.K. (2000). The Staden Package, 1998. Bioinf Methods Protoc 132: 115-130.

States, J.S., Christensen, M., Kinter, C.L. (2001). Soil fungi as components of Biological Soil Crusts. In: Belnap J, Lange O (Ed) Ecological studies. Biological soil crusts: structure, function and management. Springer, Berlin Heidelberg New York, S. 155-166.

Stohlgren, T.J., Otsuki, Y., Villa, C.A., Lee, M., Belnap, J. (2001): Patterns of plant invasions: a case example in native species hotspots and rare habitats. Biol Inv 3: 37-50.

Strasburger, E. (Begr.), Sitte, P., Weiler, E., Kadereit, J.W., Bresinsky, A., Körner, C. 82002). Lehrbuch Botanik für Hochschulen. Spektrum Akademischer Verlag, Heidelberg.

Su, Y.G. , Li, X.R., Cheng, Y.W., Tan, H.J., Jia, R.L. (2007). Effects of biological soil crusts on emergence of desert vascular plants in North China. Plant Ecol 191: 11-19.

Tamura K, Dudley J, Nei M \& Kumar S (2007) MEGA4: Molecular Evolutionary Genetics Analysis (MEGA) software version 4.0. Mol Biol Evol 24: 1596-1599.

Tamura, K., Nei, M. und Kumar, S. (2004). Prospects for inferring very large phylogenies by using the neighbor-joining method. Proc Nati Acad Sci USA 101: 11030-11035.

Tamura, K., Dudley, J., Nei, M. und Kumar, S. (2007). MEGA4: Molecular Evolutionary Genetics Analysis (MEGA) software version 4.0. Mol Biol Evol 24:1596-1599.

Ten, L.N., Xu, J.J, Jin, F.X, Im, W.T, Oh, H.M., Lee, S.T (2009). Spirosoma panaciterrae sp. nov., isolated from soil. Int J Syst Evol Microbiol 59: 331-335. 
ter Braak, C. J. F. (1986). Canonical correspondence analysis: a new eigenvector method for multivariate direct gradient analysis. Ecol 67, 1167-1179.

ter Braak, C. J. F. (1994). Canonical community ordination. Part I: Basic theory and linear methods. Ecosci 1, 127-140.

Thompson, J.D, Higgins, D.G., Gibson, T.J. (1994). Clustal W: improving the sensitivity of progressive multiple sequence alignment through sequence weighting, position-specific gap penalties and weight matrix choice. Nucl Acids Res 22 (22): 4673.

Timdahl, E. (1986). A revision of Psora (Lecideaceae) in North America. Bryol 89(4): 253275.

Timdahl, E., Zhurbenko, M.P. (2004). Psora indigirkae, a new species from eastern Siberia, with key to the Asian species of Psora. Symb Bot Ups 34(1): 25-29.

Tsegmed, T. (2001). Checklist and Distribution of Mosses in Mongolia. Arct 10: 1-18.

Tstetsegma, D., Ulziikhutag, N. (1985). Some new information from the algae survey in the People's Republic of Mongolia. Booklet of Research Centre of Botanics, 11, 51-57. Auf Mongolisch.

Türk, R. und Gärtner, G. (2001). Biological Soil Crusts in the Alps. In: Belnap J, Lange O (Ed.) Ecological studies. Biological soil crusts: structure, function and management. Springer, Berlin Heidelberg New York, pp. 241-261.

Ulziikhutag, N., Tsetsegma, D. (1980). Summary on algae in Mongolia. Booklet of Research Center of Botanics, 6, 145-161. Auf Mongolisch.

Vipper, P.B. (1953) Forests of the Southwestern Khentey Mountains; (auf Russisch) Trudy Mongol'skoy Kommissii 54: 1-55.

Vipper, PB. (1968). Vliyanie travyano-kustarnichkogo pokrova I podstilki na mikroklimat I pochvu v lesakh Zabaikal'ya. Tr Ins. Lesa Drev Akad Nauk SSSR 54: 30-61.

Vostokova, E.A., Gunin, P.D. (Ed.) (2005). Ecosystems of Mongolia Atlas. Russian Academy of Sciences, Moskau.

Walther, H. (1974). Die Vegetation Osteuropas, Nord- und Zentralasiens. Gustav-Fischer-Verlag, Stuttgart, S. $287 \mathrm{ff}$.

Warren, A.W. (2001). Valley slide slopes. In: Warren, A., French, J.R. (Ed.) Habitat Conservation- Managing the Physical Environment. John Wiley \& Sons, LTD, Chichester, New York, Weinheim, Brisbane, Singapur, Toronto.

West, N.E. (1990). Structure and function of microphytic soil crusts in wildland ecosystems of arid to semi-arid regions. Adv Ecol Res, 20, 179-223.

Wirth, V. (1987). Die Flechten Baden- Württembergs. Ulmer, Stuttgart. 
Wirth, V. (1995). Flechtenflora: Bestimmung und ökologische Kennzeichnung der Flechten Südwestdeutschlands und angrenzender Gebiete. 2. Aufl., Ulmer, Stuttgart.

Wyss, D. (2006). Waldmanagement in der Mongolei. Dissertation, FU Berlin.

Xu, J.L, Liu, Q., Yu,H., Jin,F., Lee, S., Im, W. (2009). Hymenobacter daecheogenensis sp. nov., isolated from stream sediment. Int J Syst Evol Microbiol 59: 1183-1187.

Zhang, H., Sekiguchi, Y., Hanada, S., Hugenholtz, P., Kim, H., Kamagata, Y., Nakamura, K. (2003). Gemmatimonas aurantiaca gen. nov., sp. Nov., a Gram-negative, aerobic, polyphosphate-accumulating micro-organism, the first cultured representative of the new bacterial phylum Gemmatimonadetes phyl. nov. Int J Syst Evol Microbiol 53: 1155-1163.

Zhang, Y. (2005). The microstructure and formation of biological soil crusts in their early development stage. Chin Sci Bull 50(2): 117-121.

Zhang, Y. (2005). The microstructure and formation of biological soil crusts in their early development stage. Chin Sci Bull50: 117-121.

Zhang, Y.M. (2002). A study on bryophyte associated with formation of soil crust in south fringe of Gurbantunggut Desert in Xinjiang. Acta Botanica Boreali-occidentalia Sinica 22: 1823.

Zheng, J.G. (2009). Study on species diversity and adaptation of mosses in biological soil crust in Gurbantunggut Desert. J Anhui Agricult Sci 2009-1. 
